\title{
Essays on individual decision making : with special references to agribusiness \& food markets
}

Citation for published version (APA):

Kalogeras, N. (2011). Essays on individual decision making : with special references to agribusiness \& food markets. [Doctoral Thesis, Maastricht University]. Datawyse / Universitaire Pers Maastricht. https://doi.org/10.26481/dis.20110114nk

Document status and date:

Published: 01/01/2011

DOI:

10.26481/dis.20110114nk

Document Version:

Publisher's PDF, also known as Version of record

\section{Please check the document version of this publication:}

- A submitted manuscript is the version of the article upon submission and before peer-review. There can be important differences between the submitted version and the official published version of record.

People interested in the research are advised to contact the author for the final version of the publication, or visit the DOI to the publisher's website.

- The final author version and the galley proof are versions of the publication after peer review.

- The final published version features the final layout of the paper including the volume, issue and page numbers.

Link to publication

\footnotetext{
General rights rights.

- You may freely distribute the URL identifying the publication in the public portal. please follow below link for the End User Agreement:

www.umlib.nl/taverne-license

Take down policy

If you believe that this document breaches copyright please contact us at:

repository@maastrichtuniversity.nl

providing details and we will investigate your claim.
}

Copyright and moral rights for the publications made accessible in the public portal are retained by the authors and/or other copyright owners and it is a condition of accessing publications that users recognise and abide by the legal requirements associated with these

- Users may download and print one copy of any publication from the public portal for the purpose of private study or research.

- You may not further distribute the material or use it for any profit-making activity or commercial gain

If the publication is distributed under the terms of Article $25 \mathrm{fa}$ of the Dutch Copyright Act, indicated by the "Taverne" license above, 


\section{ESSAYS ON INDIVIDUAL DECISION MAKING}

WITH SPECIAL REFERENCES TO AGRIBUSINESS \& FOOD MARKETS

NIKOLAOS KALOGERAS 
Print Datawyse / Universitaire Pers Maastricht ISBN 9789461590367

(C) Nikos Kalogeras, Maastricht 2010 


\section{ESSAYS ON INDIVIDUAL DECISION MAKING}

WITH SPECIAL REFERENCES TO AGRIBUSINESS

\& FOOD MARKETS

\section{PROEFSCHRIFT}

ter verkrijging van de graad van doctor aan de Universiteit Maastricht, op gezag van de Rector Magnificus, Prof. mr. G.P.M.F. Mols, volgens het besluit van het college van Decanen, in het openbaar te verdedigen, op vrijdag 14 januari 2011 om 10:00 uur door

NIKOLAOS KALOGERAS

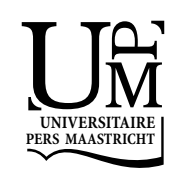




\section{Promotor}

Prof. dr. ir. J.M.E. Pennings

\section{Assessment committee}

Prof. dr. P. Eichholtz (chairman)

Prof. dr. P. Garcia, University of Illinois at Urbana-Champaign, IL, USA

Prof. X. Gellynck, Ghent University, Belgium

Prof. dr. K. de Ruyter

The following institutions and/or organizations contributed financially to the creation of this dissertation:

1. AST Chair in Commodity Futures Markets, Wageningen University, the Netherlands.

2. Office for Future \& Options Research (OFOR) and Marketing \& Decision Sciences Group, University of Illinois at Urbana-Champaign, Illinois, US.

3. Chair of Cooperative Theory \& Practice, Wageningen University, the Netherlands \& National Council for Cooperatives in the Netherlands (NCR).

4. US Homeland Security Office, Illinois, US.

5. VTN/The Greenery Ltd., the Netherlands.

6. Marketing-Finance Research Lab, Maastricht University, the Netherlands. 
Ta Panta Rei

(Everything Floats)

Heraclitus, $6^{\text {h }}$ century BC

To the One who showed me "The Way". To Prof. dr. Mathew T.G. Meulenberg: Pioneer in Marketing \& Decision Sciences.*

*After an impressive career as a marketing professor Mathew T.G. Meulenberg passed away in September, 2006. 



\section{TABLE OF CONTENTS}

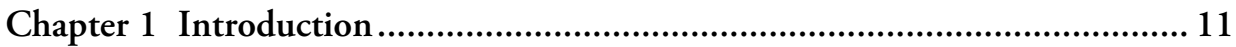

1.1 General Context: Individual Market Participants' Behavior ....................... 12

1.1.1 Importance of Studying Individuals' Behavior in the Food Industry ......... 12

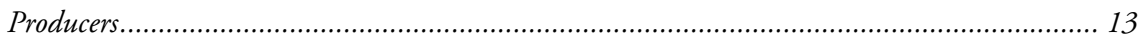

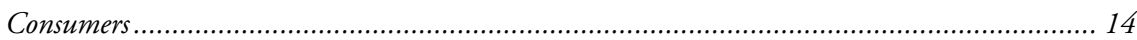

1.2 Theoretical Approaches to Studying the Behavior of Individual Market

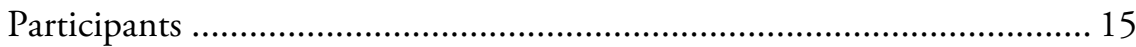

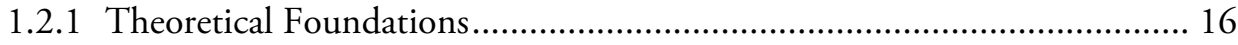

Business Structures as System of Attributes........................................................................ 16

Latent Heterogeneity in Preference Structures ................................................................. 17

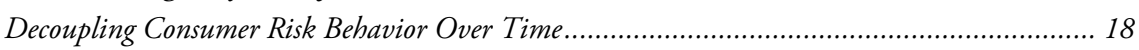

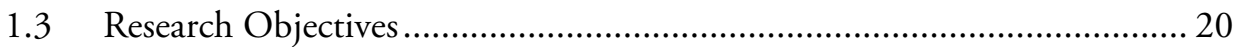

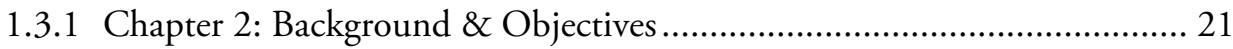

1.3.2 Chapter 3: Background \& Objectives ...................................................... 23

1.3.3 Chapter 4: Background \& Objectives ...................................................... 24

1.4 Decision Context Characteristics ........................................................ 26

1.4.1 Individual's Relevance to the Decision Environment ................................. 26

Member-investor Preferences for the Restructuring of an MC ……………………………. 26

Consumers' Risk Response in Times of a Product-Harm Crisis......................................... 27

1.4.2 Disaggregate Analysis of "Real" Decision Maker Behaviors........................ 28

Field Studies with Individual Member-Investors of an MC firm ........................................... 28

Individual Consumers' Risk Behavior in a Highly Uncertain Environment ............................. 29

1.4.3 Sample Size \& Measurement Techniques .................................................. 30

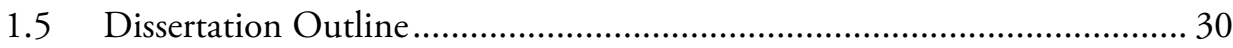

Chapter 2 The Structure of a Marketing Cooperative: a Member-Investors' Perspective ...................................................................................... 33

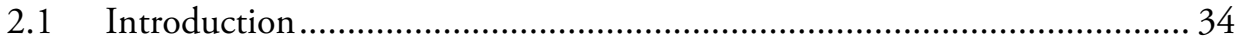

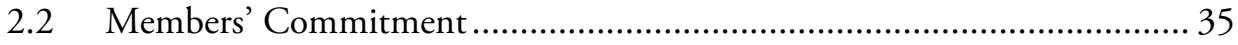




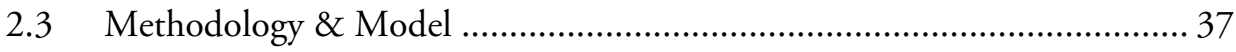

2.4 Decision Context: VTN/The Greenery ……………................................... 39

2.4.1 From an Auction to a Marketing Co-op ………………………………..... 39

2.4.2 The Structure of the New Co-op ............................................................ 40

Cost-Benefits Distribution …………………………………………………………........ 40

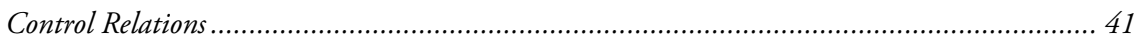

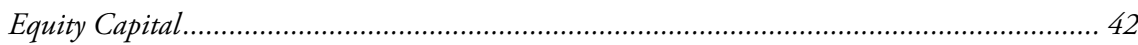

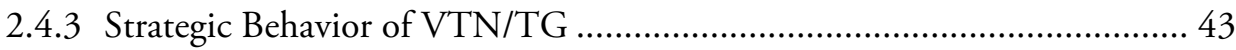

2.4.4 Members' Response: Loss of Commitment............................................... 43

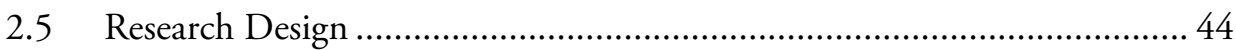

2.5.1 Identification of Attributes: A Focus-Group Study ................................... 44

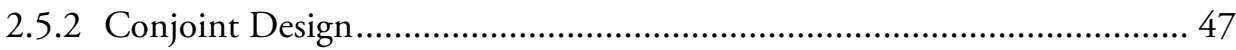

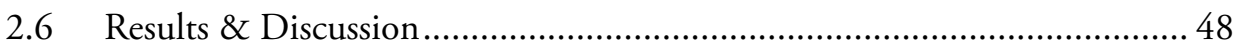

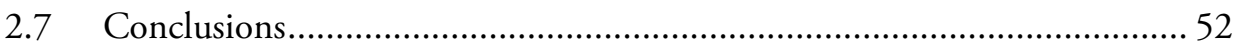

Chapter 3 Understanding Heterogeneous Preferences of Cooperative Member-

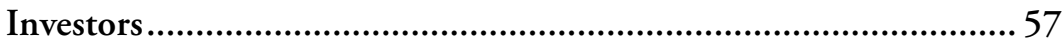

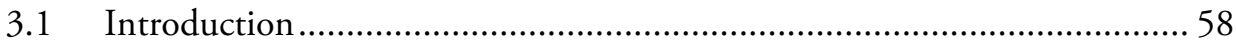

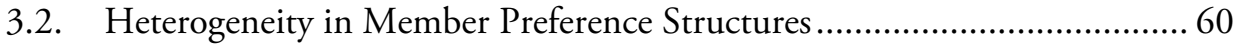

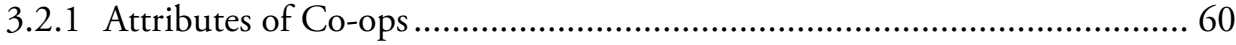

3.2.2 What Influences Members' Heterogeneity?.................................................. 61

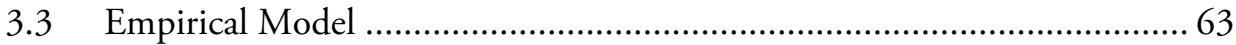

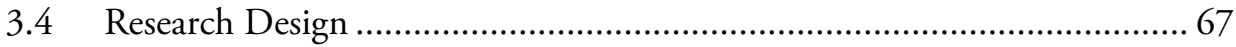

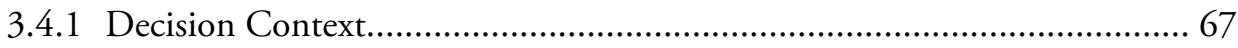

3.4.2 Relevant Attributes: Focus-Groups Findings................................................69 69

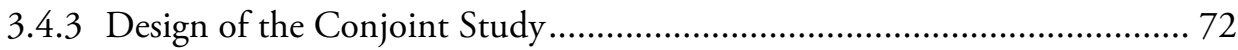

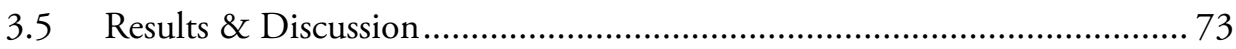

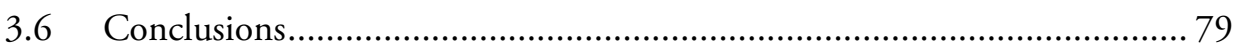

Chapter 4 Consumer Risk Behavior in Times of Crisis: A Natural Experiment 83

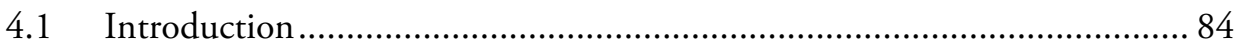

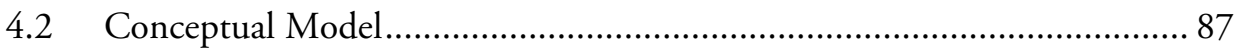

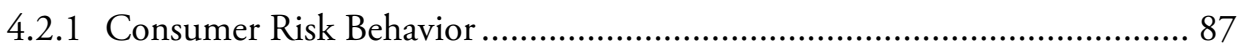

4.2.2 Risk Behavior: A Two-layered Consumer Decision System....................... 89

4.2.3 Consumer Risk Behavior in a Dynamic Decision Environment................ 92 Consumer Risk Reactions in Specific Crisis Phases........................................................... 93 
Adaptiveness of Risk Behavior: A Contingent-Context Perspective........................................... 95

4.2.4 Risk Attitudes \& Perceptions: The Role of Knowledge and Trust............ 98

The Role of Knowledge ..................................................................................................... 99

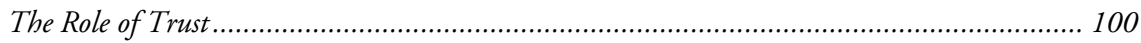

4.3 Implications of the Proposed Framework.......................................... 103

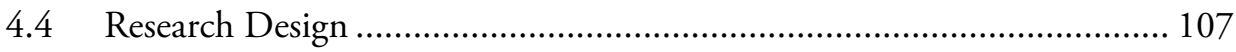

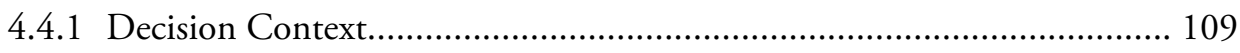

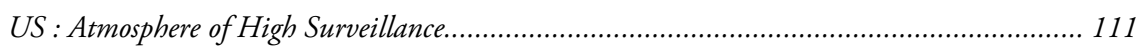

Germany: Fragmented Market Reactions ..................................................................... 115

4.4.2 Field Studies Design ................................................................... 118

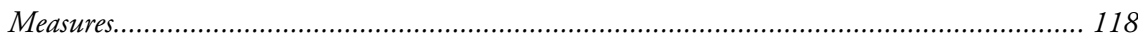

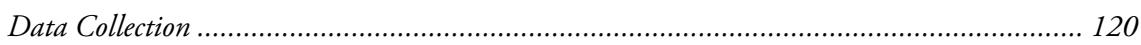

4.5 Empirical Modeling Approach................................................... 120

4.5.1 Modeling Consumer Participation \& Quantity-Reduction

Decisions.................................................................................. 123

4.5.2 Dynamics of Consumer Decision Drivers.......................................... 126

4.5.3 Modeling Factors Impacting Risk Attitudes \& Perceptions in Crisis Phases......................................................................................... 126

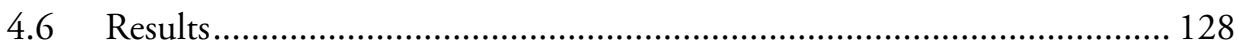

4.6.1 Risk Measures with Respect to Beef Consumption .............................. 128

4.6.2 Consumer Decisions in Different Crisis Phases..................................... 130

The Influence of Changing Risk Attitudes \& Perceptions on Consumer Decisions ................... 130

Participation Decision: Results in 2001 \& 2004 ............................................................ 133

Quantity-Reduction Decisions: Results in 2001 \& 2004................................................. 134

4.6.3 Results of the Effect of Time on Consumer Decisions ........................... 136

4.6.4 Results of Factors Impacting Risk Attitudes \& Perceptions in Crisis Phases......................................................................................... 137

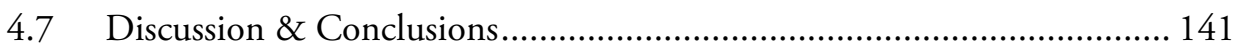

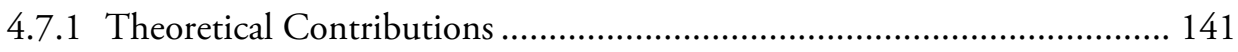

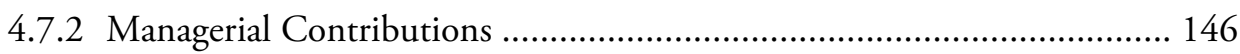

4.7.3 Limitations \& Further Research ....................................................... 147

Chapter 5 Conclusion ............................................................................. 149

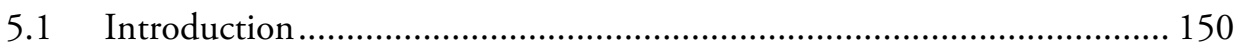

5.2 Discussion: Summary of Results, Theoretical \& Managerial Implications150

5.2.1 Member-investors' Perspective on the Structure of an MC .................... 151

5.2.2 Heterogeneous Preferences of MCs' Member-investors.......................... 153 
5.2.3 Decoupling Consumer Risk Behavior Over Time............................... 154

5.3 Research Challenges ................................................................... 156

5.4 A Final Thought............................................................................. 158

Appendix 3.1: Description of Risk Attitude Scale ................................... 159

Appendix 4.1: Decoupling Risk-taking Behavior .................................. 160

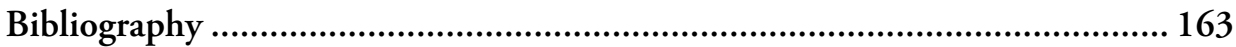




\section{Chapter 1}

\section{INTRODUCTION}

In this chapter, we introduce the theoretical foundations, research objectives, and the characteristics of the empirical domains used in this dissertation. First, we provide a short discussion on the importance of studying individual market participants' behavior in the food industry. This is followed by a brief description of approaches used to study the decision-making behavior of individual market participants in economics, marketing, and finance. The theoretical foundations of each chapter are discussed. Next, the research objectives are defined, followed by a discussion of the distinguishing characteristics of the empirical studies. Finally, an outline of the chapters is presented. 


\subsection{General Context: Individual Market Participants' Behavior}

Recent research in investment and consumer behavior has put the human decisionmaking process in the spotlight (Smith, 1982; 2003). The great challenge nowadays for economists, marketers, and financial analysts is the understanding of economic phenomena, which are the revealed outcomes of the human decisionmaking process (Pennings et al., 2005). Scholars and practitioners show an increasing interest in identifying and understanding these outcomes in order to make better predictions of (economic) phenomena, develop successful corporate strategies, and suggest better and updated public policies (Camerer et al., 2004). Particularly, scholars in business economics emphasize the need for more interdisciplinary studies into the composition and structure of human decision-making processes (Heckman, 2001). Despite this recognized need, the study on revealed economic behavior of market participants is still dominated by theoretical, normative, and aggregate approaches, which cannot directly observe and capture the dynamics and changes in the latent decision-making process of individual market participants (Smidts, 1990, 1997; Wedel \& Kamakura, 1998, Heckman, 2001).

In this dissertation, we recognize that the study of economic behavior (i.e., preferences, decisions) of individuals with respect to investing and consuming requires the consideration of their latent decision-making process both from an adequate methodological as well as measurement-based perspective (Keeney \& Raiffa, 1972, 1993; Little, 1986; Schoemaker, 1982; 1993). This study contributes to the understanding of economic behavior of individual producers and consumers in the food industry, who are experiencing dynamic strategic processes. In our study, we use and integrate theoretical, methodological, and modeling approaches from economics, the marketing-finance interface, and psychology.

\subsubsection{Importance of Studying Individuals' Behavior in the Food Industry}

The food industry is a dynamic one and in a constant state of flux (Kohls \& Uhl, 2002). The successive liberalization of food markets forces the food industry to respond to rapid and radical changes in the marketplace through globalization and large-scale operations (Tilburg et al., 2000). Understanding changing economic behavior at different stages of the food supply chain is critical in formulating updated and well-informed corporate investment and marketing strategies (Wierenga 
et al., 1997). We study the revealed economic behavior of individual food producers and consumers who are market participants at upstream and downstream stages of the food supply chain, respectively.

\section{Producers}

Studying the economic behavior of food producers who are member-investors of co-operative (co-op) firms is important. Co-ops are important economic players. Recent figures of International Co-op Alliance (ICA) show that the 300 top co-op firms globally are responsible for an aggregate turnover of $\$ 1.1$ trillion (ICA, 2008). Financial co-ops, including credit unions, serve millions of memberinvestors and some of the largest retailers in the world are consumer co-ops. The co-op sector worldwide has about 800 million members in over 100 countries, and it is estimated that co-ops account for more than 100 million jobs around the world (UN, 2009). In the European Union (EU) co-op firms represent over 256,000 enterprises operating with 5.4 million employees and 163 million members (EUCC, 2008). Co-op enterprises in the United States (US) serve 120 million members, or 4 in 10 Americans (NCBA, 2009). Four thousand two hundred $(4,200)$ European co-op banks, under the protection and supervision of the European Association of Cooperative Banks, serve 149 million clients, including small and medium enterprises, and 49,000 credit unions serve 177 million members in 96 countries, which operate under the supervision of the World Council of Credit Unions (ICA, 2008).

Meanwhile, agribusiness co-ops account for a significant part of agricultural and food production and marketing. The EU has 132,000 agribusiness co-ops with 83.5 million members (CEC, 2007), and the US has 47,000 co-ops with 100 million members (USDA, 2002). One third of the world's food production passes through agribusiness co-ops (Pattison, 2000), and it is estimated that 50 per cent of global agricultural output is marketed through co-ops (Bibby \& Show, 2005). In the EU, co-ops are responsible for over $60 \%$ of the harvesting, processing, and marketing of agricultural products, with a turnover of 210 billion Euros (Galdeano et al., 2005). The sheer figures indicate that the co-op firm is a widespread organizational form in both the European and the American market. Agribusiness co-ops worldwide have been instrumental in providing market access and competitive returns to their member-investors. As market conditions change rapidly, questions arise as to how the organizational structures of co-ops can meet the challenges that 
these new conditions pose to satisfying the demand and achieving the co-alignment in economic interests of their member-investors. Acquiring information about and knowledge of the member-investors' needs and demands, may aid co-op policymakers in continuously developing and improving co-op services provided to participating producers and better balancing their demands and heterogeneous preferences.

\section{Consumers}

Studying consumer risk reactions to a food product crisis over time is also important. Property damages, injuries and deaths related to market crises cost over $\$ 700$ billion annually in the US (US Consumer Product Safety Commission, 2005). In 2000, the US Surgeon General stated that food safety emerged as a significant global issue with international trade and public health implications (Satcher, 2000). For instance, food-borne pathogens have been estimated to cause 70 percent of the roughly 1.5 episodes of stomach irregularities and 3 million deaths of children under the age of 5 annually (WHO, 2000). Unexpected natural hazards (e.g., food scares) may cause global consumer panic due to the heightened media attention (Kamins, et al. 1997). Consumer risk reactions during a product-harm crisis may substantially have a devastating impact on the demand of food products and other services, affect business reputations and sales, and compromise the performance of marketing channels of an entire industry (e.g., Dawar \& Pilluta, 2000; Van Heerde et al., 2007).

The financial losses for the companies involved in the operation of these channels also tend to be substantial. For instance, the food poisoning scandal in Japan incurred a loss of 51.6 billion yen for the producing company (Snow Brand Milk) in 2001, compared to a net profit of 3.3. billion in 2000 (Finkelstein, 2005). Nonetheless, consumer reactions vary greatly among countries because of cultural differences and diverging public and industry risk-management policies regarding the communication of the "actual" level of risk (Schroeder et al., 2007). Knowledge of the drivers of consumers' reactions over time may reveal crucial information on how marketing strategies and public policies might adapt to contingent market conditions in times of a product-harm crisis. 


\subsection{Theoretical Approaches to Studying the Behavior of Individual Market Participants}

Three main fundamental approaches to the study of the decision making of individual market participants can be distinguished in the economics and marketingfinance literature. First, in the utility theory approach, the expected-utility rule, derived from a limited rule of axioms, dominates the field. This rule is based on the seminal work of Von Neumann and Morgenstern (1947) and describes how an individual decision maker chooses between alternatives. Recently, attention has been given to the development of new or weakened axioms that account for discrepancies between the choice behavior predicted by the expected-utility rule and actual behavior (Machina, 1982; Smidts, 1997). Second, in the behavioral decision approach, the focus is on how an individual market participant decides and on which simplifying rules individuals apply to reach decisions in complex (risky) situations (Kahneman \& Tversky, 1979; Pennings \& Smidts, 2003). The application of this approach gives rise to descriptive decision-making models as alternatives to the expected-utility model.

In the utility theory approach, the emphasis is clearly on theoretical and normative models. In contrast, behavioral decision theory is dominated by experimental research. A third approach, the decision utility analysis, reconciles the aforementioned approaches in that it attempts a synthesis of notions from both theories in applications to important, unstructured, multi-attributed, and complex decisionmaking problems (Winterfeldt \& Edwards, 1986; Keeney \& Raiffa, 1993). Decision analysis benefits from the behavioral decision theory since this theory clarifies when, how and why people make risky decisions that depart from the normative models supplied by utility theory (Smidts, 1997). It consists of a set of techniques and procedures aiming to help organizations and individuals make inferences and better decisions. Nowadays, apart from the psychologically minded economists, theoretical mainstream economists have also begun to recognize the importance of decision utility analysis (Kahneman et al., 1997). Refinements of the utility concept (i.e., a relaxation of the normative properties of representative utility functions) have been continuously attempted and have been derived empirically over the last three decades (Loewenstein, 1999).

In this dissertation, theoretical utility notions and methodological considerations taken from all three approaches will be used in order to study the revealed 
economic behavior of individual market participants in turbulent, complex, and dynamic decision environments. Below, we discuss in more detail the theoretical foundations on which each study relies.

\subsubsection{Theoretical Foundations}

One of the major objectives of this dissertation is to examine the underlying decision-making behavior of individual market participants by following the behavioral and experimental microeconomic school of thought (e.g., Smith, 1982; 2003; Harrison \& List, 2004). Experimental microeconomics includes, among others, the empirical study of "real” individuals' decision-making behavior. Consideration and empirical examination of the unobservable (i.e., latent) and observable factors that drive individual behavior may portray a more complete and, potentially, more accurate picture of the development of the decision-making process in specific decision contexts. A number of theories have played a dominant role in the development of research models in this dissertation. We briefly describe these theories and their interconnections hereafter.

\section{Business Structures as System of Attributes}

Scholars have analyzed the nature of co-ops as organizations that seek to "maximize a single objective function" (e.g., Sexton, 1990; Feinerman \& Falkovitz, 1991), as a "coalition" of utility-maximizing subgroups (e.g., Staatz, 1983; Zusman \& Rausser, 1994; Bourgeon and Chambers, 1999), and as a "nexus of contracts" wherein business relationships among co-op stakeholders are viewed as contractual relationships (e.g., Eilers \& Hanf, 1999; Hendrikse \& Bijman, 2002). All three theoretical angles view co-op member-investors as rational market participants who aim to maximize utility from their participation in a collective equity and governance business structure. Yet, member-investors exhibit puzzling economic interests. While they are tied up contractually to collective economic interests on a voluntary basis, they often strive to influence corporate strategies to reflect their own economic self-interest. We argue that one may shed light on this puzzling behavior by studying the utility that member-investors derive, rather than maximize, from the ownership, governance, allocation of benefits, and strategic marketing relationships that they develop among themselves and within the co-op. In delineating these relationships we draw on industrial organization theory, in which organizations are viewed as a system of attributes (Milgrom \& Roberts 1990). This theoretical per- 
spective proposes that firms are composed of attributes which represent certain aspects, whereby each aspect has certain alternatives (Holmstrom \& Milgrom, 1994).

While the idea of viewing co-ops as a system of attributes has been introduced in the co-op economics literature (Hendrsike \& Veerman, 1997; Bijman, 2002; Feng \& Hendrikse, 2008), it has, however, received little systematic attention at an empirical level. Yet, existing (analytical) studies account only for the ownership- or governance-related attributes and not for the strategic attributes of co-ops. Building on principles of co-op organization (Barton, 1989; Cook \& Chaddad, 2004) and drawing from recent literature that emphasizes the market challenges that co-ops face (Meulenberg, 1979; 1997; 2000; Van Dijk \& Mackel, 1991, Kyriakopoulos, 2000, Hernandez-Espallardo \& Arcas-Lario, 2003), we focus on two sets of attributes: intra-organizational and strategic attributes. We support the notion that the subjective utility (i.e., preferences) that member-investors attach to particular attributes signals the level of their commitment to the co-op's organizational and strategic business activities. That is, we adopt notions from the theory of market participants' commitment in the operations of marketing channels (e.g., Stern \& ElAnsary, 1990; Anderson \& Weitz, 1992; Gilliland \& Bello, 2002). We explicitly emphasize member-investors' commitment to the business activities of a co-op by examining the preference structure of members for a mix of intra-organizational and strategic attributes that compose a co-op firm rather than intra-organizational attributes only. The identification of the preferred structure of member-investors is achieved through the application of mutli-attribute utility theory (Luce \& Tukey, 1964). We decompose the utility that member-investors attach to co-op attributes and their corresponding alternatives by applying a multi-attribute utility research framework (Green \& Srinivasan, 1978; 1990).

\section{Latent Heterogeneity in Preference Structures}

We recognize that the average preferences may mask critical relationships when studying business structures and producers' economic behaviors (Pennings \& Leuthold, 2000). Hence, we account for the heterogeneity in the member-investors' preference structure for the attributes that make up a co-op firm. Memberinvestors involved in collective action often strive to influence corporate structure and decisions to reflect their self-interest and preferences, resulting in organizational policies that fail to benefit the membership as a whole (Olson, 1971, Vitali- 
ano, 1983; Cook, 1995). As such, member-investors exhibit opportunistic behavior and may have different preferences for specific intra-organizational and strategic attributes of co-ops (Buccola \& Subaei, 1985; Banerjee et al., 2001). Opportunism follows from the notion that partners in an economic exchange are motivated by self-interest and are likely to exploit the situation, if they can, to further their selfinterest and economic incentives (Singh \& Sirdeshmukh, 2000). That is, memberinvestors can possess disparate preferences for attribute alternatives, and disagreements can emerge as to which combination is the most desirable (Zusman, 1992).

Whereas co-op research has traditionally focused on the consequences of apriori heterogeneous preferences for single pricing and governance attributes (Cook et al., 2004), latent segmentation theory argues that unobserved heterogeneity in economic behavior can be identified through the careful examination of the underlying (latent) decision-making process of individual market participants (e.g. producers, investors, and consumers) in specific market contexts (Wedel \& Kamakura, 1998; Pennings \& Garcia, 2009). To capture the influence of latent heterogeneity in the member-investors' preference structure, we draw upon an approach that emphasizes the role of theory in the empirical analysis as attributes are used to discriminate among segments of members with similar preferences as well as to identify how observable (e.g., business size) and latent factors (e.g., risk attitude) affect the diversity in member preferences. The procedure allows for segmentation of member-investors based on their underlying (latent) decision-making process, and it is consistent with Heckman's (2001) thinking that the identification of unobservable heterogeneity is instrumental in explaining real-world economic phenomena, which are the outcomes of revealed economic behavior of market participants. We adopt this thinking and use latent segmentation theory to advance our understanding of how segments of member-investors may strive for corporate policies that reflect their own preference structure (e.g., derived utility) for co-op attribute alternatives.

\section{Decoupling Consumer Risk Behavior Over Time}

Recent research has argued that, while 'perceived risk' has often been used as an explanatory variable in studying risk behavior, the decisions of market participants can be better understood by decoupling their risk behavior into the separate components attitude and perception (e.g., March \& Shapira, 1987; Weber \& Milliman, 1997; Pennings et al., 2002; Pennings \& Wansink, 2004; Nosic \& Weber, 2007). Particularly, Pennings et al., (2002) propose a new framework for examining con- 
sumer risk behavior as consisting of two dimensions that play a crucial role in how consumers make decisions in a market crisis situation: a) the content of risk; and b) the chance of exposure to the risk content. These two dimensions are strongly linked to the two fundamental drivers of an individual's decision-making behavior under risk: risk attitude and risk perception. This approach is different from the perceived-risk approach, which is often taken in marketing and consumer-behavior studies. It is rooted in disciplines such as economics and statistical decision theory and it is particularly useful in financial and health-related domains where there can be wide differences between the risk attitudes and perceptions of individual market participants (March \& Shapira, 1987; MacCrimmon \& Wehrung, 1990; Schroeder et al., 2007)

Based on the seminal works of Arrow (1971) and Pratt (1964) regarding the drivers of risk premium, Pennings et al., (2002) and Pennings \& Wansink (2004) provide further insights into the separate components of consumer risk behavior. They argue that not only risk attitude and risk perception, but also the interaction between risk attitude and perception, drive consumer risk behavior (see: Pennings $\&$ Wansink, 2004). By decoupling consumer risk behavior into the separate components of risk attitude, risk perception, and the interaction of the two, a more robust conceptualization and prediction of the puzzling consumer reactions to a market crisis situation may be possible. Consumers risk reactions are not often consistent with the "actual" level of risk that they face in different crisis phases. We expand the economics and statistical decision view of consumer risk behavior by hypothesizing that risk attitude, risk perception and their interaction not only drive a consumer's decision with respect to participation in the consumption of a product, but also his/her decision about the amount of product to be consumed over time. Specifically, we draw on recent management science theory which argues that the ongoing update of the components of the decision-making process have an incremental and continuous character in context-based decision environments (Hogarth 1981; Kleinmuntz, 1985; Endsley, 1995). We account for the dynamic adjustment of the determinants of consumer risk behavior in and across market crisis phases (i.e., pre, incipient and post-phases of a product-harm crisis). Therefore, we view the decision-making behavior of a consumer as a part of a dynamic decision problem that does not simply terminate with a decision at a specific point in time (i.e., in a specific crisis phase). Instead, the behavior of an individual consumer during the phas- 
es of a product-harm crisis may be adaptive to the contingent conditions occurring in a dynamic decision environment.

In sum, we mainly employ industrial organizational theory, commitment theory, multi-attribute decision theory, latent segmentation theory, and consumer risk-behavior foundations rooted in economics and statistical decision theory in developing the conceptual frameworks in each of the chapters. Using these theoretical foundations allows us to make predictions about the latent and observable factors that drive revealed economic behavior (i.e., derived utility) of individual market participants in dynamic and naturalistic decision environments. ${ }^{1}$ Hence, a more comprehensive array of knowledge is generated regarding the behavior of market participants (in the food industry), who are increasingly confronted with important and complex decisions.

\subsection{Research Objectives}

This dissertation bundles three empirical studies that revolve around the revealed economic behavior of individual market participants, as well as the latent and observable factors that drive this behavior. The insights that emerge from these studies have implications for marketers, financial analysts, and public policy-makers when it comes to the design of organizational and supply-chain management strategies. The major link between these three studies is the overall focus on identifying and understanding the nature and the drivers of the latent decision-making process of "real" individual market participants (Figure 1.1)

\footnotetext{
${ }^{1}$ The terms naturalistic decision-making and naturalistic decision environment emerged in economics research in the late 1980s and refer to the study of how people make decisions in real-world settings (see: Zsambok \& Klein, 1997).
} 


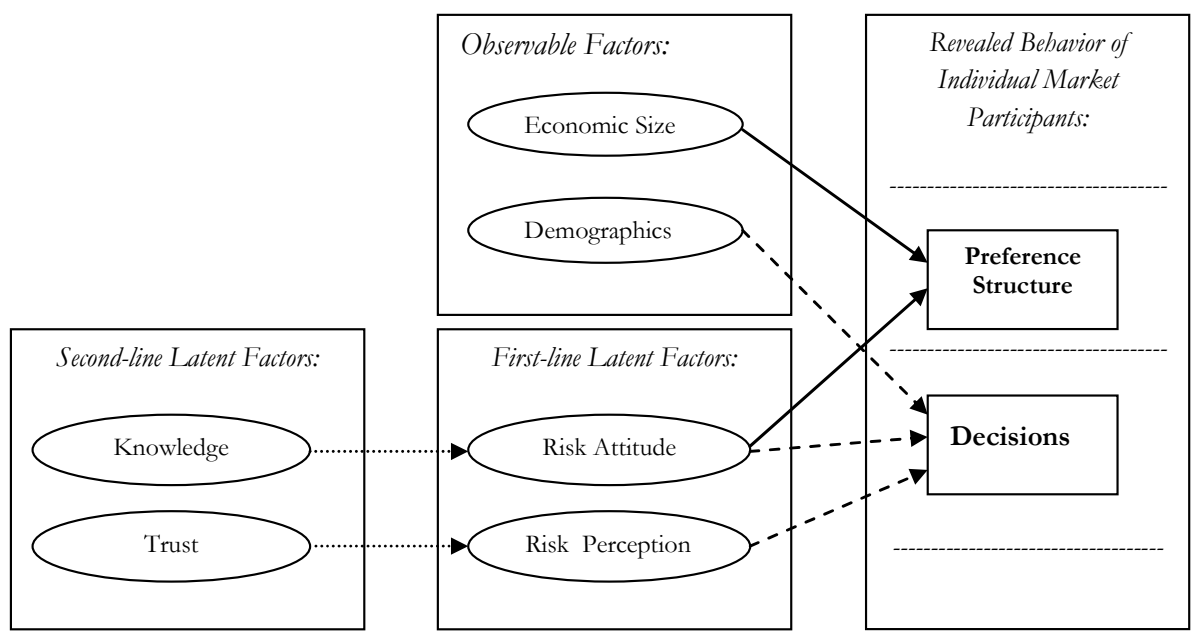

Figure 1.1 Revealed Economic Behavior: Relationships Examined in this Dissertation

Specifically, chapter two analyses the overall utility that member-investors derive from the multidimensional structure of a marketing institution. Chapter three identifies the heterogeneous preferences of member-investors for the attributes that make up the structure of a marketing institution, as well as the factors (economic size and risk attitude) that drive heterogeneity. In Figure 1.1., these relationships are displayed with solid arrows. Finally, chapter four examines the drivers (first-line latent factors: risk attitude, risk perception and the interaction of the two) of consumer risk behavior within and across the phases of a product-harm crisis and the factors (second-line latent factors: knowledge and trust) that influence the changes of these drivers over time. In the figure above, the hypothesized relationships are indicated by the dashed arrows. Below, we discuss in more detail these hypothesized relationships and we define the research objectives of each study.

\subsubsection{Chapter 2: Background \& Objectives}

Chapter two addresses member-investors' preferences for the structure of a voluntary marketing institution (VMI). According to Meulenberg (1997; 2000), these institutions take an intermediate position in the spectrum of different marketing institutions: Government-owned marketing institutions - Government-controlled marketing institutions - Government-supported marketing institutions - Voluntarily marketing institutions (VMI) - Individual Company or Investor-owned firm (IOF). The economic function of a VMI is the maximization of net proceeds for its 
participating member firms, which can be achieved by, e.g., adding value to the members' products or services. A prominent example of a VMI is the marketing co-op (MC) firm. Although voluntary co-operation has a long history and increasingly represents common innovation and branding strategies (Karantininis \& Nilsson, 2007), many collective partnerships tend to fail (Sivadas \& Dwyer, 2000) because the implementation of growth and market-oriented strategies require additional equity capital for the implementation of strategic marketing plans, which is not always available (Hart \& Moore, 1996; Hansmann, 1996).

In order to align the equity-capital requirements with a market-oriented strategic focus, MCs often emulate the organizational structure of investor-owned firms (IOFs). The lack of funding from internal sources, such as direct investments of participating member firms, forces MCs to seek for other funding sources and opportunities. MCs often merge, allow individualized equity shares, invite nonmember parties to finance their operations, and issue initial public offerings (Cook $\&$ Chaddad, 2004). Yet, these efforts are not always in line with the interests of the member-investors and may therefore reduce their commitment (Fulton, 1999; Fulton \& Giannakas, 2001). Commitment implies that market participants are confident about the stability of the economic relationships that they develop with other parties (Anderson \& Weitz, 1989). The realization of long-term benefits requires the development of stable relationships among market participants who pursue common strategic goals (Dwyer et al., 1987).

Commitment to the activities of a marketing institution is critical for an MC's success in the marketplace. This success is linked to a marketing institution's ability to develop differentiated products or services that are desired by its customers (Anderson \& Weitz, 1992). The development of niche products may raise the product's/service's price without a significant decrease in market share (Robinson \& Fornell, 1985; Kalyanaram et al., 1995). Marketing institutions that enjoy high commitment have also developed a niche product/service that is highly desired by its investors (Stern \& El-Ansary, 1990; Anderson \& Narus, 1990). Commitment is important to MCs because the active participation and loyalty of their memberinvestors are crucial for the success of these co-ops in the marketplace (Hakelius, 1996). Co-op policies that provide member-investors with additional benefits (e.g., investments further down the supply chain) may provide solutions to problems associated with opportunistic behavior by member-investors (Olson, 1971; Sexton 
\& Sexton, 1987). Member-investors may perceive an MC as low-quality when they believe that aspects of its organizational structure do not capture their economic incentives. The source of this perceived quality is the overall utility (e.g., preferences) that member-investors derive from patronizing the MC (Fulton \& Giannakas, 2001). The revealed preference structure (i.e., derived utility) of memberinvestors for several aspects of an MC may provide useful insights on which aspects are more preferred than others and hence enhance their commitment to the economic activities of this firm, for example, through extra investments.

Therefore, the objective of chapter two is to examine how member-investors evaluate the aspects that make up the structure of an $\mathrm{MC}$ and that are hypothesized to be important for members' commitment. Specifically, building on the premise that an MC can be viewed as a system of attributes (Milgrom \& Roberts, 1990; Holmstrom \& Milgrom, 1994; Hendrikse \& Veerman, 1997; Bijman, 2002), we assess the utility that individual member-investors derive from the intraorganizational and strategic attributes of an MC's organizational structure.

\subsubsection{Chapter 3: Background \& Objectives}

Chapter three examines the heterogeneous preferences of an MC's memberinvestors. This examination has been inspired by Heckmann's Nobel lecture (2001), which emphasizes that the heterogeneity in economic behavior can only be understood when identifying and examining the underlying decision-making process of individual market participants. Zusman, (1992) and Bijman (2002), among others, argue that member-investors of an MC firm can possess diverse preferences for attribute alternatives, and disagreements can emerge as to which combination is most desirable. Conflicting preferences, which are most likely to emerge in periods of organizational transition (Holmstrom, 1999), can cause inefficient resource allocation (Staatz, 1983) and force co-ops to adapt (Cook, 1995). As analyzed by several co-op scholars (e.g., Vitaliano, 1983; Hansmann, 1996; Cook et al., 2004), financial economists (e.g., Jensen \& Mecking, 1974; Copeland \& Weston, 1983; Jensen, 1993), and theoretical economists (e.g., Myerson, 1979; Holmstrom \& Milgrom, 1994), the divergence in incentives and preferences of member-investors with diverse characteristics is particularly problematic for the assignment of contractual property rights and corporate governance/control.

Member-investors of an MC with different characteristics and conflicting preferences are expected to compete for rents (e.g., Staatz, 1983; Buccola \& Subaei, 
1985; Banerjee et al., 2001) due to their diverse economic interests and characteristics such as their business size and risk attitude. Differences in member-investors' business size and risk-taking behavior have been hypothesized to affect their efforts to capture rents generated by the risk-bearing capital activities of co-ops (e.g., Banerjee et al., 2001; Gripsurd et al., 2001; Zusman, 1992). These differences often result in increasing conflicting preferences of member-investors. Subsequently, increasing heterogeneity in preferences may result in member-investors' declining commitment, decreasing willingness to provide equity capital, increasing influence costs, and incoherent strategic focus (Cook, 1995, Hansmann, 1996, Fulton \& Giannakas, 2001).

Therefore, the objective of chapter three is to extend the literature by identifying the heterogeneity in member-investors' preferences (i.e., utility) for intraorganizational and strategic co-op attributes, and examine the effects of business size and risk attitude on these preferences. We focus on the study of attributes related to the co-op's equity, control, benefits' allocation, and strategic positioning. We selected these attributes because they are at the core of collective co-op structures and important for understanding the relationship between the internal structure and the co-op's choice, particularly in a competitive marketing environment (e.g., Meulenberg, 1979, 2000; Barton, 1989; Hendrikse \& Veerman, 1997; Bijman, 2002). Further, we examine how the inconsistency in the revealed preference-structure between segments of member-investors is affected by their business size and risk attitude (e.g., Banerjee et al., 2001; Buccola \& Subaei, 1985; Staatz, 1983; Zusman, 1992) to explain differences in preferences.

\subsubsection{Chapter 4: Background \& Objectives}

In chapter four, we study consumer risk behavior during a market crisis (i.e., a product-harm crisis). Marketing and financial economics research indicate that a product-harm crisis may substantially affect business reputations and sales, change consumers' perceptions and behaviors with respect to a particular product, service or brand, and compromise an entire industry (e.g., Shrivistava et al., 1988; Dawar \& Pillutla, 2000; Marsh et al., 2004; Chu et al., 2005). Recent research suggested that decomposing consumer risk behavior into the separate components of risk perception and risk attitude leads to a more robust conceptualization and prediction of consumers' risk responses (Shapira, 1995; Pennings et al., 2002; Pennings $\&$ Wansink, 2004). Furthermore, it has been argued that the influence of risk atti- 
tudes and risk perceptions on consumer behavior can be used to formulate effective marketing strategies in case of a product-harm crisis (Pennings et al., 2002; Schroeder et al., 2007).

In addition, recent research showed that the influences of the risk attitude and risk perception on consumer risk behavior vary across different segments of the population at specific points in time and therefore suggest that each segment requires specific strategies and policies (e.g., Pennings et al., 2002; Schroeder et al., 2007). Yet, the impact of these risk variables on risk behavior changes over time, for example, due to changes in the decision environment. Studies in marketing (e.g., van Heerde et al., 2007; Cleeren et al., 2008) and health economics (e.g., Viscusi, 1993) suggest that the risk reactions of consumers may change across the different phases of a product-harm crisis (pre-, incipient- and post-crisis phases) as a result of changes in consumers' assumptions about safety. The decision-making behavior of individuals has been argued to be adaptive to the specificities of "realworld" contingent market conditions (e.g., Hogarth, 1981; Klein et al., 1993, Wiggins \& O’Hare, 1995). Thus, time variation in the determinants of consumer risk behavior (i.e., risk attitudes, risk perceptions and the interaction between them) should be taken into account to better understand the dynamic nature of consumers' decision-making processes. The presence of time effects captures the dynamics of the decision environment (i.e., the contingent context) within and across the different phases of a product-harm crisis (Lowenstein \& Mather, 1990; Johnston, 2001; Kotler, 2002).

Moreover, consumers may change their attitudes and perceptions as they gain experience with the nature of a decision event or the attributes of a product/service (e.g., Hoch \& Deighton, 1989). Differences in attitudes and perceptions arise as consumers become more knowledgeable over time with respect to the content of the attributes of a product/service and gain more trust in the information provided about this content (e.g., Moorman et al., 1992; Alba \& Hutchinson, 2000). In other words, the identification and examination of the drivers of risk attitudes and perception over time may reveal crucial information about the impact of these factors on consumer decision making within and across different phases of a product-harm crisis. Therefore, the objectives of chapter four are: a) to evaluate consumer risk attitudes towards and risk perceptions of a harmed product across different countries in which different contingent market conditions occur b) to quan- 
tify how these attitudes and perceptions affect the consumption of the harmed product within and across different crisis phases, and c) to examine how latent factors (e.g., knowledge, trust) influence consumers' risk attitudes and perceptions within different crisis phases.

\subsection{Decision Context Characteristics}

The empirical studies in this dissertation include the following distinguishing features in their decision contexts: the individuals' relevance to the decision environment; the high familiarity of "real" individual decision makers with the decision contexts; the fairly large samples; and the combined application of direct measurement techniques (qualitative and quantitative) at a highly disaggregate level.

\subsubsection{Individual's Relevance to the Decision Environment}

The first distinguishing characteristic of the empirical studies in this dissertation is the highly relevant decision environment in which individual market participants were asked to express their preferences, make decisions, and express their attitudes and perceptions. The systematic measurement of behavior was conducted in naturalistic and dynamic decision contexts: the interviews with producers were conducted at their farms, and the interviews with consumers were conducted at grocery malls.

\section{Member-investor Preferences for the Restructuring of an $M C$}

In chapters two and three, we study empirically the behavior of member-investors of an MC (VTN/The Greenery-TG) in the Netherlands. The VTN/TG offers a unique opportunity to study member behavior because it has passed through several restructuring phases historically. Co-ops are dominant in the Dutch economy, particularly in banking, financial services and agribusiness. In the last decade, similar to many US co-ops, Dutch co-ops have restructured their economic activities, evolving towards entrepreneurial organizations that increasingly adopt IOF-like organizational characteristics. The Nationale Cooperatiëve Raad (NCR) - the Federation of Agricultural Cooperatives in the Netherlands - indicated that the interest in co-ops continued to increase in 2008, despite the effects of the credit crisis in the Dutch and European agribusiness sector (AGD, 2008). In response to the 
changing economic environment, the structure of many co-ops and their relationship with members has changed considerably.

We had the opportunity to study member-investor preferences for an MC's organizational structure at a point when there were several indications of a lack of commitment due to the co-op's equity constraints and a perceived mismatch between the vision of the members and the corporate strategic goals of the institution. Particularly, member-investors felt that their interests were not represented in the corporate decision-making procedures and that they had lost control over the marketing policy. These conditions resulted in the exit of large-sized members, which had a substantial impact on the financial performance of the MC. Members regularly expressed their concerns regarding the transparency of management and the high degree of uncertainty with respect to cost-benefit-allocation mechanisms. Several efforts have been made to develop an organizational decision-making structure that could satisfy the members' demands and needs. In fact, the organizational restructuring of the VTN/The Greenery is an ongoing process, highlighting the importance of this research from a methodological as well as an applied economics perspective.

\section{Consumers' Risk Response in Times of a Product-Harm Crisis}

In Chapter 4 we study empirically the puzzling behavior of consumers in a marketcrisis setting in two major economies: the US and Germany. We conducted natural experiments when the devastating impact of the mad cow crisis on the demand for beef was in the headlines of the Wall Street Journal, Financial Times, CNN, and other global media networks. Consumer concerns about the BSE crisis were aligned with the scientific fact that contaminated beef can cause the fatal "Creutzfeldt-Jacob Disease - (CJD)". It seems that consumer behavior in these types of product-harm crisis is not always consistent with the actual level of risk faced. Although the World Health Organization had confirmed that the chance of contracting CJD by eating beef was extremely small (clearly below 1\%), beef consumption decreased dramatically in Germany when the first BSE case was detected (November 26, 2000). In some cases, beef sales plunges of up to 90 percent were reported (Gfk, 2001). Although German beef consumption recovered slightly afterwards, demand kept showing an overall decline.

Only two years after the BSE outbreaks in Germany, outbreaks in the US were reported on December 23, 2003, causing the US to lose access to its traditional 
export market in Japan. Evidence shows that the security values of firms in the beef sector were negatively affected by the BSE event for a period of about three months (Tse \& Hackard, 2006; Jin \& Kim, 2008). Stock prices for restaurants and other food-related companies fell by up to $6 \%$ (Goldstein \& Wilson, 2005), and declining trends were visible in several other markets including Feeder Cattle Futures (FCF), which were decreased by up to $9 \%$ (FAS, 2004). Yet, the reactions of American consumers were much milder than those of German consumers: the decrease in beef sales was limited in the US and the downward effect dissipated within two weeks after the first media announcements of BSE (Kuchler \& Tegene, 2006).

\subsubsection{Disaggregate Analysis of "Real" Decision Maker Behaviors}

Most previous empirical studies have analyzed and modeled the decision-making behavior of individual market participants (e.g., producers' preferences for the structure of a marketing firm or consumers' reactions to a market crisis) only in descriptive case-based settings. Rather than attempting to quantify latent behavior, they focus on suggesting marketing strategies. These studies are typically conducted with convenient samples (i.e., students) rather than relevant samples (i.e., real producers and consumers), use hypothetical decision contexts (e.g., lab experiments) rather than non-hypothetical decision contexts (e.g., field studies), and employ aggregate (macroeconomic) performance indicators rather than disaggregate (microeconomic) analytical measures. Furthermore, the use of experimentally manipulated hypothetical decision contexts limits the external validity of insights and inferences drawn from them, and the use of aggregate performance metrics may not be as informative as more disaggregate measures. Following closely the thinking of Vernon, L. Smith (1982; 2003), Nobel prize winner in economics in 2002, we focus our examination on the behavior of "real" market participants (i.e., producers and consumers), who are "real" decision makers familiar with non-hypothetical decision contexts in which their decisions have real consequences for them. We seek to quantify latent behavior at a highly disaggregate level.

\section{Field Studies with Individual Member-Investors of an MC firm}

The research objectives of chapter two and three were addressed by using a combination of qualitative (i.e., archived data sources, in-depth interviews and focusgroup discussions) and quantitative survey techniques (conjoint design). As noted, 
the producers (i.e., farmers) are member-investors of an MC firm that has passed through several re-structuring phases. Member-investors participated in two focusgroup discussions and were selected to provide a wide range of characteristics including age; region; differences in products; enterprise age and structure; and involvement in the corporate decision making of the MC. Members who participated in the conjoint interviews were selected using a stratified sample design accounting for their economic size and involvement in corporate decision making. The structure of this sample design allowed for a representative range of investor-members who were aware of the restructuring phases of the MC. Both the use of a case-study method (i.e., examining the behavior of the member-investors of only one marketing co-op) and the quantification of individuals' decision-making processes provide an opportunity to gain insights regarding member preferences for the co-op's structure at a highly disaggregated level. This research design allows the empirical assessment of the factors, which, in more aggregate analysis, are often hypothesized to drive economic behavior.

\section{Individual Consumers' Risk Behavior in a Highly Uncertain Environment}

Chapter four employed a longitudinal between-subjects research design to examine the risk reactions of American and German consumers to the BSE crisis in different crisis phases (e.g., pre-crisis, incipient, and post-crisis phases). Since natural hazards and product-related crises (e.g., food scares, disease epidemics, weather calamities, terrorist attacks, etc.) are unexpected and can compromise an entire industry, the selected decision context entailed high risk and uncertainty (e.g., a deadly outcome for consumers). This highly uncertain and risky decision context provided us with a unique opportunity to observe and analyze consumers' risk reactions to a market crisis over time. We conducted a qualitative study on risk-analysis dimensions (assessment, management, and communication) and risk reactions of consumers in both countries across several crisis phases in the period 2001-2004. We collected relevant information based on archived data sources including policy reports, newspaper articles, media, and industry announcements. The final field studies were conducted during a period in which the harmful effects were being highly publicized by the global media. The first data were collected during the first months of 2001. At the time, several cases of infected cattle had been reported in Germany - with the first case reported on November 26, 2000 - but no cases had yet been reported in the US. The second data were collected in the first two 
months of 2004, shortly after BSE had been confirmed in the US on December 23,2003 . The interviews in both countries and in each crisis phase were conducted in different cities and states in the US and Germany, resulting in a geographically diverse and representative sample of consumers in both countries.

\subsubsection{Sample Size \& Measurement Techniques}

Most studies dealing with the behavior of individual member-investors of an MC or consumers' risk reactions to a market crisis typically employ only a small number of respondents. Also, they do not use direct measurement techniques (face-toface interviews) but rather online data-gathering instruments. The empirical studies in this dissertation employ fairly large samples collected through face-to-face interviews. In chapters two and three, several co-op experts and managers of the VTN/TG participated in in-depth interviews, 30 member-investors participated in two focus-group discussions (15 in each session), 8 member-investors participated in a pilot test, and 120 member-investors participated in the final field study. In chapter four, a total of 228 Americans and 298 Germans were interviewed in 2001; 595 American and 301 German consumers were interviewed in 2004 while a pilot test on 10 consumers was conducted in each country to check the degree to which consumers could easily understand the content of the questions.

\subsection{Dissertation Outline}

The dissertation contains three empirical studies dealing with the behavior of individual market participants, which are discussed in chapters two, three and four, respectively. The data for these studies were collected in large-scale field studies of the Dutch agribusiness sector and in the American and German food-retailing markets. Table 1.1 offers a summary of the outline of the chapters with respect to their objectives, research context, data-collection procedures, as well as modeling approaches employed for the analyses. The final chapter, chapter 5 , contains a summary of the major findings of the empirical studies, offers an overview of the theoretical and managerial implications, and discusses several research caveats and directions for future research. 
Table 1.1 Overview of Chapters

Chapter Study Objectives Research Context $\begin{aligned} & \text { Data-collection } \\ & \text { Procedure }\end{aligned} \quad$ Model

$1 \quad$ Introduction

2 Study 1: The struc- Evaluating those ture of a marketing aspects of a marketco-op: ing co-op's structure A member-investors' that are hypothesized perspective to be important for member-investors' commitment

3 Study 2: UnderIdentifying the standing the hetero- heterogeneity in geneous preferences member-investor of co-op member- $\quad$ preferences (i.e., investors utility) for the attributes of a marketing co-op and assessing the factors that affect these preferences Study 3: Consu-mer Exa risk behavior in times of crisis:

Examining the drivers of consumer A natural experiment and across different phases of a productharm crisis and the factors impacting changing risk attitudes and perceptions.
158 Dutch produc- 2 focus-groups (15 ers, member-investors participants in each of a marketing co-op session); 8 face-to-face interviews for the pilot test; and 120 face-toface interviews on an individual basis in the final field study

158 Dutch produc- 2 focus-group discus- Generalized ers, member-investors sions ( 15 participants in mixture model of a marketing co-op each session); 8 face-to face interviews for the pilot test; and 120 faceto-face interviews on an individual basis in the final field study

238 American and 308 German con-

10 face-to-face interviews for the pilot test and bivariate sumers in 2001; and in the US and Germany censored regres595 American and in 2001. Face-to-face sion 301 German con- $\quad$ interviews with 228 sumers in 2004 in the Americans and 298 food-retailing market Germans in 2001 and 595 Americans and 301 Germans in 2004 in grocery malls of big cities across different states 



\section{Chapter 2}

\section{The STRUCTURE OF A MARKETING COOPERATIVE: A MEMBER-INVESTORS' PERSPECTIVE}

This chapter examines marketing cooperative's (MC's) structure from a memberinvestors' perspective. We support the notion that the utility that member-investors (i.e., producers) derive from the attributes of an MC structure enhances our insight in producers' commitment. Using a conjoint experimental design, we elicit the utility that producers attach to attributes of an MC. These attributes are related to the MC's intraorganizational structure and strategic behavior. The results of 120 producers of a Dutch $M C$ operating in the horticultural sector show that the selected attributes are significant drivers of producers' utility. In particular, producers attach high importance to strategic attributes and prefer a more individualized intra-organizational structure.

This chapter has been published as Kalogeras, N., Pennings, J.M.E., Van Dijk, G., Van der Lans, I.A. (2007). The Structure of a Marketing Cooperative: A Members' Perspective. In: Karantinis, K., \& Nilsson, J. (Eds.) Vertical Markets and Cooperative Hierarchies. Dordrecht, The Netherlands: Springer Academic Publications, pp. 73-92. 


\subsection{Introduction ${ }^{2}$}

Many marketing cooperatives (MCs) in the agribusiness sector have modified their organizational structures because of changes in agricultural policy (Sexton, 1990), technology and member-investors' individualism (Fulton, 1995), consumer concerns about food quality and safety (Meulenberg, 2000), and globalization (Cook, 1997). ${ }^{3}$

In response to the changing economic environment, the structure of many cooperatives (co-ops) and the relationships with their members have changed considerably after the 1990s. Today's co-ops have changed or are considering a change in their corporate governance operations, equity structures, benefits allocation mechanisms, and strategic business behavior. During this transition process co-ops abandon their passive service-oriented role and move towards an active customeroriented role (Van Dijk \& Mackel, 1991) by adopting more "member-investor"oriented (Cook \& Chaddad, 2004) and/or “individualized" (Van Bekkum, 2001) organizational structures. However, the effect of these structural changes for co-op members' commitment and satisfaction has raised questions for scholars and practitioners.

Members' dissatisfaction seems to have increased as new forms of governance and strategic behavior have led producers to question whether co-ops are acting in their best interest (Fulton, 1999). Active participation and member loyalty are crucial for the success of the co-ops (Hakelius, 1996). Hence, attention is centered on the member firms and the question that emerges is how one can evaluate the co-op's organization structure in the light of members' commitment. Failure to identify and evaluate members' preferences for the aspects of co-op structures may result in declining market shares (Fulton \& Gibbings, 2000) and financial pressures (Anderson \& Henehan, 2002). Co-op quality might be perceived to be low when members believe that the elements of its structure do not capture their economic interests (Fulton \& Giannakas, 2001).

The research question addressed in this paper is how members evaluate the aspects that make up a co-op structure and that are hypothesized to be important for

\footnotetext{
${ }^{2}$ The authors gratefully acknowledge all the members of the VTN/The Greenery, who participated in the focus-group sessions (30), pilot test-study (8) and final field study (120).

${ }^{3}$ Henceforth, we refer to "member-investor(s)" as "member(s)".
} 
members' commitment. Information about these structural aspects may be crucial for the management and re-structuring of co-ops. Co-op policies that provide members with additional benefits (e.g., to invest further down the supply chain) to those being provided collectively may solve collective action problems (Olson, 1971) such as opportunistic behavior of members to deliver their produce to an investor-owned firm (IOF) if they are given the incentive (better price) (Sexton $\&$ Sexton, 1987). Cotterill (2001) calls for empirical advances (i.e., solid case studies and quantitative analysis of real world applications) beyond the conceptual stage to study membership commitment. Therefore, the empirical study of member preferences for an MC structural aspects, which are directly linked to the degree that an $\mathrm{MC}$ is perceived to act as an agent that captures their economic interests, is a challenging task.

We study members' preferences for two classes of attributes (i.e., intraorganizational and strategic) that make up the structure an $\mathrm{MC}$ and that are hypothesized to be important for members' commitment. The empirical study concerns a Dutch MC operating in the horticultural sector, the VTN/The Greenery. The remainder of the paper is structured as follows. First, we discuss the crucial role of member commitment in a co-op business setting. Second, we specify the methodology and model to study members' preferences for co-op structures. Third, we elaborate on the formation of the VTN/The Greenery's structure. Fourth, the study's design is described in detail. The presentation of the results and a discussion on them follow. Finally, managerial implications of the results are mentioned and suggestions for further research are made.

\subsection{Members' Commitment}

Commitment implies that market participants are confident about the stability of the economic relationships that they develop with other parties (Anderson \& Weitz, 1989). The realization of benefits requires the development of stable relationships among investors who pursue common strategic goals (Dwyer et al., 1987). Marketing institutions that enjoy high commitment, also develop a niche product/service that is highly desired by its investors (Stern \& El-Ansary, 1990; Anderson \& Narus, 1990). Member commitment is a critical issue for co-ops' success in the marketplace, because it may be viewed as a measure of how well a coop is able to differentiate itself from an investor-owned firm - IOF (Hakelious, 
1996; Fulton, 1999). The greater the co-op's ability to differentiate from an IOF, the greater the retaining and expansion of its market share (Fulton \& Giannakas, 2001).

There are three principles that distinguish the aspects of co-op's organizational structure from other businesses' structures (e.g., from an IOF): user-owner, usercontroller, and user-benefit principles. Members are those persons, market participants, who own, use and control the co-op and receive co-op benefits on the basis of their use (Barton, 1989). Yet, in order to align the equity-capital requirements with a market-oriented strategic focus and maintain member commitment, co-ops often emulate the organizational structure of IOFs. The lack of funding from internal sources, such as direct investments of participating member firms, forces MCs to seek for other funding sources and opportunities. For instance, MCs often merge, allow individualized equity shares, invite non-member parties to finance their operations, and issue initial public offerings (Cook \& Chaddad, 2004, Van Bekkum and Bijman, 2006). However, these efforts are not always in line with the interests of co-op members and may therefore reduce their commitment (Fulton, 1999; Fulton \& Giannakas, 2001). Co-op policies that provide member with additional benefits (e.g., investments further down the supply chain) may provide solutions to free rider problems (Olson, 1971; Sexton \& Sexton, 1987).

Members may perceive an MC as low-quality when they believe that aspects of its organizational structure do not capture their economic incentives. Fulton (1999) supports that members may have dual incentives; while they would like to see the co-op raise the product prices paid to its members or advance its processing capacities and technology, they may not necessarily have the incentive to use co-op services or to invest more of their own equity into co-op activities. Fulton \& Giannakas (2001) explain that commitment to co-op activities (e.g., contribute capital to the co-op) increases when members perceive co-op's quality as high. The source of this perceived quality reflects the overall utility (e.g., preferences) that members derive from patronizing the MC. The revealed preference structure (i.e., derived utility) of members for several aspects of an MC may provide useful insights on what aspects are more preferred than others, and hence enhance their commitment to the economic activities of MCs.

Therefore, one may assume that members derive utility from selected aspects of an MC's structure. Building on the premise that a firm can be viewed as a sys- 
tem of attributes (Milgrom \& Roberts, 1990; Holmstrom \& Milgrom, 1994; Hendrikse \& Veerman, 1997; Bijman, 2002), we assess the utility that individual members derive from the attributes of an MC. Based on previous research that dealt with market-oriented and/or market-driven co-ops (e.g., Staatz, 1987a; Cobia, 1989; Peterson \& Anderson, 1996; Nilsson \& Van Dijk, 1997; Sykuta \& Cook, 2001; Kyriakopoulos et al., 2004), we propose that a MC's structure consists of two classes of attributes: intra-organizational attributes (MC's internal structure) and strategic behavior attributes. The control, equity formation and benefit allocation mechanisms are the three organizational attributes of the MC's internal structure. ${ }^{4}$ The strategic behavior attributes are related to the MC's strategic choices in developing and implementing a plan for success in the market place.

\subsection{Methodology \& Model}

Applied research in agribusiness economics and marketing-finance should confront models with micro-level data to investigate the drivers of behavior of market participants (e.g., producers) (Brorsen \& Irwin, 1996). In the organizational and management sciences literature the use of methodologies that are rooted in experimental and behavioral economics are emerging to study empirically the utility that individual decision makers derive from the attributes of a product or service (Schoemaker, 1982; 1993, Little, 1986). In the context of this study a behavioral methodology may be properly used to examine the utility that individual members derive from the attributes of an MC's structure. The assessment of this utility demands the consideration of subjective values (Keeney \& Raiffa 1972; 1993). Hence, the application of a suitable methodological approach, which allows the measurement and analysis of multi-attribute preferences, should consider how preference measurement parameters are elicited from the members' (subjects') holistic evaluative responses (overall utility) to different combinations of all the attributes. Statistical methods should then be applied to estimate the contribution of

\footnotetext{
${ }^{4}$ A detailed description about the different co-op attributes (i.e., intra-organizational) and models that vary from traditional to co-op inversed in an IOF (individualized business structure), is given by Cook \& Chaddad (2004), and Van Bekkum (2001) who uses an extreme classification of a collective versus an individualized structure in order to describe differences in the functionality of their organizational attributes.
} 
the attributes (and their levels) to the overall utility that members derive from a particular MC structure.

We use conjoint analysis to determine members' preferences for MC structures. Conjoint analysis is a multivariate market research technique which allows for the evaluation of the relative importance of a product's/service's attributes using preference ratings (Green $\&$ Wind, 1975). In contrast to expectancy-value models that utilize compositional approaches, conjoint methodology is based on a decompositional approach, in which subjects judge a set of "full profile" descriptions. Full profiles are constructed as combinations of levels of all attributes (one per attribute). They are bundles of attributes that make up the product, service or, in the context of this study, the organizational structure of the MC. This approach, which is based on some type of an additive or multiplicative rule, results in a set of part worths (i.e., values) for individual attributes that are most consistent with the subject's overall preferences (Green \& Srinivasan, 1978).

The use of conjoint analysis is grounded in the basic utility framework and assumes that decision-makers derive utility from the attributes of a product or service (Green \& Srinivasan, 1990). In this study it is assumed that the levels of the selected MC attributes contribute in an additive way to the members' overall utility as given in Equation 2.1:

$$
y_{j k}=\sum_{p=1}^{P} \sum_{l=1}^{L_{p}} x_{j k l p} \beta_{j l p}+e_{j k}
$$

where: $y_{j k}$ is the preference of member $j(j=1, \ldots, J)$ for profile $k(k=1, \ldots, K)$ which represents a hypothetical MC design; $p(p=1, \ldots, P)$ is an index for attributes, with $P$ being the total number of attributes; $l\left(l=1, \ldots, L_{p}\right)$ is an index for attribute levels with $L_{p}$ being the number of levels defined for attribute $p ; x_{j k l p}$ is a dummy variable that takes a value of 1 when level $l$ of attribute $p$ holds in profile $k$ for $j$ and $x_{j k l p}=0$ otherwise; $\beta_{j l p}$ is the utility that member $j$ attaches to level $l$ of attribute $p$, and $e_{j k}$ is a normal i.i.d. error term with variance $\sigma^{2}$. Based on the structure of preferences $\left(y_{j k}\right)$, which is often defined in terms of a specific scale or metric and the value of the dummy variables $\left(x_{j k l p}\right)$, the utility weights $\left(\beta_{j l p}\right)$ can be estimated for each member. The formulation simply assumes that the members add-up the values for each attribute (the part-worths) to assess the total value (sum of part-worths) for a combination of attributes that describes an MC's profile. 
In order to first explore and then examine the behavioral aspects of subjects' (members') decision making process, there is a need for a case study (Vazsonyi, 1990). In agribusiness marketing-finance research the use of case studies generates a robust and comprehensive array of knowledge (Sterns et al., 1998). We estimate the conjoint model specified in Equation 2.1 using experimental data collected from members of a Dutch MC operating in the horticultural sector. This research design allows us to examine the relative importance of an MC's intraorganizational and strategic attributes.

\subsection{Decision Context: VTN/The Greenery}

An example of an MC in which members have a prominent influence in the collective organizational structure and strategy is The Greenery (TG), which is a distribution, sales and marketing company of fresh produce (fruits and vegetables) established and operating in The Netherlands. The shares of the TG are owned by the horticultural co-op Voedings Tuinbouw Nederland (VTN). The VTN/TG emerged after a merger of nine co-op fruit and vegetable auctions in 1996. Here, we discuss the reasons for the transition of the co-op auctions into a single $\mathrm{MC}$ and the reaction of members to the transition, particularly their responses to the institutional arrangements. The VTN/TG is a representative example of the changes that have emerged in MCs because it has passed through several re-structuring phases and it provides a unique decision context because of the extent of information available in the form of past research.

\subsubsection{From an Auction to a Marketing Co-op}

The auctions had long been the logistic centers and the locus of price formation of fruit and vegetables marketing in The Netherlands. A serious disadvantage of the auction systems was that the information flow through the supply chain was limited to price information. The information flow through the chain about delivery conditions (special quality aspects, packaging, time and quantity of delivery, assortment) was low (Bijman, 2002). In addition, transaction costs in the auction system were high, particularly for large buyers since they had to have buying agents at each auction. Because the information flow regarding quality demanded by customers was not effective in the auction system, large buyers (e.g., supermarkets) 
started to bypass the auction and conduct business with the larger producers directly.

As a result, the co-op auctions were unable to keep the members loyal because solidarity among producers had disappeared. The merger of all horticultural auctions in order to achieve sufficient scale resulted in the VTN/TG. The business goal of the new organization was to rely on principles that reflect both market and production developments. The business plan involved: a) the separation of the coop (VTN) from the marketing company (TG) through the creation of autonomous legal entities to facilitate market-oriented strategies, and b) the appointment of professional managers to take over activities related to the organization's transition and marketing strategy (Veerman, 1998).

The organizational attributes (i.e., intra-organizational and strategic) of the new-established co-op and the response from its members are discussed. The information presented is based on a synthesis of various sources (personal contact with VTN/TG's members; managers; and personnel, annual reports and recent studies using the VTN/TG as a case study).

\subsubsection{The Structure of the New Co-op}

After the VTN/TG was established, both members and the leaders of TG had considerable freedom to pursue their views. The constitution of TG determined how business was to be conducted in the co-op setting. The case of TG is unique in that members are not as dependent on their co-op, for instance, as are the dairy farmers or the sugar beet growers (Van Dijk, 1999). The producers of fruit and vegetables are in the position to determine the product attributes themselves and, for the most part, are able to do the essential post-harvest handling as well. We discuss the developments and transition of internal organization of VTN/TG for the period 1996-2002.

\section{Cost-Benefits Distribution}

The VTN/TG developed a cost-benefit differential system based on cross-subsidies between various groups of producers. This mechanism discriminated prices per product category to reflect market prices and differentiated cost tariffs based on the volumes delivered by the producers. This pricing mechanism resulted in complaints as members questioned the transparency of the price formation. Some 
groups of members (e.g., cucumber producers) formed their own producer associations that negotiated product-related issues with the TG and with food retailers.

\section{Control Relations}

The VTN/TG's governance structure was developed such that the decision-making between TG and VTN is separated. In VTN, which has the legal structure of a coop, the ownership rights of members are exercised via regional representation (Figure 2.1). The general assembly of VTN consists of 105 members $(M)$ of regional boards (each of 15 regions provides seven representatives). These members elect the 11 members of VTN's board of directors (BOD). The VTN also has a supervisory board that consists of nine members. The co-op VTN is the owner of TG, which has the legal structure of a limited liability company under Dutch law (BV). For the period 1998-1999, TG was governed by a management board (six professionals: $P$ ) and was supervised by a board consisting of seven VTN members, other than the members in the BOD or in the Board of Supervisors of VTN. The Board of Supervisors of TG also included non-members.

\section{VTN Cooperative}
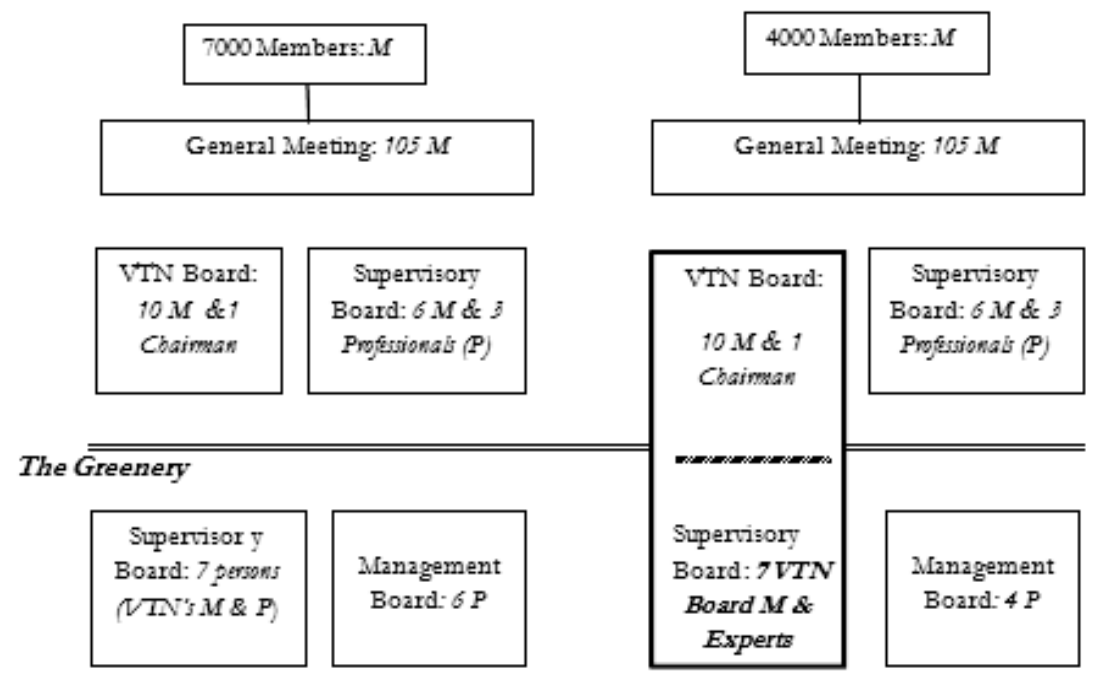

$1996-1999$

Figure 2.1 VTN/TG’s Corporate Control 
From the very beginning of the new organization's establishment, members did not only exercise control rights in VTN. They were also represented in the transaction relationship with TG through their Product Market Advisory Committees (PMACs). These committees acquired a formal decision-making role since 1999. PMACs aimed to be co-decision making bodies for different product market combinations and discuss product transaction issues. In PMACs both professional employees of TG and member representatives held a position. However, the formal separation in decision-making resulted in poor communication among members and VTN's BOD regarding the control of TG. Several times TG's management board was involved in conflicts with PMACs concerning selling policies. Members felt that the influence on TG's marketing policy was lost and their interests were not well represented by the governance structure of the organization (Van Dijk, 1999). Many of them exited VTN at that time. In 1998 several members of VTN's BOD and supervisory board resigned. Also, cost cutting strategies resulted in the canceling of positions of the management board of TG.

A direct and transparent link between VTN's Board and TG's supervisory board was demanded by members. Hence, a new corporate governance structure was formed after 1999. Since that time the BOD's members of VTN became members of the board of supervisors of TG at the same time. Also, in the supervisory board of TG participated non-member directors (i.e., experts), including the chairman (VTN Annual Reports 1998; 1999). Figure 2.1 depicts the role of various bodies with respect to these control relationships in VTN/TG in the two different periods. The number of member representatives (BOD) and professionals participating in these decision-making bodies are mentioned.

\section{Equity Capital}

The transition from an auction to an MC organization turned out to be more costly than expected. Additional equity capital needed to come from members' "out-ofpocket" investments for financing the implementation of the ambitious marketing plan. Special financial instruments (e.g., loans) were developed in cooperation with credit organizations (e.g., Rabobank) but were not successful because of members' low willingness to invest. The TG started issuing individual ownership titles (certificates) in addition to its equity capital in 1998 (TG Annual Report, 1998). Each member received $2.5 \%$ of his average patronage the last three years before the merger. Approximately $30 \%$ of shares were represented by unallocated equity. These 
were called A-shares and collectively held by VTN. The B-shares were allocated to members, who held certificates of B-shares. The VTN's BOD represented the control rights of both A-shares and B-shares. The income rights of B-shares were individualized (Kyriakopoulos, 2000).

\subsubsection{Strategic Behavior of VTN/TG}

The stated objective of VTN/TG was that it would be a market-oriented company. Market-orientation implies that marketing plays a central role in organizational policies. As a result, VTN/TG planned to implement some aggressive marketing strategies, but the high costs for marketing and innovation in combination with a low solvency made TG's marketing plan too ambitious and it could not always be executed. Marketing strategies that have been implemented include product differentiation, brand promotion, market research, product planning and innovation, logistics of high quality, and managerial expertise (TG Annual Report 2002). The market-oriented focused strategic plan was forced upon the producers by coercion (Kyriakopoulos, 2000).

\subsubsection{Members' Response: Loss of Commitment}

The members' lack of commitment because of the perceived mismatch between producers' and management's vision, resulted in the exit of a considerable number of members (Bijman, 2002). Members felt that their interests were not represented in the corporate decision-making procedures and they had lost control on the marketing policy. The exit of members had a substantial impact on the financial performance of TG as a large share of turnover was lost.

In the effort to "raise their voice" in the marketing of their produce the remaining members established producer associations. This development was also strongly stimulated by subsidies from the European Union (EU) for the establishment of marketing associations. The TG gradually acknowledged these associations and developed a "unity in diversity" policy that carries the greenery brand name for building a strong business image (TG Annual Report, 2002). The TG also acquired a few strong wholesale and exporting firms and integrated these with their own business units. This move towards forward integration in wholesaling activities was considered necessary for the successful implementation of its marketing strategy. 
Members regularly expressed their concerns regarding the transparency in the corporate management of the organization and regarding the high uncertainty with respect to cost-benefit allocation mechanisms. Several efforts were made for the development of an organizational decision-making structure which satisfies the members' demands and needs. In fact, the organizational restructuring of VTN/TG has been an ongoing process (personal contact, 2003).

In the next section, the design of the survey is presented.

\subsection{Research Design}

A field study was conducted in 2003. We used both qualitative and quantitative research techniques. Focus-group discussions were held with VTN/TG's members in spring and winter 2003. The results of these discussions were used as input for the design of conjoint data collection instrument. Below we present in detail the development of our data-gathering instrument.

\subsubsection{Identification of Attributes: A Focus-Group Study}

We identified the attributes of the $\mathrm{MC}$ and the corresponding levels based on the literature of co-ops. In addition we collected data of members using the focusgroup technique to empirically verify the attributes identified by our desk research (Shocker \& Srinivasan, 1979). This research design ensures that the attributes that we use in our final field study are based on theory and are relevant for our decision context, thereby minimizing response biases. Two focus-group sessions were conducted. Members were selected on the basis of demographic (lifetime of member's enterprise, region at which company is located), product related (nature of produce, protected or unprotected cultivation), economic (business size and structure), and the degree to which they are involved in the MC's decision making (e.g., participation in PMACs) criteria, to ensure that we had a representative sample of all members of the VTN/TG. Each session consisted of 15 members.

In both sessions members were asked to discuss the two broad categories of attributes (i.e., intra-organizational and strategic) that were assumed to make up the VTN/TG's structure. The two sessions were coordinated by an expert on co-op policy issues and an expert on research methodology to ensure a high degree of accuracy in the arguments and opinions of interviewed members. Members identified six attributes, each with two levels, as attributes that are very important to 
them when choosing among different types of MCs (table 2.1). Below we explain the attributes and their corresponding levels (i.e., alternatives).

Members' benefits. Members' opinions on how net income should be allocated were split. Some participants supported the traditional notion that performance should be based primarily on net price through a well-defined contract between the co-op and the member (i.e., based on a proportional pricing mechanism). Other members preferred a mechanism based on return on capital invested in addition to the product price.

Corporate governance. The need to ensure corporate control of VTN/TG's activities by effective collaboration among members, the board of directors (BODmembers' representatives) and hired managers was important to all participants. However the preferred structure of control (governance) varied. One form placed corporate control primarily in the hands of the BOD which would directly administer VTN (co-op) and supervise hired managers who would assume the role of board of directors of TG (marketing firm). The alternative form was for hired managers to administer VTN under the supervision of the BOD, and for managers to also administer TG (as in previous form) but under the supervision of a professional board. This professional supervisory board of directors (PSB) would include external non-member professionals (i.e., experts) and the member representatives would be a minority. The general assembly of members would appoint and supervise the PSB.

Product-related decision making. The relevant question here is: Who should determine VTN/TG's product quality, price setting and sales methods for different market segments? Members indicated their dissatisfaction with current pricing procedures and marketing strategies. Some members wanted to make decisions directly on these product-related issues themselves (through VTN BOD's, PMACs', and established crop-specific associations' representation), while others indicated that they were more comfortable placing the decisions in the hands of knowledgeable market managers.

Financial structure. Members explained that capitalization was a contentious and major problem for implementing VTN/TG's marketing plan. The introduction of individual ownership titles gave the residual right to members for cumulative preferential dividends and resulted in low equity/debt ratios for TG through 2002. Some members indicated that establishment of a traditional general reserves 
system might be the solution for increasing equity capital through retained earnings. In contrast, others preferred increasing VTN/TG's equity by issuing individual ownership titles.

Table 2.1 MC Attributes and Levels Identified in Focus-Group Study ${ }^{a}$

\begin{tabular}{|c|c|}
\hline Attributes & Attribute Levels (Alternatives) \\
\hline \multicolumn{2}{|l|}{ Intra-organizational } \\
\hline \multirow[t]{2}{*}{ Members' Benefits } & 1. Product price \\
\hline & 2. Product price and return on capital \\
\hline \multirow[t]{2}{*}{ Corporate Governance } & $\begin{array}{l}\text { 1.VTN: Board of Directors (BOD); } \\
\qquad G \text { : Managers supervised by VTN's BOD }\end{array}$ \\
\hline & $\begin{array}{l}\text { 2.VTN: Managers supervised by VTN's BOD; } \\
\text { TG: Managers supervised by } \text { PSB }^{c}\end{array}$ \\
\hline \multirow[t]{2}{*}{ Product-Related Decision Making } & 1. Members \\
\hline & 2. Managers \\
\hline \multirow[t]{2}{*}{ Financial Structure } & 1. General reserves \\
\hline & 2. Individualized equity \\
\hline \multicolumn{2}{|l|}{ Strategic } \\
\hline \multirow[t]{2}{*}{ Business Issue/Scope } & 1. Market-oriented organization \\
\hline & 2. Intermediary organization \\
\hline \multirow[t]{2}{*}{ Product Quality } & 1. General grading of products \\
\hline & 2. Client-specific grading of products \\
\hline
\end{tabular}

${ }^{a}$ MC refers to the VTN, which is the horticultural co-op Voedings Tuinbouw Nederland. TG is the Greenery (marketing firm) that markets fresh produce for the co-op VTN who is its only shareholder. ${ }^{\mathrm{b}}$ Each attribute has two levels (alternatives).

${ }^{\mathrm{c}} \mathrm{PSB}=$ professional supervisory board.

Business issue/scope. Members were concerned that the scope of VTN/TG's business operations did not capture their economic interests. Members indicated that VTN/TG needs to maintain its user orientation as it increases in economic size and managerial complexity. However, there were differences regarding whether VTN/TG should solely act as an intermediary channel that buys and sells its members' produce or be active in developing a more comprehensive market-oriented firm in its own right. 
Product quality. Finally the critical role of product quality in VTN/TG's marketing strategy received considerable attention. Two main strategies emerged. Several members felt that the co-op should follow a more traditional path of selling rather generic products using the market's general grading schemes. This strategy would be based on competitive prices, efficiency in production and logistics, and serve price-conscious consumers. In contrast, other members felt strongly that VTN/TG should focus on marketing products to meet client-specific quality needs.

\subsubsection{Conjoint Design}

The number of attributes allowed us to use a full-profile conjoint design. The main advantage of a full-profile approach is that it gives a realistic description of stimuli by defining the levels of each of the factors (Green \& Srinivasan, 1978). A 2 (Members' Benefits) $\times 2$ (Corporate Governance) $\times 2$ (Product-Related DecisionMaking $) \times 2$ (Financial Structure $) \times 2$ (Business Issue/Scope $) \times 2$ (Product Quality) fractional-factorial main-effect-only design generated a set of eight calibration profiles. In addition, three pairs of holdout profiles were generated. We chose the fractional-factorial main-effects-only design to keep the number of profiles to be evaluated at a level that could be managed by the respondents (Green, 1974, Hair et al., 1998).

A pilot test consisting of eight face-to-face interviews was conducted to check the face validity and degree of comprehensiveness of the conjoint task. Based on these interviews, the wording of the attributes was changed at some places. Respondents indicated that they understood the selected attributes and levels included in the hypothetical MC profiles and that they are actionable (i.e., realistic). ${ }^{5}$ The respondents in the pilot test expressed a desire to "build" their own VTN/TG's profile by choosing one of the two given levels of each examined attribute.

\footnotetext{
5 The evaluation process of communicable and actionable measures determines the degree to which the attributes and levels are easily communicable for realistic evaluation and capable of being put in practice, respectively. These technical terms as well as the evaluation of first-order interactions among the attributes of a product/service are described in detail by Hair et al., 1998 (pp. 405-407).
} 
We tested first-order interactions of the pilot test's preference data. No interactions were identified except for a low-level interaction between the attributes of financial structure and members' benefits. ${ }^{6}$

In the large-scale field study, respondents were asked to rate the eight calibration profiles according to their preferences on a nine-point rating scale, which ranged from one (least preferred) to nine (most preferred). Subsequently, the respondents were asked to choose their most preferred profile for each pair of holdout profiles, and rate the extent of their preference for that profile on a seven-point rating scale ranging from one (a little more preferred) to seven (much more preferred). The two rating scales adopted for the evaluation of conjoint profiles and holdout cases are interval and commonly used in conjoint experiments (Wedel \& Kamakura, 1998). Respondents were also asked to design their preferred co-op structure by selecting one of the two levels for each attribute.

For the large scale field study, respondents were selected on the basis of their economic size (i.e., members with high annual turnovers so they are not at margin and represent the future of co-op) and the degree of their involvement in the VTN/TG's decision-making functioning (e.g., participation in PMACs, BOD). Most interviews were conducted at the farm of the respondent and some at the annual meeting of the members in 2003. A total of 120 producers participated. All interviews were held on an individual basis and they were presented to the members through a computer-assisted display.

\subsection{Results \& Discussion}

The results of the additive conjoint model are presented in the table 2.2. The partworth estimates (i.e., the utilities of the attribute levels) show that for the attributes of corporate governance and product-related decision making the first levels are more preferred. That is, members prefer that the BOD of VTN also supervises TG. A similar result is found for the product-related decision-making attribute: Members prefer that they hold the control regarding decisions on transaction conditions (quantity, cost and quality of their produce). For the other two attributes of

\footnotetext{
${ }^{6}$ Such an interaction was somehow expected considering that the members' gains are closely related to the co-ops's net income allocation and equity redemption mechanisms. However, we kept these attributes within the conjoint design as they were stated by members participated in focus-group sessions.
} 
the intra-organizational structure of the VTN/TG the second levels were more preferred. That is, members prefer a more individualized equity structure based on dividend reward on their invested equity in addition to product price.

The conjoint results show that in the case of the strategic attributes members prefer to participate in a market-oriented organization. This implies a business model that is responsive to market intelligence and that supports grading lines based on product quality to fulfill the wishes of its existing or potential market segments. These findings confirm the theoretical work done by Van Dijk \& Mackel (1991); Cook (1995); Van Dijk (1999); Meulenberg (2000); and Cook \& Chaddad (2004), among others, who argue that many MCs adopt more individualized organizational structures (alike IOFs) and customer-oriented strategies. The regression coefficients of all six attributes (represented by average part worths - APWs - for each attribute level in table 2.2) indicate that the selected attributes are significant drivers of member preferences for the MC's structure, substantiating the validity of the chosen attributes in our experimental design.

In table 2.2 descriptive statistics of individual part worths are also presented. The standard deviation of part worths (presented in second column of table 2.2, Std.D., for each attribute) are relatively small compared to the estimated average values (mean) for each attribute and indicate that the $A P W s$ are accurate representations of members' ratings. In addition, the standard errors (second column of table 2.2, Std.E.), are small relative to sample mean ( $A P W$ of each attribute presented in first column of table 2.2) and imply that most individual member part worths are similar to the total sample mean. So we have several indications that the $A P W s$ of each attributes are accurate reflections of individual members' part worths. However, looking at the part worths for different percentiles (see percentiles presented in last three columns of table 2.2) some variability among individual preferences is identified. Individual member part worths vary below different percentile levels $(25,50,75)$. For example, the $75^{\text {th }}$ percentile (of a set of 100 numbers) for the attribute 'Business Issue/scope' has the value 0.625 , hence $75 \%$ of the estimated part worths have a value smaller than 0.625 ; the median of the set is the $50^{\text {th }}$ percentile. The percentile results show that the estimated conjoint model for each individual member follows a specific distribution based on his/her estimated part worths. These results indicate that individual member preferences vary in the sample. This may be due to the fact that the overall utility, which is the conceptual 
basis for measuring value in conjoint analysis, is a subjective judgment of preference unique to each individual.

Table 2.2 Average Part Worths (APWs) of MC's Attributes Based on Individual Estimates $(\mathrm{N}=120)^{\mathrm{a}, \mathrm{b}}$

\begin{tabular}{|c|c|c|c|c|c|c|}
\hline & \multirow[t]{2}{*}{$A P W s$} & \multirow[t]{2}{*}{ Std. D. } & \multirow[t]{2}{*}{ Std.E. } & \multicolumn{3}{|c|}{ Percentiles } \\
\hline & & & & 25 & 50 & 75 \\
\hline \multicolumn{7}{|l|}{ Intra-organizational Attributes } \\
\hline \multicolumn{7}{|l|}{ Members' Benefits } \\
\hline 1.Product price & -0.213 & & & & & \\
\hline 2.Product price $\&$ return on capital & $0.213^{*}$ & 0.515 & 0.047 & -0.125 & 0.125 & 0.500 \\
\hline \multicolumn{7}{|l|}{ Corporate Governance } \\
\hline \multicolumn{7}{|l|}{ 1. VTN: Board of Directors (BOD); } \\
\hline $\begin{array}{l}\text { 2.VTN:Managers supervised by VTN's BOD } \\
T G \text { : Managers supervised by } \text { PSB }^{c}\end{array}$ & -0.183 & 0.643 & 0.054 & -0.125 & 0.125 & 0.625 \\
\hline \multicolumn{7}{|l|}{ Product-Related Decision-making } \\
\hline 1.Members & $0.247^{*}$ & & & & & \\
\hline 2.Managers & -0.247 & 0.636 & 0.058 & -0.125 & 0.250 & 0.625 \\
\hline \multicolumn{7}{|l|}{ Financial Structure } \\
\hline 1.General reserves & -0.215 & & & & & \\
\hline 2.Individualized equity & $0.215^{*}$ & 0.501 & 0.046 & 0.500 & -0.125 & 0.125 \\
\hline \multicolumn{7}{|l|}{ Strategic Attributes } \\
\hline \multicolumn{7}{|l|}{ Business Issue/Scope } \\
\hline 1.Market-oriented organization & $0.309^{*}$ & & & & & \\
\hline 2.Intermediary organization & -0.309 & 0.560 & 0.051 & 0.000 & 0.250 & 0.625 \\
\hline \multicolumn{7}{|l|}{ Product Quality } \\
\hline 1.General grading of products & -0.271 & & & & & \\
\hline 2.Client-specific grading of products & $0.271^{*}$ & 0.571 & 0.052 & -0.125 & 0.250 & 0.625 \\
\hline
\end{tabular}

a Table 2.2 presents the estimated part-worth results for the selected attributes that drive members' overall utility of the MC's structure (dependent variable) based on individual estimates. The levels that have a positive APW (value) are the preferred ones.

b We tested the predictive validity for the individual part worth estimates by computing the Tucker Coefficient (Zegers and Berge, 1985) in order to identify the degree of association between the predicted and the observed ratings of holdout pairs. The results showed that almost all individual part worths' predictive validity is satisfactory. An extra validity test using the self-constructed MC most preferred levels revealed similarity with the predicted results derived from the ratings of the calibration profile.

${ }^{\mathrm{c}} \mathrm{PSB}=$ professional supervisory board.

${ }^{*} p<0.05$. 
In addition, we calculated the attributes' relative importance, based on the range of the attribute part-worth estimates (see Figure 2.2). ${ }^{7}$ The attributes related to the co-op strategic behavior, business issue/scope and product quality strategy are the most important. Members attach a high importance to the business issue/scope $(21.4 \%)$ and the product quality strategy $(18.7 \%)$. The attributes related to the intra-organizational structure are almost equally important except for the productrelated decision-making attribute $(17.2 \%)$. The attributes of the financial structure (14.9\%) and members' benefits $(14.8 \%)$ are less important. The corporate governance attributes has the lowest relative importance (13\%). These results indicate that members consider the examined strategic attributes as very important for the MC's structure. Members prefer the VTN/TG to behave as an entrepreneurial and market-oriented organization using a market segmentation strategy based on the superior quality of its products. The last reveals their high interest for investing via collective action in forward integration in the food supply chain. These findings are in line with notions from the theory of market participants' commitment in the operations of marketing channels and their participating institutions (e.g., Stern $\&$ El-Ansary, 1990; Anderson \& Weitz, 1992; Gilliland \& Bello, 2002). The members of the VTN/TG seem to anticipate benefits through the development of longterm, strategic, relationships between TG and other stakeholders (e.g., retailers, consumers) engaged in the food sector. Members also assign a high importance to the decision-making issues regarding the pricing, quantity and quality of their produce. This result may be caused by the fact that the members of TG were dissatisfied regarding the poor communication between members and experts on productrelated and marketing issues.

\footnotetext{
7 The range of the part-worth estimates was calculated for each attribute by taking differences between the highest and the lowest part-worth estimate. The sum of the ranges of all attributes equals to the total range. Dividing every individual attribute's range by the sum of the ranges across attributes and multiplying by 100 gives the relative importance of each attribute for members' preferences in terms of a percentage. For a more detailed description of attribute-importance calculations in conjoint analysis experiments see Hair $e t$ al., (1998).
} 
Members' Benefits

Corporate Governance

Product-related DM

Financial Structure

Business Issue/Scope

Product Quality

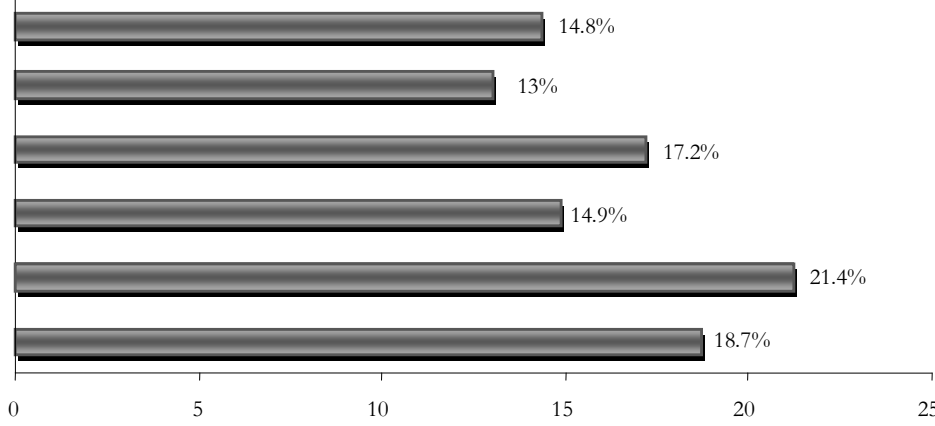

(\%)

Figure 2.2 Importance of MC's Attributes

Our findings confirm previous research in the co-op economics literature (e.g., Shaffer, 1987; Staatz, 1987b; Schrader, 1989; Peterson \& Anderson, 1996; Hakelious, 1996; Fulton, 1999; Kyriakopoulos et al., 2004) that argued that co-ops should better communicate product and service specification needs backward (member-suppliers) and forward (retailers, final consumers) in the food market chain in order to create value for their members' produce and enhance their members' commitment. Furthermore, these results confirm recent neo-institutional economic (organizational economic and strategic management) theoretical advances (e.g., Teece et al., 1997; Lewin \& Volberda, 1999; Sykuta \& Cook, 2001), namely that the competitive environment is reflected in the organizational structures and strategies of businesses.

\subsection{Conclusions}

An explicit hypothesis in the MCs' literature is that perceived quality of the co-op is the source of members' commitment. Perceived quality can be conceptualized as the utility that members derive from the use of the services provided by the co-op. The perceived quality will be high when members believe that the co-op operates on behalf of their interests as it attempts to meet the challenges posed by a competitive market place (Fulton \& Giannakas, 2001). In this study we investigated an MC's structure based on the attributes that are related to the internal organization and the strategic behavior of MCs. This paper is the first that empirically identifies 
the relevance of these attributes for co-op organizations from a member's perspective.

We developed an empirical research design to identify and evaluate the subjective utility that individual members attach to an $\mathrm{MC}$ attributes. The empirical context is the Dutch horticultural MC, the VTN/TG, an organization that resulted from a merger of co-op auctions. The transformation into an MC was confronted with a decline of members' commitment. The declining commitment of the VTN/TG members was caused by the corporate decision-making plan, product-related issues, and the transparency about cost-benefit allocations. The results show that members prefer to participate in a more entrepreneurial and marketoriented organization which will involve them in long-term relationships and develop a more direct link between its members and market segments. The high importance that members attach to product-related decision-making attributes reveals their preference for more active participation in functional operations at the upstream and downstream stages of the food supply chain. In addition, members prefer that their MC's equity structure moves from the proportional type of financial arrangements to a more investor-oriented one. This implies that members desire that the MC distributes benefits to members' shareholdings in addition to product price. The latter is a fundamental shift from the traditional co-op paradigm (Cook, 1995; Cook \& Chaddad, 2004). The results of the empirical analysis also show that the attributes that we identified (i.e., intra-organizational and strategic attributes), drive members' preferences (utility) regarding the MC's structure.

The findings of this study may have managerial implications for MC's organizations. The great importance that members attach to the strategic attributes suggests that members prefer to benefit from market opportunities via the vertical integration offered by an MC. This may be an element which substantially reinforces their commitment toward co-op participation and willingness to invest in collective actions. Such information may be utilized by co-op policy makers when re-structuring an MC. Recent research in behavioral economics shows the importance of the information revealed through market participants' preferences. Preferences are constructed, hence driven, by variables that describe the environment such as the competitive environment (e.g., see: Bettman et al., 1998). Therefore, relying on this kind of information, managers of co-ops may develop policies that satisfy the needs and demands of members. Likewise, members' commitment and 
willingness to invest in collective activities may be reinforced by adjusting internal organization and strategic behavior.

Traditionally, the theoretical study on MC's formation involves only pricing as a unique attribute from which members derive utility. Our results clearly show that several other intra-organizational attributes (e.g., product-related decision making) and the strategic behavior (e.g., product quality) of co-ops can also significantly drive member preferences for an MC's structure. Overall, strategic attributes are considered by members as more important rather than the attributes related to pricing policy (i.e., members' benefits) and financing (i.e., financial structure). These findings may provide guidelines and fruitful thought for further theoretical and empirical research on the res-structuring of marketing institutions. That is, future research may build on these results and examine whether other strategic attributes (e.g., brand-orientation) of marketing institutions, which are highly desired by several stakeholders in the same marketing channel, may also be the ones that can drive stakeholders' commitment and willingness to invest in the long-term business goals of these institutions. Moreover, two major limitations of our research should be mentioned here. First, we conceptualized and measured attributes related to internal organization and strategic behavior of an MC operating in the horticultural sector. Although the focus-group discussions and the pre-testing of our hypothetical MC profiles characterized the combinations of these attributes as actionable and coherent, we suggest that further empirical research should pay special attention on the design of different attribute and level combinations. In particular, future research may account for the interaction effects among attributes within the existing range of co-op models (i.e., ranging from traditional to more individualized co-op models). Second, we assumed that the membership has homogeneous preferences. We mentioned the actions undertaken by various groups of the VTN/TG's members in order to better represent their interests via the collective action. We also indicated briefly how the individual preferences vary in the sample. Our analysis did not account for the fact that members may value the attributes of the co-op structure differently. This may be caused by differences in member firms' structure (Staatz, 1983), entrepreneurial skills (Karantininis \& Zago, 2001), and risk preferences regarding operational and strategic co-op issues (Vitaliano, 1983; Cook, 1995). The heterogeneity in members' behavior may adversely influence members' commitment when co-ops expand and diversify (Sex- 
ton, 1986). Taking the heterogeneity of members into account is a challenging task since one has to allow the part-worth (value for an attribute) to differ across groups of members. In the next chapter we examine the impact of members' heterogeneity on co-op structural designs.

\section{Notes:}

Beside the publications referenced in the text and listed above, the following sources have been used for this study:

VTN Annual Reports 1998 and 1999

The Greenery Annual Reports, 1998, 1999, 2000, 2001, 2002

Interviews with Prof. M.T.G. Meulenberg, Wageningen University, The Netherlands, September, 2003; Prof. G. Van Dijk, General Director of the Dutch National Co-op Council for Horticulture and Agriculture, Den Haag, October, 2003; A.J.M. van De Riet, Manager Co-operative Affairs, Utrecht, February, 2003 and March, 2003; Sabien Henselmans, Administrative Staff of Co-operative Affairs Office, March, 2003; Dr. O. F. van Bekkum, Senior Researcher of The Netherlands Institute for Co-op Entrepreneurship (NICE), June, 2003, the Netherlands. 



\section{Chapter 3}

\section{UNDERSTANDING HETEROGENEOUS Preferences of CoOperative MeMber- INVESTORS}

We study the heterogeneity in the preference structure of cooperative member-investors (i.e., members). Using conjoint analysis the utility that members attach to intraorganizational and strategic attributes of their cooperative is elicited. Recognizing that members are not homogenous a concomitant finite-mixture regression model is employed to allow preferences to vary across different member-segments. With data from 120 cooperative members, we find that most members demonstrate rather similar preferences for strategic attributes, but differ with respect to the intra-organizational attributes of control and management. Members' preference structures are affected by business size and attitudes towards risk.

This chapter has been published as Kalogeras, N., Pennings, J.M.E., Van der Lans, I.A., Garcia, P., Van Dijk, G. (2009). Understanding Heterogeneous Preferences of Cooperative Members. Agribusiness: An International Journal 25(1): 90-111. 


\section{$3.1 \quad$ Introduction}

Identifying the preferences of member-investors and the heterogeneity for the attributes of cooperatives (co-ops) is fundamental for understanding co-ops' structure and behavior. ${ }^{8}$ Members involved in collective action often strive to influence corporate structure and decisions to reflect their preferences, resulting in organizational policies that fail to benefit the membership as a whole (Olson, 1971). Conflicting preferences can generate problems in a co-op setting. Increasing heterogeneity in members preferences may result in declining member commitment (Fulton \& Giannakas, 2001), decreasing member willingness to provide equity capital (Van Bekkum, 2001), increasing costs related to damaging influence activities (Cook, 1995), laborious decision-making processes (Hansmann, 1996), and incoherent strategic focus (Hendrikse \& Bijman, 2002). Despite their recognized importance within collective decision making and resulting organizational policies, knowledge of actual members' preferences for the attributes of co-op structure is limited. Most research has maintained a primarily analytical focus and studied the consequences of a priori heterogeneous preferences for single pricing and governance attributes (Cook et al., 2004). The lack of empirical evidence, which can negatively affect the quality of decision-maker choice and researcher understanding of co-op behavior, is due in part to data constraints, and difficulties in determining member's preferences - which are not always directly observable - and in accounting for their heterogeneous nature.

Kalogeras et al., (2007) have conducted empirical research on members' preferences for attributes related to internal organization and strategic behavior of Dutch marketing co-ops to reveal what kind of co-op structure members mostly desire. They show that members on average prefer a more market-oriented management and an internal co-op structure closer to an investor-owned-firm (IOF), rather than the traditional proportional type. However, such average preferences may mask critical relationships when studying and analyzing agribusinesses' structures and producers' economic behavior (Pennings \& Leuthold, 2000). For instance, one might expect that not all members necessarily have the same preferences' structure because of differences in their own firm's characteristics. Here, we expand the literature by identifying the heterogeneity in member preferences (i.e.,

\footnotetext{
${ }^{8}$ Henceforth, we refer to "member-investor(s)" as "member(s)".
} 
utility) for intra-organizational and strategic co-op attributes and assessing the factors that affect members' heterogeneous preferences for these attributes. We investigate attributes related to co-op's equity, control, benefits' allocation, and planning and implementation of strategic positioning, and examine the effects of business size and risk attitude on preferences. We select these attributes because they are at the core of collective co-op structure and because of their importance for understanding the relationship between internal structure and co-op choice particularly in a competitive marketing environment (e.g., Meulenberg, 1979, 2000; Hendrikse \& Veerman, 1997, Bijman, 2002). We investigate the effect of business size and risk attitude on preferences since these are common factors that emerge in the co-op literature (e.g., Staatz, 1983; Reynolds, 1997; Buccola \& Subaei, 1985; Banerjee et al., 2001, Zusman, 1992) to explain differences in preferences.

To address our objectives, we use a research design that includes focus groups, individual member interviews, conjoint analysis and a concomitant finite mixture regression model. In the empirical analysis, we investigate the preferences of agricultural co-op members of a Dutch marketing co-op, VTN/The Greenery (VTN/TG). Co-ops are dominant in the Dutch economy, particularly in banking, financial services, and agribusiness. In the last decade, similar to many US co-ops, Dutch horticultural co-ops have restructured their economic activities, evolving toward entrepreneurial organizations which increasingly adopt IOFs'-like organizational attributes. Investigation of the VTN/TG which is experiencing this change permits an opportunity to develop an understanding of producer concerns and their implications for co-op structure during this transition. Our use of a casestudy method is consistent with Sterns, Schweikhardt, \& Peterson's (1998) call for more detailed investigations of business firms in agriculture, and Cotterill's (2001) recommendations for agricultural co-op research to develop a better understanding of economic behavior. The elicitation framework combined with the concomitant mixture approach permits us to identify segments in which members posses a similar preference structure and relate these segments to member characteristics (Wedel \& Kamakura, 1998). The analysis provides an opportunity to gain insight at a highly disaggregate level into member preferences for their co-op structure, and the degree of heterogeneity that exists even in one marketing co-op (MC). Further, the investigation allows for a more comprehensive understanding of the behavior of co- 
op members, and permits an assessment of the factors affecting behavior which often are the maintained hypotheses in more aggregate analysis.

The remainder of the paper is structured as follows. The second section discusses the organizational attributes of co-ops and the factors influencing heterogeneity in member preference structures. The third section explains the statistical specifications of our empirical model. The fourth and fifth sections describe the research design and present the empirical findings. Finally conclusions and implications follow.

\subsection{Heterogeneity in Member Preference Structures}

This study focuses on the diversity in members' preferences for co-op attributes. Emphasis is placed on the individual and subgroups preferences for these key organizational attributes of a co-op. First, we discuss these attributes and then the factors affecting heterogeneity in member preferences.

\subsubsection{Attributes of Co-ops}

Building on principles of co-op organization and drawing from recent literature that emphasizes market challenges that co-ops face, we focus on two set of attributes: intra-organizational and strategic attributes.

Intra-organizational attributes are based on the definition of co-op as userowned and user-controlled business that distributes benefits on the basis of use (USDA, 1995). The definition encompasses the basic foundation on which a coop's internal structure is built: collective equity, control and benefit allocation to user-owners. Agricultural co-ops have traditionally adhered to exclusive members' ownership in the form of direct investments or retained patronage refunds (Knoeber \& Baumer, 1983), democratic control (Barton, 1989) and uniform pricing policy (net income allocation through product prices). However, many co-ops in order to adapt to agricultural industrialization have relaxed one or more of these traditional principles, allowing for individualized equity shares, inviting nonmember parties to partially finance their operations, applying proportionality in decision control, and allocating net benefits through price and personal shares. The extent to which co-ops relax their definitional principles influences their organizational 
form, ranging from traditional to more individualized (Van Bekkum, 2001) or IOF-like entities (Chaddad \& Cook, 2004). ${ }^{9}$

Strategic attributes refer to strategic market choices made by co-ops. Co-ops' emulation of IOF-like organizational structures permits the acquisition of risk capital for the implementation of growth-related strategies to increase competitiveness (Bergman, 1997; Oustapassidis et al., 1998). Specific strategic choices determine the core characteristics of co-ops' marketing mix and positioning (Meulenberg, 1979; Van Dijk \& Mackel, 1991). For example, co-ops must choose among cost-leadership, product differentiation, and focus-segmentation strategies that can increase their competitive advantage (Meulenberg, 2000). Strategic management theory suggests a firm's competitive advantage is derived from its ability to produce value by acquiring leadership in market knowledge and bringing its resources to their optimum value in a sustainable manner (e.g., Porter, 1985; Bucklin \& Sengupta, 1993). The co-op's choice among different market strategies is especially critical in dynamic agricultural markets (Peterson \& Anderson, 1996) or in periods of structural change where products become outdated and adaptation is required (Goldsmith \& Gow, 2005).

\subsubsection{What Influences Members' Heterogeneity?}

Co-op members have direct access to the decision-making process and can influence its financing, benefits allocation, corporate governance and strategic choices (Staatz, 1987a; Hansmann, 1996). Members can possess disparate preferences for attribute alternatives and disagreements can emerge as to which combination is most desirable (Zusman, 1992). Conflicting preferences which are most likely to emerge in periods of transition (Holmstrom, 1999) can cause inefficient resource allocation (Staatz, 1983) and force co-ops to adapt (Karantininis \& Zago, 2001). As analyzed by Hansmann (1996) and discussed by Vitaliano (1983), and Cook (1995) the divergence in incentives and preferences is particularly problematic for the assignment of contractual property rights among members with diverse charac-

\footnotetext{
${ }^{9}$ For instance, in a "member-investor" co-op model, members' benefits are realized either through dividends distribution to shares and/or appreciability of shares in addition to patronage. For a detailed description of the organizational attributes of various co-op models and the problems encountered with the different collective structures, see: Cook \& Iliopoulos (2000) and Chaddad \& Cook (2004).
} 
teristics. That is, members with different characteristics and conflicting preferences are inclined to compete for rents.

Research has demonstrated that a decision-maker's environment can influence decision criteria and preferences (March \& Shapira, 1987; Smidts, 1990; Pennings \& Leuthold, 2000; Pennings \& Garcia, 2004). In a related vein, co-op researchers have maintained that the variance in the business size of members (e.g., Staatz, 1987a,b; Reynolds, 1997; Iliopoulos \& Cook, 1999; Gripsurd et al., 2001; Banerjee et al., 2001) and risk attitude (e.g., Vitaliano, 1983; Buccola \& Subaei, 1985; Zusman, 1992) are relevant factors influencing differences in members' preferences for a co-op's governance structure. In this context, the "large versus small" effect is the most important paradigm for explaining heterogeneity. Differences in members' cost efficiency associated with business size (large low-cost compared to small high-cost producers) have been hypothesized to affect their efforts to capture the rents generated by the risk-bearing capital activities of co-ops.

A co-op's ability to help members to successfully manage the riskiness of their assets is often subject to an equity acquisition problem, known in co-op literature as "portfolio problem" (Cook, 1995). The cause of this problem which often occurs within traditional co-ops is the absence of secondary markets for trading, liquidating, and investing residual claims (lliopoulos, 1998). The absence of relevant secondary markets may prevent members from adjusting co-op asset portfolio to their own risk preferences (Vitaliano, 1983). In this situation, members with differing risk preferences may argue for differentiated governance policies that better represent their risk portfolio (Cook \& Iliopoulos, 2000).

In the paper we follow an approach which emphasizes the role of theory in the empirical analysis as attributes are used to discriminate among segments of members with similar preferences as well as to identify how business size and risk attitude affect the diversity in member preferences. The procedure allows for segmentation of co-op members based on their underlying latent decision-making process, and is consistent with Heckman's (2001) thinking that heterogeneity in economic behavior can only be understood when identifying and examining the underlying decision-making process of individual market participants (e.g., producers, investors, consumers) 


\subsection{Empirical Model}

The subjective utility that members attach to particular attributes is identified using an additive conjoint model. Conjoint analysis assumes that decision makers derive utility from the attributes of a product or service (Green \& Rao, 1971). Levels (alternatives) of the selected co-op attributes contribute to members' overall utility as given in Equation (3.1):

$y_{j k}=\sum_{p=1}^{P} \sum_{l=1}^{L_{p}} x_{j k \mid p} \beta_{j l p}+e_{j k}$

where: $y_{j k}$ is the preference of member $j(j=1, \ldots, J)$ for profile $k(k=1, \ldots, K)$ which represents a hypothetical MC design; $p(p=1, \ldots, P)$ is an index for attributes, with $P$ being the total number of attributes; $l\left(l=1, \ldots, L_{p}\right)$ is an index for attribute levels with $L_{p}$ being the number of levels defined for attribute $p$; $x_{j k l p}$ is a dummy variable that takes a value of 1 when level $l$ of attribute $p$ holds in profile $k$ for $j$ and $x_{j k l p}=0$ otherwise; $\beta_{j l p}$ is the utility that member $j$ attaches to level $l$ of attribute $p$, and $e_{j k}$ is a normal i.i.d. error term with variance $\sigma^{2}$. Based on the structure of preferences $\left(y_{j k}\right)$, which is often defined in terms of a specific scale or metric and the value of the dummy variables $\left(x_{j k l p}\right)$, the utility weights $\left(\beta_{j l p}\right)$ can be estimated for each member. Often, assuming that the attribute-level utilities are the same for all members, preferences are combined. Here, we allow for heterogeneity of attribute-level utilities across members.

To account for heterogeneity, we apply a finite-mixture regression model to the conjoint data (DeSarbo et al., 1992). In finite-mixture regression models the sample of observations arises from a specified number of underlying populations (i.e., segments) of unknown proportions. A specific form of the density of observations in each of the underlying populations is specified. In our case, we specify these densities in terms of regression equations (Equation 3.1) that are, apart from to be estimated segment-specific regression weights and segment-specific variances of the error term, identical across segments. The approach permits simultaneous identification of segments and their respective sizes and the estimation of attributelevel utilities for each identified segment. In addition, posterior probabilities of segment membership are obtained for each co-op member in the sample. 
Members are assumed to come from a population that is composed of $S$ unobserved segments, with relative mixing proportions $\pi_{1, \ldots,} \pi_{s}$ that are subject to the following constraint

$$
\sum_{s=1}^{s} \pi_{s}=1, \pi_{s} \geq 0 \text {, and } s=1, \ldots, S \text {. }
$$

The mixing proportion $\pi_{s}$ is the prior probability that a member belongs to segment $s$.

The distribution of $y_{j k}$, given that the member $j$ comes from segment $s$, is from the exponential family of distributions and denoted as $f_{j k \mid}\left(y_{j k}\right)$. The exponential family includes the normal, binomial, Poisson, and gamma distributions. We assume a normal distribution since it has been shown to work well for rating-scaled conjoint data (DeSarbo et al., 1992), and the multivariate statistical nature of additive conjoint framework allows the joint effects of the independent variables to be normally distributed (Harris 1975). Given segment $s$ the expectation of $y_{j k}$ is denoted by a linear predictor $\partial_{s j k}$ with i.i.d. error term and variance $\sigma_{s}{ }^{2}$. Within segments, these expectations are a function of the set of explanatory variables $\left(\begin{array}{ll}\sum_{p=1}^{p} & \sum_{l=1}^{L_{p}} \mathcal{X}_{j k l p}\end{array}\right)$ - the representation of the attributes - and the segment-specific utility weights $\beta_{l p s}$ in segments $s$

$$
g\left(\vartheta_{s j k}\right)=\sum_{p=1}^{P} \sum_{l=1}^{L_{p}} x_{j k \mid p} \beta_{l p s}
$$

where $g($.$) is a link function. The function links the expectations of member prefer-$ ence measurements to the co-op attributes in segment $s$. The $\beta_{l p s}$ and the $\sigma_{s}{ }^{2}$ differ across segments.

The unconditional probability density function of an observation $y_{j k}$ is now expressed in the finite mixture form

$$
f_{j}\left(y_{j k} \mid \Phi\right)=\sum_{s=1}^{s} \pi_{s} \prod_{k=1}^{K} f_{j k \mid s}\left(y_{j k} \mid \beta_{s}\right)
$$

where $\Phi$ is the vector including all parameters $\left(\pi_{s}, \beta_{l p s}\right.$, and $\left.\sigma_{s}\right)$ and the likelihood for $\Phi$ is

$$
L(\Phi ; y)=\prod_{j=1}^{J} f_{j}\left(y_{j} \mid \Phi\right)
$$


where $y_{j}$ is the observation vector $y$ of member $j$.

As discussed, we expect that the business size and risk attitude of members will affect differences in member preferences. These factors are incorporated in the finite-mixture models as so-called concomitant variables (cf. Wedel \& Kamakura, 1998). That is, we now specify the conditional distribution of the member's preference structure for MC's design, given the two concomitant variables. The core of this sub-modeling is that the prior probabilities of each potentially identified segment can be re-parameterized by a multinomial logit model in terms of function of the concomitant variables as shown in Equation 3.6.

$$
\pi_{s \mid Z}=\frac{\exp \left(\sum_{\lambda=1}^{1} \gamma_{\lambda s} z_{j \lambda}\right)}{\sum_{s=1}^{S} \exp \left(\sum_{\lambda=1}^{1} \gamma_{\lambda s} z_{j \lambda}\right)}
$$

where: $\lambda=1, \ldots, \Lambda$ is an index for concomitant variables, $\gamma_{\lambda}$ denotes the impact of the $\lambda^{\text {th }}$ concomitant variable on the prior probability of segment $s, z_{j \lambda}$ the value of $\lambda^{\text {th }}$ concomitant variable for member $j$, and $z_{j}$ is a vector of values of respondent $j$ on the $\Lambda$ concomitant variables. For identification purposes it is commonly assumed that $\gamma_{\lambda s}=0$. The parameters of the multinomial logit sub-model are specific to each concomitant variable and member segment. A positive $\gamma_{\lambda s}$ implies that a higher value of a concomitant variable increases the probability that a member $j$ belongs to segment $s$.

The unconditional probability of $y_{j}$ is now obtained by combining the unconditional probabilities of Equation 3.4 with the re-parameterized probabilities from Equation 3.6. So, $\pi_{s}$ is replaced by $\pi_{s \mid z}$ which varies systematically across members.

$$
f_{j}\left(y_{j k} \mid \Phi\right)=\sum_{s=1}^{s} \pi_{s \mid Z} \prod_{k=1}^{K} f_{j k \mid s}\left(y_{j k} \mid \beta_{s}\right)
$$

Equation 3.7 accounts for influence of the concomitant variables on the conjoint equation's probability density function. The parameter vector $\Phi$ (also including the $\gamma_{\lambda s}$ ) in Equation 3.7 is estimated via maximum likelihood using the expectationmaximization (EM) algorithm. The likelihood describes the probability that the data are generated given the specific set of model parameters, and its maximization gives the set of parameters most likely to have given rise to the data. The EM algorithm is used because dummy indicators (i.e., the $0 / 1$ membership of the producers in the segments) are introduced that specify to which particular segment each 
member belongs, but are considered to be missing. The EM algorithm involves calculating posterior membership probabilities according to Bayes' rule and the current parameter estimates of $\Phi$ and substituting them into the likelihood as estimates of the unknown dummy indicators, in an E (expectation)-step. Once this is accomplished, the likelihood is maximized over the parameter space $\Phi$, in an $M$ (maximization) step. Given new estimates of $\Phi$, new posteriors are calculated in the next E-step, followed by a new M-step to find a new $\Phi$. The E- and M-steps are repeated until convergence. ${ }^{10}$

The actual number of member segments is unknown and, in practice, must be inferred. We use Bozdogan's (1987) consistent Akaike's information criterion (CAIC) to determine the number of segments. ${ }^{11}$ The CAIC is defined as

$$
C A I C=-2 \ln L+(P \cdot S+S-1)(\ln (J)+1)
$$

The CAIC gives a trade-off between the likelihood and the number of estimated parameters. The number of segments for which CAIC reaches a minimum is supposed to give the best trade-off. In addition, for any set of identified segments an Entropy statistic, $E_{s}$, is calculated to assess whether the segments are well separated. $E_{s}$ is defined by

$$
E_{s}=1-\sum_{j=1}^{J} \sum_{s=1}^{s}-a_{j s} \ln a_{j s} \mid J
$$

where $\alpha_{j s}$ is the posterior probability that member $j$ comes from latent segments $s$. The posterior probability is also affected by the concomitant variables and is used to classify members in a specific segment. It can be calculated for each observation vector $y_{j}$ given an estimate of $\Phi$ using Bayes' Theorem

\footnotetext{
${ }^{10}$ A general description of the procedure is given by Wedel \& Kamakura (1998).

${ }^{11}$ Formal tests for the number of segments, such as the likelihood ratio test, cannot be applied to this class of mixture models because the asymptotic properties of these tests do not hold (Aitkin \& Rubin, 1985; Titterington, 1990). We follow the mixture literature by using the CAIC, which also is burdened by the same difficulty, as a heuristic guide for determining the number of segments. Evidence from Monte Carlo and other studies find that the framework works well except when many parameters are estimated and the segments are not well separated (Wedel \& DeSarbo, 1995; Pennings \& Garcia, 2004). Deterioration in performance has been ascribed to convergence to local optima. In light of these findings, we use different starting values and determine whether the segments are well separated to support our analysis.
} 
$a_{j s}\left(y_{j}, \Phi\right)=\frac{\pi_{s \mid z} \prod_{k=1}^{K} f_{j k \mid s}\left(y_{j k} \mid \beta_{s}\right)}{\sum_{s=1}^{s} \pi_{s \mid z} \prod_{k=1}^{K} f_{j k \mid s}\left(y_{j k} \mid \beta_{s}\right)}$.

$E_{s}$ in Equation 3.9 is a relative measure bounded between 0 and 1, and describes the degree of separation in the estimated posterior probabilities. $E_{s}$ values close to 1 indicate that the posterior probabilities of the respondents are close to 1 and 0 and therefore the segments are well defined. $E_{s}$ values close to 0 indicate that segments are not well defined.

\subsection{Research Design}

Case studies can be useful in developing an in-depth understanding of economic behavior of agribusinesses (Sterns et al., 1998) and agricultural co-ops (Cotterill, 2001). They permit a detailed assessment of the factors affecting behavior which often are the maintained hypotheses of more aggregate analysis. The focus of the case-study on member preferences for combinations of $\mathrm{MC}$ attributes and the factors that influence their heterogeneity may generate a more comprehensive understanding of the behavior of co-op members, and can assist in supporting more aggregate analyses.

To study preferences, complementary qualitative and quantitative methods are used. Qualitative data on relevant co-op attributes are collected from archived data sources and focus-group discussions with co-op members which later inform the design of the conjoint study. Rohner (1977) and Eisenhardt (1989) argue that such a research design provides an accurate description and evaluation of preferences since data on a topic are collected using independent methods that do not share similar potential bias.

\subsubsection{Decision Context}

For empirical analysis, a decision context is required where members have a prominent influence on the internal organization of a co-op as well as the development of its marketing strategy. MCs operating in the horticultural sector meet this requirement since members, who produce highly perishable products, are in the position to determine the product attributes, and for the most part are able to provide essential post-harvest handling. We investigate the preferences of co-op mem- 
bers of a Dutch fruit and vegetable MC, VTN/TG. Co-ops are dominant in the Dutch economy, particularly in agribusiness sector. In the last decade, Dutch horticultural co-ops have evolved toward entrepreneurial organizations that increasingly adopt IOF-like structural attributes (Van Bekkum \& Van Dijk, 1997). VTN/TG is experiencing such a transition.

The Greenery (TG) sells, distributes, and markets fresh produce. It was established in 1996 and its shares are owned by the horticultural co-op Voedings Tuinbouw Nederland (VTN) which emerged from a merger of nine vegetable co-op auctions because members were dissatisfied with the marketing performance of the auction system. The 3,500 producer-owned members of VTN market/sell their products through TG (VTN/TG Annual Report, 2003). The co-op VTN is the only shareholder of TG whose business goal is to realize for their members the best product price/income by an effective and efficient marketing and selling policy. VTN/TG sells a wide variety of fresh horticultural commodities, including: paprika, cucumbers, tomatoes, green-salads, apples, and strawberries. The participating member firms are mostly family owned and the manager is often the owner. Based on sales value, VTN/TG is the largest fruit and vegetable company in the Netherlands (Bijman \& Hendrikse, 2003). Recently, due to a reduction in members' commitment to TG's operations and growing members' heterogeneity VTN/TG has passed through several re-structuring phases.

The transformation of co-op auctions, which maintained traditional co-op attributes, into a marketing business entity resulted in a collective venture that combined both collective and IOF-like organizational attributes. VTN/TG offered a mix of collective and individual ownership titles to members in order to raise adequate equity capital to support the implementation of its marketing strategy. Its residual decision rights were exercised by members, professional management and supervisory boards in which both members (represented by VTN's Board of Directors - BOD) and market experts participate. Members and managers also participate in product-market decisions. Adaptation to this organizational form was influenced by diversity in economic interests of participating members.

Differences in members' interests led to the establishment of Product Market Advisory Committees (PMACs). From the start, members have exercised control rights in VTN, and represented themselves in transactions with the TG through PMACs. Also, the EU's subsidizes to establish additional marketing associations in 
the European agribusiness sector stimulated VTN producers to form various product-specific bargaining associations. Hence, VTN producers further splintered into subgroups with different crop-specific interests and concerns. The formation of these associations was mainly influenced by members' dissatisfaction with the lack of transparency between VTN/TG's supervisory board and TG's management board, inadequate management of product-related grading, pricing and selling, and a benefit system that disproportionately cross-subsidized specific groups (Bijman, 2002). Members were concerned by a loss of control over TG's marketing policies which they felt were implemented without sufficient producer input (Kyriakopoulos, 2000). In response, VTN/TG has attempted on several occasions to implement policies to reinforce its members' commitment and to attract members' investments for its marketing operations.

\subsubsection{Relevant Attributes: Focus-Groups Findings}

In winter 2003, TG's sites were visited to develop an understanding of member preferences for attributes of VTN/TG. Differences in economic interests among members and conflicting views on the organizational structure and strategic behavior of VTN/TG were apparent. The substantive change from a co-op auction system to a marketing organization that entails both traditional co-op' and IOF's-like organizational attributes, was the issue of concern. To identify more precisely the relevant attributes, two focus groups sessions were conducted. Fifteen members, selected to provide a wide range of characteristics including age, region, differences in products, enterprise age and structure, and involvement in the co-op, participated in each session. Members were asked to discuss VTN/TG's intraorganizational and strategic attributes.

Discussions identified six attributes, each with two levels (i.e., alternatives), as important attributes of VTN/TG (table 3.1). Four intra-organizational attributes (member benefits, corporate governance, product-related decision making, and financial structure) and two strategic attributes (business scope and product quality/grading) emerged which we summarize below with the alternatives or questions that reflect the diversity in members' preferences. $^{12}$

\footnotetext{
${ }_{12}$ The research design and date set is identical to Kalogeras et al., 2007 (chapter 2 in this dissertation).
} 
Members' benefits. Members' opinions on how net income should be allocated were split. Some participants supported the traditional notion that performance should be based primarily on net price through a well-defined contract between the co-op and the member (i.e., based on a proportional pricing mechanism). Other members preferred a mechanism based on return on capital invested in addition to the product price.

Corporate governance. The need to ensure corporate control of VTN/TG's activities by effective collaboration among members, the board of directors (BODmembers' representatives) and hired managers was important to all participants. However the preferred structure of control (governance) varied. One form placed corporate control primarily in the hands of the BOD which would directly administer VTN (co-op) and supervise hired managers who would assume the role of board of directors of TG (marketing firm). The alternative form was for hired managers to administer VTN under the supervision of the BOD, and for managers to also administer TG (as in previous form) but under the supervision of a professional board. This professional supervisory board of directors (PSB) would include external non-member professionals (i.e., experts) and the member representatives would be a minority. The general assembly of members would appoint and supervise the PSB.

Product-related decision making. The relevant question here is: Who should determine VTN/TG's product quality, price setting and sales methods for different market segments? Members indicated their dissatisfaction with current pricing procedures and marketing strategies. Some members wanted to make decisions directly on these product-related issues themselves (through VTN BOD's, PMACs', and established crop-specific associations' representation), while others indicated that they were more comfortable placing the decisions in the hands of knowledgeable market managers.

Financial structure. Members explained that capitalization was a contentious and major problem for implementing VTN/TG's marketing plan. The introduction of individual ownership titles gave the residual right to members for cumulative preferential dividends and resulted in low equity/debt ratios for TG through 2002. Some members indicated that establishment of a traditional general reserves system might be the solution for increasing equity capital through retained earn- 
ings. In contrast, others preferred increasing VTN/TG's equity by issuing individual ownership titles.

Table 3.1. Intra-organizational and strategic attributes: VTN/The Greenery ${ }^{\mathrm{a}}$

\begin{tabular}{|c|c|}
\hline Attributes & Attribute Levels (Alternatives) ${ }^{\mathrm{b}}$ \\
\hline \multicolumn{2}{|l|}{ Intra-organizational } \\
\hline \multirow[t]{2}{*}{ Members' Benefits } & 1. Product price \\
\hline & 2. Product price and return on capital \\
\hline \multirow[t]{4}{*}{ Corporate Governance } & 1.VTN: Board of Directors (BOD); \\
\hline & $T G$ : Managers supervised by VTN’s BOD \\
\hline & 2.VTN: Managers supervised by VTN's BOD; \\
\hline & $T G$ : Managers supervised by PSB $^{c}$ \\
\hline \multirow[t]{2}{*}{ Product-Related Decision Making } & 1. Members \\
\hline & 2. Managers \\
\hline \multirow[t]{2}{*}{ Financial Structure } & 1. General reserves \\
\hline & 2. Individualized equity \\
\hline \multicolumn{2}{|l|}{ Strategic } \\
\hline \multirow[t]{2}{*}{ Business Issue/Scope } & 1. Market-oriented organization \\
\hline & 2. Intermediary organization \\
\hline \multirow[t]{2}{*}{ Product Quality } & 1. General grading of products \\
\hline & 2. Client-specific grading of products \\
\hline
\end{tabular}

a MC refers to the VTN, which is the horticultural co-op Voedings Tuinbouw Nederland. TG is the Greenery (marketing firm) that markets fresh produce for the co-op VTN who is its only shareholder.

${ }^{\mathrm{b}}$ Each attribute has two levels (alternatives).

c $\mathrm{PSB}=$ professional supervisory board.

Business Issuelscope. Members were concerned that the scope of VTN/TG's business operations did not capture their economic interests. Members indicated that VTN/TG needs to maintain its user orientation as it increases in economic size and managerial complexity. However, there were differences regarding whether VTN/TG should solely act as an intermediary channel that buys and sells its members' produce or be active in developing a more comprehensive market-oriented firm in its own right.

Product quality. Finally the critical role of product quality in VTN/TG's marketing strategy received considerable attention. Two main strategies emerged. Sev- 
eral members felt that the co-op should follow a more traditional path of selling rather generic products using the market's general grading schemes. This strategy would be based on competitive prices, efficiency in production and logistics, and serve price-conscious consumers. In contrast, other members felt strongly that VTN/TG should focus on marketing products to meet client-specific quality needs.

\subsubsection{Design of the Conjoint Study}

The findings from the group sessions were used to design the conjoint study. The method allows members to evaluate the tradeoffs of VTN/TG's attributes (Hauser $\&$ Rao, 2005). The number of identified attributes permits a full-profile conjoint design (Green \& Srinivasan, 1990). A 2 (Members' Benefits) $\times 2$ (Corporate Governance $) \times 2($ Product-Related Decision-Making $) \times 2$ (Financial Structure $) \times 2$ (Business Issue/Scope $) \times 2$ (Product Quality) fractional factorial main-effect-only design generated a set of eight calibration profiles. Profiles refer to hypothetical MC designs described by combinations of attributes' alternatives identified in table 3.1. A main-effects design was selected to keep the number of profiles manageable for respondents.

Members who participated in the conjoint interviews were selected using a stratified sample design. Producer degree of involvement in VTN/TG's decision making (holding positions/participating in decision or co-decision making bodies, e.g., PMACs), economic size (sales value $>75,000$ Euros), and primary income from on-farm activities were the sample selection criteria. Involvement in decision making was seen as important to determine awareness of the situation faced by the co-op. The sales value was selected to reflect a level of active market participation, while still permitting for a representative range of producers. VTN/TG's public relations office provided us with a list of 500 members satisfying the criteria. Each member was contacted twice (via mail and telephone). Initially, 172 members expressed interest in participation. Later, some members declined to participate when informed that the conjoint task required a 45 minutes interview. Other practical reasons (i.e., time and cost constraints) led us to conduct the large-scale conjoint 
interview with 120 members. ${ }^{13}$ The average age of participating members was 41.6 and the majority $(70.1 \%)$ had a college degree (a skilled farm management degree). Also, the vast majority of members reported no off-farm business activities $(81.7 \%)$, and a sharing of firm equity among family members $(79.2 \%)$.

All interviews were computer-guided and performed on an individual basis. Care was taken to build a user-friendly interface. A pilot test based on eight producers was conducted to check the degree in which members understood the conjoint task. Prior to evaluation of the hypothetical MC profiles, members were permitted to study definitions of the attributes and their levels and to ask clarifying questions. No serious problems were encountered in the interviews.

To reflect preferences, members were asked to rate the eight profiles using a nine-point rating scale which ranged from one (least preferred) to nine (most preferred). Members were also asked to indicate the degree of their agreement with statements referring to their own risk behavior using a seven-point scale (Appendix $3.1)$.

\subsection{Results \& Discussion}

Prior to estimating the conjoint mixture model the preference ratings for each member were centered. This procedure helps avoid biases that can emerge when respondents use different reference points to evaluate the profiles (Dillon et al., 1985) and can reduce the effects of possible errors that may arise in the measurement of directly unobservable preferences. The conjoint model (Equation 3.1) using the mixture regression framework was applied the data allowing for up to 6 segments, $S=1$ to 6 . The log-likelihoods, CAIC statistics, $R^{2}$ and entropy value $\left(E_{s}\right)$ are reported in table 3.2 .

Based on the minimum of CAIC statistic, we select $S=2$ as the appropriate number of segments. The solution has a log likelihood of -1846.859 and an $R^{2}$ of 0.198 . The entropy value $\left(E_{s}\right)$ of 0.759 indicates that the segments are well separated; the posteriors are close to 1 or to 0 . In table 3.3 the regression coefficients for each attribute, the coefficients of the members' business size and risk attitudes (concomitant variables), and the relative size of each identified segment are pre-

\footnotetext{
${ }^{13}$ The managing director of VTN/TG affairs and secretary to the VTN's BOD indicated that the 120 members who participated in the conjoint study maintained average sales values similar to the producers identified in our stratified sampling design.
} 
sented. For the attributes, the sign of the coefficient indicates which attribute level (see table 3.1 for the alternatives) is preferred. A positive sign (the utility weigh is increasing) indicates that level 2 is preferred to level 1 , while a negative sign (the utility weight is decreasing) indicates the opposite. For example, a positive sign for the member benefits attribute indicates that the benefit plan that combines product price and return on capital is preferred over the plan based only on product price. ${ }^{14}$ For the concomitant variables, positive coefficients indicate higher values of business size and/or an increased willingness to accept risk increase the probability that a member belongs to segment $s .{ }^{15}$

Table 3.2 Fit Statistics of the Mixture Models for the Segments, $S=1$ to $S=6$

\begin{tabular}{lllll}
\hline Segment $(S)$ & Log likelihood & CAIC $^{a}$ & $E_{s}$ & $R^{2}$ \\
\hline 1 & -1921.240 & 3905.417 & 1.000 & 0.023 \\
2 & -1846.859 & 3827.456 & 0.756 & $\mathbf{0 . 1 9 8}$ \\
3 & -1828.403 & 3861.347 & 0.749 & 0.285 \\
4 & -1807.532 & 3890.307 & 0.790 & 0.327 \\
5 & -1798.519 & 3943.184 & 0.764 & 0.362 \\
6 & -1786.457 & 3989.861 & 0.791 & 0.424 \\
\hline
\end{tabular}

${ }^{a}$ CAIC is the consistent Akaike's information criterion and is used to determine the optimal number of segments. $E_{s}$ is the entropy statistic which is bounded between 0 and 1 , and describes the degree of separation in the estimated posterior probabilities. $E_{s}$ values close to 1 indicate that the posterior probabilities of the managers belonging to specific segment are close to either 0 or 1 ; the segments are well defined.

Using our procedure, statistical tests can be performed to determine whether an attribute effectively explains the preference structure (i.e., drives the utility of individual members) in a particular segment (table 3.3). In both segments, members demonstrated rather well-defined preferences for attributes as gauged by their statistical significance $(p<0.05)$, substantiating the overall structure of the research

\footnotetext{
${ }^{14}$ In table 3.3, we identify the preferred level that corresponds to table 1 below the estimated attribute coefficients in brackets.

${ }^{15}$ Business size is a ranking from 1 through 6 to reflect producer annual sales classifications (see table 3.4) used in the interview. The risk-attitude measure described in the text was validated using confirmatory factor analysis (Pennings \& Smidts, 2000). The reliability measure, which ranges between 0 and 1 with higher values indicating superior reliability (see: Hair et al., 1998), is 0.78 .
} 
design and supporting the notion that attributes contribute additively to member's utility. The results demonstrate the existence of two member-segments with dissimilar preferences for several attributes. In the two segments, three intraorganizational attributes have different signs while the signs for member benefits' and strategic attributes are the same. Members in segment 1 want VTN/TG to act as a market-oriented organization administered mainly by professionals for corporate and product-related issues that implements a marketing strategy based on client-specific product quality. In particular, these members prefer corporate management delegated to hired managers under the supervision of the VTN's BOD. Hired managers are also preferred to administer TG under the supervision of PSB (professional supervisory board) consisting mainly of external non-member professionals. Also, they prefer to receive benefits through a mechanism that combines product price and return on capital. Members in segment 2 have similar preferences for the strategic attributes and member benefits' mechanism. However, they favor a governance structure where the BOD holds almost full decision control at corporate level, and where the members exercise product-related decision making through the BOD or PMACs. They also favor opportunity for individualized equity which was not significant for segment 1 .

The importance of the concomitant variables provides insight into the factors affecting the differences in preferences between the two segments. Increases in business size and risk attitudes significantly affect but in opposite directions the probability of being in the segments. Increases in business size increase the probability of being in segment 1 than in segment 2 . Increases in risk attitude increase the probability of being in segment 1 , but negatively affect (although not statistically significant) the probability of being in segment 2 . Further, the estimated values of the regression coefficients of the concomitant variables are larger in segment 1 , implying that these factors have a stronger effect on membership in this segment. 
Table 3.3 Mixture Regression Results for the Two-Segment Solution

\begin{tabular}{|c|c|c|}
\hline \multirow[b]{2}{*}{ Explanatory variables } & \multicolumn{2}{|c|}{ Regression Coefficients $^{\text {a }}$} \\
\hline & Segment 1 & Segment 2 \\
\hline \multicolumn{3}{|l|}{ Intra-organizational Attributes } \\
\hline Members' Benefits & $\begin{array}{c}0.354^{*} \\
{[2]}\end{array}$ & $\begin{array}{c}0.444^{*} \\
{[2]}\end{array}$ \\
\hline Corporate Governance & $\begin{array}{c}0.186^{*} \\
{[2]}\end{array}$ & $\begin{array}{c}-0.604^{*} \\
{[1]}\end{array}$ \\
\hline Product-related Decision-Making & $\begin{array}{c}0.169^{*} \\
{[2]}\end{array}$ & $\begin{array}{c}-0.778^{*} \\
{[1]}\end{array}$ \\
\hline Financial Structure & $\begin{array}{c}-0.092 \\
{[1]}\end{array}$ & $\begin{array}{c}0.653^{*} \\
{[2]}\end{array}$ \\
\hline \multicolumn{3}{|l|}{ Strategic Attributes } \\
\hline Business Issue/Scope & $\begin{array}{c}-0.308^{*} \\
{[1]}\end{array}$ & $\begin{array}{c}-0.738^{*} \\
{[1]}\end{array}$ \\
\hline Product Quality & $\begin{array}{c}0.291^{*} \\
{[2]}\end{array}$ & $\begin{array}{c}0.636^{*} \\
{[2]}\end{array}$ \\
\hline \multicolumn{3}{|l|}{ Concomitant Variables $^{\text {b }}$} \\
\hline Business Size & $0.995^{*}$ & $-0.445^{*}$ \\
\hline Risk Attitude & $0.279^{*}$ & -0.126 \\
\hline Relative Segment Size & 0.311 & 0.688 \\
\hline
\end{tabular}

${ }^{\text {a }}$ A positive sign for the coefficient of an attribute indicates that alternative 2 is preferred to level 1 (table 3.1), and a negative sign the opposite. For instance, the positive sign for coefficient of members' benefits indicates that the "product price and return on capital" is preferred to "product price." The preferred attribute level also is displayed below the value of the regression coefficients using [1] and [2] for the levels.

b A positive sign for the coefficient of the concomitant variables indicates that increases in the factor increase the probability of being in a segment, a negative sign the opposite.

* denotes significant at $p<0.05$.

To gain further insight, characteristics of the identified segments are presented (table 3.4). A clear picture begins to emerge. While the proportions of the members in fruit and vegetable production are similar, the segments differ based on business size. Segment $1(n=37)$ is characterized by larger-sized enterprises with almost 50\% percent reporting annual sales of more than 1 million Euros and employing an average of 26 workers. In contrast, segment $2(n=83)$ contains smaller enterprises with an average of 5 workers and almost $75 \%$ reporting annual sales of 
less than 750,000 Euros. These profiles support the significant effect of business size as a discriminating factor of the preference structure in both segments.

Table 3.4 Descriptive Statistics of the Two-Segment Solution

\begin{tabular}{lll}
\hline & $\begin{array}{l}\text { Segment } 1 \\
(n=37)\end{array}$ & $\begin{array}{l}\text { Segment } 2 \\
(n=83)\end{array}$ \\
\hline $\begin{array}{l}\text { Percentage of Member Type in Segments } \\
\text { Fruit producers }\end{array}$ & $32.4 \%(n=12)$ & $25.3 \%(n=21)$ \\
Vegetable producers & $67.6 \%(n=25)$ & $74.7 \%(n=62)$ \\
Number of employees ${ }^{\mathrm{a}}$ & 26 & 5 \\
Annual Gross Revenue (in Euros) $)^{\mathrm{a}}$ & & \\
$<100,000$ & $0.0 \%$ & $8.4 \%$ \\
$100,000-250,000$ & $2.7 \%$ & $19.3 \%$ \\
$250,000-500,000$ & $15.05 \%$ & $28.9 \%$ \\
$500,000-750,000$ & $24.3 \%$ & $19.3 \%$ \\
$750,000-1,000,000$ & $10.8 \%$ & $4.8 \%$ \\
$>1,000,000$ & $48.6 \%$ & $19.3 \%$ \\
Risk Attitude $^{\mathrm{b}}$ & 5.0 & 4.2 \\
\hline
\end{tabular}

${ }^{a}$ The number of employees and average annual gross revenue are for 2002.

${ }^{\mathrm{b}}$ Risk attitude is measured as the sum score of the risk-attitude scale, where 1 is highly risk averse and 7 least risk averse. The risk attitudes between the two segments are significantly different $(p<0.05)$.

The revealed preferences demonstrate that members agree that VTN/TG should act as a market-oriented organization from which its members as users and investors capture benefits from marketing and selling policies that target end-user demand. These findings support and extend the conclusions identified by Van Dijk \& Mackel (1991), Meulenberg (1979, 2000), Bergman (1997), Kyriakopoulos (2000), among others, that co-ops offer higher benefits to participating members when focused on long-run planning and invest in aggressive marketing strategies to increase their growth and market power. In contrast, the results show a lack of consensus between the two segments on issues related to the intra-organizational control. Larger-sized members in segment 1 appear to believe that market leadership can be captured only by experts and such a corporate governance plan is better suited to TG in its pursuing of market-oriented strategies. Smaller-sized members 
in segment 2 disagree with this governance scheme, opting for more memberoriented control for both VTN and TG. The lack of transparency in corporate control and product-related management may have made members in segment 2 realize that their own product-portfolio interests are not well addressed by VTN/TG's governance structure. The findings support the assumptions employed in past analytical works (e.g., Vitaliano, 1983; Zusman, 1992; Reynolds, 1997; Banerjee et al., 2001) used to determine that subgroups of members with differing asset ownership (e.g., landholdings, labor input, or amount of product marketed) can lead to conflicting preferences for intra-organizational co-op structure even if all subgroups pursue the same strategic goals. The findings are also in line with the limited empirical evidence (Iliopoulos \& Cook, 1999; Banerjee et al., 2001; Gripsurd et al., 2001) that variance in size of members' operations is an important determinant of co-op structure.

In contrast, differences in the statistical importance of the financial structure on producer membership in the segments offer another instructive interpretation of the relationship among the attributes. The insignificant coefficient in the segment 1 is likely reflective of the small number of producers in the group and the high degree of collinearity that exists between their preferences for members' benefits and financial structure. The positive and significant coefficient in segment 2 , indicating small-sized producers prefer individualized equity, may also be informative by suggesting that even smaller-sized members can see benefits of developing individualized equity opportunities in a highly market-oriented environment like VTN/TG. In a more general context, these findings raise the likelihood that the member preferences structure is not only multidimensional as postulated but also interactive, and underscore the importance of research design for understanding economic behavior. ${ }^{16}$

Finally, differences in risk-attitude coefficients between the segments seem to partially support the notion that heterogeneity in member preferences for VTN/TG's intra-organizational control is affected by risk preferences. Focusing on risk attitude, we find that risk-attitude has a positive statistical significant effect on

\footnotetext{
${ }^{16}$ The importance of these relationships can be further developed by recognizing the interdependencies among the unique co-op attributes and, allowing different attributes to interact in the research design. Accounting for this possibility by adding profiles can enrich a research design, but at the risk of making it more difficult for respondents to effectively complete the conjoint task (Hair et al., 1998).
} 
the probability of membership in segment 1 . In conjunction with the results from tables 3.3 and 3.4, it appears that larger-sized producers are more willing to risk relinquishing direct producer control of the co-op's operations and direction in hope of adding value through professional management. In contrast, smaller-sized members in segment 2 who are more risk averse prefer critical corporate and product-related decisions control by their representatives.

\subsection{Conclusions}

The heterogeneity in the preferences of co-op members has been recognized as an important research topic in the agribusiness economics and marketing-finance literature. In this paper we provide a first effort to directly identify and measure the structure of member preferences for a mix of intra-organization and strategic attributes, and to measure factors that affect their heterogeneous nature.

We find that members have rather well-defined preferences for the selected attributes, but value the attributes differently. Most members demonstrate rather similar preferences for strategic attributes, but differ with respect to the intraorganizational attributes of control and management. In general, members with large sales who employ a considerable number of workers and exhibit less riskaverse preferences preferred more involvement of professional managers in corporate and product-related decisions. Members with smaller sales and fewer employees and who were more risk averse were more willing to delegate corporate and product marketing control to their representatives who presumably promote their interests more effectively. The similarity in preferences of strategic attributes suggests that members are willing to take similar collective action to capture market advantages. We also find some evidence that strategic and intra-organizational attributes may interact, such that even smaller-sized producers see benefits in nontraditional financial structures. However, the differences in intra-organizational preferences highlight the difficulties that co-ops face in allocating resources efficiently and balancing their commitments to their members.

On balance, the results confirm and extend previous analytical and empirical work on the presence of and likely influence of heterogeneous members' preferences (e.g., Staatz, 1983; Zusman, 1992; Reynolds, 1997; Banerjee et al., 2001). The identified differences in preferences for the control mechanisms support the assumptions used to investigate and address co-op organizational inefficiencies in 
the presence of diverse characteristics. The "large versus small" cost efficiency argument is indeed an important dimension of member preferences for co-op structure and behavior, but our findings also support the recent work identifying the importance of risk attitudes (e.g., Smidts, 1990; Pennings \& Leuthold, 2000; Pennings \& Garcia, 2004) and are consistent with the presence and importance of managing risk in co-op literature (e.g., Buccola \& Subaei, 1985, Sexton, 1986; Schrader, 1989; Zusman, 1992). Our findings also indicate that the structure of member preferences may be both multidimensional and interactive, and reinforce the notion that understanding economic behavior within co-ops is challenging and requires careful investigation of the decision context (Zusman, 1982; Cotterill, 2001).

Overall, our analysis identifies a high degree of heterogeneity which may be problematic for co-op governance and management initiatives. Since the efficiency of resources allocation is threatened as members' heterogeneity increases (Staatz, 1983), the continuous improvement of governance mechanisms that serve various member-segments interests is of value (Reynolds, 1997). Internalization of members' heterogeneous needs and demands enhances co-ops' ability to avoid outcomes associated with declining member commitment and financial pressures (Fulton $\&$ Giannakas, 2001). At a more practical level reconciling heterogeneous preferences on a daily basis is a challenge. Nevertheless, identifying the attributes, levels, and factors that influence the preference structure in different member-segments may permit decision makers to extract the essential aspects of a situation. With an understanding of core problems, policies and well-defined ownership structures to meet the fundamental needs of the members may be more readily developed.

Knowledge of the existence of member-segments and an understanding of their preferences may be useful also to co-op policy makers to better evaluate efforts by member-subgroups who may strive to influence governance policies. Acquiring such crucial information, conflicting situations that undermine co-op's success in the market may be prevented and continuous development and improvement of services that better balance member demands may be achieved. Balancing members' demands and avoiding conflicting situations may require the creation and maintenance of formal and informal institutions such as common norms, formal decentralized decision-making procedures and performance evaluation by outside experts (Hansmann, 1996: 98). Fulton \& Gibbings (2000) also 
propose that the creation of an "umbrella co-op" - a holding organization within which a number of different activities could be carried out - may satisfy the need for a high degree of integration between members' heterogeneous interests and coop structure. Our results may highlight this need. The diversity in member preferences regarding corporate control and product management may signal the emergence for a multi-string governance structure that embodies a wide range of ownership agreements and integrates the revealed preference structure of each participating member-segment.

Several caveats and challenges should be mentioned. First, co-ops have recently experienced an inherently dynamic re-structuring process, yet our analysis provides a cross-sectional assessment of members' preference structure for co-op attributes at a specific time. A deeper understanding of the dynamic impact of members' preferences on the structure of co-ops and how this relationship is affected by different economic conditions and changing members' characteristics awaits further empirical analysis. Second, we conceptualized and measured a mix of intra-organizational and strategic attributes in the context of a horticultural MC. Further research is needed to determine the relative usefulness of these attributes and the factors influencing preference heterogeneity for other types of co-ops. Developing a taxonomy of member preferences by co-op type and the factors that affect these preferences will permit a richer understanding of co-op structure and behavior. 



\section{Chapter 4}

\section{CONSUMER Risk BEHAVIOR IN TIMES OF CRISIS: A NATURAL EXPERIMENT}

Recent research has argued that by decoupling the risk behavior of consumers into the separate components of risk perception and risk attitude, a more robust conceptualization and prediction of consumers' risk responses is possible. Furthermore, it is argued that the influence of risk attitudes and risk perceptions on consumer behavior can be used to formulate effective marketing strategies in case of a product-harm crisis. The question arises whether or not the impact of these risk variables changes over time (i.e., due to changes in the decision environment), and what drives these changes. The BSE (mad cow disease) crises in the US and Germany in 2001 and 2004 provided us with a natural experiment to examine the relationship between risk attitudes and perceptions and behavior during different crisis phases. The results show that the relative importance of risk attitudes and risk perceptions indeed changes during these crisis phases and, hence, that marketing strategies need to be adapted. Changes in the relative importance of risk attitudes and perceptions are affected by consumers' knowledge and trust in the information provided by their governments about the harmed product. Marketing and policy implications are discussed.

This chapter was presented in Marketing Science/INFORMS, 2010 (Cologne, Germany, EU). A shorter version of this chapter was nominated as best paper based on a $\mathrm{PhD}$ dissertation by the int/nal scientific committee of the European Marketing Academy (EMAC), (EMAC conference, Brighton, UK, 2008). 


\subsection{Introduction}

Marketing researchers, financial analysts, industry managers, and public policy makers developed a strong interest in understanding the effects of economic or product-related crises on the performance of firms and, in particular, in using effective strategies to manage these crises. Past research indicates that well-publicized events may substantially affect business reputations and sales, change consumer perceptions and behaviors for a particular product/service or brand, and compromise an entire industry (e.g., Shrivistava et al., 1988; Nilson, 1995; Dawar \& Pillutla, 2000). Recently, media attention has focused on the calamities that have struck the agri-food markets where various outbreaks of diseases (e.g., foot and mouth disease; mad cow disease; avian influenza, swine fever) caused consumer panic with a devastating impact on the demand of food products and other services (e.g., Jin \& Koo, 2003; Cleeren et al., 2007). These crises emphasize the need to understand the drivers of consumer risk response to product-harm crises that involve life-threatening design flaws. Knowing the drivers of consumer risk response and how they change during a crisis may allow marketers and the industry to make more informed strategic decisions to manage the crisis.

Recent research argued that by decoupling the risk-response behavior of decision makers into the separate components of risk perception and risk attitude, a more robust conceptualization and prediction of consumers' reactions is possible (e.g., Keller, 1985; March a\& Shapira, 1987; Shapira, 1995; Pennings \& Wansink, 2004; Schoeder et al., 2007). Specifically, Pennings et al., (2002) and Schroeder et al., (2007) provide evidence that consumer reactions to product-harm crises across many nations are driven by the decoupled components of consumer risk behavior: risk attitude and risk perception. The results of these studies suggest that, while effective communication is sufficient for some countries, other countries require more drastic measures with respect to the product supply (e.g., full product elimination and recalls). The question arises whether or not the influence and magnitude of risk variables (i.e., risk attitudes and risk perceptions) change over time and, hence, whether marketing strategies must be adapted. This issue is of particular importance to the marketers and public policy makers since the increasing complexity of production systems often causes unexpected and frequent productharm crises (Dawar \& Pilutta, 2000). These crises become more visible to the public globally due to the heightened media attention (Kamins et al., 1997) and lead to 
puzzling consumer reactions, which are not always consistent with the actual level of risk (Viscusi, 1991; 1993). However, in spite of the devastating impact that such a crisis might have on the performance of marketing channels in the food industry, very limited attention has been devoted to the study of consumer risk reactions to a product crisis involving life-threatening design flaws in and across different crisis phases.

Most research on product-harm crises in the marketing-management literature are descriptive and case-study based (Mirtoff \& Kilmann, 1984, Weinberger et al., 1993; Schroeder, et al., 2007), their measurements and analyses based on data derived from lab experiments (Alhluwalia et al., 2000; Dawar \& Pilluta, 2000) or they are focused on security-price reactions by using aggregate performance indicators (e.g., Marsh et al., 2004; Chu et al., 2005). Descriptive studies do not quantify the extent of the damage incurred and provide little direction for understanding the underlying demand mechanisms through which crises harm the channel activities in an industry (Ahluwalia et al., 2000). Laboratory studies carry limited external validity due to their experimentally manipulated hypothetical decision contexts (Van Heerde et al., 2007). Studies using performance metrics to capture the dynamics of market participants' dynamic behavior throughout a crisis are based on aggregate indicators, which may not be as informative as more disaggregate analysis. They do not account for the fact that different segments of market participants may also have reacted differently to the same crisis and across different crisis phases (Klein \& Dawar, 2004; Griffin et al., 1991). Moreover, existing studies focusing on consumer reactions to a product-harm crisis (e.g., Pennings et al., 2002; Schroeder, et al., 2007) examine consumer risk behavior at the spot (i.e., at a specific crisis phase). Although they acknowledge the changing consumer reactions to product-harm crises, do not explicitly examine consumers' risk behavior over time (e.g., across the crisis phases). The magnitude levels of consumers risk attitudes and perceptions though, may change over time, because they follow a continuous update pattern driven by the conditions occurring in contingent-driven decision environments. Also, the influence of risk attitudes and risk perceptions on behavior may change during a crisis, which has consequences for firms' marketing strategies and corporate investments. To fill this gap in the literature, we examine how risk attitudes and risk perceptions and their relative influence on behavior change across 
crisis phases and how these changes influence the adaptation of marketing strategies and public policies.

We study the Bovine Spongiform Encephalopathy (BSE) crisis in two major economies: the US and Germany. In 2001, the BSE crisis had spread across most EU countries including Germany, but it did not reach the US until the end of 2003. The BSE crisis caused consumer panic and substantially disrupted the meat markets worldwide (e.g., Burton \& Young, 1996; Fox \& Peterson, 2004). The main concern of consumers regarding BSE is that contaminated beef may cause Creutzfeldt-Jacob Disease (CJD) in humans. Although the chance of contracting CJD by eating beef is very small (less than 1\%), it seems that consumer reactions in such a product crisis are puzzling since they are not always consistent with the true level of risk they face. For instance, beef consumption decreased dramatically in Germany when the first BSE case was detected, but it did not happen the same in the US. Beef consumption in the US remained at almost the same levels as before the outbreak of the crisis. How can these inconsistent reactions of consumer in these two countries towards the same product-harm crisis be explained?

The objectives of this study are to: a) evaluate consumer risk attitudes towards and risk perceptions of a harmed product across different countries b) to quantify how these attitudes and perceptions affect the consumption of the harmed product within and across different crisis phases, and c) to examine how latent factors influence consumers' risk attitudes and perceptions within different crisis phases. Building on recent advances in marketing and management science, we hypothesize that the components of consumer risk behavior follow ongoing update patterns and hence adapt to the environmental idiosyncrasies (e.g., conditions) of particular market settings (e.g., Hogarth, 1981; Klein, 1993, Bettman et al., 1998; Moorman et al., 2004). To accomplish the study's objectives, we propose and illustrate a twolayered conceptual model showing how risk attitudes and risk perceptions influence risk behavior within and across crisis phases and how latent factors may explain the changes in risk attitudes and perceptions between crisis phases.

The remainder of the paper is organized as follows. First, building on recent risk behavior literature, we introduce a dynamic model that explains consumer risk reactions in times of product-harm crisis. The main drivers in the model are risk attitudes and risk perceptions. Factors impacting the dynamics of risk attitudes and perceptions are also considered and conceptualized. Moreover, we discuss manage- 
rial outcomes of our conceptualized framework. Second, we present our research design which includes an extensive qualitative analysis of our decision context and the design of the field studies. Third, we explain and present the statistical specifications of our empirical model. Fourth, we report on the results of the empirical study. We conclude by discussing our findings and their theoretical and managerial implications.

\subsection{Conceptual Model}

\subsubsection{Consumer Risk Behavior}

Risk plays a critical role in human behavior, particularly when a decision maker is confronted with uncertainty (Hauser \& Urban, 1979; Schoemaker, 1982). A considerable amount of research in marketing, finance and decision sciences literature has been devoted to examining the factors that influence decision-making behavior in risky decision contexts, which is referred to as risk behavior. In most theoretical and empirical studies, risk behavior is conceptualized and analyzed in terms of perceived risk (e.g., Bettman, 1973; Taylor, 1974; Dowling, 1986; Srinivasan \& Ratchford, 1991; Mitchell, 1992; Dowling \& Staelin, 1994). Perceived Risk Theory was initially introduced by psychologists and marketing researchers to understand the individual's purchasing decisions under conditions that entail high risk and uncertainty (Bauer, 1967). Specifically, Cox (1967) and Cunningham (1967) first described perceived risk as consisting of two components: uncertainty and adverse consequences. The predominant issue of this theoretical approach is the action adopted by a decision-maker in order to reduce or avoid the risk related to negative outcomes. For instance, a consumer contemplating a purchasing action will think explicitly in terms of the a) magnitude of the negative consequences, and b) probabilities that these consequences occur when (s)he consumes a specific product (Dowling \& Staelin, 1994). However, this conceptualization is limited by the specific framing of risk behavior with respect to negative outcomes related to the consumption of a specific product (Pennings et al., 2002). This risk-taking behavior is shaped more by the severity of the negative consequences than by the probability of occurrence (Slovic et al., 1980; Diamond, 1988).

Recent research argued that, while 'perceived risk' has often be used as an explanatory variable in studying risk behavior, the decisions of market participants can be better understood by decoupling their risk behavior into the separate com- 
ponents attitude and perception. Such an approach makes possible more robust conceptualizations and predictions of individual market participants' contracting (e.g., MacCrimmon \& Wehrung, 1990; Pennings \& Wansink, 2004), investment (e.g., March \& Shapira, 1987; Weber \& Milliman, 1997; Nosic \& Weber, 2007), and consumption decisions (e.g., Pennings et al., 2002, Schroeder et al., 2007). Particularly, Pennings et al., (2002) propose a new framework for examining consumer risk behavior as consisting of two dimensions that play a crucial role in how consumers make decisions in a product-harm-crisis situation: a) the content of risk; and b) the chance of exposure to the risk content. These two dimensions are strongly linked to the two fundamental drivers of an individual's decision-making behavior under risk: risk attitude and risk perception. Risk attitude is formed by one's predisposition to the content of the risk in a specific market situation and reflects a consumer's interpretation of this risk content in a consistent way. Risk perception is related to second dimension, i.e., the likelihood of one's exposure to the content of the risk. It may be formed on the basis of the consumer's own assessment of the chance to be exposed to the risk content associated with a particular market condition or inherent in a product-related risky situation.

Based on the seminal works of Arrow (1971) and Pratt (1964), Pennings et al., (2002) and Pennings \& Wansink (2004) provide further insights into the separate components of consumer risk behavior. They argue that not only risk attitude and risk perception, but also their interaction, drive consumer risk behavior (Pennings and Wansink, 2004; Pennachi, 2008; Appendix 4.1). The interaction for risk attitude and risk perception reflects that relatively risk-averse consumers may engage in behavior that reduces risk, and that this becomes more prominent as consumer perceives relatively more risk (Pennings \& Smidts, 2000). Based on this risk approach (i.e., decoupling risk-taking behavior into the separate components of risk attitudes, risk perception, and their interaction), we hypothesize that an individual consumer's decision-making behavior (i.e., the decision whether or not to reduce consumption of a harmed product due to an unexpected crisis) in a product-harm crisis situation (e.g., the BSE crisis) can be formulated as:

$$
C R B_{i}=f\left(R A_{i}+R P_{i}+R A_{i}^{*} R P_{i}\right)
$$

where: i) $C R B_{i}$ is the risk behavior of consumer $i$, ii) $R A_{i}$ is the risk attitude of consumer $i$, iii) $R P_{i}$ is the risk perception of consumer $i$, and iv) $R A_{i}{ }^{*} R P_{i}$ is the interac- 
tion between risk attitude and perception of consumer $i$. We further elaborate on this framework by considering its separated but interdependent dimensions and its dynamic features.

\subsubsection{Risk Behavior: A Two-layered Consumer Decision System}

Research in economics has demonstrated that the behavior of market participants with respect to consumption and investment may share a separate but interdependent decision-making structure (e.g., Jones, 1989; Garcia \& Labeaga, 1996 Holloway et al., 2002; Pennings, 2002; Ojah \& Manrique, 2005; Humphrey et al., 2009). These types of decisions often deal with both the intentions of individuals to participate in economic activities (e.g., food consumption, stock investing) and the extent to which these individuals participate in this activity (e.g., the quantity of purchasing, the level of investment). Although these two decisions may be viewed as separate components of a multi-goal decision problem, they may also be interdependent. A decision-maker increases or decreases her/his level of participation in an activity (e.g., the amount of bank debt), since (s)he has already decided to undertake the activity (e.g., incurring a bank debt). Hence, one's decision about the level of activity undertaken is conditional to the decision about participation in the economic activity. Separate but interdependent decisions of individuals may provide a more parsimonious representation of decision-making behavior (Bucklin $\&$ Sismeiro, 2003), improve our understanding of the true behavioral patterns, lead to correct conclusions, and generate useful policy recommendations (Haines et al., 1988).

In the context of our study, consumer risk behavior may be conceptualized as comprising two decisions that share the same decision-making structure: a) the decision of a consumer to participate in the consumption of a harmed product (participation decision) and b) the decision about the amount of harmed product to consume (quantity reduction decision). We therefore consider these two separate decisions as reflecting the reduction in the consumption of a harmed product. Although these decisions are separate, they are interdependent at the same time. The decision of consumer $i$ regarding the amount of harmed product to consume is conditional to the occurrence of her/his decision to reduce consumption due to a product-harm crisis (Schroeder, et al. 2007). 


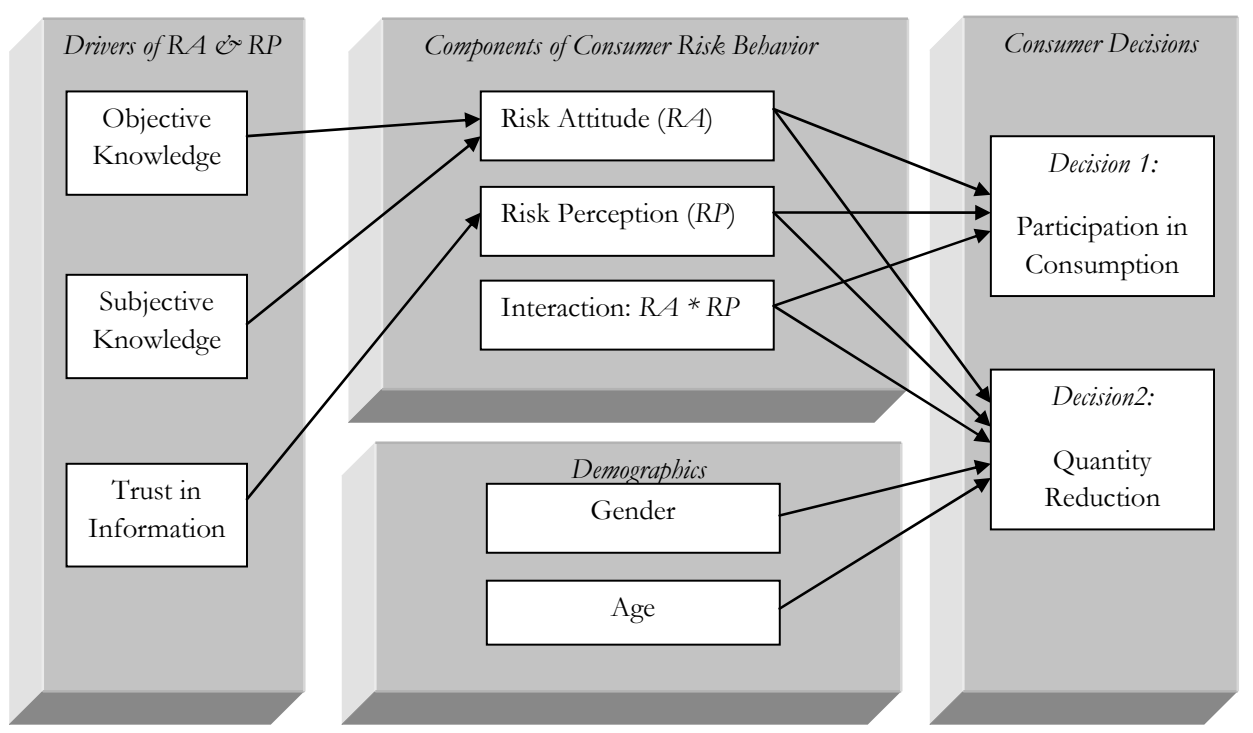

Figure 4.1 A Framework of Consumer Risk Behavior in a Product-Harm Crisis

We hypothesize that the two consumer decisions are driven by a common set of determinants: the components of consumer risk behavior as specified in Equation 4.1 and displayed in Figure 4.1. Thus, we hypothesize that risk attitude, risk perception and their interaction not only drive a consumer's decision with respect to participation in the consumption of a harmed product, but also his/her decision about the amount of harmed product to consume. In addition, the latter decision may be driven by the demographic characteristics of decision-makers, as supported by a number of articles in the marketing and psychology literature. Flynn et al., (1994), Palsson (1996), Byrnes et al., (1998), Laufer and Gillispie (2004), Laufer et al., (2005), among others, found differences among male and female as well as younger and older individuals' consumption and purchasing behavior in risky situations. Women as well as older consumers often exhibit stronger risk reactions to uncertain outcomes of investment risks (Olsen and Cox, 2001) and natural hazards (Dosman et al., 2001; Baker, 2003). Therefore, we hypothesize that, apart from the separated components of consumer risk behavior, gender and age influence the quantity-reduction decisions of consumers. The two-stage decisionmaking process of consumers in a product-harm crisis can be formulated as: 


$$
C R B_{i}=\left\{\begin{array}{l}
D_{i}=f\left(R A_{i}+R P_{i}+R A_{i} * R P_{i}\right) \\
Q_{i}=f\left(R A_{i}+R P_{i}+R A_{i}^{*} R P_{i}+A G E_{i}+G E N_{i}\right), \quad \text { iff } D_{i}>0
\end{array}\right.
$$

where: i) $C R B_{i}$ is the risk behavior of the consumer $i$, ii) $D_{i}$ is the participation of consumer $i$ in the consumption of a harmed product, iii) $Q_{i}$ is the quantity reduction decision of consumer $i$, given that $D_{i}>O$ (i.e., consumer $i$ already decided to reduce his/her participation - in the consumption - of the harmed product), iii) $R A_{i}$ is the risk attitude, iv) $R P_{i}$ is risk perception, v) $R A_{i}{ }^{*} R P_{i}$ is the interaction of the risk attitude and perception, vi) $A G E_{i}$ is age and vii) $G E N_{i}$ is the gender of consumer $i$. Consistent with our discussion, the following two sets of hypotheses are provided with respect to the:

a. participation decision of consumer $i\left(D_{i}\right)$ in the consumption of a harmed product

$\mathrm{H}_{1 \mathrm{~A}}$ : A relatively more (less) risk-averse consumer, will be likely to participate less (more) in the consumption of a harmed product.

$\mathrm{H}_{1 \mathrm{~B}}$ : A consumer who perceives relatively high (low) risk from a product-harm crisis, will be likely to participate less (more) in the consumption of a harmed product.

$\mathrm{H}_{1 \mathrm{C}}$ : As a consumer is relatively more (less) risk-averse, (s) he is more likely to participate less in the consumption of a harmed product when (s)he perceives relatively high (low) risk.

b. quantity-reduction decision $\left(Q_{i}\right)$ of consumer $i$, who has already decided to participate less in the consumption of the harmed product

$\mathrm{H}_{2 \mathrm{~A}}$ : As a consumer becomes relatively more (less) risk-averse, the likelihood of reducing the quantity of consumption of a harmed product increases (decreases).

$\mathrm{H}_{2 \mathrm{~B}}$ : As a consumer perceives relatively high (low) risk, the likelihood of reducing the quantity of consumption of a harmed product increases (decreases)

$\mathrm{H}_{2 \mathrm{C}}$ : As a consumer is relatively more (less) risk-averse, (s) he is more likely to participate less in the consumption of a harmed product when (s)he perceives relatively high (low) risk.

$\mathrm{H}_{2 \mathrm{D}}$ : Female consumers are more likely to reduce the quantity of consumption of a harmed product. 
$\mathrm{H}_{2 \mathrm{E}}$ : Older consumers are more likely to reduce the quantity of consumption of a harmed product.

We use these hypotheses (Equation 4.2) to study whether consumers' riskattitudes, risk perceptions and their interaction play a key role in understanding consumer participation and quantity-reduction decisions. The model is depicted in Figure 4.1. We conceptualized separate but interdependent consumer reactions to a product-harm crisis as a two-layered decision system. The first layer refers to the consumer's participation in the consumption of the harmed product, and the second layer refers to her/his quantity- reduction decision regarding the amount of consumption of a harmed product, given that (s)he already decided to decrease his/her (participation in the) consumption of this product. Consumer risk attitudes, risk perceptions, and the interaction of the two are hypothesized to drive both decisions.

Next, we elaborate on the same framework by accounting for the dynamics of the decision environment.

\subsubsection{Consumer Risk Behavior in a Dynamic Decision Environment}

In fast-moving market environments, the process of decision-making behavior requires analysis on an ongoing basis (Hoffman, 2007). Pennings and Garcia (2004) explain that in several decision environments the risk content (e.g., price fluctuations) is often well understood by individual decision makers (i.e., individual traders or investors) in each specific phase of the decision-making process. In these decision environments the likelihood that an individual will be exposed to the risk content may not follow a random walk due to price fluctuations with equal probability over time (e.g., Cargill \& Rausser, 1975). The likelihood that individual investors will be exposed to the risk content associated with the pricing of commodities traded in futures exchanges can be formulated over time on the basis of concrete probabilities. However, in more uncertain decision environments, such as market crisis due to natural hazards, risks are unexpected and probabilities are not easy to identify due to high uncertainty (Lipshitz et al., 2001). Consumer decisions may change in a later crisis phase because of contingent circumstances in the decision environment (i.e., more objective knowledge about the risk content is acquired, and, hence, more concrete probabilities regarding the potential outcomes of 
a product-harm crisis may be identified). A flexible and dynamic model is needed to accommodate such behavioral patterns.

Although most theoretical models of consumer behavior, especially those of an information-processing type, acknowledge explicitly or implicitly the effects of time on consumer choices (e.g., Hoch \& Loewenstein, 1991; Payne et al., 1993; Erdem \& Keane, 1996; Bettman et al., 1998; Cleeren et al., 2007), the explicit treatment of the effects of time on consumer risk behavior has been sporadic and has lacked systematic elaboration (Johnston, 2001). It has been argued though that trend in the structure and nature of the marketplace itself may involve time effects on several aspects of the decision-making process. Winter (1975) and Bettman et al., (1998) supports that the environmental setting, under which information is provided in the marketplace, plays a crucial role in consumer information absorption, and, consequently, affects consumer decision-making behavior. This environmental setting may be characterized by contingent conditions (e.g., economic, political, technological, cultural) that occur in different time points (i.e., cross sectional instants at which consumer behavior events occur). Contingent conditions in the decision environment may result in the dynamic adjustment of the determinants of decision-making behavior. This adjustment may be captured by the impact of time-varying effects on quantity-related purchasing decisions (e.g., Pauwels et al., 2002), price promotions (e.g., Nijs et al., 2001), and marketing-mix effectiveness (e.g., Van Heerde et al., 2007). We develop hypotheses regarding the dynamic adjustment of the determinants of consumer risk behavior in specific crisis phases and over time.

\section{Consumer Risk Reactions in Specific Crisis Phases}

Public risk concern may change over time in response to fluctuations in problem severity (Loewenstein \& Mather, 1990). This might imply that consumer risk reactions may change in the different phases of a product-harm crisis. We distinguish three main crisis phases: a) pre-crisis phase; b) incipient crisis phase, c) post-crisis phase. A country (i.e., a segment of the population) is in a pre-crisis phase when a crisis is spread only outside its borders. The industry managers and governmental agencies are often concerned with prevention and preparation. The incipient-crisis phase starts when a particular harmful incident occurs, which entails considerable risks. In this phase, industry management and public policy must urgently and actually respond to risk-related threats. The post-crisis phase comes after the first 
harmful incidents happen in the country and consumers are confronted directly with the risks associated with these incidents. In the post-crisis phase public agencies and industry managers look for ways to better prepare for the next crisis and fulfill requirements made during the incipient-crisis phase including follow-up information.

More specifically, in a pre-crisis phase consumers are simply confronted with news about a novel potential risk and, hence, they may exhibit milder risk reactions (e.g., being less risk-averse, perceiving relatively low risk) than in a later phase of a crisis (e.g., incipient crisis phase). These mild risk reactions may be caused by the consumer's response to the appropriate disseminated information flows by public institutions charged with product-related safety communication (JohansenStenman, 2008) and/or the fact that consumers underestimate life- and healthrelated risks since they are not directly confronted with them (Viscusi, 1993). However, after the outbreak of a crisis (i.e., incipient crisis phase), public concern is raised as the risk factor becomes a major element of interest in public debate and in the media (Pearson \& Clair, 1998). When a crisis occurs, individuals may lose their sense of control, see themselves as weak and helpless, and their personal assumptions about the "state" of real-world events may change (Jannof-Bulman, 1992). Thus, individuals' assumptions about the risk inherent in the consumption of an affected product may also change (e.g., what was assumed to be "safe" may no longer be safe). In this crisis phase, the change in consumer assumptions may be reflected in their attempt to avoid the risk content associated with products and services which are found to be defective or even dangerous (Dawar \& Pillutla, 1998).

Moreover, in the incipient crisis phase, the behavior of consumers is often unrelated to the true level of risk (Pennings et al., 2002) since little is known about the risks entailed in the consumption of the affected product (Slovic, 1987) and negative news regarding the chance of exposure to risk content is reported frequently and vividly (Weinberger et al., 1993). As a consequence, confusion regarding the true level of risks and negative and intensified publicity about the triggering event may lead to exaggerated consumer reactions (Pearson and Clair, 1998). Usually, in the incipient phase of a product harm-crisis, a substantial reduction in consumption, reflected in sales volume, of the suspect product often occurs (van Heerde et al., 2007). 
Naturally, public response to the risks related to the consumption of the harmed product may decrease in a post-crisis phase due to the consumer's familiarity with the level of risk exposure to the product's affected attributes (Alba \& Hutchinson, 1987). Yet, the results of domain-specific empirical studies show that the foodsafety outbreaks may have both short-term and long-term impacts on consumer preferences (e.g., Burton \& Young, 1996; Piggott \& Marsh, 2004; Mangen \& Burrel, 2003). The gradual changes in consumer preferences may be attributed to trends and seasonality effects (i.e., news intensity during winter) or other sociopolitical contingent conditions (i.e., slow information dissemination about the risks) existing in the market environment (Mowen, 1980). The lack of accurate, timely information regarding the true level of risk entailed in a critical incident may amplify the crisis threat (Weick, 1993). In particular, when an organization neither confirms nor denies information about the risks entailed in the consumption of a product/service, this may cause chronic low-level anxiety among consumers, even in post-crisis phases. This anxiety may persist and lead to a resurgence of the risk factors in a later phase of a product-harm crisis (Beardsworth \& Keil, 1996; Anand, 1998).

We hypothesize the impact (influence and magnitude) of consumer risk attitudes, risk perceptions and their interaction to be different in specific phases of a product-harm crisis. Specifically, we hypothesize that:

$H_{3 A}$ : The impact of consumer risk attitudes and perceptions and their interaction on consumer decisions is more likely to decrease in the pre-and post-phases than in the incipient-phase of a product harm crisis.

\section{Adaptiveness of Risk Behavior: A Contingent-Context Perspective}

Contingent consumer attitudes, perceptions, and decisions reflect the fascinating ability of individual decision makers to adapt to a wide variety of environmental conditions. Although being adaptive may be hard to define, we generally mean consumers' ability to make decisions or form attitudes and perceptions that are affected not purely by the availability of internal resources (e.g., physiological, cognitive) but also through external contingent resources and constraints (e.g., physical, political, financial, or social). There is a growing research consensus that supports this view. Scholars have claimed that attitude and perception formations as well as change are driven by exposure to episodic events occurring in dynamic market environments (e.g., Rogers, 1997; Abelson et al., 1982). This notion is also 
explicitly addressed in the newly developed field of naturalistic decision-making (Wiggins \& O’Hare, 1995; Lipshitz et al., 2001). The impact of environmental idiosyncrasies (i.e., the contingent context of a particular market situation) on decision-making behavior is more prominent in this research stream. The decisionmaking behavior of individuals claimed to be adaptive to the specificities of "realworld" contingent market conditions (Klein et al., 1993).

The specificities of current or concurrent contingent conditions occurring in dynamic decision environments may lead to the adjustment and hence adaptiveness of consumption, purchase, and investment decisions over time (Lowenstein, 1992; Vlaev, 2007). When consumers make decisions or judge the attributes of choice options (e.g., utilities, probabilities) at different points in time, they are often unable to infer absolute magnitudes for these attributes. Instead, they rather infer relative magnitudes for their attitudes and perceptions, which are fundamentally context-specific (McCrimmon \& Wehrung, 1990; Pennings \& Garcia, 2001). In economics literature, context specificity has traditionally been regarded as involving the decision-maker's response to the properties and characteristics of a decision task (e.g., Simonson \& Tversky, 1992; Benarzi \& Thaler, 2001). This response may be reflected through the activation of consumer cognitive heuristics (e.g., a changing format of a specific task context and/or the availability of time for responding to this task). However, context specificity may also being viewed from another theoretical perspective as an ongoing update of the components of the decision-making process that has an incremental and continuous character in contingent, context-based decision-making environments (Hogarth 1981; Kleimuntz, 1985; Klein, 1993). For instance, a marketing-manager performs a marketing cost analysis at a specific point in time and, based on projections, decides to set levels for the funding of distributional and promotional strategies for a specific product. Next, $s(h)$ e observes the performance of distributional activities and turnover periodically. Subsequently, (s)he may alter his/her decision and adjust the funding levels for these strategies in accordance with the available performance figures at different points in time. This is a sort of adaptive response that often occurs in contingent-driven decision contexts in which decision makers use their experiences from different points in time to make decisions under specific market settings.

A product-harm crisis involving life-threatening design flaws has many features of a contingent-driven decision environment. These events come very sud- 
denly (Johansen-Stenman, 2008), are almost impossible to anticipate (Wansink, 2004), hence ruling out the presence of a possible self-selection effect on the absorption of new risk information (Adda, 2007). To account for the dynamic nature of consumer risk behavior in such turbulent decision environments, the impact of the direct effect of time on the determinants of consumer decisions might be taken into consideration (Kotler, 2002). Thereby, one may allow for the longitudinal evolution of the determinants of consumer risk behavior by hypothesizing the presence of time effects that capture the dynamics of the decision environment (i.e., the contingent-context) in the different phases of a product-harm crisis (Johnston, 2001).

In this work, we recognize that the decision-making behavior of a consumer is a part of a dynamic decision problem that does not simply terminate with a decision at a specific point in time (i.e., in a specific crisis phases). Instead, the behavior of an individual consumer during the phases of a product-harm crisis may adapt to the contingent conditions (i.e., contingent contexts) occurring in a dynamic decision environment. One important property of this perspective is that the impacts of risk attitudes and perceptions on risk behavior are not based on the evaluation of an invariant algorithm (i.e., a weighted adding model), but they are rather sensitive to a specific decision context's contingent conditions. This may imply, in turn, that consumer attitudes and perceptions may change as consumers experience more local problem structures during the course of making decisions (Hoch \& Deiton, 1989; Bettman et al., 1998). We hypothesize that the decoupled components of consumer risk behavior may adapt to the contingent conditions over the different phases of a product-harm crisis. Thereby, we place our initial conceptualization (see: Figure 4.1/Equation 4.2) in a dynamic context by incorporating the element of time effect that captures and reflects the contingent conditions occurring in a product-harm crisis situation as:

$$
C R B_{i t}=\left\{\begin{array}{l}
D_{i t}=f_{t}\left(\mathrm{R} A_{i}+R P_{i}+R A_{i}^{*} \mathrm{RP}\right)_{i} \\
Q_{i t}=f_{t}\left(\mathrm{R} A_{i}, R P_{i}, R A_{i} * R P_{i}+A G E_{i}+G E N_{i}\right) \text { iff } D_{i t}>0
\end{array}\right.
$$

where: i) $C R B_{i t}$ is the risk behavior of the consumer $i$ in crisis phases $t$; $t$ denotes the product-harm's crisis phases as $t=1, \ldots, T$, ii) $D_{i t}$ is the participation of consumer $i$ in the consumption of a harmed product in crisis phase $t$, iii) $Q_{i t}$ is the quantity-reduction decision of a consumer $i$ for a harmed product in crisis phase $t$, 
given that $D_{i}>O$ (i.e., the consumer $i$ already decided to reduce his participation in the consumption of a harmed product), iv) $R A_{i}$ is the risk attitude, $\left.v\right) R P_{i}$ is risk perception, vi) $R A_{i}{ }^{*} R P_{i}$ is the interaction of risk attitude and risk perception, vii) $A G E_{i}$ is the age of consumer $i$, viii) $G E N_{i}$ is the gender of consumer $i$ in crisis phase $t$, viii) the subscript $t$ indicates the dynamics of the determinants (iv - viii) of both consumer decisions $\left(D_{i t}\right.$ and $\left.Q_{i t}\right)$ over the $t=1, \ldots, T$ crisis phases (e.g., pre-, incipient-, and post-crisis phases). This formulation also implies that the impact of gender and age may also change over time. This implies that the reactions of a consumer segment including older and female consumers may adapt to the changing conditions of the product-harm crisis since this segment of consumers may become more familiar with the risk content over time as their product-related experiences increased (Alba \& Hutchinson, 1987). Thus, they may exhibit less riskaverse behavior and perceive relatively lower levels of risk. Equation 4.3 allows the formulation of the following hypotheses:

$\mathrm{H}_{4 \mathrm{~A}}$ : The decoupled components of consumer risk behavior significantly influence consumer decisions across phases of a product-harm crisis.

$\mathrm{H}_{4 \mathrm{~B}}$ : The impact of time effects on the determinants of consumer participation and quantity-reduction decisions is significant across phases of a product-harm crisis.

\subsubsection{Risk Attitudes \& Perceptions: The Role of Knowledge and Trust}

Although the role of knowledge and trust in consumer decision-making has been conceptualized extensively, studies regarding their impacts on risk perceptions and attitudes in different crisis phases are scarce. Theory and empirical testing provide more insights into the dynamic relationships among beliefs, knowledge, trust and risk perceptions rather than risk attitudes. Risk attitudes have been argued to be more invariant than risk perceptions due to their definitional pattern: interpretation of the content of the risk in a consistent way (MacCrimmon \& Wehrung, 1990; Weber \& Milliman, 1997). Yet, one may assume that the extent of the attitude's rigidness may not be viewed as a valid assumption if/when consumers may modify their preferences as function of whether they expect repeated exposure to stimuli and/or as a function of the cost-avoiding aversive stimuli during repeated exposure (Gibbs, 1996). Consumers may modify their willingness to accept certain levels of risk in order to allow themselves to extract higher utility from subsequent choices regarding the consumption of a product or service (e.g., Hoch \& Loewenstein, 1991; Kahn \& Luce, 1997). 
Research in marketing also suggests that consumers may alter their decisionmaking representations because of their increasing experience with the nature of a decision event or the attributes of a product (e.g., Hoch \& Deiton, 1989). Differences among these representations arise as consumers acquire more experiences over time related to the content of the attributes of a product/service and exhibit higher levels of trust in the information provided about this content (e.g., Moorman et al., 1992; Alba \& Hutchinson, 2000). Although we recognize that risk attitude and risk perception are two different concepts, here, we assume that the experience-based factors such as knowledge about the risk content inherent in a product-harm crisis event and consumer trust in information about safety may affect the dynamics of consumer risk attitudes (i.e., the willingness of a consumer to accept the risk content) and risk perceptions (i.e., the subjective interpretation of consumer of the probability to be exposed to the content of the risk), respectively, in different crisis phases.

\section{The Role of Knowledge}

The role of consumer knowledge in the subsequent information processing and decision making has been extensively discussed in consumer research (e.g., Moorman \& Matulich, 1993; Bettman, et al., 1998; Sen, 1998; Wood \& Lynch, 2002; Hui et al., 2009). As Moorman et al., (2004) explain, knowledge in consumer research has been assumed to have two facets: objective and subjective knowledge. Objective knowledge refers to accurately stored information while subjective knowledge refers to the individual's self-beliefs about their own knowledge. Alba and Hutchinson (2000) further explain that objective knowledge is dependent mostly on the consumer's ability or expertise whereas subjective knowledge is based on expertise as well as experience. In other words, objective knowledge may reflect what a consumers knows, and subjective knowledge may reflect what a consumer thinks (s)he knows. Jacoby (1984) argued that the issue of how consumer knowledge affects behavior should the preliminary focus of the entire public policy.

Marketing theory suggests that consumers with high expertise (objective knowledge) and experience (subjective knowledge) may have more detailed knowledge structures (e.g., Hoch \& Deaton, 1989). The consumer's expertise, experience and familiarity with the risks associated with the consumption and purchase of a specific product may increase the level of accurately stored information and update the consumer's self-beliefs (Brucks, 1985). That is, the objective and subjective 
knowledge are likely to be updated when changes in the decision environment occur and due to increases in the consumer's learning from the dissemination of new information about the risk content entailed in a the use or consumption of a product/service (Perachio \& Tybout, 1996). As a consequence, consumers may use new information about the risk content entailed in a specific crisis-phase and they may update their prior self-beliefs (Viscusi, 1991, Liu et al., 1998).

We expect the risk attitude of an individual (i.e., willingness to take the risk) in dynamic decision environments (i.e., product-harm crisis) to be subject to increased levels of objective knowledge (i.e., accurately stored information) as well as subjective knowledge (i.e., self-beliefs about their own knowledge). Consumers may acquire more precise information about the risk content entailed in a productharm crisis in the course of making subsequent decisions because of their increased expertise on the risk content inherent in particular decision environments over time (i.e., subsequent phases of a product harm crisis). Moreover, the release of more precise information about the risk content entailed in a product-harm crisis situation may alter their self-beliefs about their own knowledge regarding this risk content in particular crisis phases. These expectations are consistent with prior research in marketing showing that, when more health information regarding the low risks inherent in the consumption of a product is disseminated, consumers exhibit less risk-averse behavior due to their accelerated expertise and experience with the risk content entailed in the consumption of this product (e.g., Smith and Johnson, 1988; Roe et al., 1999; Kozup et al., 2003). Thus, we hypothesize that:

$\mathrm{H}_{5 \mathrm{~A}}$ : Greater objective knowledge of consumes will be likely associated with less riskaverse behavior in the subsequent phases of a product-harm crisis.

$\mathrm{H}_{5 \mathrm{~B}}$ : Greater subjective knowledge of consumers will be likely associated with less riskaverse behavior in the subsequent phases of a product-harm crisis.

\section{The Role of Trust}

Kramer (1999) offers a comprehensive review of the trust literature that emphasizes the crucial importance of trust in understanding the consumer decision-making process under risk and uncertainty. Trust can be defined as the extent to which one party believes that other parties will not act to exploit one's vulnerabilities (Mayers et al., 1995). In a more specific context regarding the transactions developed among different parties, trust may be viewed as increasing one's susceptibility to the risk of opportunistic behavior of one's transaction partner (Zand, 1972). 
Without susceptibility (i.e., vulnerability) to the risk of opportunism, there is no need to trust. That is, some degree of risk must be present to be able to speak of trust (Dasgupta, 2009). Moreover, Bradach and Eccles (1989) define trust as a belief or expectation that an exchange partner will not engage in opportunistic behavior, even in the face of countervailing short- and long- term incentives and uncertainty about long-term benefits. These definitions address risk either explicitly or implicitly, and it becomes evident that trust is a concept inextricably linked to risk behavior.

Several recent studies have looked at the impact of trust on consumer perceptions by distinguishing between specific actors, for example, consumer trust in retailers, wholesalers, governmental agencies, and the health system (e.g., Horning et al., 2003; Siergist et al., 2003; Van Kleef et al., 2007). Slovic (1992) and Johnson and Slovic (1995) support that the decision-making behavior of consumers is likely to alter at different points in time as it depends on the extent to which a consumer trusts the information about consumption safety issues provided by institutions charged with the dissemination of health information. Boker and Hanf (2000) have shown that high levels of consumer trust in information provided about a potentially harmed product, positively affect consumer behavior under risk and uncertainty (i.e., consumers perceive low levels of risk). Also, Eiser et al., (2003) suggest that any erosion of public trust in response to products hazards is likely to lead to the perception of higher risk levels. These studies imply that the impact of trust on consumer perceptions may be different in different phases of a product-harm crisis.

Specifically, in a pre-crisis phase, the information provided by industry institutions and governmental agencies is often not doubted since consumers are not directly confronted with the potential hazards and are unaware of or unconcerned about the potential risk factors (Beardsworth \& Keil, 1996). They may also incur higher search and substitutions costs when attempting to find products with credence attributes or buying non-preferred products (Campo et al., 2000). Consumers often exhibit a degree of tacit trust in the dominant cultural institutions and the regulatory-governance mechanisms charged with providing product-related safety information and in the accurateness of this information that these institutions provide (Giddens 1991). Thus, consumers' trust in the safety information from these institutions may result in a relatively low perception of risk in a pre-crisis phase 
because the probability that they will be exposed to the content of the risk is perceived by them as low. However, the bad publicity surrounding the incipient-phase of a product-harm crisis tends to be weighted heavily by consumers when making product- purchasing and consumption decisions. This phenomenon is known as negativity bias as it is perceived both as diagnostic and surprising (Herr et al., 1991). Consumer trust in the information provided by the regulatory governance mechanisms protecting the public welfare may decrease and influence consumers' risk perceptions negatively. That is, consumers may perceive more risk in the incipient-phase of a product-harm crisis because they consider the chance to be exposed to the content of the risk as higher. In this study, we examine the influence of consumers' trust in the safety information provided by the governmental agencies on consumer risk perceptions since these institutions carry the greatest responsibility in disseminating health information to other market actors throughout the supply chain (e.g., Miller, 1999).

In the course of a crisis (e.g., the post-crisis phases), consumers may regain their trust in the product-safety information provided by institutions, having acquired more expertise, experience and more detailed knowledge regarding the prevention of potential health hazards. Familiarity with risk factors may make consumers weight the negative outcomes with the consumption of a potentially harmed product and the negative news surrounding these outcomes less heavily (Jolly \& Mowen, 1985). Recovering of one's trust may result in increasing consumer confidence and, hence, the perception of lower levels of risk (De Jonge et al., 2008). That is, the probability that consumers will be exposed to the content of risk is perceived by them as lower. However, continuous negative publicity in the post-crisis phases as well as cultural susceptibility towards potentially compromising alliances between science, corporate interests, and government agencies may lead to reflexive doubt and a slow recovery of consumer's trust in food safety information (Thompson, 2005). Reflexive doubt may be viewed as the public's skepticism about the level of risk, caused by complex technological systems and sociopolitical and economic forces that may affect risk attitudes and perceptions (Beck, 1999). A slow recovery of consumer trust in food-safety information due to reflexive doubt may lead to the perception of higher levels of risk. We hypothesize that: 
H6A: Greater (lower) consumer trust in safety information is associated with the relatively lower (higher) risk perception in the pre-and post-phases than in the incipient phase of a product-harm crisis.

\subsection{Implications of the Proposed Framework}

From a marketing and/or public policy perceptive, the insights that result from decoupling risk attitudes and risk perceptions in a dynamic and natural decision context as well as the impacts of consumer knowledge on risk attitudes and trust in health information on risk perceptions in specific crisis phases, can yield important managerial implications for marketers and policy makers coping with puzzling consumer reactions in different phases of a product-harm crisis. We consider the following six implications regarding potential outcomes of consumer risk behavior in the different crisis phases $\left(t_{1}, t_{2}, \ldots, t_{n}\right)$ :

Implication \#1: Suppose that risk attitude is the main driver of consumer reactions to a BSE crisis in crisis phase $t_{1}$ (e.g., incipient-crisis phase). In such a case, the interest of policy-makers and marketers should be centered on the identification of ways to eliminate the risk (e.g., a total recall and elimination of the product: testing and slaughtering all suspected cows) because, even if the probabilities of being exposed to risk are small, effectively communicating these probabilities will have not any substantial influence on consumers' decisions. However, if at $t_{2}$ (e.g., post-crisis phase) risk attitude does not influence consumers' risk behavior, the marketing strategy has to be adapted to the new conditions and these tough measures should be gradually abandoned. The extent of gradual-product elimination strategies will be based on level(s) of the decreasing magnitude of risk-aversion over the different crisis phases.

Implication \#2: Suppose that the risk perception drives consumer decisions in crisis phase $t_{1}$ (e.g., pre-crisis phase). This would suggest that effectively communicating the 'true' probabilities of being exposed to the risk (when available) is a useful way to shape the consumers' risk response to a product-harm crisis in this phase. If in a later phase of the crisis, $t_{2}$ (e.g., incipient-crisis phase), the influence and the magnitude of risk perception on consumer behavior will have increased substantially, marketers and policy makers should focus on strengthening the communication strategies by heightening the budgets that enhance effective communication. If the influence and the magnitude at decreased substantially at $t_{2}$, 
policy-makers, industry managers and marketers may focus on other ways (e.g., gradual beef recalls, partial product elimination and recall) to decrease the uncertainty of the risk content inherent in this particular crisis phase.

Implication \#3: Suppose that the interaction of risk attitude and risk perception drives consumer decisions to reduce their beef consumption in crisis phase $t_{1}$ (e.g., incipient-crisis phase). The solution in this case may be a combination of the 2 strategies (implication 1 and 2) mentioned above: both tough policy measures and marketing strategies (e.g., product recalls and elimination) and effective dissemination of health information are required. If the relative importance of this factor to consumers' decisions diminishes in a later phase of the crisis, $t_{2}$ (post-crisis phase), the emphasis of the marketing strategies has to be placed on influencing consumer risk attitudes or risk perceptions, depending on which factor has a higher relative importance.

Table 4.1 Managerial Implications based on Changing Consumer Risk Behavior in Different Product-harm Crisis Phases

\begin{tabular}{|c|c|c|c|}
\hline & \multirow[t]{2}{*}{ Pre-crisis phase } & \multicolumn{2}{|c|}{ Incipient-crisis phase ${ }^{\mathrm{a}}$ Post-crisis phase ${ }^{\mathrm{b}}$} \\
\hline & & $\begin{array}{l}\text { Increased influence \& } \\
\text { magnitude }\end{array}$ & $\begin{array}{l}\text { Decreased influence \& } \\
\text { magnitude }\end{array}$ \\
\hline Risk Attitude (RA) & $\begin{array}{l}\text { Product elimination and } \\
\text { recalls } \\
\text { (e.g., eliminate risk by slaugh- } \\
\text { tering of animals) }\end{array}$ & $\begin{array}{l}\text { Full product-elimination } \\
\text { and recall strategies (e.g., } \\
\text { detection and evaluation of } \\
\text { all products suspected to be } \\
\text { "weak") }\end{array}$ & $\begin{array}{l}\text { Partial product-elimination and } \\
\text { recall strategies (e.g., detection } \\
\text { and elimination of "weak" prod- } \\
\text { ucts only) }\end{array}$ \\
\hline $\begin{array}{l}\text { Risk Perception } \\
(R P)\end{array}$ & $\begin{array}{l}\text { Communication strategies } \\
\text { (i.e., industry and governmen- } \\
\text { tal campaigns to communicat- } \\
\text { ing the "actual" level of risk) }\end{array}$ & $\begin{array}{l}\text { Investing more in communi- } \\
\text { cation strategies (e.g., heigh- } \\
\text { tening budgets for commu- } \\
\text { nication strategies) }\end{array}$ & $\begin{array}{l}\text { Investing less in communication } \\
\text { strategies }\end{array}$ \\
\hline $\begin{array}{l}\text { Interaction: } R A^{*} \\
R P\end{array}$ & $\begin{array}{l}\text { Mixture of strategies based on } \\
\text { the relative importance of RA } \\
\text { \& RP }\end{array}$ & $\begin{array}{l}\text { Strengthening both product- } \\
\text { elimination and communica- } \\
\text { tion strategies }\end{array}$ & $\begin{array}{l}\text { Partial product-elimination and } \\
\text { investing less in communication. }\end{array}$ \\
\hline
\end{tabular}

a The strategies proposed for the incipient-crisis in this table are based on the scenario that the influence and the magnitude of consumer risk attitude, risk perception, and the interaction of the two, on their decisions, increased.

b The strategies proposed for the post-crisis phase in this table are based on the scenario that the influence and the magnitude of consumer risk attitude, risk perception, and the interaction of the two, on their decisions, decreased. 
Implication \#4: Suppose that risk attitude is driven by the extent of the consumer's objective knowledge about the risk content entailed in a product-harm crisis phase $t_{1}$ (e.g., incipient-crisis phase). This would suggest that marketers' interest may lie in designing strategies to communicate effectively the health-related risks (i.e., risk content) evolved in a product-harm crisis situation. These strategies may focus on maintaining, ensuring, and increasing the levels of consumers' accurate information about the risk content, by using intensified and frequent health briefings and commercial messages regarding product-related safety (e.g., through presentation of scientific facts, advertising, etc). More accurately stored information on the risk content among consumers may lead to less risk-averse behavior. If in a later phase of the crisis, $t_{2}$ (e.g., post-crisis phase), the impact of objective knowledge on risk attitudes decreases, the storage strategies may require that marketers and policy-makers invest more in resources and time and target their efforts to reaffirm accurate information regarding potential risks in order to further induce the accuracy of consumer knowledge. This re-affirmation should make sure that accurate information about the risk content is readily available to the consumers.

Implication \#5: Suppose that subjective knowledge drives risk attitude in crisis phase $t_{1}$ (e.g., pre-crisis phase). In such a case, the focus of policy-makers and marketers may be on the development of communication strategies to re-direct consumer's subjective knowledge about the risk content away from rumor-stimulated associations. Thus, consumers' own interpretation about the risk content may be made in a consistent way. In other words, the implementation of strategies that eliminate consumers' negative bias may be the solution. Such a strategy may be implemented by using successful message framing and through the development of consumer (health-) educational programs. These messages and programs may prevent the association of a harmed-product threat with imprecise information flows. If in a later phase of the crisis, $t_{2}$ (e.g., incipient-crisis phase), the influence and the magnitude of subjective knowledge on risk perceptions diminishes, adaptation towards more intensive communication efforts for selective persuasive messages regarding the risk content may be required in order to alter consumer self-beliefs about what they know (e.g., public announcements that focus mainly on communicating the low level of risk - factors - in the consumption of a product and further investing in appealing product presentations in retail outlets). 
Implication \#6: Suppose that consumer trust in information about safety issues provided by governmental institutions drives the risk perception in crisis phase $t_{1}$ (e.g., pre-crisis phase). Greater trust in this source of information may result in a relatively low perception of risk because consumers consider the chance (i.e., probability) to be exposed to the content of the risk as low. One way to maintain the high levels of consumer trust in the information provided by governmental institutions is to avoid mismatching of crucial information

Table 4. 2. Managerial Implications based on the Factors Impacting Risk Attitude (RA) and Risk Perception (RP) in Crisis Phases

\begin{tabular}{|c|c|c|c|c|c|c|}
\hline & \multicolumn{2}{|l|}{ Pre-crisis phase } & \multicolumn{4}{|c|}{ Incipient-crisis phase ${ }^{\mathrm{a}}$ Post-crisis phase } \\
\hline & & & $\begin{array}{l}\text { Decreased inf } \\
\text { magnitude of } \\
\text { TRUST }\end{array}$ & $\begin{array}{l}\text { uence \& } \\
O K, S K\end{array}$ & $\begin{array}{l}\text { Increased influe } \\
\text { magnitude } \\
\text { of } O K, S K, T R\end{array}$ & $\begin{array}{l}\text { nce \& } \\
\text { UST }\end{array}$ \\
\hline & $R A$ & $R P$ & $R A$ & $R P$ & $R A$ & $R P$ \\
\hline $\begin{array}{l}\text { Objective } \\
\text { Knowledge } \\
(\mathrm{OK})\end{array}$ & $\begin{array}{l}\text { Storage strate- } \\
\text { gies for com- } \\
\text { municating the } \\
\text { "actual" level } \\
\text { of risk }\end{array}$ & & $\begin{array}{l}\text { Reaffirmation } \\
\text { of accurate } \\
\text { risk informa- } \\
\text { tion }\end{array}$ & & $\begin{array}{l}\text { Less extensive } \\
\text { use of storage } \\
\text { strategies }\end{array}$ & \\
\hline $\begin{array}{l}\text { Subjective } \\
\text { Knowledge } \\
(S K)\end{array}$ & $\begin{array}{l}\text { Retrieval } \\
\text { strategies for } \\
\text { eliminating the } \\
\text { negativity bias } \\
\text { associated with } \\
\text { the risk con- } \\
\text { tent }\end{array}$ & & $\begin{array}{l}\text { Intensive } \\
\text { communica- } \\
\text { tion } \& \text { ap- } \\
\text { pealing } \\
\text { product } \\
\text { presentations } \\
\text { in retail } \\
\text { outlets }\end{array}$ & & $\begin{array}{l}\text { Less intensive } \\
\text { communication } \\
\text { for guarantee- } \\
\text { ing the elimina- } \\
\text { tion of negativ- } \\
\text { ity bias. }\end{array}$ & \\
\hline $\begin{array}{l}\text { Trust in } \\
\text { Information } \\
\text { provided by } \\
\text { Government } \\
\text { (TRUST) }\end{array}$ & & $\begin{array}{l}\text { Open \& trans- } \\
\text { parent commu- } \\
\text { nication strat- } \\
\text { egy targeting } \\
\text { confidence \& } \\
\text { social em- } \\
\text { beddedness. }\end{array}$ & & $\begin{array}{l}\text { Increase } \\
\text { public in- } \\
\text { vestments in } \\
\text { communica- } \\
\text { tion \& syner- } \\
\text { gies among } \\
\text { government, } \\
\text { industry \& } \\
\text { media. }\end{array}$ & & $\begin{array}{l}\text { Gradual } \\
\text { decrease of } \\
\text { investments in } \\
\text { communica- } \\
\text { tion strategies } \\
\text { at the level that } \\
\text { consumer trust } \\
\text { is maintained. }\end{array}$ \\
\hline
\end{tabular}

${ }^{a}$ The strategies proposed for the incipient-crisis in this table are based on the scenario that the influence and the magnitude of $O K$ and $S K$ on $R A$ and TRUST on RP decreased

b The strategies proposed for the post-crisis phase in this table are based on the scenario that the influence and the magnitude of $O K$ and $S K$ on $R A$ and TRUST on RP increased. 
regarding the potential health risks associated with the consumption of a harmed product. The public dissemination strategy should always rely on concrete, open and transparent information. Hence, a signaling strategy containing cues of confidence (assurance) and social embeddedness may be adopted in order to maintain consumer trust (e.g., investing in the creation of logos that endorse the credibility of information). If in a later crisis phase, $t_{2}$ (e.g., incipient crisis phase), consumer trust decreases and, as a consequence, consumers will perceive relatively more risk, policy-makers may consider further increasing public investments and developing synergies with other market actors (media and industry managers) in order to enhance consumer confidence and eliminate their disappointment and negative emotions related to the consumption of a harmed product.

Table 4.1 summarizes the managerial implication of our proposed framework with respect to the impact of risk attitudes, risk perceptions and their interaction on consumer decisions between different crisis phases. This table does not cover the managerial implications of demographics (i.e., gender and age). That is, the gender and age of populations are factors that public policy and industry managers may have limited influence on. However, their changing impact on consumer decisions across the crisis phases may reveal useful information for marketers to improve product placement in retail outlets and the design of segmentation strategies during the phases of a product harm-crisis. Finally, table 4.2 summarizes the managerial implications with respect to the impacts of consumer knowledge on risk content and trust in information on risk attitudes and perceptions.

Next, we discuss the research design of our empirical study which allows the testing of the proposed framework and may reveal important information for marketers and policy-makers.

\subsection{Research Design}

To address whether consumers' risk behavior adapts to the changing conditions of decision environments in and across the phases of a product-harm crisis, we examined the risk reactions of consumers to the BSE crisis in the US and Germany in the different crisis phases during 2001 and 2004. As displayed in Figure 4.2 the risk reactions of American consumers were examined in the pre- (2001) and incipient-BSE crisis phases (2004) and the Germans in the incipient- (2001) and postcrisis phases. 
The selected decision context entails high uncertainty namely the possibility of a deadly outcome for consumers due to the spread of unexpected life-threatening design-flows. Hence, it provides a unique opportunity for carrying out natural experiments which allow the evaluation of consumers' reactions to a market crisis in and across different crisis phases. Several types of natural-hazards, such as food scares, disease epidemics, weather calamities, and terrorist attacks, are unexpected, can destroy corporate businesses and disrupt the consumption of an entire product category (Pearson \& Clair, 1998). Thus, the current decision context also provides the opportunity to observe and analyze consumers' risk reactions to a market crisis that involves an entire product category, in our case, beef.

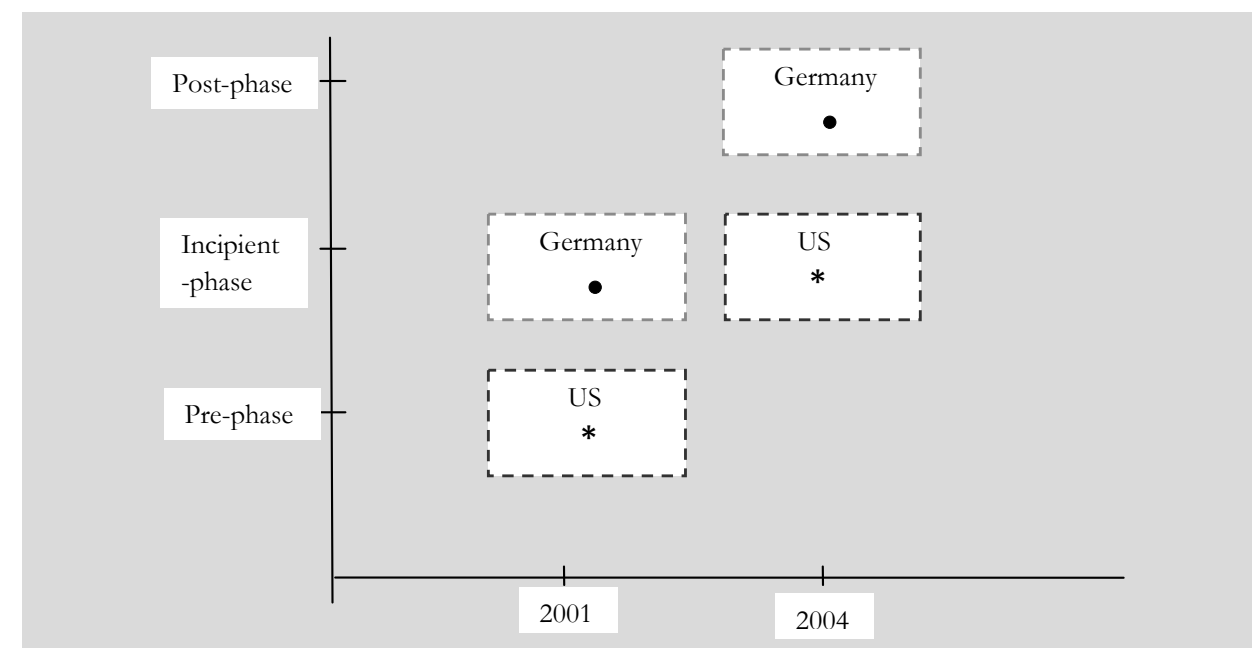

Figure 4.2 BSE Crisis Phases for the US and Germany in 2001-2004.

Many governmental agencies (e.g., Economic Research Service USDA; Canadian Animal Health Coalition, EU Commission) and scholars (e.g., ) have focused heavily on the assessment of the economic impact of the BSE crises on beef and other meat prices and on the effectiveness of a series of measures to safeguard health and restore confidence in beef (e.g., Byrne, 2002). However, there are no systematic reports focusing on the BSE crisis developments and consumer reactions to the BSE crisis in different countries in different phases (i.e., pre-, incipient-, and postcrisis phases). In this section we discuss our decision context regarding the ramifications of the BSE crisis on a timeline basis. We attempt to shed light on the contingent conditions occurred in the marketplace of the two countries in each crisis 
phase. Table 4.3 summarizes the results of this qualitative study by displaying the different BSE crisis developments (risk assessments, management and communication strategies, as well as consumer reactions) in the US and Germany for the pe$\operatorname{riod} 2001-2004$.

\subsubsection{Decision Context}

Consumer concerns with the BSE crisis are aligned with the scientific fact that contaminated beef can cause the fatal "Creutzfeldt-Jacob Disease - (CJD)". Although the World Health Organization confirms that the chance of contracting CJD by eating beef is extremely small, it seems that the behavior of consumers in such a product crisis is not always consistent with the true level of risk they face. For instance, beef consumption decreased dramatically in Germany when the first BSE case was detected (November 26, 2000). At the height of the rush to fill festive Christmas tables and despite the fact that German beef and meat consumption used to reach its annual peak in December, butchers reported plunges of up to 90 percent in the sales of beef and sausages (Reuters, 2000; Gfk, 2001). At the same time, poultry and horse meat prices surged. Figure 4.3 shows that in the next three years, beef consumption recovered slightly in Germany maintaining an overall decreasing trend, undoubtedly, due to the ramifications of the well-publicized BSE crisis events, which put intense pressure on governmental agencies, industries, and marketers globally.

Only two years after the BSE outbreaks in Germany, the US lost access to its traditional export markets (e.g., Japan) following a BSE discovery on December 23, 2003. In contrast with the German case, American consumption remained at almost the same level as in 2002. It is indeed striking the inconsistency in reactions among the American and German consumers towards the same product-harm crisis entailing the same risk content. How can this inconsistency in risk reactions be explained? 
United States

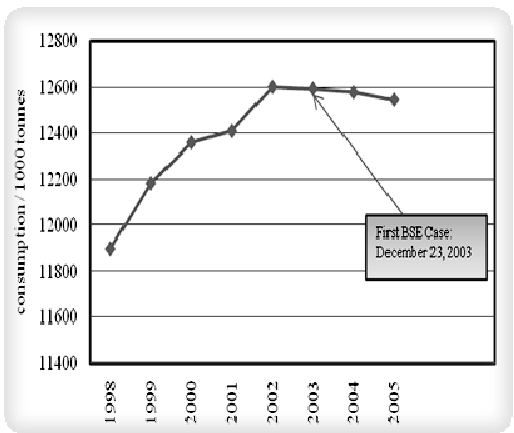

Germany

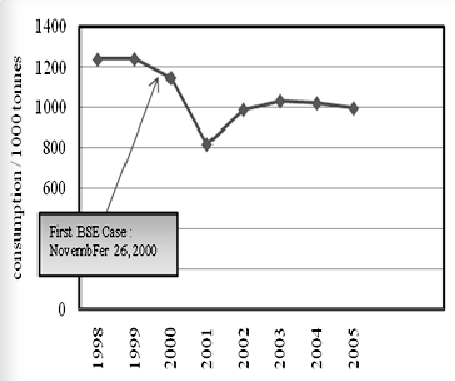

Figure 4.3 American and German Gross Consumption of Beef from 1998-2005

(Source: Eurostat \& USDA, 2007)

In order to gain a complete and informative view of the situation in each country, we first discuss the developments in the two countries in the light of: a) risk assessment, b) risk management, and c) risk communication (FAO/WHO, 1997). Risk assessment focuses on the efforts made in each country to estimate the risk that BSE will negatively affect a population or subpopulation. Risk management's primary goal is the protection of public health by controlling risk associated with the BSE as effectively as possible through the selection of appropriate policies and strategies. Risk communication refers to the interactive exchange of information and opinions concerning risk and risk management among risk assessors, risk managers, consumers, and other interested parties. Second, we provide descriptive information regarding consumer reactions to the BSE crises in each country over the examined period. These descriptions are based on a systematic collection of relevant information by using archived press releases, media announcements and governmental factsheets and reports over the period 2001-2004. We accessed relevant information from more than 50 web-pages and 100 business-, regulatory-, and country-specific reports, and popular articles regarding the developments of BSE crises in both countries for the period 2001-2004. ${ }^{17}$

Below, we discuss in more detail how the political and market actors responded to the BSE crisis in the two countries by using (and displaying) selected

\footnotetext{
${ }^{17}$ The information collected from on-line sources and business reports is available upon request to the author.
} 
sources, which allow us to make-up a coherent synthesis of the BSE crisis developments during the period 2001-2004.

\section{US : Atmosphere of High Surveillance}

Under the cloud of fear created by a wave of European BSE outbreaks, American policy-makers took proactive measures to prevent the introduction and potential spread of BSE in the US Surveillance measures targeted those cattle populations where the disease was most likely to be found (APHIS, 2006). In late 2001, a study conducted by the Harvard Center for Risk Assessment supported that the implementation of these measures, which were initiated by the United States Department of Agriculture (USDA), was largely responsible for keeping the BSE out of the US, and it would have prevented the BSE from spreading on the American beef market, if it had ever entered the country (Cohen et al., 2001).

The US Food and Drug Administration estimated a loss of $\$ 15$ billion in sales revenue, resulting from a 24 percent decline in beef sales and 80 percent decline in beef and live cattle exports, if a BSE incident were to occur in the county (FDA, 2001). Moreover, slaughter and disposal costs of infected cattle would amount to about $\$ 12$ billion. To prevent BSE from entering the American food supply chain, the public administration expanded its surveillance activities, including testing an increased number of cattle samples and inspections at US entry ports (GAO, 2005).

Policy-makers and meat industry managers supported the implementation of the effective surveillance programs aimed at the elimination of infected beef and its byproducts from the food chain. Although the level of testing in US was minuscule, only 20.000 tests were conducted in the US in 2002 compared to 8.5 million animals tested in Europe (Fox \& Peterson, 2004), the administration invested substantial resources to strengthen BSE protection systems, including significant funding increases for risk analysis, education, and public-awareness programs. A series of educational seminars on the BSE-related risks were organized for cattle producers, veterinarians, industry groups, and the general public through numerous briefings and press conferences. The wide distributions of fact sheets, videotapes on the causes and harms of BSE, guidelines for compulsory notification requirements, on-line web support, and information packets to veterinarians, extension offices, universities and industry groups, attempted to strengthen precautionary programs to keep the BSE out of the US (USDA, 2002). The level of surveil- 
lance in the US increased steadily after 2000 and jumped significantly at the beginning of 2004 when the USDA and the US Department of Health and Human Services (USDHHS) enhanced surveillance activities following the first BSE discovery of December 23, 2003.

The detection of the first BSE infected cow in the US sparked the instant implementation of an action plan under the supervision of the USDHHS. This plan included several activities such as the protection of consumer health which was assigned to the Food and Drug Administration (FDA) as its primary responsibility, and risk analysis which was conducted by the National Institute of Health (NIH). The FDA investigators also assisted the USDA officers in meat recalls checks at retail stores, and they witnessed the destruction of beef and byproducts at landfills (FDA, 2004). At the same time, the American government provided daily briefings to update the public on the BSE status (USDA, 2003). To protect the public health and maintain the confidence of consumers, industry, and trading partners, the government announced the implementation of stricter regulations in order to further prevent human exposure to BSE. In addition, the government appointed an international panel of scientific experts to provide an objective review of the US response actions and areas for potential enhancement and to recommend appropriate strategies for communicating to the general public the low probability of adverse health effects associated with beef consumption.

Only one day after the BSE discovery in the US, stock prices for restaurants and other food-related companies fell sharply. The stock prices of McDonald's Corp. and Wendy's fell 6\% and 4.5\% respectively (Goldstein \& Wilson, 2005). Figure 4.4 shows that other barometers indicating market expectations, such as the index Feeder Cattle Futures (FCF) of the Chicago Mercantile Exchange (CME) and the Thomson-Reuters Live Cattle index, shaded approximately by $9 \%$ and $6 \%$ respectively, within the first two weeks after the outbreaks of BSE in the US. ${ }^{18}$ Jin and Kim (2008) provide empirical evidence that the security values of firms in the beef sector were negatively affected by the BSE event for a period of about three months. Pritchet et al., (2005) summarize estimates using agribusiness-level studies

\footnotetext{
${ }^{18} \mathrm{CME}$ Feeder Cattle Futures contracts are risk management instruments to hedge risks arising in the cattle commodity markets due to natural hazards caused by weather conditions, crop diseases, etc. The level of trade in these contracts also gives an indication of market participants' expectations and risk taking behaviour (see: Pennings, 1998; Tse \& Hackard, 2006).
} 
that show that the BSE's outbreak in the US lowered beef prices by $13 \%$ between December 22nd and January 8th , while fed cattle prices fell by about $20 \%$ during the same time period and the negative impact on the slaughter industry persisted until 2004. However, the reactions of American consumers were limited and dissipated within two weeks after the first media announcements of the first BSE case in the US (Kuchler \& Tegene, 2006).

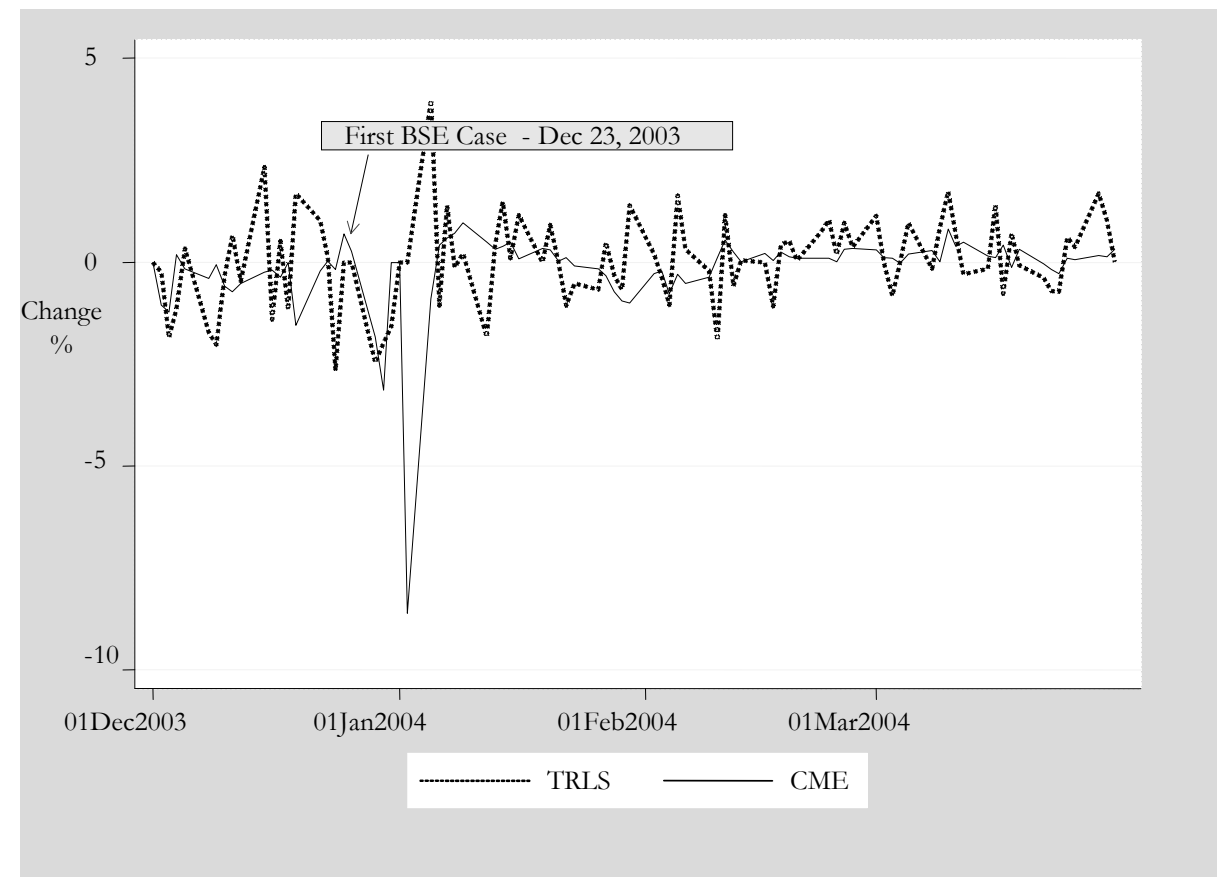

Figure 4.4 Percentage of Changes in CME Feeder Cattle and Thomson-Reuters Live Stock Cattle (TRLC) Indexes: December 1, 2003 to March 31, 2004

A CNN/USA TODAY/Gallup Poll taken from January 2-5, 2004 revealed that most Americans believed that BSE was a minor problem (63\%) and insisted that they did not cut back or stop eating beef as a result of BSE in the US (81\%). Likewise, various press releases reported that BSE had not set any panic in the sales of beef in American restaurants and grocery stores and they remained steady (Wahlreng, 2004). For instance, the American McDonalds restaurants did not show any decrease in beef consumption due to the BSE events, contrary to double-digit decreases in Europe and Japan after BSE had broken out (Leung, 2004). 
Table 4.3 Risk Analysis and Consumer Reactions in the US \& Germany during 2001-2004

\begin{tabular}{|c|c|c|c|c|}
\hline & Risk Assessment & Risk Management & Risk Communication & Consumer Reactions \\
\hline \multirow[t]{2}{*}{$U^{\mathrm{a}}$} & $\begin{array}{l}\text { Pre-phase: active } \\
\text { surveillance and early } \\
\text { (homeland) protec- } \\
\text { tion measures. }\end{array}$ & $\begin{array}{l}\text { Pre-phase: testing of } \\
\text { selected cattle samples } \\
\text { and high investments to } \\
\text { strength BSE protec- } \\
\text { tion systems. }\end{array}$ & $\begin{array}{l}\text { Pre-phase: intensive educa- } \\
\text { tion of producers, industry } \\
\text { groups and general public } \\
\text { on the BSE risks.. }\end{array}$ & $\begin{array}{l}\text { Pre-phase: unchanged } \\
\text { consumer behavior and } \\
\text { confidence to American } \\
\text { food system. }\end{array}$ \\
\hline & $\begin{array}{l}\text { Incipient phase: } \\
\text { continuing robust } \\
\text { surveillance programs. }\end{array}$ & $\begin{array}{l}\text { Incipient phase: product } \\
\text { recalls and checks at } \\
\text { retail stores and land- } \\
\text { fills; scientific expertise } \\
\text { for regulatory and } \\
\text { consumption-related } \\
\text { issues. }\end{array}$ & $\begin{array}{l}\text { Incipient phase: daily } \\
\text { briefings on the BSE status } \\
\text { by governmental agencies } \\
\text { and industry groups }\end{array}$ & $\begin{array}{l}\text { Incipient phase: beef retail } \\
\text { sales remained almost } \\
\text { steady; a slight decline in } \\
\text { the stock prices of food- } \\
\text { related and beef compa- } \\
\text { nies. }\end{array}$ \\
\hline \multirow[t]{2}{*}{ Germany $^{b}$} & $\begin{array}{l}\text { Incipient phase(s): } \\
\text { increased audit } \\
\text { capacity and industry- } \\
\text { led initiatives for } \\
\text { quality assurance. }\end{array}$ & $\begin{array}{l}\text { Incipient Phase: exten- } \\
\text { sive product elimina- } \\
\text { tion. }\end{array}$ & $\begin{array}{l}\text { Incipient phase: highly } \\
\text { publicized event by media } \\
\text { only. }\end{array}$ & $\begin{array}{l}\text { Incipient phase: hysteric } \\
\text { reactions ; tremendous } \\
\text { decline in consumption } \\
\text { and sales }\end{array}$ \\
\hline & $\begin{array}{l}\text { Pos- phase(s): uncoor- } \\
\text { dinated actions } \\
\text { between government } \\
\text { and federal states: non } \\
\text { transparent auditing } \\
\text { capacity and industry- } \\
\text { led initiatives. }\end{array}$ & $\begin{array}{l}\text { Post-phase(s): inspec- } \\
\text { tions and tests } \\
\text { throughout the beef } \\
\text { supply chain (e.g., } \\
\text { farms, processing units, } \\
\text { super-markets) }\end{array}$ & $\begin{array}{l}\text { Post-phase(s): moderate } \\
\text { communication efforts by } \\
\text { governmental agencies, } \\
\text { industry and media: BSE as } \\
\text { a proportion to general } \\
\text { food safety issues }\end{array}$ & $\begin{array}{l}\text { Post-phase (s): consumer } \\
\text { moderately regained trust } \\
\text { but blamed the govern- } \\
\text { ment and the industry } \\
\text { for low communication } \\
\text { transparency. }\end{array}$ \\
\hline
\end{tabular}

${ }^{a}$ The BSE was fanned out in the US in December 2003. The risk analysis dimensions and consumer reactions to the BSE crisis refer to pre- and incipient BSE crisis phases (before and after December 23, 2003).

b The first BSE outbreak in Germany was on November 26, 2000. The risk analysis dimensions and consumer reactions refer to the incipient and later BSE crisis phases (from the November 2001 - first BSE outbreaks in Germany - to 2004).

Therefore, it appears that the atmosphere of high surveillance in the pre-crisis phase prevented consumer panic and disruption of the retail beef markets in the US (Thilmany et al., 2004). At the end of 2004, the US administration claimed to be strongly committed to this very robust surveillance program for public health protections against BSE. Despite this, the future of the US surveillance programs has not yet been decided. Several calls were made by industry groups and officials to scale back measures and actions which were costly for both government and industry. However, in the light of continuous BSE crises and other food-related 
scares (e.g., Avian Influenza) spreading globally, some consumer advocacy groups favor testing on a wider scale (Fox et al., 2005).

\section{Germany: Fragmented Market Reactions}

Germany was considered as "free to BSE" until 2000 as a result of political conflict between diverse economic interests in the country. Protection of different market actors (e.g., food producers, wholesalers, retailers, consumers) was attempted at the political level by the growing divergence between ministries. The interest of the Federal Ministry of Agriculture was to protect farmers against economic losses while the Federal Ministry of Health protected of consumer health (Lenz, 2006). Political, agribusiness, and food- industry managers simply showed a lack of awareness regarding EU policies on import restrictions. The BSE crisis was treated as an external event until 2000. Policy makers and industry leaders sustained the view that if Germany were to face BSE crisis, attempts would have to be made to solve the problem within the subsequent stages of the German food chain without drawing public attention (Luhmann, 2001).

At the end of 2000 (November-December), the first BSE cases were discovered in Germany. The first BSE outbreaks resulted in an almost eight-percent reduction in beef sales in Germany by mid-February 2001 and German beef exports plunged by up to $50 \%$ due to the fact that 34 countries globally banned German beef imports (Gfk, 2001). Shortly after the outbreaks in January, 2001, the ministers of agriculture and health resigned from their positions under the pressure of the panic stricken consumers and allegation from the meat industry and farmers' associations (Weber, 2001). The German government initially responded by slaughtering of 400.000 dairy cows during March-June, 2001, with estimated losses of more than $\$ 2$ billion Euros (Klett-Aktualitatendienst, 2002). Next, the government announced the reform of the German agribusiness sector under the motto "Class not Mass" (Kunast, 2001), seeking to change the agricultural policy towards a more organic-oriented model. The most prominent change, however, was the renaming of Federal Ministry of Agriculture and Forestry into the Federal Ministry of Consumer Protection, Food and Agriculture in 2001. This change was accompanied by a strengthened audit capacity of the German government as well as the establishment of more quality-assurance schemes, which shifted regulations away from the publicly mandated food-safety regulations toward industry-led initiatives. The Federal Institute for Risk Assessment (BfR) was established in order to 
enforce these industry-led initiatives along with a series of measures regarding extensive information rights for consumers. Risk assessment and scientific advice was considered the domain of BfR while the German states were responsible for the enforcement and supervision of the inspections on a municipal level (GAO, 2005).

Moreover, the establishment of the Federal Agency for Consumer Protection and Food Safety (BVL) aimed at improving coordination of crisis communication, for which the federal states were also assumed to provide increased support, and improving BSE-related research. To further communicate and assure (greater) safety to consumers, other actions were introduced by the German government: food controllers were sent to supermarkets to inspect the safety and quality standards of the beef (DPA, 2001), and the minister of health initiated (the expansion of) drastic and preemptive measures for coping with the BSE crisis in the beef supply chain (e.g., the tests were expanded to cover more and younger animals) (PIB, 2001).

These risk-management actions and changing regulations were communicated through press releases of the different administrative districts in the country. The policies introduced and actions taken by the government seemed, at least to a certain extent, to regain the confidence of the consumers since beef consumption started to increase again slowly in 2001 (DPA, 2001). However, the political leadership in the state's ministries did not support the co-ordination of activities in the beef supply chain, and the meat industry considered these changes as disadvantageous because producers felt that only consumers' concerns had been prioritized (BVDF, 2001). In 2002, the minister of consumer protection increased political pressure on the states responsible for deficient BSE tests in Germany due to the strict remarks of EU officials (Focus, 2002). The tightening of the reins was again quickly communicated to the public via the media because the government and meat industry feared that publicity about inaccurate tests might damage regained consumer trust (Dausend, 2002). The media highlighted that the German public was disappointed with regard to information transparency and that the expectation of an effective information system regarding consumer health had not actually been fulfilled (Der Spiegel, 2002). Moreover, the German media and governmental press releases used to simply treat the BSE-related issues as just another foodrelated problem (NABU, 2001). 
The lack of coordination in risk-management actions between the federal government and the states regarding the implementation of BSE-tests and the establishment of a crisis communication framework was an issue of great concern for German politicians and industry groups during the period 2001-2003 (Lenz, 2006). Consumers exhibited skepticism with regard to the states' abilities to protect consumers against life threatening design flaws or food contamination (PIB, 2003). The German government came under pressure again due to the allegations of inefficient management and communication measures from the industry and consumer associations. In 2004, the government communicated that it had fulfilled its duties and that the responsibility for the appropriate actions lay with the states (PIB, 2004). Furthermore, the participation and involvement of German states in the actions of new federal institutions, which were supposed to deal with risk communication, among others, had focused on the development of research and pricing policies, rather than on communication of the real probabilities of food contamination to the public, even by the end of 2004. In an effort to regain consumer trust in the German food system, the minister of consumer protection announced that his ministry aimed to include the consumer protection in constitutional law (Anders, 2004).

To sum up, four years after the incipient phase of the BSE crisis in Germany, the public and private sector administrators and managers still had to cope with the severe effects of the crisis and design strategies aimed at increasing consumer trust in beef products. The lack of transparency in communication and the fragmented policy actions of federal and state auditing and food-safety authorities led to rather moderate results with respect to increasing consumer trust and, consequently, beef consumption in the country.

Overall, one may observe that the US government and industry groups were quite well-prepared for a potential spreading of the BSE crisis in the country, which might have lessen consumers' suspicion of domestic beef. At the incipient face of the crisis, the US public administration and industry managers were even able to tighten the already existing surveillance programs in every stage of the beef chain while briefing the general public on the status of BSE on a daily basis. Thus, firms did not cope with the crisis shock in the long-term. In contrast, the lack of auditing transparency and the fragmented actions of the federal government and the states might have led to hysterical consumer reactions and a dramatic decline in 
beef consumption and sales just after the first BSE outbreaks in Germany. Although the federal government attempted to increase the audit capacity of public services and organizations several times throughout the examined period (20012004), consumer trust was only moderately regained, and the BSE crisis was communicated to the general public as a part of general food-safety issues. Below, we elaborate on a research design that operationalized the way in which consumers in both countries reacted to these different conditions in the American and German food retailing markets.

\subsubsection{Field Studies Design}

To measure consumer risk behavior in different crisis phases, we developed a longitudinal between-subjects research design. That is, we used an identical research design for conducting field studies in each crisis phase. This research design allows for evaluation of consumer risk behavior within and across different crisis phases, in which the contingent conditions of the decision environment changed due to contingent conditions in the American as well as the German markets. In order to measure risk attitudes and perceptions of individual consumers in specific crisis phases, the psychometric approach was utilized. The individual consumers were asked about the extent to which they (dis)agreed with specific statements (i.e., items) on psychometric scales. The advantage of this approach is that it is very easy for individuals to comprehend the selected items and express their relative risk aversion and perception (Churchill, 1979; Pennings and Smidts, 2000). In addition, the questions can be placed in the context of the decision environment (i.e., consumer risk behavior to the BSE crisis within and across specific crisis phases).

\section{Measures}

The respondents were asked to state their decisions with respect to the reduction in beef consumption and respond to a number of items. First, they were asked to state whether they had reduced their beef consumption due to the BSE crisis. This was measured with a dichotomous variable (yes-no). Given that a consumer stated a reduction in beef consumption, (s)he was then asked to state the percentage (\%) of her/his quantity reduction in beef consumption.

Building on the work of MacCrimmon and Wehrung (1990), Pennings et al., (2002) and Pennings and Wansink (2004), the scales (i.e., constructs) used in the field studies were consistent with the definitions of our two key-variables: risk atti- 
tude and risk perception. Specifically, each construct used in the final surveys consisted of a 9-point semantic differential scale and included 3 items. For the risk attitude scale, we measured the following three items: (1) For me eating beef is worth the risk ("strongly disagree" to "strongly agree"); (2) I am "not willing to accept" to "willing to accept" the risk of eating beef, and 3) I do not accept the risk of eating beef ("strongly disagree" to "strongly agree"). The measures of risk perception consisted of the following three items: (1) When eating beef, I am exposed to "much risk" to "not much risk", 2) I think eating beef is risky ("strongly disagree" to "strongly agree", and 3) For me, eating beef is . .."risky" to "not risky". All measures, used in the field studies conducted in 2001 and 2004, were reliable, exceeding $\alpha=0.7$ (Hair et $a l .$, 1998). The psychometric validity of our constructs was satisfactory since all factor loadings were greater than 0.4 and significant $(p<$ 0.05) in 2001 and 2004, supporting the convergent validity of the constructs (Churchill, 1979; Pennings \& Smidts, 2000).

Considering the time availability of our respondents (i.e., we aimed at interviewing consumers while they were shopping), we measured other variables by using single-item measures (Robins et al., 2001). ${ }^{19}$ The extent of objective knowledge was measured through a single-item question in which knowledge was measured as consumers responded to the following statement: "What do you think the Creutzfeldt-Jacob Disease (CJD) will do to you?" The answer of the respondents was ranging from 1 (= I would simply feel ill, but recover fast); 2 = I would get ill, and will recover after some time; 3 = I would get very ill and the illness would be chronically; 4 = I might die, but there is a treatment and a chance of surviving) to 5 (= I would definitely die, there is not treatment). Consumers' subjective knowledge was measured by asking: "How much knowledge do you have about BSE/CJD?", with values ranging from 1 (= no knowledge) to 9 (= much knowledge). Likewise, trust was measured directly by the question "Do you trust the information that the government provides?" ranging from the value 1 (= do not trust at all) to 9 (= fully trust).

\footnotetext{
19 Single-item measures have several practical virtues. They are advantageous in large-scale surveys, longitudinal studies, and other research contexts in which time constraints limit the number of items that can be administered. Moreover, a single-item measure may eliminate item redundancy and, hence, it may reduce frustration and boredom associated with answering highly similar questions repeatedly when the time at the respondent's disposal is limited (Robins et al., 2001)
} 


\section{Data Collection}

The first set of data was collected during the first months of 2001. At that time, several cases of infected cattle had been reported in Germany (with the first case reported on November 26, 2000), but no case had been reported in the US The second data set was collected in the first two months of 2004, just after BSE had also reached the US: December 23, 2003. Hence, we collected data in the pre(2001) and incipient-crisis (2004) phases of BSE in the US and in the incipient(2001) and post-crisis (2004) phases in Germany.

We assumed that consumers were likely to be under time constraints, so we maintained an average interviewing time of 8 minutes. We conducted the field studies at grocery malls in several US and German states in 2001 and 2004, permitting for a representative sample of consumers in both countries. A total of 228 American and 298 Germans were interviewed in 2001; 595 Americans and 301 German consumers were interviewed in 2004. American consumers who participated in the field studies had an average age of 41 in 2001 and 38 in 2004. Germans had an average age of 38 in 2001 and 47 in 2004. The percentage of American women was $60 \%$ in the 2001 sample and $58 \%$ in 2004 . The percentage of German women was $51 \%$ and 58\% in the 2001 and 2004 samples, respectively.

All interviews were held on an individual basis and special care was taken to maintain the precise wording through backward translation since the same questionnaire was being used in two countries with different languages. The backwardtranslation procedures were conducted by academic experts. A pilot test on ten consumers in each country was conducted to check the degree to which consumers could easily understand the content of the questions. No serious problems were encountered in these interviews.

\subsection{Empirical Modeling Approach}

The objective of our modeling approach is twofold. The first objective is to capture the changing influence and magnitude of the components of risk behavior, which are hypothesized to influence consumer decisions regarding reduction in beef consumption due to the BSE crisis. We model consumer decisions in each BSE crisis phase (i.e., in 2001: the pre- crisis phase for the U.S. and the incipient crisis phase for Germany; and in 2004: the incipient crisis phase for the US and the post-crisis phase for Germany) and, also, by accounting directly for the effect of time during 
the crisis (i.e., 2001-2004). The second objective of our modeling approach is to capture the changes in influence and magnitude of the unobservable drivers of consumer risk attitudes and perceptions in each crisis phase. Table 4 displays the three major steps of our modeling approach.

Step 1: With respect to the first objective, we specified two consumer decisions regarding changes in beef consumption: Firstly, the consumer decision of whether or not to consume beef due to the BSE crisis was specified, the so-called participation decision. Secondly, the quantity-reduction decision of an individual consumer was specified, measuring the percentage of reduction in beef consumption. To examine whether differences in the influence and magnitude of the components of consumer risk behavior in 2001 and 2004 are related to stated changes in beef consumption, we estimated a two-stage model including both consumer decisions. In the first stage, we modeled the factors hypothesized to drive the participation decision of consumers: risk attitude, risk perception, and their interaction. In the second stage, we modeled the factors hypothesized to drive the quantity-reduction decision of consumers: risk attitude, risk perception, their interaction, age and gender.

Step 2: In order to gain more insight into the dynamics of the factors influencing the participation and quantity-reduction decisions of American and German consumers, we accounted for the effect of time by expanding the list of the explanatory variables for both consumer decisions by accounting directly for the effect of time and its interaction with each explanatory variable determining these decisions.

Step 3: With respect to the second objective, we modeled the factors (i.e., consumer objective and subjective knowledge and trust in information provided by governmental agencies) hypothesized to influence the two critical determinants (i.e., risk attitude and perception) of consumer decisions, through the formulation of a bivariate censored model. The utilization of such an empirical model allows us to examine changes in the influence and magnitude of the drivers of consumer risk attitudes and perceptions between the two crisis phases that may be driven by unobservable factors such as consumer knowledge and trust in safety information. Yet, in order to control for the other unobservable factors discussed above (consumer expertise and familiarity with product-related safety issues and attributes, intensity and frequency of safety news, reflexive doubt, exposure to negative news) 
that may affect both risk attitudes and perceptions, we applied a bivariate simultaneous equation system containing censored two-limit tobit models (e.g., Van der Laan, 1996; Van der Laan \& McKeague, 1998). This modeling approach ensures that the extent to which other, for instance, latent factors (i.e., unmeasured characteristics of individuals) may have an impact on risk attitudes and perceptions is taken into account and measured empirically (Cornick et al., 1994; Yoo, 2005).

Table 4.4 Empirical Modeling Approach for Consumer Risk Behavior in Product-harm Crises (e.g., BSE)

\begin{tabular}{|c|c|c|c|c|}
\hline Decision Problem & Dependent Variable & Independent Variables & Model & $\begin{array}{l}\text { Model } \\
\text { Specification }\end{array}$ \\
\hline \multirow[t]{2}{*}{$\begin{array}{l}\text { Step 1: consumer risk } \\
\text { behavior in each crisis } \\
\text { phase }\end{array}$} & $\begin{array}{l}\text { Stage 1: Consumer } \\
\text { participation decision } \\
\text { (Di) }\end{array}$ & $\begin{array}{l}\text { Risk Attitude (RA); Risk } \\
\text { Perception (RP); Interac- } \\
\text { tion: RA* RP }\end{array}$ & Double-hurdle & Probit \\
\hline & $\begin{array}{l}\text { Stage 2: Consumer } \\
\text { quantity-reduction } \\
\text { decision (Qi) }\end{array}$ & $\begin{array}{l}\text { RA; R;, RA*RP; Gender; } \\
\text { Age }\end{array}$ & & $\begin{array}{l}\text { Double- } \\
\text { bounded tobit }\end{array}$ \\
\hline \multirow[t]{2}{*}{$\begin{array}{l}\text { Step 2: Two-stage consumer } \\
\text { risk behavior over time }\end{array}$} & $\begin{array}{l}\text { Stage 1: Consumer } \\
\text { participation Decision } \\
\text { (Di) }\end{array}$ & $\begin{array}{l}\text { RA; RP; RA*RP, Time } \\
\text { (T); RA*T; RP*T; } \\
\text { RA*RP*T }^{*}{ }^{*} \text {; }\end{array}$ & Double-hurdle & Probit \\
\hline & $\begin{array}{l}\text { Stage 2: Consumer } \\
\text { quantity-reduction } \\
\text { decision (Qi) }\end{array}$ & $\begin{array}{l}\text { RA; RP; RA*RP; Gen- } \\
\text { der; Age; T); RA*T; } \\
\text { RP*T; RA*RP*T; Gen- } \\
\text { der*T; Age*T }\end{array}$ & & $\begin{array}{l}\text { Double- } \\
\text { bounded tobit }\end{array}$ \\
\hline \multirow[t]{2}{*}{$\begin{array}{l}\text { Step 3: Factors impacting } \\
\text { risk attitude and perception } \\
\text { in each crisis phase }\end{array}$} & Risk Attitude (RA) & $\begin{array}{l}\text { Objective Knowledge; } \\
\text { Subjective Knowledge }\end{array}$ & $\begin{array}{l}\text { Bivariate simul- } \\
\text { taneous regres- } \\
\text { sion }\end{array}$ & $\begin{array}{l}\text { Censored two- } \\
\text { limit tobit }\end{array}$ \\
\hline & Risk Perception (RP) & Trust & $\begin{array}{l}\text { Bivariate simul- } \\
\text { taneous regres- } \\
\text { sion }\end{array}$ & $\begin{array}{l}\text { Censored two- } \\
\text { limit tobit }\end{array}$ \\
\hline
\end{tabular}

Our modeling approach includes both the modeling of separate but interdependent consumer decisions (participation and quantity-reduction decisions) and the modeling of the most prominent drivers (risk attitude and perception) of these decisions. Such an approach determines the changing risk behavior of consumers in a dynamic context. Below, we discuss in detail the specifications of these empirical models. First, we specify the two-stage model for the two consumer decisions. Second, we discuss the expansion of this model by accounting directly for the effect of 
time. Third, we present the simultaneous regression of the censored two-limit tobit models, which allows the estimation of the impacts of the unobservable factors that drive consumer risk attitudes and perceptions in each crisis phase.

\subsubsection{Modeling Consumer Participation \& Quantity-Reduction Decisions}

Several generalizations of the models which divide the decision-making process of market participants in two separate steps were first introduced by Cragg (1971) and later applied and further developed by Lin and Schmidt (1984), Blundel and Meghir (1987), Jones (1989), Kenskel (1991), DeSarbo and Choi (1999), and Smiths et al., (2001), among others. In this paper, we employ a variation of Cragg's (1971) double-hurdle model for estimating separate but interdependent consumer decisions in different crisis phases. This modeling framework permits for no bias, which might be involved if the two decisions are naively assumed to be independent (Blundel \& Meghir, 1987), and, hence, allows us to test whether the separate components of risk behavior drive separate but interdependent decisions regarding changes in beef consumption in each crisis phase. Both consumer decisions were modeled and estimated simultaneously. That is, a probit part determines the participation decision (i.e., a binary choice to participate in beef consumption due to the BSE crisis), and a double-bounded tobit part determines the quantity reduction decision (i.e., the percentage of reduction in beef consumption) ${ }^{20}$

Specifically, to observe reduction in beef consumption decisions, two hurdles must be passed. The first hurdle specifies the participation decision of consumers. In the first stage of our model, this decision is given by:

$D_{i}=X_{i}^{\prime} \beta+\varepsilon_{i}$

where: $D_{i}$ is a binary discrete variable $\left(D_{i}=1\right.$ if consumer $i$ reduced beef consumption in each crisis phase, $=0$ otherwise), $X_{i}$ is a vector of explanatory variables (risk attitude, risk perception, and their interaction), $\beta$ is a coefficient vector to be estimated, and $\varepsilon$ is a random error $\varepsilon \sim N\left(0, \sigma_{D}{ }^{2}\right)$.

\footnotetext{
${ }^{20}$ Cragg's specifications separate a probit model (for 0-1) and then apply a truncated regression for the non-limit (non 0) observations only. The advantage of this approach is that the probability of a non-limit observation is determined apart from the level of the non-limit outcome. So, a variable may have a positive effect on the probability that an observation is non-limit and a negative probability on its outcome (its size, if it is non-limit).
} 
The second hurdle specifies the quantity-reduction decision of an individual consumer. That is, for each consumer indicating a reduction in beef consumption due to BSE (i.e., $D_{i}=1$ at each crisis phase), his/her quantity-reduction decision was modeled in a second stage as:

$Q_{i}^{*}=Z_{i}^{\prime} \theta+v_{i}$

where: $Q_{i}{ }^{*}$ is a latent, unobserved variable representing beef-consumption reduction (i.e., the optimal percentage of reduction in beef consumption), $Z_{i}$ is a vector of explanatory variables (risk attitude, risk perception, the interaction of risk attitude and perception, age, and gender), $\theta$ is a coefficient vector to be estimated, and is a random error term $v \sim N\left(0, \sigma_{D}{ }^{2}\right)$. We actually observed $Q_{i}$ in a censored fashion between 0 and 100 as:

$$
\begin{aligned}
& Q_{i}=0 \text { iff } Q_{i}^{*} \leq 0 \\
& Q_{i}=Q_{i}^{*} \text { iff } Q_{i}^{*}>0
\end{aligned}
$$

The $Q_{i}$ is censored at 0 as only positive levels of beef reduction are observed by a subset of consumers in our sample. The errors of these two equations are assumed to be normally distributed. When these two equations are jointly estimated, the double-hurdle model has a bivariate normal error covariance with $\operatorname{COV}(\varepsilon, v)=\rho$. The model is estimated using a maximum likelihood, and its correlation coefficient $(R h o)$ indicates whether the error terms ( $\varepsilon$ and $v)$ in the two equations, which underlie the specification of a double-hurdle model, are significantly related. If $R h o$ is not statistically different from zero, then the specification of a double-hurdle model is not necessary (Greene, 2003). In addition, Blundel and Meghir (1987) and Jones (1989) suggest a log-likelihood-ratio test statistic for testing the specification of a tobit model by omitting the participation decision (the first hurdle). This loglikelihood-ratio test statistic is based on the comparison of the two maximum likelihood estimators generated by maximizing the constrained and unconstrained likelihood function, which is asymptotical $x^{2}(r)$ (Lin \& Schmidt, 1984). ${ }^{21}$ Further,

\footnotetext{
${ }^{21}$ Practically speaking, in order to estimate the log-likelihood-ratio test statistic (LRT), a four-step analysis has to be performed (Lin \& Schmidt, 1984). First, the log-likelihoods are derived by estimating a tobit model. Second, the log-likelihoods are estimated by utilizing a probit model given the binary nature of the decision (between 0 and 1 observations; where 1 type of observations are all those observations with a non 0 response). Third, the log-likelihoods of a truncated regression for those with a non 0 response, are derived. Finally, the estimation of the likelihood-ratio test statistic is con-
} 
McFadden's pseudo $R^{2}$ measure or rho-square $\left(\rho^{2}\right)$ is usually reported as a goodness-of-fit measure for the probit model (the first hurdle) based on the loglikelihood-ratio test statistic (Maddala, 2006). McFadden (1979) suggested that $\rho^{2}$ values of between 0.2 and 0.4 should be taken to represent a very good fit of the model.

To account for the changes in probabilities of observing both participation and quantity-reduction decisions of consumers in each crisis phase, we estimated the marginal effects of each explanatory variable included in the first and second hurdle of our model. Marginal effects of each independent variable are evaluated on sample means, denoted by $\bar{X}$ and $\bar{Z}$, and provide more useful information than simple coefficient estimates (Maddala, 2006). The marginal effects of the continuous variables (risk attitude, risk perception, and their interaction) for the first hurdle (probit model) were calculated using sample means (Greene, 2003; p.668) as:

$$
\frac{\partial E[D \mid \bar{X}]}{\partial X_{k}}=\varphi\left(\bar{X}^{\prime} \beta\right) \beta_{k}
$$

where: $E[\cdot]$ denotes the expectations operator and $\varphi[\cdot]$ is the standard normal density. For the second stage of our model, the double-bounded tobit, the marginal effects of the continuous variables are identified as:

$$
\frac{\partial E\left[Q_{i}^{*} \mid \bar{Z}\right]}{\partial Z_{k}}=\theta_{k} * F\left(\frac{Z_{i} \theta}{\sigma}\right)
$$

where: $F[\cdot]$ is the cumulative normal distribution. The marginal effects of the binary variables (e.g., gender) are calculated by taking the difference in the predicted values with the binary variable equal to 0 and 1 (Greene, 2003, pp. 764-766):

$$
\begin{aligned}
& E\left[Q_{i}^{*} \mid Z_{i}\right)=F\left(\frac{Z_{i} \theta}{\sigma}\right) *\left(Z_{i} \theta+\sigma \lambda_{i}\right) \\
& \text { where: } \lambda_{i}=\varphi\left(\frac{Z_{i} \theta}{\sigma}\right) / F\left(\frac{Z_{i} \theta}{\sigma}\right)
\end{aligned}
$$

ducted as: $L R T=2(\log$ for probit $+\log$ for truncated $-\log$ for tobit $)$. If the result indicates that the Cragg's specification holds, one may employ a double-hurdle or a sample selection model (Heckman's or other type). 


\subsubsection{Dynamics of Consumer Decision Drivers}

Using the derivations specified in the previous subsection (Equations 4.4 to 4.11 ), we estimated the marginal effects of the explanatory variables which are hypothesized to drive the participation and quantity-reduction decisions of consumers in both countries in different crisis phases. Using this procedure, statistical tests (e.g., Chow test) were performed to determine whether the differences in the magnitude of the marginal effects of explanatory variables for both consumer decisions between the crisis phases are gauged with statistical significance.

To gain further insight into the dynamics of the determinants of participation and quantity-reduction decisions of consumers in both countries, we performed additional analyses that account directly for the effect of time. That is, we expanded our modeling framework by accounting directly for the effect of time $(T)$ and the interaction of it with each of our explanatory variables that are hypothesized to influence consumers' participation and quantity-reduction decisions due to the BSE crisis. By performing such an analysis, one can gain insights as to whether consumers' risk behavior in each country changed between the two phases of the crisis and whether the magnitude of these changes was gauged with statistical significance, hence influencing the consumers' separate but interdependent decisions over time. That is, we estimated the marginal effects of the determinants of $D_{i}$ and $Q_{i}$ not only separately in each crisis phase $\left(t_{1}=2001\right.$ and $\left.t_{2}=2004\right)$, but also through a dynamic modeling specification. We included a dummy variable $T$ defined as $T=$ $[0,1]$, where 0 and 1 indicate the first (2001: the pre-phase for the U.S. and the incipient phase for Germany) and second crisis phase (2004: the incipient phase for the US and the post-phase for Germany), respectively. We accounted for the interaction of the time (dummy) variable with each of our explanatory variables in each stage of the double-hurdle specification (Equations 4.4 to 4.11 ).

\subsubsection{Modeling Factors Impacting Risk Attitudes \& Perceptions in Crisis Phases}

As discussed, we expect various factors such as knowledge (objective and subjective) and trust in product-related safety information to impact the risk attitudes and risk perceptions of consumers in each crisis phase. To account for these impacts, we estimated bivariate censored-regression (two-limit tobit) models for two reasons. First, our dependent variables (risk-attitude and risk-perception scales) are cen- 
sored. ${ }^{22}$ Second, other unobservable factors omitted from our model (e.g., consumer expertise and familiarity with product-related safety issues and attributes, intensity and frequency of safety news, reflexive doubt, exposure to negative news) are also accounted. The formulation of the two-limit tobit models takes the form (Greene, 2003, p. 764):

$$
\begin{aligned}
& y_{i}^{*}=X_{i}^{\prime} \beta+\varepsilon_{i}, \\
& y_{i}=0 \text { if } y_{i}^{*} \leq 0, \\
& y_{i}=y_{i}^{*} \text { if } 0<y_{i}^{*}<8, \\
& y_{i}=8 \text { if } y_{i}^{*} \geq 8
\end{aligned}
$$

where: $y_{i}^{*}$ is a latent variable (i.e., risk attitude or perception) which is associated with each individual consumer $i, x_{i}$ is a $1 \times k$ vector of explanatory variables (objective knowledge and trust for risk attitude; and subjective knowledge and trust for risk perception), $\beta$ is a coefficient vector that has to be estimated, and $\varepsilon$ is an error term following a bivariate normal distribution which has a zero mean, standard deviations $\sigma$ for risk attitude and risk perception, and correlation $\rho$. If $\rho$ is not zero, the use of a simultaneous system of censored two-limit tobit regressions is sufficient (Van der Laan, 1996). Both equations were estimated simultaneously by using the log-likelihood function:

$$
\ln L=\sum_{y=0} \ln \Phi\left[\frac{0-X_{i}^{\prime} \beta}{\sigma_{\varepsilon}}\right]+\sum_{0<y<8} \ln \frac{1}{\sigma_{\varepsilon}} \varphi\left[\frac{y_{i}-X_{i}^{\prime} \beta}{\sigma_{\varepsilon}}\right]+\sum_{y=8} \ln \left[1-\Phi\left(\frac{8-X_{i}^{\prime} \beta}{\sigma_{\varepsilon}}\right)\right]
$$

where: $\Phi$ is the cumulative normal distribution and $\varphi$ is the density function. Utilizing derivations provided by Greene (2003, p. 765), the marginal effects of the continuous explanatory variables for each individual consumer can be identified by using:

$$
M E_{k, i}=\frac{\partial E\left[y_{i} \mid x_{i}\right]}{\partial x_{k, i}}=\frac{\partial x_{i} \beta}{\partial x_{k, i}} * \operatorname{Prob}\left[0<y_{i}^{*}<8\right]
$$

\footnotetext{
${ }^{22}$ Our risk attitude and risk perception scales from values of 1 to 9. However, our utilization of LIMDEP NLOGIT 4 (Greene, 2008) to estimate the presented models required the adjusting of these scales to range from 0 to 8 .
} 


$$
=\beta_{k, i} * \Phi \frac{8-x_{i}^{\prime} \beta}{\sigma_{\varepsilon}}-\Phi \frac{0-x_{i}^{\prime} \beta}{\sigma_{\varepsilon}}
$$

Equation (4.17) is a derivation based on McDonald and Moffitt's (1980) decomposition of the marginal effects for a two-limit tobit model. This decomposition allows a change in $x_{k}$ to affect: a) the conditional mean of $y_{i}^{*}$ in the positive part of the distribution and b) the probability that the $i^{\text {th }}$ observation will fall in that part of the distribution (Newman et al., 2003).

\subsection{Results}

\subsubsection{Risk Measures with Respect to Beef Consumption}

In this section we present descriptive results regarding consumers' risk attitudes, risk perceptions with respect to beef consumption in the US and Germany in each crisis phase. Risk attitude, ranges from relatively risk-seeking (i.e., preference for a risky outcome) to relatively risk-averse (i.e., not willing to accept risk under any conditions) while risk perception ranges from perceiving relatively low risk to perceiving relatively high risk. We assume that the interaction between the risk attitude and risk perception of a consumer reflects that relatively risk-averse consumers may engage in behavior that reduces risk, and that this becomes more prominent as a consumer perceives relatively more risk (Pennings \& Smidts, 2000).

Based on descriptive findings, Germans are significantly $(p<0.05)$ more riskaverse than American consumers. Specifically, German consumers appear to be significantly more risk-averse (risk attitude score of 5.40 in the incipient-crisis phase - 2001 - and 6.51 in the post-crisis phase -2004) than Americans (2.02 in the pre-crisis phase - 2001- and 2.45 in the incipient-crisis phase - 2004). They also seem to perceive significantly more risk (risk perception score of 5.15 in 2001 and 4.9 in 2004) than American consumers (scores of 3.72 in 2001 and 3.81 in 2004).

With respect to the knowledge of consumers, table 4.5 shows that the objective knowledge of both American and Germans increased across the crisis phases (Americans' score is 2.11 in 2001 vs. 3.82 in 2004 and Germans' score is 3.73 in 2001 vs. 4.75 in 2004). Although the reactions of German consumers have become milder over time (e.g., concern with eating beef decreased from 6.27 in 2001 to 4.93 in 2004), they still remain stronger than Americans. The milder reactions of Germans might due to the slight increase of their trust in the information that the 
German government provides (i.e., 3.42 in 2001 vs. 3.83 in 2004). In contrast, American consumers' trust toward the information provided by the US government has decreased (5.93 in 2001 vs. 4.65 in 2004). This decrease might be caused by the fact that the spread of the BSE crisis in the US after December 2003 erode American consumers' confidence about governmental food safety policies.

Table 4.5 Cross-Country Differences about CJD and Beef Consumption Over Time

\begin{tabular}{|c|c|c|c|c|}
\hline & \multicolumn{2}{|c|}{ United States } & \multicolumn{2}{|c|}{ Germany } \\
\hline & 2001 & 2004 & 2001 & 2004 \\
\hline Risk Attitude & 2.02 & 2.45 & 5.40 & 6.51 \\
\hline Risk Perception & 3.72 & 3.81 & 5.15 & 4.09 \\
\hline What do you think contracting CJD from eating beef will do to you? ${ }^{a}$ & & & & \\
\hline $\begin{array}{l}\text { (1=I would simply feel ill, but recover fast; } 7 \text { I would die, there is not } \\
\text { treatment). }\end{array}$ & 2.11 & 3.82 & 3.73 & 4.75 \\
\hline 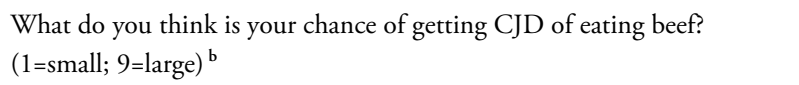 & 2.92 & 2.39 & 3.42 & 3.22 \\
\hline $\begin{array}{l}\text { Are you concerned with eating beef? }(1=\text { not concerned; } 9=\text { very con- } \\
\text { cerned })^{b}\end{array}$ & 3.74 & 3.55 & 6.27 & 4.93 \\
\hline $\begin{array}{l}\text { Do you trust the information that your government provides? }(1=\text { do not } \\
\text { trust; } 9=\text { fully trust })^{\text {b }}\end{array}$ & 5.93 & 4.65 & 3.42 & 3.83 \\
\hline Do you eat less beef because of BSE contamination? ${ }^{a}$ & $17.8 \%$ & $8.9 \%$ & $58.1 \%$ & $29.0 \%$ \\
\hline By what proportion have you reduced beef consumption? ${ }^{a}$ & $54.6 \%$ & $43.5 \%$ & $77.7 \%$ & $66.5 \%$ \\
\hline
\end{tabular}

a The differences in knowledge; reduction of beef consumption; proportion of reduction; and switching to other substitutes, among countries were significant. The chi-square tests on the independence among countries resulted in $p$-values less than 0.03 in 2001 and 2004.

b The hypotheses that the means of these variables in each crisis phase were equal was rejected at the $5 \%$ level using ANOVA.

The descriptive results show some consistency in risk behavior of different segments (i.e., at county level) of the population over time and confirm Hofstede's (1980; 1983) and Pennings et al., (2002) findings that Germans score higher with respect to the uncertainty avoidance index than Americans. Further, we analyzed the relationship between demographic variables (age and gender) and the risk measures for both countries and in each crisis phase. We found that they did not significantly differ. These findings further substantiate the work of Hofstede 
(1983). That is, risk behavior is partially culturally driven rather than demographic driven.

\subsubsection{Consumer Decisions in Different Crisis Phases}

The empirical double-hurdle model of Equations (4.4) - (4.11) was estimated using the LIMDEP NLOGIT 4.0 statistical package (Greene, 2008). Results of the maximum-likelihood estimations are presented in table 4.6. We first test whether the yes/no decision to consume beef due to the BSE crisis (i.e., the first hurdle or participation decision) and the reduction percentage of beef (i.e., the second hurdle or quantity-reduction decision) are based on the same decision-making structure. Significance of the correlation coefficient $(\rho)$ in each model suggests that employing a univariate framework would be insufficient. In addition, the log-likelihood ratio test is highly significant with scores of 134.6 in 2001 and 143.2 in 2004 for American consumers and 161.3 and 131.6 for German consumers, respectively. Thus, the log-likelihood-ratio test estimations overwhelmingly reject using a tobit model by omitting the participation decision (first hurdle). We also find that McFadden's $R^{2}$ values of the probit model (the participation decision) range between 0.29 to 0.33 .

These results suggest a satisfactory goodness of fit of our estimated models for each country in each crisis phase and suggest that employing a double-hurdle model for analyzing the changes in consumers' decisions in different phases of the product crisis in both countries is sufficient. This finding implies that the hypothesized determinants drive both separated and interdependent consumer decisions since the probability of consumers reducing their participation in beef consumption has the same decision-making structure as quantity-reduction. Thus, we maintain the double-hurdle specification over potential alternatives (e.g., singleequation model approach).

\section{The Influence of Changing Risk Attitudes \& Perceptions on Consumer Decisions}

Although the results that can be readily interpreted are those of marginal effects, the comparison of the estimated risk-attitude and risk-perception coefficients in the participation equation with those in the quantity-reduction equation reveals interesting insights. Significant variations were found between the interdependent decisions of American and Germans consumers among the different crisis phases. Table 4.6 shows that the determinants of consumer risk behavior (risk attitude; risk per- 
ception and their interaction) influence significantly, though in varied ways, the risk behavior of consumers in both countries in both years. However, the influence of the determinants of consumer decisions, as reflected by the absolute values of the regression coefficients, differ between the examined crisis-phases for both countries.

Risk attitude $\left(\alpha_{p 1}=-0.186 ; p<0.02\right)$ and the interaction of risk attitude and risk perception drive $\left(\alpha_{p 3}=0.024 ; p<0.00\right)$ the participation decisions of American consumers in 2001 (pre-crisis phase). However, the participation decision of Americans in 2004 (incipient-crisis phase) was driven only by their risk perception $\left(\alpha_{p 2}=\right.$ 0.234, $p<0.00)$ and the interaction of risk attitude and risk perception $\left(\alpha_{p 3}=\right.$ $0.145 ; p<0.00)$. The quantity-reduction decision of Americans in 2001 was influenced by their risk attitude $\left(\alpha_{q 1}=-1.596 ; p<0.02\right)$ and the interaction of risk attitude and risk perception $\left(\alpha_{q 3}=1.770 ; p<0.03\right)$. The age of consumers $\left(\alpha_{q 4}=0.298\right.$; $p<0.02$ ), also influenced the quantity-reduction decisions of Americans in the precrisis phase. In the incipient-crisis phase, the quantity-reduction decisions of American consumers were driven by risk perception $\left(\alpha_{q 2}=2.180 ; p<0.02\right)$, the interaction of risk attitude and risk perception $\left(\alpha_{q 3}=1.960 ; p<0.03\right)$, age $\left(\alpha_{q 4}=0.667 ; p<\right.$ $0.03)$, and gender $\left(\alpha_{q 5}=1.199 ; p<0.03\right)$. Interestingly, the consumer decisions of Americans between the two crisis phases share some similarities: in the pre-crisis phase, both decisions were driven by risk attitude and the interaction of risk attitude and risk perception while risk perception and the interaction of risk attitude and perception drove their decisions in incipient-crisis phase.

The participation decision of German consumers in 2001 (incipient-crisis phase) was driven by risk attitudes $\left(\alpha_{p 1}=-0.535 ; p<0.02\right)$ and risk perceptions $\left(\alpha_{p 2}=0.680 ; p \leq 0.00\right)$. In 2004 (post-crisis phase), the Germans' participation decision was driven by all the separate components of consumer risk behavior: risk attitude $\left(\alpha_{p 1}=-0.649 ; p<0.01\right)$, risk perception $\left(\alpha_{p 2}=0.342 ; p<0.000\right)$, and the interaction of risk attitude and perception $\left(\alpha_{p 3}=0.148 ; p<0.02\right)$.

In the incipient-crisis phase, the quantity-reduction decision of German consumers was influenced by their risk attitude $\left(\alpha_{q 1}=-2.791 ; p<0.01\right)$ risk perception $\left(\alpha_{q 2}=12.814 ; p<0.04\right)$, age $\left(\alpha_{q 4}=0.839 ; p<0.02\right)$, and gender $\left(\alpha_{q 5}=3.750 ; p<\right.$ $0.03)$. In the post-crisis phase, this decision was driven by risk perception $\left(\alpha_{q 1}=\right.$ 9.084; $p<0.01)$, the interaction of risk attitude and risk perception $\left(\alpha_{q 3}=2.712 ; p\right.$ $<0.02)$, and age $\left(\alpha_{q 4}=1.231 ; p<0.02\right)$. 
Table 4.6 Double-Hurdle Model of Consumer Decisions in 2001 and 2004 ${ }^{a}$

\begin{tabular}{|c|c|c|c|c|c|c|c|c|}
\hline \multirow[b]{4}{*}{$\begin{array}{l}\text { Stage 1: Participation } \\
\text { Decision }\end{array}$} & \multicolumn{4}{|c|}{ American Consumers } & \multicolumn{4}{|c|}{ German Consumers } \\
\hline & \multicolumn{2}{|c|}{ Coefficient } & \multicolumn{2}{|c|}{ Marginal Effect } & \multicolumn{2}{|l|}{ Coefficient } & \multicolumn{2}{|c|}{ Marginal Effect } \\
\hline & 2001 & 2004 & 2001 & 2004 & 2001 & 2004 & 2001 & 2004 \\
\hline & pre-phase & $\begin{array}{l}\text { incipient- } \\
\text { phase }\end{array}$ & pre-phase & $\begin{array}{l}\text { incipient- } \\
\text { phase }\end{array}$ & $\begin{array}{l}\text { incipient- } \\
\text { phase }\end{array}$ & post-phase & $\begin{array}{l}\text { incipient- } \\
\text { phase }\end{array}$ & post-phase \\
\hline Intercept & -1.180 & -0.860 & & & -3.290 & -3.178 & & \\
\hline Risk Attitude (RA; $\alpha_{p I}$ ) & $0.186^{*}$ & 0.039 & $0.037^{*}$ & 0.021 & $0.535^{*}$ & $0.649^{*}$ & $0.181^{*}$ & $0.261^{*}$ \\
\hline Risk Perception (RP; $\left.\alpha_{p 2}\right)$ & 0.126 & $0.234^{*}$ & 0.043 & $0.084^{*}$ & $0.680^{*}$ & $0.342^{*}$ & $0.273^{*}$ & $0.132^{*}$ \\
\hline $\operatorname{RA} \times \operatorname{RP}\left(\alpha_{p 3}\right)$ & $0.024^{*}$ & $0.145^{*}$ & 0.012 & $0.019^{*}$ & 0.440 & $0.115^{*}$ & $0.149^{*}$ & $0.071^{*}$ \\
\hline McFadden's $R^{2}$ & 0.31 & 0.31 & & & 0.32 & 0.33 & & \\
\hline \multicolumn{9}{|c|}{ Stage 2: Quantity-Reduction Decision } \\
\hline Intercept & -16.198 & -12.126 & & & -31.132 & -21.963 & & \\
\hline Risk Attitude (RA; $\left.\alpha_{q I}\right)$ & $1.596^{*}$ & 3.756 & $-1.184^{*}$ & -1.478 & $2.791^{*}$ & 0.353 & $5.307^{*}$ & $2.151^{*}$ \\
\hline Risk Perception (RP; $\left.\alpha_{q 2}\right)$ & 1.697 & $2.180^{*}$ & $1.472^{*}$ & $1.761^{*}$ & $12.814^{*}$ & $9.084^{*}$ & $7.219^{*}$ & $6.084^{*}$ \\
\hline $\operatorname{RA} \times \operatorname{RP}\left(\alpha_{q 3}\right)$ & $1.770^{*}$ & $1.960^{*}$ & 0.427 & $1.385^{*}$ & 4.934 & $2.712^{*}$ & 2.501 & $1.665^{*}$ \\
\hline Age $\left(\alpha_{q^{4}}\right)$ & $0.298^{*}$ & $0.667^{*}$ & $1.112^{*}$ & $0.248^{*}$ & $0.839^{*}$ & $1.231^{*}$ & $0.471^{*}$ & $0.486^{*}$ \\
\hline Gender $\left(\alpha_{q 5}\right)$ & 1.052 & $1.199^{*}$ & 0.054 & $0.040^{*}$ & $3.750^{*}$ & 0.159 & $1.501^{*}$ & 0.679 \\
\hline Sigma & $18.972^{*}$ & $29.006^{*}$ & & & $66.970^{*}$ & $27.010^{*}$ & & \\
\hline Rho & $0.450^{*}$ & $0.830^{*}$ & & & $0.814^{*}$ & $0.740^{*}$ & & \\
\hline Log-Likelihood function & -1736 & -1505 & & & -1926 & -1655 & & \\
\hline Log-Likelihood ratio test & $134.601^{*}$ & 143.204 & & & $161.302^{*}$ & $131.643^{*}$ & & \\
\hline Number of observations & 228 & 595 & & & 298 & 301 & & \\
\hline
\end{tabular}

${ }^{\text {a }}$ An asterisk indicates that each parameter is statistically significant at the $5 \%$ level

Thus, both consumer participation and quantity-reduction decisions are driven by the components of consumer risk behavior in varied ways in the U.S. as well as in Germany among the different crisis phases. Returning our attention to the impact of risk attitudes and risk perceptions and the interaction of the two based on their marginal-effect estimations reveals additional insights. Below, we discuss these results with respect to each consumer decision separately. 


\section{Participation Decision: Results in $2001 \& 2004$}

The results in table 4.6 show that the probability that American and German consumers reduced beef consumption due to BSE events in each crisis phase is associated, in varied ways, with the three main components of consumer risk behavior.

In the pre-crisis phase (2001), each one-unit increase on the risk-attitude scale caused a 3.7\% increase in the likelihood that American consumers reduced their participation in beef consumption due to the BSE crisis. However, the picture changed in the US when the BSE crisis reached its incipient phase in 2004 as: a) each unit increase on the risk-perception scale caused an $8.4 \%$ increase in the likelihood that American consumers reduced their beef consumption and b) each unit increase in the scale for the estimated interaction of risk attitude and risk perception caused a $1.9 \%$ increase in the probability that Americans decreased their beef consumption due to the BSE crisis. These results confirm the hypotheses that the risk attitude drives the participation decision of American consumers in both the pre- and post-crisis phases $\left(\mathrm{H}_{1 \mathrm{~A}}\right)$ and that the interaction of risk attitude and risk perception drives the participation decision of American consumers in the incipient-crisis phase $\left(\mathrm{H}_{1 \mathrm{C}}\right)$.

In Germany in the incipient-crisis phase (2001), each unit increase in the riskattitude scale increased the likelihood that German consumers decreased their participation in beef consumption due to BSE crisis by $18.1 \%$. In addition, each unit increase in the risk-perception scale increased the likelihood that they decreased their participation in beef consumption by $27.3 \%$ in the incipient phase of the BSE crisis (early 2001). Each unit increase in the scale measuring the interaction of risk attitude and perception also increased the probability that Germans reduced their participation in beef consumption by $14.9 \%$. In the post-crisis phase (2004), each unit increase in the risk-perception scale and the scale for the estimated interaction of risk attitude and risk perception caused an increase of $13.2 \%$ and $7.1 \%$, respectively in the probability that Germans reduced their participation in beef consumption. Thus, the hypotheses $\mathrm{H}_{1 \mathrm{~A}}$ (risk attitude drives the participation decision of German consumers in the incipient crisis phase), $\mathrm{H}_{1 \mathrm{~B}}$ (risk perception drives the participation decision of German consumers in both the incipient- and postcrisis phases), and $\mathrm{H}_{1 \mathrm{C}}$ (the interaction of risk attitude and risk perception drives German consumers participation decision in both the incipient and post-crisis phases) are confirmed. 
The results in table 4.6 show that, for each unit increase in the determinants of participation decisions, the likelihood of consumers' reducing their participation in beef consumption due to the BSE crisis is higher for Germans than for Americans in the incipient-phase of the BSE crisis in each country.

\section{Quantity-Reduction Decisions: Results in 2001 \& 2004}

Results from estimating the marginal effects of the determinants of the quantityreduction decision have similarities with the results of the consumers' participation decisions for both countries. Risk attitude, risk perception and their interaction are not only important determinants of the participation decisions of American and German consumers, but also of their quantity-reduction decisions (though in varied ways) in each crisis phase.

The key variables of consumer risk behavior drive the quantity reduction of American consumers in the pre- and incipient- phases of the BSE crisis in the US. Each unit increase on the risk-attitude scale increased the probability that American consumers reduced the quantity of their beef consumption by $1.1 \%$, and each unit increase on the risk-perception scale is associated with a $1.4 \%$ quantity reduction in the pre-crisis phase (2001). In the incipient-crisis phase in the US (2004), each unit increase in the risk perception scale increased the probability that American consumers decreased the quantity of their beef consumption by $1.7 \%$, and each unit increase in the interaction of risk attitude and perception increased the likelihood that they reduced their beef quantity by $1.3 \%$. These results confirm that as a consumer becomes more risk-averse the likelihood of reducing the consumption of a harmed product increases $\left(\mathrm{H}_{2 \mathrm{~A}}\right)$; as consumer perceives relatively high risk the likelihood of reducing the consumption of harmed product increases $\left(\mathrm{H}_{2 \mathrm{~B}}\right)$; and as consumer is more risk averse and perceives relatively high risk the likelihood of reducing the consumption of harmed product increases hypotheses $\left(\mathrm{H}_{3 \mathrm{C}}\right)$ in the incipient-phase (2004) of the BSE crisis in the US.

Among the American consumers that reduced the quantity of their beef consumption, older consumers reduced their quantity of beef consumed more. More specifically, each additional 10 years of age increased the probability that American consumers reduced the quantity of their beef consumption by $1.1 \%$ in the precrisis phase (2001) and by $2.5 \%$ in the post-crisis phase (2004). These results support that older consumers are more likely to reduce the quantity of consumption of a harmed product $\left(\mathrm{H}_{2 \mathrm{E}}\right)$. Finally, the results indicate that the gender of the con- 
sumers influences the quantity-reduction decision, too. Each unit increase in the gender (i.e., discrete variable: 1: male; 2: female) increased the probability that American consumers reduced the quantity of their beef consumption in the incipient-phase of the BSE crisis by $0.4 \%$ in 2004 . That is, women reduced their beef consumption more than men in the incipient phase of the BSE crisis in the U.S. This result confirms that female consumers are more likely to reduce the quantity of consumption of a harmed product $\left(\mathrm{H}_{2 \mathrm{D}}\right)$.

The results (table 4.6) show that the impact of risk attitude and perceptions on the quantity-reduction decisions of consumers is greater for German consumers than Americans in the incipient-phase of the BSE crisis. Each unit increase in risk attitude increased the likelihood that Germans reduced the quantity of their beef consumption by $5.3 \%$, and each unit increase on the risk-perception scale was associated with a $7.2 \%$ decrease in the incipient-phase of the BSE crisis in Germany (2001). In the post-phase of the BSE crisis, in 2004, each unit increase in the risk attitude of Germans increased the probability that they reduced the quantity of their beef consumption by $2.1 \%$, and each unit increase in their risk perception increased the probability that they reduced their quantity of beef consumption by almost $6.1 \%$. The interaction of risk attitude and risk perception increased the probability that Germans reduced the quantity of their beef consumption by approximately $1.7 \%$ in the post-phase of the BSE crisis in Germany. These results confirm (although in varied ways) the hypotheses about the influence of the risk attitude $\left(\mathrm{H}_{2 \mathrm{~A}}\right)$, risk perception $\left(\mathrm{H}_{2 \mathrm{~B}}\right)$ and the interaction of the two $\left(\mathrm{H}_{2 \mathrm{D}}\right)$, on the quantity-reduction decision of German consumers in the incipient- and postphases of the BSE crisis.

Further, the results indicate that, for German consumers, the impact of age on the quantity-reduction decision is higher than for consumers in the US. Each additional 10 years of age resulted in about a 5\% quantity reduction in beef consumption in the incipient- and post-phases of the BSE crisis. The gender of Germans drove, also, their quantity-reduction decision: each unit increase in gender increased the probability that German consumers reduced the quantity of their beef consumption at the incipient-phase of the BSE crisis in the country by $1.5 \%$. Thus the hypotheses $\mathrm{H}_{2 \mathrm{D}}$ and $\mathrm{H}_{2 \mathrm{E}}$ are confirmed.

In order to identify whether the magnitude of the parameters of the hypothesized determinants of the participation and quantity-reduction decisions are equal 
for each country among the examined crisis phases, we performed a Chow test (Wooldridge, 2006, p.251). The null hypothesis was rejected at the 5\% level for Germany $(F=25.6)$ and at the $10 \%$ level for the US $(F=3.9)$. Hence, these results show that the participation and quantity-reduction decisions of German consumers had substantially changed between the incipient- and post-crisis phases whereas American consumer behavior had changed to a lesser extent. The hypothesis $\left(\mathrm{H}_{3 \mathrm{D}}\right)$ that the impact of consumer risk attitudes and perceptions and their interaction on consumer decisions is likely to be lower in the pre- and post-phases than in the incipient-phase of the BSE crisis is confirmed.

\subsubsection{Results of the Effect of Time on Consumer Decisions}

To gain further insights into the dynamics of the influence of consumers' risk attitudes, risk perceptions and their interaction on participation and quantityreduction decisions, we performed additional analyses that account directly for the effect of time. That is, we pooled our data from 2001 and 2004 per country and accounted for the impact of time $(T)$ and the interaction of it with each of our explanatory variables hypothesized to influence consumers' participation and quantity-reduction decisions. Table 4.7 shows that our model has a satisfactory fit. The log-likelihood ratio tests are significant for each country's pooled sample over time, and the significance of the correlation coefficient in each model suggests that employing a univariate framework would be insufficient. The value of McFadden's $R^{2}$ is 0.24 for the US and 0.37 for Germany.

With respect to the participation decisions, each unit increase in the risk perception over time increased the likelihood that American consumers decreased their participation in beef consumption by roughly $4 \%$, and each unit increase in the interaction of risk attitude and perception increased the likelihood that they reduced their participation in beef consumption by $1.7 \%$. German consumer reactions over time were found to be stronger than those of Americans. The three components of consumer risk behavior influenced substantially their participation in beef consumption throughout the period 2001-2004. Each unit increase on the risk-attitude scale increased the likelihood that Germans participated less in beef consumption by $8 \%$ over time. Each unit increase on their risk-perception scale increased the likelihood that they decreased their participation in beef consumption even further by $14.1 \%$. Each unit increase in the interaction of risk attitude 
and risk perception was found to be associated with a $7.8 \%$ decrease in their participation in beef consumption over time.

Table 4.7 Double Hurdle Model of Consumer Decisions Over Time ${ }^{\text {a }}$

\begin{tabular}{|c|c|c|c|c|}
\hline & \multicolumn{2}{|c|}{ American Consumers } & \multicolumn{2}{|c|}{ German Consumers } \\
\hline & Coefficient & Marginal Effect & Coefficient & Marginal Effect \\
\hline \multicolumn{5}{|c|}{ Stage 1: Participation Decision over Time } \\
\hline Intercept & -0.225 & & -0.127 & \\
\hline Risk Attitude (RA) & $0.186^{*}$ & $0.037^{*}$ & $0.535^{*}$ & $0.649^{*}$ \\
\hline Risk Perception (RP) & 0.126 & 0.043 & $0.680^{*}$ & $0.342^{*}$ \\
\hline $\mathrm{RA} \times \mathrm{RP}$ & 0.024 & 0.072 & 0.440 & $0.115^{*}$ \\
\hline Time $(\mathrm{T})$ & $1.262^{*}$ & $0.024^{*}$ & $3.742^{*}$ & $0.138^{*}$ \\
\hline $\mathrm{RA} \times \mathrm{T}$ & 0.225 & 0.116 & $0.114^{*}$ & $0.080^{*}$ \\
\hline$R P \times T$ & $0.108^{*}$ & $0.041^{*}$ & $-0.338^{*}$ & $-0.141^{*}$ \\
\hline$(\mathrm{RA} \times \mathrm{RP}) \times \mathrm{T}$ & $0.121^{*}$ & $0.017^{*}$ & $0.325^{*}$ & $-0.078^{*}$ \\
\hline McFadden's $R^{2}$ & 0.24 & & 0.37 & \\
\hline \multicolumn{5}{|c|}{ Stage 2: Quantity-Reduction Decision over Time } \\
\hline Intercept & -4.082 & & -9.269 & \\
\hline Risk Attitude (RA) & $1.596^{*}$ & $1.184^{*}$ & 2.791 & $5.307^{*}$ \\
\hline Risk Perception (RP) & 1.697 & 1.472 & $12.814^{*}$ & $7.219^{*}$ \\
\hline $\mathrm{RA} \times \mathrm{RP}$ & $1.770^{*}$ & 0.427 & 4.934 & 2.501 \\
\hline Age & $0.298^{*}$ & $1.112^{*}$ & $0.839^{*}$ & $0.471^{*}$ \\
\hline Gender & 1.052 & 0.054 & $3.750^{*}$ & $1.501^{*}$ \\
\hline Time $(\mathrm{T})$ & 1.067 & 0.021 & $3.373^{*}$ & $0.131^{*}$ \\
\hline $\mathrm{RA} \times \mathrm{T}$ & 2.160 & 0.294 & $2.438^{*}$ & $3.156^{*}$ \\
\hline $\mathrm{RP} \times \mathrm{T}$ & $0.483^{*}$ & $0.289^{*}$ & $3.730^{*}$ & $-1.135^{*}$ \\
\hline$(\mathrm{RA} \times \mathrm{RP}) \times \mathrm{T}$ & $0.190^{*}$ & $0.958^{*}$ & $-2.222^{*}$ & $-0.836^{*}$ \\
\hline Age $x \mathrm{~T}$ & $0.369^{*}$ & $-0.086^{*}$ & $0.392^{*}$ & 0.015 \\
\hline Gender $\mathrm{x} T$ & $0.148^{*}$ & -0.012 & $3.591^{*}$ & $0.177^{*}$ \\
\hline Sigma & $31.005^{*}$ & & $38.891^{*}$ & \\
\hline Rho & $0.799^{*}$ & & $0.868^{*}$ & \\
\hline Log-Likelihood function & -2621 & & -1968 & \\
\hline Log-Likelihood ratio test & $179.107^{*}$ & & $161.221^{*}$ & \\
\hline Number of Observations & 823 & & 599 & \\
\hline
\end{tabular}

${ }^{a}$ An asterisk indicates that each parameter is statistically significant at the $5 \%$ level

The results for the direct effect of time on the quantity-reduction decisions of American and German consumers also reveal interesting insights. For Americans, 
each unit increase on the risk-perception scale and the interaction of risk attitude and perception was associated with a $2.8 \%$ and $9.5 \%$ decrease in the quantity of their beef consumption over time. For Germans, each unit increase in their risk attitude, risk perception and interaction of risk attitude and risk perception were associated with a respective $3.1 \%, 1.1 \%$ and $8.3 \%$ decrease in the quantity of their beef consumption over time. Finally, the results also show that, among the American consumers, older consumers reduced the quantity of beef consumed more than young consumers over time. Among the German consumers, women reduced their beef consumption more than men over time.

Overall, these findings support our prediction $\left(\mathrm{H}_{4 \mathrm{~A}}\right)$ that the decoupled components of consumer risk significantly influence both consumer decisions (though in varied ways) across the crisis phases. In addition, we performed a joint test to see whether the subgroup of our explanatory variables interacting with the time effect explains the variation in the decision to reduce beef consumption and the quantity of beef consumed. Thus, the subset of these regression coefficients is jointly assumed to be zero (see: Pindyck and Lubinfeld, 1996, pp.128-129). The null hypothesis that the time effect does not influence risk attitudes and risk perceptions was rejected at the 10\% level of significance for the US and the 5\% level for Germany. These results imply that the impact of time effects on the determinants (i.e., risk attitudes, risk perceptions and their product) of consumer participation and quantity-reduction decisions with respect to the BSE crisis events over time is significant, and thereby confirm the hypothesis $\mathrm{H}_{4 \mathrm{~B}}$.

\subsubsection{Results of Factors Impacting Risk Attitudes \& Perceptions in Crisis Phases}

The results of the maximum-likelihood estimations of the bivariate censored models that are laid out by Equations 4.11-4.17 are presented in table 4.8. In both risk-attitude and risk-perception models, the marginal-effect estimates of objective and subjective knowledge about the content of risk entailed in eating beef and trust in information provided by the governmental agencies were statistically significant in varied ways in each crisis phase. We reject the hypothesis of independence between risk-perception and risk-attitude regressions as the bivariate model's correlation $(\rho)$ coefficient is significant in the estimated models, for each country, in each crisis phase, and for each criterion variable. For the American segment of consumers, $\rho$ equals 0.281 in 2001 and 0.347 in 2004 for the risk-attitude model and 0.237 in 2001 and 0.345 in 2004 for the risk-perception model. For the German 
segment of consumers, $\rho$ equals 0.249 in 2001 and 0.254 in 2004 for the riskattitude model, and 0.213 in 2001 and 0.277 in 2004 for the risk-perception model. All these coefficients are significantly different from zero at the $5 \%$ level. The positive signs of the estimated correlation coefficients indicate that other unobservable factors that have not been modeled explicitly have the same influence on risk attitudes and risk perception as those which have already been included.

A look at the regressors of the estimated models reveals that the results are for the most part consistent with our hypotheses. Our hypothesized determinants (objective knowledge and subjective knowledge about the content of risk, and trust in information provided by the governmental agencies) significantly drive the risk attitudes $\left(\mathrm{H}_{5 \mathrm{~A}}\right.$ and $\left.\mathrm{H}_{5 \mathrm{~B}}\right)$ and risk perceptions $\left(\mathrm{H}_{6 \mathrm{~A}}\right)$ of consumers, respectively, in each country in each crisis phase.

Table 4.8 Factors Impacting Risk Attitude and Risk Perception in 2001 and 2004a,b

\begin{tabular}{|c|c|c|c|c|c|c|c|c|}
\hline & \multicolumn{4}{|c|}{ American Consumers } & \multicolumn{4}{|c|}{ German Consumers } \\
\hline & \multicolumn{2}{|c|}{ Coefficient } & \multicolumn{2}{|c|}{ Marginal Effect } & \multicolumn{2}{|c|}{ Coefficient } & \multicolumn{2}{|c|}{ Marginal Effect } \\
\hline & 2001 & 2004 & 2001 & 2004 & 2001 & 2004 & 2001 & 2004 \\
\hline \multicolumn{9}{|c|}{ Factors Impacting Risk Attitude } \\
\hline Intercept & 1.270 & 1.458 & & & 1.895 & 2.172 & & \\
\hline Obj. Knowledge & $0.116^{*}$ & $0.323^{*}$ & $0.108^{*}$ & $0.181^{*}$ & $0.237^{*}$ & $0.347^{*}$ & $0.197^{*}$ & $0.227^{*}$ \\
\hline Subj. Knowledge & 0.153 & $0.218^{*}$ & 0.032 & $0.094^{*}$ & 0.067 & $0.249^{*}$ & 0.020 & $0.047^{*}$ \\
\hline Sigma & $1.578^{*}$ & $2.178^{*}$ & & & $1.631^{*}$ & $1.848^{*}$ & & \\
\hline Rho & $0.281^{*}$ & $0.347^{*}$ & & & $0.249^{*}$ & $0.254^{*}$ & & \\
\hline Log-likelihood function & -1229 & -1207 & & & -1678 & -2879 & & \\
\hline \multicolumn{9}{|c|}{ Factors Impacting Risk Perception } \\
\hline Intercept & 3.201 & 3.581 & & & 2.194 & 4.054 & & \\
\hline Trust & $-0.377^{*}$ & $-0.174^{*}$ & $0.221^{*}$ & $0.107^{*}$ & $-0.206^{*}$ & $-0.417^{*}$ & $0.126^{*}$ & $0.277^{*}$ \\
\hline Sigma & $1.756^{*}$ & $1.943^{*}$ & & & $1.782^{*}$ & $1912^{*}$ & & \\
\hline Rho & $0.237^{*}$ & $0.345^{*}$ & & & $0.213^{*}$ & $0.277^{*}$ & & \\
\hline Log-likelihood function & -3.017 & -3792 & & & -2903 & -3794 & & \\
\hline Number of Observations & 228 & 595 & & & 298 & 301 & & \\
\hline
\end{tabular}

${ }^{a}$ The RA ranges from 0 (relatively high risk aversion); to 8 (relatively low risk aversion) the RP ranges from 0 (relatively low risk perception) to 8 (relatively high risk perception). Objective knowledge ranges from 1 ( = I would simply fall ill, but recover fast) to 5 (= I would definitely die, there is not treatment), subjective knowledge ranges from 1 (= no knowledge) to 9 (= much knowledge). Trust in information provided by governmental agencies for BSE/CJD ranges from 1 (= no trust at all) to (=fully trust)

${ }^{\mathrm{b}}$ An asterisk indicates that each parameter is statistically significant at the 5\% level. 
Based on the estimates of the marginal effects, several interesting insights are revealed. American consumers' risk attitudes are influenced by both objective knowledge and subjective knowledge about the about CJD's impact on human health. Each unit increase in objective knowledge increased the likelihood that Americans became less risk averse by almost $11 \%$ in the pre-phase and by almost $18.1 \%$ in the incipient-phase of the BSE crisis in the US Each unit increase in subjective knowledge increased the likelihood that American consumers perceived relatively low risk by almost $9.5 \%$ in the incipient-phase of the BSE crisis. With respect to the risk perception of Americans, the results show that each unit increase in trust in information about safety, Americans' likelihood to perceive relatively less risk increased by $22.1 \%$ in pre-phase and by $10.7 \%$ in incipient-phase of the crisis. We thus see that the likelihood that consumers perceived relatively low risk decreased in the incipient-phase compared to the pre-phase of the BSE crisis in the US due to consumers' eroded trust in the information about beef safety provided by the American governmental agencies.

Further, the results indicate that German consumers showed different reactions than their American counterparts in the corresponding crisis phases. That is, each unit increase in objective knowledge increased the likelihood that Germans became relatively less risk-averse by almost $19.7 \%$ in 2001 (incipient-crisis phase) and by almost 23\% in 2004 (post-crisis phase). Each unit increase in the subjective knowledge increased the likelihood that German consumers were more likely to perceive low risk by $4.7 \%$ in the post-crisis phase of the BSE crisis (i.e., 2004). Thus, we see that both greater objective and subjective knowledge is associated with relatively less risk-averse behavior in the subsequent phases of the BSE-crisis. Finally, with respect to risk perception, our results show that for each unit increase in their trust in information about food safety increased the likelihood that consumers in Germany perceived relatively low risk by almost 13\% in the incipientphase, and by almost $28 \%$ in the post-phase. Thus, the likelihood of Germans perceiving relatively lower risk in the post-phase than in the incipient-phase grew which might be due to the fragmented risk management strategies followed by the German government and industry managers after the incipient-phase of the BSE crisis in the country.

By performing a Chow test, we found that the parameter estimates and marginal effects of the explanatory variables for both the American and German con- 
sumers substantially changed between the crisis phases (the null hypothesis was rejected at the $5 \%$ level for each country). This result further validates our choice to examine the variance in impacts that risk attitude and risk perceptions had on the consumers' participation and quantity-reduction decisions within and across the BSE crisis phases.

\subsection{Discussion \& Conclusions}

This study was designed to address the following questions: Do the separate components of consumer risk behavior, namely risk attitudes, risk perceptions, the interaction of risk attitudes and perceptions, and demographics drive consumer decisions which share the same decision-making structure in a product-harm crisis which involves life-threatening design flaws? Does this framework provide a robust conceptualization and prediction for studying consumer risk behavior in and across the phases of a product-harm crisis? Finally, what drives consumer risk attitudes and risk perceptions in different phases of a product-harm crisis? Table 4.9 displays our research hypotheses associated with each of the above-mentioned research questions and also provides information on whether these hypotheses were supported by our empirical findings (i.e., yes, implies support, no implies lack of support, a dash implies no relevance for the specific phase/time period).

\subsubsection{Theoretical Contributions}

Our results indicate that risk consumer behavior towards risks entailed in a global market crisis appears to lead to inconsistent risk reactions among the segments (i.e., countries) of the population (Hofstede, 1983). Specifically, our findings confirm and extend previous work on consumer risk behavior in several ways. First, our findings confirm the hypothesis that the participation and the quantity-reduction decisions of consumers in both countries and in as well as across each crisis phase share the same decision-making structure. That is, the participation in consumption and quantity-reduction decisions in a product-harm crisis have a common bivariate error covariance term and hence can be viewed as separate but interdependent parts of a two-layered decision system. Risk attitudes, risk perceptions, and the interaction between them drive (albeit in varied ways) both decisions in the US and in Germany in and across different crisis phases. These results confirm hypotheses $\mathrm{H}_{1 \mathrm{~A}}-\mathrm{H}_{2 \mathrm{~B}}$ and provide support for our conceptualization. 
Table 4.9 Summary of Empirical Evidence *

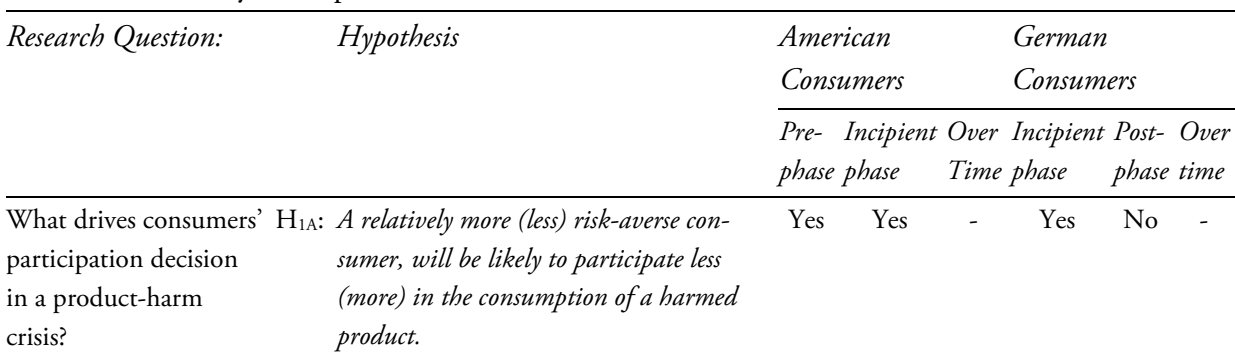

$\mathrm{H}_{1 \mathrm{~B}}$ : A consumer who perceives relatively high No No - $\mathrm{Nes}_{\text {Y }}$ Yes (low) risk from a product-harm crisis will be likely to participate less (more) in the consumption of a harmed product.

$\mathrm{H}_{1 \mathrm{C}}$ : As a consumer is relatively more (less) risk-averse, (s) he is more likely to participate less in the consumption of a harmed product when (s) he perceives relatively high (low) risk.

What drives consumers' $\mathrm{H}_{2 \mathrm{~A}}$ : As a consumer becomes relatively more quantity-reduction (less) risk averse, the likelihood of reducing decisions in a productthe quantity of consumption of a harmed harm crisis? product increases (decreases).

$\mathrm{H}_{2 \mathrm{~B}}$ : As a consumer perceives relatively high (low) risk, the likelihood of reducing the quantity of consumption of a harmed product increases (decreases)

$\mathrm{H}_{2 \mathrm{C}}$ : As a consumer is relatively more (less) risk-averse, (s) he is more likely to reduce the quantity of consumption of a harmed product when (s) he perceives relatively high (low) risk.

$\mathrm{H}_{2 \mathrm{D}}$ : Female consumers are more likely to reduce the quantity of consumption of a harmed product.

No Yes - Yes Yes Yes Yes - Yes Yes No Yes - Yes Yes Older consumers are more likely to reduce Yes Yes - Yes Yes the quantity of consumption of a harmed product.

What drives consumer decisions in specific phases of a productharm crisis?
$\mathrm{H}_{3 \mathrm{~A}}$ : The impact of consumer risk attitudes and Yes Yes ${ }^{\mathrm{a}}-\mathrm{Yes}^{\mathrm{a}}$ Yes perceptions and their interaction on consumer decisions is likely to be lower in the pre-and post-phases than in the incipient phase of a product-harm crisis. 


\begin{tabular}{|c|c|c|c|c|c|c|c|c|}
\hline \multirow[t]{2}{*}{ Research Question: } & & \multirow[t]{2}{*}{ Hypothesis } & \multicolumn{2}{|c|}{$\begin{array}{l}\text { American } \\
\text { Consumers }\end{array}$} & \multicolumn{4}{|c|}{$\begin{array}{l}\text { German } \\
\text { Consumers }\end{array}$} \\
\hline & & & $\begin{array}{l}\text { Pre- } \\
\text { phase }\end{array}$ & $\begin{array}{l}\text { Incipient } \\
\text { phase }\end{array}$ & $\begin{array}{l}\text { Over } \\
\text { Time }\end{array}$ & & $\begin{array}{l}\text { Post- } \\
\text { phase }\end{array}$ & $\begin{array}{l}\text { Over } \\
\text { time }\end{array}$ \\
\hline \multirow{2}{*}{$\begin{array}{l}\text { What drives consumer } \\
\text { decisions over time } \\
\text { (across the crisis phas- } \\
\text { es)? }\end{array}$} & $\mathrm{H}_{4 \mathrm{~A}}:$ & $\begin{array}{l}\text { The decoupled components of consumer } \\
\text { risk behavior significantly influence } \\
\text { consumer decisions across the crisis phases. }\end{array}$ & - & - & Yes $^{b}$ & - & - & Yes $^{b}$ \\
\hline & $\mathrm{H}_{4 \mathrm{~B}}$ : & $\begin{array}{l}\text { The impact of time effects on the determi- } \\
\text { nants of consumer participation and } \\
\text { quantity-reduction decisions is significant } \\
\text { across the crisis phases. }\end{array}$ & - & - & Yes $^{c}$ & - & - & Yes $^{\mathrm{c}}$ \\
\hline \multirow[t]{3}{*}{$\begin{array}{l}\text { What drives risk } \\
\text { attitude and risk } \\
\text { perceptions in different } \\
\text { phases of a product- } \\
\text { harm crisis? }\end{array}$} & $\mathrm{H}_{5 \mathrm{~A}}$ & $\begin{array}{l}\text { Greater objective knowledge of consumers } \\
\text { is likely to be associated with relatively less } \\
\text { risk-averse behavior in the subsequent } \\
\text { phases of a product-harm crisis. }\end{array}$ & - & Yes & - & - & Yes & - \\
\hline & $\mathrm{H}_{5 \mathrm{~B}}:$ & $\begin{array}{l}\text { Greater subjective knowledge of consumers } \\
\text { is likely to be associated with relatively less } \\
\text { risk-averse behavior in subsequent phases } \\
\text { of a product-harm crisis. }\end{array}$ & - & Yes & - & - & Yes & - \\
\hline & $\mathrm{H}_{6 \mathrm{~A}}:$ & $\begin{array}{l}\text { Greater (lower) consumer trust in safety } \\
\text { information is associated with relatively } \\
\text { lower (higher) risk perception in the pre- } \\
\text { and post-phases than in the incipient } \\
\text { phase of a product-harm crisis }\end{array}$ & Yes & Yes & - & Yes & Yes & - \\
\hline
\end{tabular}

*A dash indicates that the hypothesis is not applicable for the specific crisis phase (period).

a The hypothesis is confirmed for the risk attitude (RA) and the interaction of risk attitude and risk perception $\left(R A^{*} R P\right)$ that determine the participation decision, and for the risk perception (RP) and RA*RP that determine the quantity-reduction decision of Americans in the incipient crisis phase in the US (2004). The hypothesis is also confirmed for the RP, RA*RP that determine the participation decision and RA and RP that determine the quantity-reduction decisions of German consumers in the incipient-phase of the BSE crisis (2001).

b The hypothesis is confirmed for the RP, RA*RP which determine the participation decision, and for the RA, RP, and $\mathrm{RA}^{*} \mathrm{RP}$, which determine the quantity-reduction decision of Americans across the crisis phases. The RA, RP, $\mathrm{RA}^{*} \mathrm{RP}$ are significant determinants of the participation decision and the RA, RP, RA*RP of the quantityreduction decision of German consumers over time.

c The hypothesis is confirmed for the RP, RA*RP which determine the participation decisions and the RA, $\mathrm{RA}^{*} \mathrm{RP}$, and AGE which determine the quantity-reduction decisions of American consumers over time. The impact of time effects is significant for the RA, RP, RA*RP on the participation decisions of Germans. The time effect also has a significant impact on RA, RP, RA*RP while GENDER impacts the quantity-reduction decisions of German consumers.

As such, these results emphasize the relevance of examining consumer risk behavior by decoupling its components and extend recent work by March and Shapira (1987), Pennings et al., (2002), Pennings and Wansink (2004), Wansink (2004), Schroeder et al., (2007), among others, which argued that the decoupling of con- 
sumer risk behavior into risk attitudes, risk perceptions and their product provides a more robust conceptualization and prediction framework. Also, the results related to the significance of consumers' age and gender for their quantity-reduction decisions $\left(\mathrm{H}_{2 \mathrm{D}}\right.$ and $\left.\mathrm{H}_{2 \mathrm{C}}\right)$ in both countries are consistent with work in psychology and marketing (e.g., Byrnes et al., 1999; Laufer \& Gillespie, 2004; Laufer et al., 2005) arguing that older and female individual market participants exhibit higher riskaversion and perceive relatively high risk, particularly in highly risky and turbulent market situations (e.g., food scares, economic crises).

Second, we demonstrate that the impact (influence and magnitude) of the decoupled components of consumer risk behavior differs between crisis phases. We find evidence that the impact of consumer risk attitudes, risk perceptions and the interaction of risk attitudes and perceptions is higher in the incipient phase than in the pre- and post-phases of a product-harm crisis. The impact of risk attitudes and the interaction of risk attitudes and risk perceptions on the participation decisions of American consumers was higher in the incipient phase (2004) than in the prephase (2001) of the BSE outbreak in the US. The same holds for the impact of Americans' risk attitudes, risk perceptions and their interaction on quantityreduction decisions. Moreover, all three components of risk behavior were found to have a higher impact on the participations and quantity-reduction decisions of German consumers in the incipient-phase of the BSE crisis in Germany (2001). These results reflect that individuals' assumptions about the "state" of safety in beef consumption changed (e.g., Jannof-Bulman, 1992), probably due to negative, frequent and vivid publicity about the triggering event (e.g., Pearson \& Clair, 1998 ) and consumers' attempts to avoid the risk content associated with a product category found to be defective or even dangerous for human health (e.g., Dawar $\&$ Pillutla, 1998).

Third, we find that the risk attitudes, risk perceptions and their interaction significantly influence the participation and quantity-reduction decisions of consumers (albeit in varied ways) across the crisis phases $\left(\mathrm{H}_{4 \mathrm{~A}}\right)$. This is reflected in the significance of the differences in magnitude between the determinants of consumer decisions $\left(\mathrm{H}_{4 \mathrm{~B}}\right)$. That is, the behavior of consumers adapts to the contingent market conditions, which reflect the dynamics of the decision environment (e.g., social, political, economic, cultural, or technological changes). Previous marketing research suggests (the presence of) an impact of time varying-effects on consumers' 
behavior across the phases of a product-harm crisis (e.g., Pauwels et al., 2002; Van Heerde et al., 2007, Cleeren et al., 2007). These effects are likely to be attributed to consumers' sensitivity towards contingent conditions occurring in the decision environment. Consumer behavior may change as consumers experience more of the local problem structures in the course of making decisions (e.g., Hogarth, 1981; Lowenstein, 1992; Bettman et al., 1998). Thus, the relative importance of risk attitudes and perceptions follows a continuous updating pattern, which is subsequently played out on their impact on consumer decisions. Therefore, the results of this study not only confirm and extend recent risk theory based on the decoupling of components of risk behavior (e.g., March \& Shapira, 1987; Pennings et al., 2002; Pennings \& Wansink, 2004), but also places this framework into a dynamic context: risk attitudes and perceptions of consumers adapt to contingent-driven decision contexts.

Finally, we show what drives the adaptive response of consumers (their risk attitudes and perceptions) during different crisis phases. We follow recent theory in marketing and consumer behavior, which supports the notion that consumers may modify their decision-making representations due to increasing experience with the nature of a decision event (e.g., Hoch \& Deiton, 1989) and their expectations of repeated exposure to stimuli and/or the avoidance of aversive stimuli during repeated exposure (e.g., Gibbs, 1996). We find that the increased objective and subjective knowledge about potential health-hazards led American and German consumers to exhibit relatively less risk-averse behavior in the subsequent phases of the BSE crisis $\left(\mathrm{H}_{5 \mathrm{~A}}\right.$ and $\left.\mathrm{H}_{5 \mathrm{~B}}\right)$. In addition, we find that greater consumer trust in product-safety information made Americans perceive relatively lower risk in the precrisis phase (2001) and Germans in the post-crisis phase (2004). Hence, the hypothesis $\mathrm{H}_{6 \mathrm{~B}}$ is confirmed, which is in agreement with several marketing and health-economics studies supporting that consumers often modify their risk behavior because of changes in their health beliefs and the extent of these changes depends on increasing expertise, experience and familiarity with the chance to be exposed to the risk content (e.g., Viscusi, 1991; Bonker \& Hanf, 2000; Moorman et al., 2004; Alba \& Hutchinson, 2000). One may note that consumer trust in the information provided by governments eroded in the incipient-phases of the BSE crisis in both countries. This may be attributed to the negativity bias that consumers exhibit in the incipient crisis phase of a product-harm crisis due to the bad pub- 
licity surrounding this phase (Herr et al., 1991; Cleeren et al., 2007). Although we have not explicitly modeled and addressed these factors in our analysis, our modeling specification allowed for capturing their effects across the crisis phases.

Overall, the results confirm and extend previous analytical and empirical work on the decoupling of consumer risk behavior into the separate components of risk attitudes, risk perceptions and their interaction, the diversity in the impact of these factors on consumer decisions in different phases of a product-harm crisis, the separate and interdependent nature of consumer decisions in a dynamic (risky) decision contexts, the presence of time effects on the determinants of consumer risk behavior, and, finally, on the impact of latent factors impacting risk attitudes and perceptions in different crisis phases of a product-harm crisis. In general, we show that the decoupled components of consumer risk behavior provide a robust conceptualization and prediction of economic behavior in contingent-driven decision environments.

\subsubsection{Managerial Contributions}

The results of this study reveal information that may be useful to marketers, industry managers, and public policy makers to design effective corporate, marketing, and supply-chain-management strategies in and across the phases of a productharm crisis. Our results show differences among the impact (influence and magnitude) of risk attitudes, risk perceptions, their interaction and demographics on consumer decisions as well as differences among the impact of consumer knowledge on risk attitudes and trust in product-safety information on risk perceptions in different crisis phases in the US and Germany. This suggests the need for strategies to be adapted: a) If the impact of risk attitude increases in the incipient phase, strategies should focus on doing whatever is necessary to eliminate the risk from the supply chain (e.g., full product-elimination, processing auditing, and product recalls from retail outlets); b) if the impact of risk perception increases across the crisis phases, strategies and policies should center their attention on effectively informing consumers of the low probability of the hazard and reassuring them that they have accurately assessed the level of the food-safety risk; c) if the interaction between risk attitudes and risk perceptions increases across the crisis phases, this implies that relatively risk-averse consumers may engage in behavior to reduce risk, which becomes more prominent as a consumer perceives relatively more risk. Thus, a combination of strategies focusing on both the elimination of the risk content 
and the effective communication of the low probability of the hazard may be the solution; d) if female and older individuals reduce their risk-taking behavior across the crisis phases, this signals the need for an adaptation of the strategies regarding the product placement of the food product in the retail stores in order to maintain product demand for specific market segments; e) if the objective knowledge of consumers decreases across the crisis phases, marketers and policy makers need to intensify their communication efforts with daily health briefings and campaigns to endorse the storage of accurate information among consumers $f$ ) if the subjective knowledge of consumers decreases across the crisis phases, the application of intensive (retrieval) communication strategies may be required to eliminate the negativity bias in the market; and g) if trust in the information provided by governments erodes, especially in the incipient phase of a crisis, policy makers should increase public investments in communication and create synergies among governmental agencies, industry groups, consumer associations, and media in order to regain the trust of the consumer.

A key take away from this paper is that it is not only important to assess the components of consumer risk behavior in specific crisis phases and make comparisons between them, but also to look across the crisis phases and find the impact of latent factors impacting these changes.

\subsubsection{Limitations \& Further Research}

Our study has several limitations, so several issues should be addressed in future research. First, we did not utilize an economically based data-gathering instrument (e.g., a choice experiment using a lottery - trade-off - technique) to elicit the components of consumer risk behavior. Instead, we utilized a scaling procedure to measure risk attitude and perception. Although detailed and crucial information can be gathered by eliciting behavior through a lottery technique, these experiments are extremely costly and time intensive, and they require great efforts from the respondents. Our current data-gathering instrument allowed us to conduct large-scale field studies in grocery malls within the time frame of an interview, which prevented reluctance to cooperate among our respondents. Second, we measured risk behavior by using a longitudinal between-subject design. The unexpected nature of BSE outbreaks did not allow us to measure the behavior of the same subjects across the crisis phases. Future research may attempt to replicate our framework and measure risk attitudes and perceptions by using a within-the- 
subject design if the nature of the decision context allows so. A within-the-subject design may reveal more detailed insights (e.g., discrete differences in the relative importance of risk attitudes and perceptions of the same subjects) into the decoupling of consumer risk behavior over time. Third, we measured consumer risk behavior in two countries which experienced the incipient phase of the same safety outbreak at different points in time. We examined seemingly inconsistent behaviors of consumers in two major economies that were confronted with different contingent conditions throughout the product-harm crisis. However, accounting for inconsistent risk responses of consumers in countries that experience the same crisis phases at the same points in time may permit a more systematic contingentdriven context analysis on the basis of cross-cultural sensitivities of consumers. Finally, we measured knowledge and trust in information by using single-item measures. Using multi-dimensional measures and accounting for the potential variation of consumers' knowledge derived from various sources, as well as trust in the information provided by various market actors, will enrich our understanding of the factors impacting the changing consumer risk attitudes and perceptions in the different phases of a market crisis. 


\section{Chapter 5}

\section{CONCLUSION}

The overall aim of this dissertation is to examine the determinants of the underlying decision-making process of individual market participants (i.e., producers and consumers) who are actively engaged in the food supply chain. This chapter serves to conclude this dissertation by providing a brief recap of the findings of the empirical studies and discussing implications for theory and practice. We end this chapter with a set of recommendations for further research. 


\subsection{Introduction}

The overall focus of this study relies on the identification and understanding of the drivers of the latent decision-making process of "real" individual market participants in turbulent, complex, and dynamic decision environments. To address this topic, each chapter presents an empirical assessment of aspects of relevant issues. Across the three main chapters, the context pertains to the revealed economic behavior of individual food producers and consumers who are market participants at upstream and downstream stages of the food supply chain, respectively. Chapter 2 focuses on the member-investor perspectives for the structure of marketing cooperative (MC). Specifically, it assesses the subjective utility (i.e., preferences) that member-investors attach to particular organizational and strategic attributes of MCs. Chapter 3 focuses on the identification of the heterogeneity in memberinvestors' preferences (i.e., utility) for intra-organizational and strategic attributes of an MC, and we examine the effects of business size and risk attitude on these preferences. Finally, chapter 4 focuses on consumer risk behavior in times of a market crisis by studying consumer risk attitudes towards and risk perceptions for a harmed product across different countries, in which different contingent market conditions occur. We study the determinants of consumer risk behavior (risk attitude and risk perception) within and across different crisis phases and we examine how latent factors (i.e., knowledge, trust) influence these determinants within different crisis phases. The theoretical, methodological, and modeling approaches used in each study are rooted in economics, the marketing-finance interface, and psychology.

In the following three sections the major findings of each study will be presented and theoretical and managerial implications will be drawn. Finally, we provide a set of recommendations for further research.

\subsection{Discussion: Summary of Results, Theoretical \& Managerial Implications}

This dissertation contributes to literature on decision-making of individual market participants in several ways. In response to the changing economic environment in the primary sector, such as the rapid changes in agricultural policy, technology, producers individualism, consumer concerns about food quality and safety, and the 
globalization of food markets, we focus on: a) how the organizational structures of MCs can meet the challenges that changing market conditions pose to satisfying member-investors needs, and b) how the puzzling consumer reactions to a market crisis situation may highlight the need for designing and implementing different marketing strategies across different segments of the population (i.e., countries). Existing studies that deal with the revealed economic behavior of several individual market participants in the agribusiness sector are scarce and still dominated by theoretical, normative, and aggregate approaches, which cannot directly observe and capture the dynamics of the latent decision-making process of individuals in the turbulent agri-food markets (Smidts, 1990; Camerer et al., 2004). We acknowledge that the quantification of latent behavior of individual market participants at a highly disaggregate level requires the study of the revealed economic behavior of "real" decision makers familiar with non-hypothetical decision contexts in which their decisions have real consequences for them (Heckman, 2001; Smith, 2003; Pennings et al., 2005). The identification and understanding of the latent decision-making processes of "real' food producers and consumers in dynamic decision contexts, help to relax the strong assumptions included in the theoreti$\mathrm{cal} /$ normative approaches, better predict (economic) phenomena, develop successful corporate strategies, and suggest better and updated public policies (Steenkamp, 2000; Pennings, 2008). The three empirical studies of this dissertation thus provide deeper insights into various aspects of these processes. We summarize the findings of each study and we discuss theoretical and managerial implications based on these findings.

\subsubsection{Member-investors' Perspective on the Structure of an $M C$}

In response to the changing economic environment, the structures of many $\mathrm{MC}$ firms and the relationships with their member-investors have changed considerably during the last two decades. MCs abandon their passive service-oriented role and move towards an active customer-oriented role by adopting more "memberinvestor"-oriented and/or "individualized" organizational structures. At the same time, the dissatisfaction of member-investors seems to have increased as new forms of governance and strategic behavior have led producers to question whether MCs are acting in their best interest. In contrast to past research in MCs that tended to mingle co-op intra-organizational attributes with market strategy, our conceptualization delineates institutional arrangements to rely on both intra-organizational 
and strategic attributes, and a range of values of each attribute level. We support the notion that the subjective utility (i.e., preferences) that member-investors attach to particular attributes signals the level of their commitment to the MC's organizational and strategic business activities. We examine how member-investors evaluate the intra-organizational and strategic attributes that make-up a MC's structure and that are hypothesized to be important for member-investors' commitment.

We show that both intra-organizational and strategic attributes related to the internal organization and strategic behavior of the MC, respectively, drive members' preferences (utility) regarding the MC's structure. Though, member-investors assign higher utility to strategic rather than intra-organizational attributes of an MC. They prefer to participate in a market-oriented organization which will involve them in long-term relationships and develop a more direct link between its members and market segments. The identification and evaluation of attributes that compose the structure of an MC are issues of strategic importance for the restructuring of co-ops firms and their success in the marketplace. The overall utility that individual member-investors attach to these structural aspects signals the degree that the co-op is perceived to act as an agent that captures their economic interests. The great importance that members attach to the strategic attributes suggests that member-investors prefer to benefit from market opportunities via the vertical integration offered by an MC. This may be an element which substantially reinforces their commitment toward participation in a voluntarily marketing institution (VMI) and willingness to invest in collective actions. Such information may be utilized by co-op policy makers when re-structuring an MC. Recent research in behavioral economics (Bettman et al., 1998; Penings \& Smidts, 2003) shows the importance of the information revealed through market participants' preferences. Preferences are constructed, hence driven, by variables that describe the environment such as the competitive environment.

Therefore, relying on this kind of information, managers of voluntarily marketing institutions (VMIs) such as MCs may develop policies that satisfy memberinvestors' demands. Likewise, member-investors' commitment and willingness to invest in collective activities may be reinforced by adjusting internal organization and strategic behavior. 


\subsubsection{Heterogeneous Preferences of MCs' Member-investors}

Member-investors involved in collective action often strive to influence corporate structure and decisions to reflect their preferences, resulting in organizational policies that fail to benefit the membership as a whole. Agribusiness economics and marketing-finance literature recognize the essence of increasing heterogeneity in member-investors' preferences. Conflicting preferences can generate problems in a MC's setting. They may result in declining member commitment, decreasing member willingness to provide equity capital, increasing costs related to damaging influence activities, laborious decision-making processes, and incoherent strategic focus. We show that member-investors have rather well-defined preferences for the selected attributes, but value the attributes differently. Most member-investors demonstrate rather similar preferences for strategic attributes, but differ with respect to the intra-organizational attributes of control and management. In general, member-investors with large sales who employ a considerable number of workers and exhibit less risk-averse preferences preferred more involvement of professional managers in corporate and product-related decisions. Member-investors with smaller sales and fewer employees and who were more risk averse were more willing to delegate corporate and product marketing control to their representatives who presumably promote their interests more effectively.

The similarity in preferences of strategic attributes suggests that memberinvestors are willing to take similar collective action to capture market advantages. Yet, the differences in intra-organizational preferences highlight the difficulties that co-ops face in allocating resources efficiently and balancing their commitments to their member-investors. The results confirm and extend previous analytical and empirical work on the presence of and likely influence of heterogeneous preferences of participating member-investors in a VMI. The identified differences in preferences for the control mechanisms support the assumptions used to investigate and address co-op organizational inefficiencies in the presence of diverse characteristics. The "large versus small" cost efficiency argument is indeed an important dimension of member-investors preferences for co-op structure and behavior, but our findings also support the recent work identifying the importance of risk attitudes and are consistent with the presence and importance of managing risk in VMI's literature. 
Overall, our results contribute to the recognition and formalization of the heterogeneous makeup of an MC firm. That is, they importantly contribute to the literature on group-choice (e.g., Zusman, 1992; Banerjee et al., 2001) and governance structure choices (e.g., Hendrikse \& Bijman, 2002) by identifying a high degree of heterogeneity which may be problematic for co-op governance and management initiatives. Since the efficiency of resources allocation is threatened as memberinvestors' heterogeneity increases, knowledge of the existence of member-investor segments and an understanding of their preferences may be useful also to co-op policy makers to better evaluate efforts by member-investors subgroups who may strive to influence governance policies. Acquiring such crucial information, conflicting situations that undermine co-op's success in the market may be prevented and continuous development and improvement of services that better balance member-investor demands may be achieved. The diversity in member-investor preferences regarding corporate control and product management may signal the emergence for a multi-string governance structure that embodies a wide range of ownership agreements and integrates the revealed preference structure of each participating member-investors' segment. Therefore, the findings of the current study advance our understanding of how the design of MCs' governance bylaws, collective-choice rules (i.e., the joint minimization of transaction costs and individual members' risk premia), and contractual relationships among co-op stakeholders, may be adjusted to the relative importance that heterogeneous member-investors assign to them.

\subsubsection{Decoupling Consumer Risk Behavior Over Time}

The last empirical chapter focuses on the evaluation of the drivers of consumer risk behavior toward a harmed product across different countries. Specifically, we quantify how these attitudes and perceptions affect the consumption of the harmed product within and across different crisis phases. Also, we examine how latent factors influence consumers' risk attitudes and perceptions within different crisis phases. Building on recent advances in marketing and management science, we hypothesize that the components of consumer risk behavior follow ongoing update patterns and hence adapt to the environmental idiosyncrasies (e.g., conditions) of particular market settings. We propose a two-layered conceptual model showing how risk attitudes and risk perceptions influence risk behavior within and across 
crisis phases and how latent factors may explain the changes in risk attitudes and perceptions between crisis phases.

The results indicate that relevance of examining consumer risk behavior by decoupling its components (i.e., risk attitudes and risk perceptions) and confirm recent work which argued that the decoupling of consumer risk behavior into risk attitudes, risk perceptions and their product provides a more robust conceptualization and prediction framework. Further, we demonstrate that the impact (influence and magnitude) of the risk attitudes and perceptions differs between crisis phases. We show that the behavior of consumers adapts to the contingent market conditions, which reflect the dynamics of the decision environment (e.g., social, political, economic, cultural, or technological changes). Consumer behavior may change as consumers experience more of the local problem structures in the course of making decisions. Thus, the relative importance of risk attitudes and perceptions follows a continuous updating pattern, which is subsequently played out on their impact on consumer decisions. Therefore, the results of this study not only confirm and extend recent risk theory based on the decoupling of components of risk behavior (e.g., Weber \& Milliman, 1997; Pennings \& Wansink, 2004; Schroeder et al., 2007) as two-layered decision system, but also place this conceptual framework into a dynamic context: risk attitudes and perceptions of consumers adapt to contingent-driven decision contexts (Hogarth 1981, Payne et al., 1993; Cleeren et al., 2007).

Finally, we show what drives the adaptive response of consumers (their risk attitudes and perceptions) during different crisis phases. We show that consumers may modify their decision-making representations due to increasing experience with the nature of a decision event and their expectations of repeated exposure to stimuli and/or the avoidance of aversive stimuli during repeated exposure. These results may reveal information that may be useful to marketers, industry managers, and public policy makers to design effective marketing and supply-chainmanagement strategies in and across the phases of a product-harm crisis. Our results show differences among the impact (influence and magnitude) of risk attitudes, risk perceptions, their interaction and demographics on consumer decisions as well as differences among the impact of consumer knowledge on risk attitudes and trust in product-safety information on risk perceptions in different crisis phases across countries. These differences suggest the need for marketing strategies (e.g., 
full vs. or partial product elimination and recall) and public policies (e.g., investing more vs. less in communication strategies and consumer education) to be adapted throughout the crisis phases.

\subsection{Research Challenges}

Specific research suggestions have been discussed at the end of each empirical study. Yet, in this section we would like to recap these suggestions and point out some rather general directions for future research in the area of decision-making of individual market participants (i.e., producers-investors, consumers) regarding the restructuring of $\mathrm{MC}$ institutions and risk behavior in and across the phases of a product harm-crisis.

We investigated the latent decision making process of producers and consumers engaged actively in dynamic decision contexts. Although, we studied the preferences of members-investors of an MC that has recently experienced an inherently dynamic restructuring process, yet our analysis provides a cross-sectional assessment of member-investors' preference structure for MC attributes at a specific time. Thus, future research should advance our understanding of the dynamic impact of member-investors' preferences on the structure of co-ops and how this relationship is affected by different economic conditions and changing members' characteristics (observable and latent). This would extend current insights on how to make-up MC structures by satisfying the need for a high degree of integration between member-investors' heterogeneous interests and collective organizational structures. In addition, we conceptualized and measured a mix of intraorganizational and strategic attributes in the context of a horticultural MC. Further research is needed to determine the relative usefulness of these attributes and the factors influencing preference heterogeneity for other types of co-ops operating in different industries and sectors such as dairy MCs, credit co-op associations, services co-ops. Developing a taxonomy of member-investors' preferences by co-op type in each sector and industry and the factors that affect these preferences will permit a richer understanding for the setting-up of co-op structure and strategic behavior. Specifically, we may better recognize, predict and explain the nature and drivers of formal (e.g., contractual relationships) and/or informal transactions and behavior that member-investors develop among them and with their co-ops. 
The puzzling consumer risk behavior in times of product-harm crises gives rise to several research challenges. These evolve around how best to communicate with each consumer segment of the population the "actual" content of risk entailed in a product-harm crisis situation. We examined the impact of American and German consumers risk attitudes and perceptions on their behavior throughout the difference phases of a product-harm crisis as well as the drivers of these attitudes and perceptions in each crisis phase. Although, we identified the drivers of puzzling consumer reactions to this type of market crisis, several research caveats and challenges should be mentioned. The unexpected nature of BSE crisis did not allow us to measure the behavior of the same subjects across the crisis phases. Future research may attempt to replicate our framework and measure risk attitudes and perceptions by using a within-the-subject design if the nature of the decision context allows so. A within subjects design may reveal discrete differences in the relative importance of risk attitudes and perceptions of the same subjects over time.

Further, we measured consumer risk behavior in two countries which experienced the incipient phase of the same safety outbreak at different points in time (i.e., 2001 and 2004). We examined seemingly inconsistent behaviors of consumers in two major economies that were confronted with different contingent market conditions throughout the product-harm crisis. However, accounting for inconsistent risk responses of consumers in countries (e.g., segments of the population) that experience the same crisis phases at the same points in time may permit a more systematic contingent-driven context analysis on the basis of cross-cultural sensitivities of consumers. Finally, we assumed that consumer reactions might have been different among segments of the population (i.e., countries) using geography as a basis for market segmentation. Hence, we assumed that consumers behave differently in different countries, wherein other contingent market-constitutions occur. Yet, future research may relax this assumption by segmenting the population based on the underlying decision- making process within and across countries. For instance, the identification of potential variations of consumers' knowledge derived from various sources, as well as trust in the information provided by various market actors, within and across different countries, may be factors that play a crucial role in segmenting the national and global markets in times of crisis. Such a research approach will enrich our understanding of the factors impacting the puzzling reactions of segments of market participants in different contexts (i.e., product con- 
sumption, investment decision) in and across the different phases of a national and/or global market (e.g., product harm, financial) crisis.

\subsection{A Final Thought}

The overall focus of this study was on identifying and understanding the nature and the drivers of the latent decision-making process of "real" individual producers and consumers. Current economic thought puts forward the notions that the underlying decision-making process of market participants drives the heterogeneity in their behavior and that risk behavior of individuals is driven by both their willingness of individuals to accept risks as well as their interpretation of being exposed to the content of these risks. Firms in the agribusiness and food markets are challenged with identifying and copying with the needs of their rapidly changing internal (e.g., producers) as well as external market segments (e.g., consumers). This dissertation attempts to contribute to business economics and marketing-finance literature by using as decision contexts the agribusiness and food markets and by integrating theoretical, methodological, and modeling approaches from economics, the marketing-finance interface, and psychology. Overall, the understanding of revealed economic behavior (e.g., preferences, decisions) of individual market participants engaged in the opposite, upstream and downstream, stages of the supply chain of an industry or a sector may provide a more accurate picture of the development of the decision-making process of the key-participants in specific decision contexts. The general take-way is that it may imperative for marketers, financial analysts, and public policy-makers to understand both individual producers' and consumers' underlying decision-making processes, when it comes to the design and update of successful corporate investment, marketing, supply-chain management, and public policies. 


\section{Appendices}

\section{APPENDIX 3.1: DESCRIPTION OF RISK ATTITUDE SCALE}

Member-investors were asked to indicate their agreement with each item of risk attitude construct (adapted from Pennings and Smidts, 2000) on a 7-point Likert scale ranging from "strongly disagree" (1) to "strongly agree" (7):

\section{Risk Attitude Scale:}

I am willing to take higher financial risk to realize higher profit.

I am willing to take large financial risks.

I am willing to take large financial risks when selling my products to realize higher than average sales.

I like to 'play it safe' in general.

Prior to calculation, the range of responses to 4) was inverted so that the most pronounced risk-averse response assumed a value of (1). 


\section{APPENDIX 4.1: DECOUPLING RISK-TAKING BEHAVIOR}

Building on Pennings and Wansink (2004) and Pennacchi (2008; pp. 11-14), risk-taking behavior can be decoupled into the separate components of risk attitude, risk perception, and their interaction. In Pratt and Arrow's work, risk management, reflected in the risk premium $\pi$ is a function of risk attitude (risk aversion $r$ ), the situation (base wealth $W$ ) and perceived risk (with a mean of $\bar{\varepsilon}$ and variance $\sigma^{2}$ of source of additional wealth $\varepsilon$ ). In their analysis, risk management is determined by the statement that the risk premium leaves the decision-maker indifferent between holding the perceived risky asset or holding its mean value minus the risk premium. That is, $E U(W+\varepsilon)=E U(W+\varepsilon-\pi)$, where $E U$ is the expected utility. In the expected utility model this translates into:

$$
E U(W+\varepsilon)=\int U(W+\varepsilon) f(\varepsilon) d \varepsilon=U\left(W+\int \varepsilon f(\varepsilon) d \varepsilon-\pi\right)
$$

where: $U($.) is the von Neuman-Morgenstern utility function and $f($.) the probability density function of additional wealth $\varepsilon$. By taking Taylor series approximation around $W$, the behavioral equation is approximately equivalent to:

$$
\begin{aligned}
& E U(W+\varepsilon)=U(W)+U^{\prime}(W) \int \varepsilon f(\varepsilon) d \varepsilon+\frac{1}{2} U^{\prime \prime}(W) \int \varepsilon^{2} f(\varepsilon) d \varepsilon \\
& =U(W)+U^{\prime}(W)\left\{\int \varepsilon f(\varepsilon) d \varepsilon-\pi\right\}
\end{aligned}
$$

For simplicity, assume that $\varepsilon=0$, then, solving for the behavioral risk premium, we obtain:

$$
\pi=\frac{1}{2} \int \varepsilon^{2} f(\varepsilon) d \varepsilon \frac{-U^{\prime \prime}(W)}{U^{\prime}(W)}
$$

which can be written as:

$$
\pi=\frac{1}{2} \sigma^{2} r(W) \text {, }
$$

where: $r(W)=-U^{\prime \prime}(W) / U^{\prime}(W)$ is the Pratt-Arrow coefficient of absolute risk aversion. From (4.1.1) to (4.1.4), it follows that risk management behavior depends on 
the interaction of perceived risk and risk aversion. The right hand side of expression (4.1.4) for the behavioral risk premium equals the interaction of risk aversion (i.e., risk attitude: $\mathrm{RA}$ ) and risk perception (RP), that is $R A \times R P=\sigma^{2} r(W)$. In the context of our study, we consider that the risk behavior of a consumer is reflected through his/her decision to participate less in beef consumption in times of product-harm crisis as well as his/her decision regarding the quantity reduction of beef in times of crisis (given that (s)he decided already to participate less in beef consumption in times of crisis). We hypothesize that both decisions are driven by the $R A, R P$ and the $R A \times R P$. 



\section{BIBLIOGRAPHY}

A

Abelson, R.P.Kinder, D.R., Peters, M.D., Fiske, S.T. (1982). Affective \& Semantic Components in Political Person Perception. Journal of Personality and Social Psychology 42(4): 619-630.

Adda, J. (2007). Behavior Towards Health Risks: An Empirical Study Using the Mad Cow Disease as an Experiment. Journal of Risk and Uncertainty 35(3): 285-305.

AGD (2008). Belangstelling Voor Coöperaties Neemt Toe, November 8, 2008 (available online at http://www.agd.nl/1064691/Nieuws/Artikel/Belangstelling-voor-coperaties-neemt-toe.htm).

Ahluwalia, R., Burnkrant, R.E., Unnava, R. (2000). Consumer Response to Negative Publicity: The Moderating Role of Commitment. Journal of Marketing Research 37(2): 203-214.

Aitkin, M., \& Rubin, D.B. (1985). Estimation and Hypotheses Testing in Finite Mixture Models. Journal of the Royal Statistical Society/Series B 47(1): 67-75.

Alba, J.W., \& Hutchinson, J.W. (1987). Dimensions of Consumer Expertise. Journal of Consumer Research 13(4): 411-454.

Anand, P. (1998). Chronic Uncertainty and BSE Communications: Lessons from (and Limits of) Decision Theory. In: Ratzan, S.C. (Ed), The Mad Cow Crisis: Health and the Public Good. NY: University Press, pp. 51-62.

Anders, F. (2004). Immer Weniger Fleischereien in Berlin. Die Welt, Germany, EU published 23.10.2004 (available online at: http://www.welt.de/print-welt/article348143/Immer_weniger_Fleischereien_in_Berlin.html).

Anderson E. \& Narus, J.A. (1990). A Model of Distributor Firm and Manufacturer Firm Working Partnerships. Journal of Marketing 54(1): 42-58.

Anderson E., \& Weitz, B. (1989). Determinants of Continuity in Conventional Industrial Dyads. Marketing Science 8(3): 310-323.

Anderson, B.L., \& Henehan, B.M. (2002). What Went Wrong at AgWay? Fact Sheets and Extension Resources, Cornell University Cooperative Enterprise Program. Cornell University, (available online at: http://cooperatives.aem.cornell.edu/pdf/resources/agway.pdf).

Anderson, E., \& Weitz, B. (1992). The Use of Pledges to Build and Sustain Commitment in Distribution Channels. Journal of Marketing Research 29(1): 18-34.

APHIS (2006). An Estimate of the Prevalence of BSE in the US. Factsheet prepared by the Animal and Plant Health Inspection Service, July 20, 2006, pp. 1-42 (available online at: http://www.aphis.usda.gov/newsroom/hot_issues/bse/downloads/BSEprev-estFINAL_7-20-06.pdf )

Arrow, K.J. (1971). Essays in the Theory of Risk Bearing. Chicago, Illinois, USA: Markham Publishing.

B

Baker, G.A. (2003). Food Safety and Fear: Factors Affecting Consumer Response to Food Safety Risks. International Food and Agribusiness Management Review 6(1): 1-11. 
Banerjee, A.D., Mookherjee, D., Munshi, K. Ray, D. (2001). Inequality, Control Rights, and Rent seeking: Sugar Cooperatives in Maharashtra. Journal of Political Economy 109(1): 138-90.

Barton, D. (1989). What is a Cooperative? In: Cobia, D. (Ed.), Cooperatives in Agriculture. Englewood Cliffs, NJ: Prentice Hall, pp. 1-20.

Bauer, R. A. (1967). Consumer Behavior as Risk Taking. In: D. F. Cox (Ed.), Risk Taking and Information Handling in Consumer Behavior, Boston, MA: Harvard University.

Bauer, R.A.(1967). Consumer Behavior as Risk-taking. In: D.F. Cox (Ed.), Risk-taking and Information Handling in Consumer Behavior. Boston, MA: Harvard University.

Beardsworth , A., \& Keil., T (1996). Sociology on the Menu: An Invitation to the Study of Food and Society. London, UK: Routledge.

Beck, U. (1992). Risk Society. London, UK: SAGE Publications.

Benartzi, S., Thaler, R.H. (2001). Naive Diversification Strategies in Defined Contribution Saving Plans. American Economic Review 91(1): 79-98.

Bergman, M.A. (1997). Antitrust, Marketing Cooperatives and Market Power. European Journal of Law and Economics 4(1): 73-92.

Bettman, R.J. (1973). Perceived Risk and Its Components, a Model and Empirical Test. Journal of Marketing Research 10(2): 184-190.

Bettman, R.J., M.F. Luce, J.W. Payne (1998). Constructive Consumer Choice Processes. Journal of Consumer Research 25(December): 187-217.

Bibby, A., \& Shaw, L. (2005). Making a Difference: Cooperative Solutions to Global Poverty. Manchester, UK: Cooperative College Inc.

Bijman, W.J.J. (2002). Essays on Agricultural Co-operatives: Governance Structure in Fruit and Vegetable Markets. Erasmus Research Institute of Management (ERIM), PhD Series in Management 15, Erasmus University Rotterdam, the Netherlands.

Bijman, W.J.J., \& Hendrikse, G.W.J. (2003). Co-operatives in Chains: Institutional Restructuring in the Dutch Fruit and Vegetables Industry. Journal on Chain and Network Science 3(2): 95-10.

Blundel, R.W., and Meghir, C. (1987). Bivariate Alternative to the Univariate Tobit Model. Journal of Econometrics 33(1-2):179-200.

Bocker, A., \& Hanf, C. (2000). Confidence Lost and - Partially - Regained: Consumer Response to Food Scares. Journal of Economic Behavior \& Organization 43(4): 471-485.

Bourgeon, J.M., \& Champers, R.G. (1999). Producer Organizations, Bargaining, and Asymmetric Information. American Journal of Agricultural Economics 81(3): 602-609.

Bourton, M.P., \& Young, D.T. (1996). The Impact of BSE on the Demand for Beef and Other Meats in Great Britain. Applied Economics 28(6): 687-93.

Bozdogan, H. (1987). Model Selection and Akaike's Information Criterion (AIC): The General Theory and its Analytical Extension. Psychometrika 52(3): 345-370.

Bradach, J.L. \& Eccles, R.G., (1989). Price, Authority, and Trust: From Ideal Types to Plural Forms. Annual Review of Sociology 15(August): 97-118.

Brorsen, B.W., \& Irwin, S.H. (1996). Improving the Relevance of Research on Price Forecasting and Marketing Strategies. Agricultural and Resource Economics Review 25(1): 68-75.

Brucks, M. (1985). The Effects of Product Class Knowledge on Information Search Behavior. Journal of Consumer Research 12(1): 1-16. 
Buccola, S.T., \& Subaei, A. (1985). Optimal Market Pools for Agricultural Cooperatives. American Journal of Agricultural Economics 67(1): 70-80.

Bucklin, L.P., \& Sengupta, S. (1993). Organizing Successful Co-marketing Alliances. Journal of Marketing 57(2): 32-46.

Bucklin, R.E., \& Sismeiro, C. (2003). A Model of Web Site Browsing Behavior Estimated on Clickstream Data. Journal of Marketing Research 40(3): 249-267.

BVDF. (2001). Annual Report of Meat Manufacturers, Berlin, Germany.

Byrne, D. (2002). EU Commissioner for Health and Consumer Protection. Speaking Note on the Olsson Report on BSE, Strasbourg, February, 5, 2002 (available on-line at: www.defra.gove.Uk/animalh/bse/index.html).

Byrnes, J.P., Miller, D.C., Schafer, W.D. (1999). Gender Differences in Risk Taking: A MetaAnalysis. Psychological Bulletin 125(3): 367-383.

$\mathrm{C}$

Camerer, C., Loewenstein, G., Rabin, M. (2004). Advances in Behavioral Economics. Princeton, NJ: Princeton University Press.

Campo, K., Gijsbrechts, E., Nisol, P. (2000). Towards Understanding Consumer Response to Stockouts. Journal of Retailing 76(2): 219-242.

Cargill, T.F., Rausser, G.C. (1975).Temporal Price Behavior in Commodity Futures Markets. Journal of Finance 30(4): 1043-1053.

CEC -Commission of European Communities. (2007). State of Implementation and Regulation (EC) No 2200. Report from the Commission to the EU's Council. Brussels, EU.

Chaddad, F. R., \& Cook, M.L. (2004). Understanding New Cooperative Models: An OwnershipControl Rights Typology. Review of Agricultural Economics 26(1): 348-360.

Chu, T.-H., Lin, C-C., Prather, L.J. (2005). An Extension of Security Price Reactions Around Product Recall Announcements. Quarterly Journal of Economics 44(3/4): 33-48.

Churchill, G. A., Jr. (1979). A Paradigm for Developing Better Measures of Marketing Constructs. Journal Marketing Research 16(1): 64- 73.

Churchill, G. A., Jr. (1979). A Paradigm for Developing Better Measures of Marketing Constructs. Journal of Marketing Research 16(1): 64- 73.

Cleeren, K., Dekimpe, M.G., Helsen, K. (2008). Weathering Product-Harm Crises. Journal of the Academy of Marketing Science 36(2): 262-270.

Cobia, D., (Ed). (1989). Cooperatives in Agriculture, Englewood Cliffs NJ: Prentice Hall.

Cohen, J., Duggar, K., Gray, G., Kreindel, S., Abdelrahman, H., Habtemariam, T., Oryang, D.,Tameru, B. Evaluation of the Potential for Bovine Spongiform Encephalopathy in the United States. Harvard Center for Risk Analysis and Center for Computational Epidemiology, Tuskegee University, November 2001.

Cook, M.L, \& Iliopoulos, C. (2000). Ill-defined Property Rights in Collective Action: The Case of US Agricultural Cooperatives. In: Ménard, C. (Ed.), Institutions, Contracts and Organizations: Perspectives from New Institutional Economics, Cheltenham: Edward Elgar Pub., pp. 335-348.

Cook, M.L. (1995). The Future of U.S. Agricultural Cooperatives: A Neo-institutional Approach. American Journal of Agricultural Economics 77(5): 1153-1159. 
Cook, M.L. (1997). Organizational Structure and Globalization: The Case of User-Oriented Firms. In: Nilsson, J., \& Van Dijk, (Eds), Strategies and Structures in the Agro-food Industries. Assen, the Netherlands: Van Gorcum, pp. 77-93.

Cook, M.L., \& Chaddad, F.R. (2004). Redesigning Cooperative Boundaries: Emergence for New Models. American Journal of Agricultural Economics 86(5): 1249-1253.

Cook, M.L., Chaddad, F.R., \& Iliopoulos, C. (2004). Advances in Cooperative Theory Since 1990: A Review of Agricultural Economics Literature. In: Hendrikse, G.W.J. (Ed.), Restructuring Agricultural Cooperatives. The Netherlands: Rotterdam School of Management Publications, Erasmus University Rotterdam, pp. 65-88.

Copeland, T.E. \& Weston, J.F. (1983). Financial Theory and Corporate Policy. $2^{\text {nd }}$ Edition, Reading MA: Addison-Wesley.

Cornick, J., Cox, T. L. Gould, B. W. (1994). Fluid Milk Purchases: A Multivariate Tobit Analysis. American Journal of Agricultural Economics 76(1): 74-82.

Cotterill, R.W. (2001). Cooperative and Membership Commitment: Discussion. American Journal of Agricultural Economics 83(5): 1280-1281.

Cox, D.F. (Ed.) (1967). Risk taking and Information Handling in Consumer Behavior. Boston, MA: Harvard University.

Cunningham, S.M. (1967). The Major Dimensions of Perceived Risk. In: Cox, D.F. (Ed.), Risk taking and Information Handling in Consumer Behavior. Boston, MA: Harvard University, pp. 82-108.

D

Dasgupta, P. (2009). Trust and Cooperation Among Economic Agents. Philosophical Transactions of the Royal Society (forthcoming).

Dausend, P. (2002). Die Felder der FDP Besetzen. Die Welt, Germany, published 10.06.2002. (available online: http://www.welt.de/printwelt/article393685/Die_Felder_der_FDP_besetzen.html).

Dawar, N., \& M. Pillutla (2000). 'Impact of Product-Harm Crises on Brand Equity: The Moderating Role of Consumer Expectations” Journal of Marketing Research 37(May): 215-226.

Dawar, N., \& Pillutla, M. (2000). Impact of Product-Harm Crises on Brand Equity: The Moderating Role of Consumer Expectations. Journal of Marketing Research 37(2): 215-226.

De Jonge, J. van Trijp, J.C.M., van der Lans, I.A., Renes, R.J., and Frewer, L.J. (2009). How Trust in Institutions and Organizations Builds General Consumer Confidence in the Safety of Food: A Decomposition of the Effects. Appetite 51(2):311-317.

DeSarbo, W.S., \& Choi, J. (1999). A Latent Structure Double Hurdle Regression Model for Exploring Heterogeneity in Consumer Search Patterns. Journal of Econometrics 89(1-2): 423-455.

DeSarbo, W.S., Wedel, M., Vriens, M., \& Ramaskamy, V. (1992). Latent Class Metric Conjoint Analysis. Marketing Letters 3(3): 273-282.

Diamond, W. D. (1988). The Effect of Probability and Consequence Levels on the Focus of Consumer Judgments in Risky Situations. Journal of Consumer Research 15(3): 280-283.

Dillon W.R., Frederick, D.G., \& Tangpanichdee, V. (1985). Decision Issues in Building Perceptual Product Spaces with Multi-attribute Rating Data. Journal of Consumer Research 12(1): 47-63. 
Dosman, D.M. Adamaovitz, W.L. and Hrudely, S.E. (2001). Socioeconomic Determinants of Health- and Food Safety-related Risk Perceptions. Risk Analysis 21(2): 307-317.

Dowling, G.R. (1986). Perceived Risk: The Concept and Its Measurement. Psychology and Marketing 3(3): 193-210.

Dowling, G.R., \& Staelin, R. (1994). A Model of Perceived Risk and Intended Risk-handling Activity. Journal of Consumer Research 21(1): 119-134.

DPA (Deutsche Presse Agentur),(2001). Die BSE - Krise. Published on 12.1.01 (available online at: https://www.spiegel.de/politik/deutschland/0,1518,111942,00.html ).

Dwyer, R., Schurr, P., Oh, S. (1987). Developing Buyer-Seller Relations. Journal of Marketing 51(2): $11-28$.

E

Eilers, C., \& Hanf, C.H. (1999). Contracts Between Framers and Farmers' Processing Cooperatives: A Principal-Agent Approach for the Potato Starch Industry. In: G. Galizzi and Venturini, L. (Eds.), Vertical Relationships and Coordination in the Food System. Heidelberg: Psysica-Verlag, pp. 267-284.

Eisenhardt, M. E. (1989). Building Theories from Case Study Research. The Academy of Management Review 14(4): 532-550.

Eiser, J.R., Miles, S., Frewer.L.J.(2003).Trust, Perceived Risk and Attitudes toward Food Technologies. Journal of Applied Psychology 32(11): 2423-2433.

Endsley, M. (1995). Toward a Theory of Situation Awareness in Dynamic Systems. Human Factors 37(1): 32-64.

Erdem, T. \& Keane, M.P. (1996). Decision-Making under Uncertainty: Capturing Dynamic Choice Processes in Turbulent Consumer Goods Markets. Marketing Science 15 (1): 1-20.

European Union Coordination Committee - EUCC (2008). Cooperatives Europe ASBL. $3^{\text {rd }}$ Draft Regulation on the Application of Articles 87 and 88 of the EC Treaty Declaring Certain Categories of Aid Compatible with the Common Market (available online at: Error! Hyperlink reference not valid.

F

FAO/WHO (1997). Report of the $12^{\text {th }}$ session of the Codex Committee on General Principles. Paris, France 25-28 November 1996 Codex Alimentarius Commission. Rome: FAO.

FAS - Foreign Agricultural Service, (2004). Livestock and Poultry-World Markets and Trade. US Department of Agriculture, Washington DC, US.

FDA (2004). Food and Drug Administration - FDA Consumer Magazine, May-June Issue, 2004 (available on line at: http://www.fda.gov/fdac/departs/2004/304_upd.html )

Feinerman, E., \& Falkovitz, M. (1991). An Agricultural Multipurpose Service Cooperative: Pareto Optimality, Price-Tax Solution, and Stability. Journal of Comparative Economics 15(1): 95-114.

Feng, L., \& Hendrikse, G. (2008). On the Nature of a Cooperative: A System of Attributes Perspective. In: Hendrikse, G., Tuunaren, M., Windsperger, J. and Cliquet, G. (Eds.), Strategy and Governance of Networks: Cooperatives, Franchising, and Strategic Alliances. Heidelberg: Physica Verlag.

Finkelstein, S. (2005). When Bad Things Happen to Good Companies: Strategy Failure and Flawed Executives. Journal of Business Strategy 26(2): 19-28. 
Flynn, J., Slovic, P., Mertz, C.K. (1994). Gender, Race and Perception of Environmental health Risks. Risk Analysis 12(3): 417-430.

Focus, (2002). Teile-und Herrsche? Aus Focus Magazine, Germany, 8(February): 46-51.

Fox, J. Mintert, J. B., Schroeder, T., Valentin, L. (2005). The Response to BSE in the United States. Choices, 20(2): 103-108.

Fox, J., \& Peterson, H. (2004). Risks and Implications of Bovine Spongiform Encephalopathy for the United States: Insights from Other Countries. Food Policy 29(1): 45-60.

Fulton, M.E. (1995). The Future of Canadian Agricultural Cooperatives: A Property Rights Approach. American Journal of Agricultural Economics 77(5):1144-1152.

Fulton, M.E. (1999). Cooperatives and Member Commitment. Finish Journal of Business Economics 4(1): 418-473.

Fulton, M.E., \& Giannakas, K. (2001). Organizational Commitment in a Mixed Oligopoly: Agricultural Co-operatives and Investor Owned Firms. American Journal of Agricultural Economics 83(5): $1258-1265$.

Fulton, M.E., \& Gibbings, J. (2000). Response and Adaptation: Canadian Agricultural Cooperatives in the $21^{s t}$ Century. Ottawa: Canadian Co-operative Association and Le Conseil Canadien de la Cooperation, October, 2000.

G

Galdeano, E. Cespedes, J., Rodriguez, M. (2005). Productivity and Quality-Environmental Changes in Marketing Cooperatives: An Analysis of the Horticultural Sector. Paper presented at the $X I^{\text {th }}$ Congress of European Association of Agricultural Economics, Copenhagen, 24-27 August, 2005.

GAO (2005). Experiences of Seven Countries in Consolidating Their Food Safety Systems. Report to Congressional Requesters - GAO-05-212, February, 2005 (available online at: http://www.gao.gov/new.items/d05212.pdf.)

Garcia, J., \& Labeaga, J.M. (1996). Alternative Approaches to Modeling Zero Expenditure: An Application to Spanish Demand for Tobacco. Oxford Bulletin of Economics and Statistics 58(3):489506.

Gibbs, B. J. (1996). Consumer as Accommodator: Inward Versus Outward Decision Making and the SelfManipulation of Tastes. Research Paper 1239, Graduate School of Business, Stanford University, CA, US.

Giddens, A. (1991 ). The Consequences of Modernity. Cambridge, UK: Polity Press.

Gilliland, D.I., \& Bello, D.C. (2002). Two Sides to Attitudinal Commitment: The Effect of Calculative and Loyalty Commitment in Enforcement Mechanisms in Distribution Channels. Journal of the Academy of Marketing Science 30(1): 24-43.

Goldsmith, P.D., \& Gow, H.R. (2004). Strategic Positioning Under Agricultural Structural Change: A Critique of Long Jump Co-operative Venture. International Food and Agribusiness Management Review 8(2): 1-21.

Goldstein, D., \& Wilson, J. (2005). Tyson, McDonald's Shares Fall on U.S. Mad-Cow Concern. Bloomberg, 13/6/2005 (available online at: http://www.mindfully.org/Food/2005/TysonMcDonalds-Mad-Cow13jun05.htm). 
Gragg, J. (1971). Some Statistical Models for Limited Depended Variables with Application to the Demand for Durable Goods. Econometrica 39(5): 829-844.

Green, P.E. (1974). On the Design of Choice Experiments Involving Multifactor Alternatives. The Journal of Consumer Research 1(2): 61-68.

Green, P.E., \& Srinivasan, V. (1978). Conjoint Analysis in Consumer Research: Issues and Outlook. Journal of Consumer Research 5(2): 103-123.

Green, P.E., \& Wind, Y. (1975). New Ways to Measure Consumers' Judgments. Harvard Business Review 53(July-August): 107-117.

Green, P.H., \& Rao, V.R. (1971). Conjoint Measurement for Quantifying Judgmental Data. Journal of Marketing Research 8(3): 355-363.

Green, P.H., \& Srinivasan, V. (1990). Conjoint Analysis in Marketing: New Developments with Implications for Research and Practice. Journal of Marketing 54(4): 3-19.

Greene, W. H. (2003). Econometric Analysis. Upper Saddle River, New Jersy: Prentice Hall, $4^{\text {th }}$ Edition.

Greene, W. H. (2008). NLOGIT Version 4.0 Reference Guide. Plainview, NY: Econometric Software.

Griffin, M., Babin, B.J., Attaway, J.S. (1991). An Empirical Investigation of the Impact of Negative Publicity on Consumer Attitudes and Intentions. Advances in Consumer Research 18(1): 334-341.

Gripsurd, G., Lenvik, G.H., Olsen, N.V. (2001). Influence Activities in Agricultural Cooperatives: The Impact of Heterogeneity. In: Borgen, S. O. (Ed.), The Food Sector in Transition. NLF Report 01-2. Oslo: Norwegian/Nordic Research, pp. 13-24.

$\mathrm{H}$

Haines, P., Guilkey, D.K. Popkin, B.M. (1988) Modeling Food Consumption Decisions as TwoStep Process. American Journal of Agricultural Economics 70(3)543-552.

Hair, J.F., Anderson, R.E., Tanham, R.L., \& Black, W.C., (Eds). (1998). Multivariate Data Analysis. Englewood Cliffs NJ: Prentice Hall.

Hakelius, K. 1996. Cooperative Values: Farmers Cooperatives in the Minds of Farmers. PhD dissertation, Swedish University of Agricultural Sciences.

Hansmann, H. (1996). The Ownership of Enterprise. Cambridge, MA: Harvard University Press.

Harris, R.J. (1975). A Primer of Multivariate Statistics. NY, US: Academic Press.

Harrison, G.W. (2004). Field Experiments and Control. Research in Experimental Economics, 10(June): $17-50$.

Harrison, G.W., \& List, J.A. (2004). Field Experiments. Journal of Economic Literature 42(4): 10091055.

Hart, O.D., \& Moore, J. (1996). The Governance of Exchanges: Members' Cooperatives versus Outside Ownership. Oxford Review of Economic Policy 12(4): 53-69.

Hauser, J. R., \& Urban, G. L. (1979). Assessment of Attribute Importances and Consumer Utility Functions: von Neumann - Morgenstern Theory Applied to Consumer Behavior. Journal of Consumer Research 5(4): 251-262.

Hauser, J., \& Rao, V. (2005). Conjoint Analysis, Related Modeling, and Applications. In: Wind, Y. \& Green, P. E. (Eds.), Market Research and Modeling: Progress and Prospects, NY, US: Springer Academic Publications, pp. 141-168. 
Heckman, J.J. (2001). Micro Data, Heterogeneity, and the Evaluation of Public Policy: Nobel Lecture. Journal of Political Economy 109(4): 673-748.

Hendrikse, G.W.J., \& Bijman, J. (2002). Ownership Structure in Agrifood Chains: The Marketing Cooperative. American Journal of Agricultural Economics 84(1): 104-119.

Hendrikse, G.W.J., \& Veerman, C.P. (1997). Marketing Cooperatives as a System of Attributes. In: J. Nilsson and G. Van Dijk (Eds.), Strategies and Structures in the Agro-food Industries. Assen, The Netherlands: van Gorcum, pp. 111-130.

Hernandez-Espallardo, M., \& Arcas-Lario, N. (2003). The Effects of Authoritative Mechanisms of Coordination on Market orientation in Asymmetrical Channel Partnerships. International Journal of Research in Marketing 20(2): 133-152.

Herr, P.M., Kardes, F. R.,\&Kim, J. (1991). Effects of Word-of-Mouth and Product-attribute Information on Persuasion: An Accessibility Diagnosticity Perspective. Journal of Consumer Research 17(4): 454-462.

Hoch, S. J., \& Deighton, J. (1989). Managing What Consumers Learn from Experience. Journal of Marketing 53(2):1-20.

Hoch, S.J., \& Loewenstein, G.F. (1991). Time-inconsistent Preferences and Consumer Self-Control. Journal of Consumer Research 17(1): 492-507.

Hoffman, R. R. (Ed.) (2007). Expertise Out of Context: Proceedings of the Sixth International Conference on Naturalistic Decision Making. Boca Raton, FL: Taylor and Francis.

Hofstede, G. (1980). Culture's Consequences: International Differences in Work-related Values. Beverly Hills, CA: Sage Publications.

Hofstede, G. (1983). The Cultural Relativity of Organizational Practices and Theories. Journal of International Business Studies 14(Fall): 75-89.

Hogarth, R.M. (1981). Beyond Discrete Biases: Functional and Dysfunctional Aspects of Judgmental Heuristics. Psychological Bulletin 90(1): 197-217.

Holloway, G., Bhavani, S., Sanzidur, R. (2002). "Bayesian Spatial Probit Estimation: A Primer and An Application to HYV Rice Adoption. Agricultural Economics 27(3): 383-402.

Holmstrom B., \& Milgrom, P. (1994). The Firm as an Incentive System. American Economic Review 84(4): 972-991.

Holmstrom, B. (1999). Future of Cooperatives: A Corporate Perspective. Finish Journal of Business Economics 48(1): 404-417.

Hornig Priest, S., Bonfadelli, H., Rusanen, M. (2003). The “trust gap” Hypothesis: Predicting Support for Biotechnology Across National Cultures as a Function of Trust in Actors. Risk Analysis 23(4): 751-766.

Hui, S.K., Fader, P.S., Bradlow, E.T. (2009). Path Data in Marketing: An Integrative Framework and Prospectus for Model Building. Marketing Science 28(2): 320-335.

Humphrey, B.R., Lee, S., Soebbing, B.P. (2009). Consumer Behavior in Lotto Markets: The Double-Hurdle Approach and Zeros in Gambling Survey Data. Working Paper No. 2009-27. Dept. of Economics, University of Alberta, Canada, November 2009. 
Iliopoulos, C. (1998). A Study of the Property Rights Constraints in US Agricultural Cooperatives: Theory and Evidence. Unpublished Ph.D. Dissertation, University of Missouri-Columbia, US.

Iliopoulos, C., \& Cook, M.L. (1999). The Efficiency of Internal Resource Allocation Decisions in Customer-owned Firms. Paper presented at the $3^{\text {rd }}$ Annual Conference of International Society for New Institutional Economics, September 17-19, 1999, Washington DC, US.

International Co-operative Alliance - ICA (2008). Cooperatives and Rural Employment. Fact Sheet of ICA (available online at: www.ica.coop).

$\mathrm{J}$

Jacoby, J. (1984). Perspectives on Information Overload. The Journal of Consumer Research 10(4): 432-435.

Jannof-Bulman, R. (1992). Shattered Assumptions: Towards a New Psychology of Trauma. NY: Free Press.

Jensen, M. C., \& Meckling, W.H. (1976). The Theory of the Firm: Managerial Behavior, Agency Costs and Ownership Structure. Journal of Financial Economics 3(4): 305-360.

Jensen, M.V. (1993). The Modern Industrial Revolution, Exit, and the Failure of Internal Control Systems. Journal of Finance 48(3): 831-880.

Jin, H.J., \& Kim, J-C. (2008). The Effects of BSE Outbreak on the Security Values of US Agribusiness and Food Processing Firm. Applied Economics 40(3): 357-372.

Jin, H.J., \& Koo, W.W. (2003). The Effect of the BSE Outbreak in Japan on Consumers' Preferences." European Review of Agricultural Economics 30(2): 173-192.

Johansen-Stenman, O. (2008). Mad Cows, Terrorism and Junk Food: Should Public Policy Reflect Perceived or Objective Risks? Journal of Health Economics 27(2): 234-248.

Johnson, B., \& Slovic, P. (1995). Presenting Uncertainty in Health Risk Assessment: Initial Studies of Its Effects on Risk Perception and Trust. Risk Analysis 15(4): 485-495.

Johnston, W.J. (2001). Time and Consumer Behavior. Advances in Consumer Research 8(1): 192194.

Jolly, D. W., \& Mowen, J. C. (1985). Product Recall Communications: The Effects of Source, Media, and Social Responsibility Information. Advances in Consumer Research 12(1): 471-475.

Jones, A.M. (1989). A Double Hurdle Model of Cigarette Consumption. Journal of Applied Econometrics 4(1): 23-39.

K

Kahn, B.E. \& Luce, M.F. (2003). Understanding High-Stakes Consumer Decisions: Mammography Adherence Following False-Alarm Test Results. Marketing Science 22(3): 393-410.

Kahneman D., \& Tversky, A. (1979). Prospect Theory: An Analysis of Decision Under Risk. Econometrica 47(2): 263-291.

Kahneman, D. Wakker, P.P. Sarin, R. (1997). Back to Bentham? Explorations of Experienced Utility. The Quarterly Journal of Economics 112(2): 375-405. 
Kalogeras, N., Pennings, J.M.E., Van Dijk, G., \& Lans, van der, I. A. (2007). The Structure of Marketing Cooperative: A Members' Perspective. In: Karantininis, K., and Nilsson, J. (Eds.), Vertical Markets and Cooperative Hierarchies, Dordrecht, The Netherlands: Springer Academic Publications, pp. 73-92.

Kalyanaram, G., Robinson, W.T., \& Urban, G.L. (1995). Order of Market Entry: Established Empirical Generalization, Emerging Generalizations, and Future Research. Marketing Science 14(3): 161-169.

Kamins, M.A., Folkes, V.S., Perner, L. (1997). Consumer Responses to Rumors: Good News, Bad News. Journal of Consumer Psychology 6(2): 165-187.

Karantininis, K., \& Nilsson, J., (Eds.) (2007). Vertical Markets and Cooperative Hierarchies: The Role of Cooperatives in the Agro-Food Industry. Dordrecht, the Netherlands: Springer Academic Publications.

Karantininis, K., \& Zago, A. (2001). Endogenous Membership in Mixed Duopsonies. American Journal of Agricultural Economics 83(5):1266-1272.

Keeney, R.L., \& Raiffa, H. (1972). A Critique of Formal Analysis in Public Decision Making. In A.W., Drake, R.L. Keeney, and P.M. Morse, eds. Analysis of Public Systems. Cambridge, MA: M.I.T. Press.

Keeney, R.L., \& Raiffa, H. (1993). Decisions with Multiple Objectives: Preferences and Value Tradeoffs. NY: Cambridge University Press.

Keller, L. R. (1985). An Empirical Investigation of Relative Risk Aversion. IEEE Transactions on Systems, Man and Cybernetics 15(4): 475-482.

Kenskel, D.S., (1991). Health Behavior, Health Knowledge, and Schooling. Journal of Political Economy 99(2): 287-305.

Klein, G. (1993). Naturalistic Decision Making: Implications for Design. State of the Art Report, CSER1AC SOAR 93-1, University of Dayton Research Institute, Fairborn, OH: Klein Associates Inc, pp. 1-182.

Klein, G. A, Orasanu, J. R., Calderwood, R., and Zsambok, C. (1993). Decision-making in Action: Models and Methods. Norwood, CT: Ablex.

Klein, J., \& Dawar, N. (2004). Corporate Social Responsibility and Consumers' Attributions and Brand Evaluations in a Product-Harm Crisis. International Journal of Research in Marketing 21(3):203-217.

Kleinmuntz, D.N. (1985). Cognitive Heuristics and Feedback in a Dynamic Decision Environment. Management Science 31(6): 680-702.

Klett-Actualitatendienst (2002). Die BSE-Krise in Deutschland und Europa Umdenken in Sachen Verbaucherschutz? Stuggart, Germany: Klett Pub.

Knoeber, C.R., \& Baumer, D.L. (1983). Understanding Retained Patronage Refunds in Agricultural Cooperatives. American Journal of Agricultural Economics 58(1), 30-37.

Kohls, R.L., \& Uhl, J.N. (2002). Marketing of Agricultural Products. $9^{\text {th }}$ Edition, Upper Saddle River, NJ: Prentice Hall, Inc.

Kotler, P. (2002). Marketing Management: Analysis, Planning, Implementation and Control. NJ: Prentice Hall. 
Kozup, J.C., Creyer, E.H., Butron, S. Making Harmful Food Choices: The Influence of Health Claims and Nutrition Information on Consumers' Evaluation of Packaged Food Products and Restaurant Menu Items. Journal of Marketing 67(2): 19-34.

Kuchler, F., \& Tegene, A. (2006). Did BSE Announcements Reduce Beef Purchase? Economic Research Service, USDA, ERR-34, pp. 1-39.

Kuchler, F., \& Tegene, A. (2006). Did BSE Announcements Reduce Beef Purchase? Economic Research Service, USDA, ERR-34, pp. 1-39.

Kunast, R. (2001). Governmental Declaration, 8 February, 2001.

Kyriakopoulos, K. (2000). The Market Orientation of Cooperative Organizations: Learning Strategies and Structures for Integrating Firm and Members. Ph.D. Dissertation, Nyenrode University. Assen, The Netherlands: van Gorsum Pub.

Kyriakopoulos, K., Meulenberg, M.T.G., Nilsson, J. (2004). The Impact of Cooperative Structure and Firm Culture on Market-Orientation and Performance. Agribusiness: An International Journal 20(4): 379-396.

L

Laufer, D., and Gillespie, K. (2004). Differences in Consumer Attributions of Blame between Men and Women: The Role of Perceived Vulnerability and Empathic Concern. Psychology \& Marketing, 21(2): 141-157.

Laufer, D., Silvera, D.H., Meyer, T. (2005). Exploring Differences between Older and Younger Consumers in Attributions of Blame for Product Harm-Crises. Academy of Marketing Science Review, 9 (article No 7) (available online at: http://www.amsreview.org/articles.htm ).

Lenz, T. (2006). Lack of Clarity, Changing Role and Responsibilities in the German Food System. Appetite 47(2): 152-160.

Leung, E. (2004). Mad Cow Disease Hasn't Set Panic. The Wall Street Journal, January, 21, 2004, pp. 12.

Lewin, A.Y., \& Volberda, H.W. (1999). Prolegomena on Coevolution: A Framework for Research on Strategy and New Organizational Forms. Organization Science 10(5): 519-534.

Lin, T-F., and Schmidt, P. (1984). A Test of the Tobit Specification Against an Alternative Suggested by Gragg. The Review of Economics and Statistics 66(1): 174-177.

Lipshitz, R., Klein, G., Orasanu, J. Salas, E. (2001). Taking Stock of Naturalistic Decision Making. Journal of Behavioral Decision Making 14(5): 331-352.

Little, J.D.C. (1986). Research Opportunities in Decision and Management Sciences. Management Science 32(1): 1-13.

Loewenstein, G. (1992). The Fall and the Rise of Psychological Explanation in the Economics of Intertemporal Choice. In: Loewenstein, G., \& Elster, J. (Eds.), Choice Over Time. NY: Russel Sage, pp. 3-34.

Loewenstein, G. (1999). Because It is There: The Challenge of Mountaineering for Utility Theory. Kyklos 52(2): 315-344.

Loewenstein, G., \& Mather, J. (1990). Dynamic Processes in Risk Perception. Journal of Risk and Uncertainty, 39(2): 155-175. 
Luce R.D., \& Tukey, J.W. (1964). Simultaneous Conjoint Measurement: A New Type of Fundamental Measurement. Journal of Mathematical Psychology 1(1): 1-27.

Luhmann, H-J. (2001). The Blindness of Society. Munich, Germany: Gerling-AkadVerl.

M

MacCrimmon, K.R., \& Wehrung, D.A. (1990). Characteristics of Risk Taking Executives. Management Science 36(4): 422-435.

Machina, M.J. (1982). Expected Utility Analysis Without the Independence Axioms. Econometrica 50(2): $277-323$.

Maddala, G.S. (2006). Limited Dependent and Qualitative Variables in Econometrics. NY: Cambridge University Press.

Mangen, M.J.J. \& Burell, A.M. Who Gains, Who Loses? Welfare Effects of Classical Swine Fever Epidemics in the Netherlands. European Review of Agricultural Economics 30(1):125-154.

March, J.G., \& Shapira, Z. (1987). Managerial Perspectives on Risk and Risk Taking. Management Science 33(11): 1404-1418.

Marsh, T.L., Schroeder, T.C., Mintert, J. (2004). Impacts of Meat Product Recalls on Consumer Demand in the USA. Applied Economics 36(9): 897-910.

Mayer, R.C., Davis, J.H., Schoorman, E.D. (1995). An Integrative Model of Organizational Trust. Academy of Management Review 20(3): 709-734.

McDonald, J.F., \& Moffit, R.A. (1980). The Uses of Tobit Analysis. The Review of Economics and Statistics 62(2): 318-321.

McFadden, D., (1979). Quantitative Methods for Analyzing Travel Behaviour of Individuals: Some Recent Developments. In: D.A. Hensher and P.R. Stopher (Eds.), Behavioural Travel Modelling. London: Croom Helm, pp. 279-318.

Meulenberg, M.T.G. (1979). Farmer Cooperatives in the Food Economy of Western Europe: An Analysis from the Marketing Point of View. European Review of Agricultural Economics 5(3-4): 255-275.

Meulenberg, M.T.G. (1997). Evolution of Agricultural Marketing Institutions: A Channel Approach. In: Wierenga, B. van Tilburg, A., Grunert, K. Steenkamp, J-B, E.M., \& Wedel, M., (Eds.), Agricultural Marketing and Consumer Behavior in a Changing World. Dordrecht, the Netherlands: Kluwer Academic Publishers, pp. 95-108.

Meulenberg, M.T.G. (2000). Voluntary Marketing Institutions in Food Marketing Systems. In Tilburg, A. van, Moll, H.A.J., \& Kuyvenhoven, A. (Eds.), Agricultural Markets Beyond Liberalization. Dordrecht, The Netherlands: Kluwer Academic Publishers, pp. 213-233.

Milgrom, P., \& Roberts, J. (1990). The Economics of Modern Manufacturing: Technology, Strategy and Organization. American Economic Review 80(4): 511-528.

Miller, D. (1999). Risk, Science and Policy: Definitional Struggles, Information Management, the Media and BSE. Social Science \& Medicine 49(9): 1239-1255.

Mirtoff, I.I., \& Kilmann, R.H. Corporate Tragedies: Product Tampering, Sabotage, and Other Catastrophes. NY, US: Praeger Pub.

Mitchell, V-M. (1992). Understanding Consumers' Behavior: Can Perceived Risk Theory Help? Management Decision 30(3): 26-31. 
Moorman C., \& Matulich, E. (1993). A Model of Consumers' Preventive Health Behaviors: The Role of Health Motivation and Health Ability. Journal of Consumer Research 20(2): 208-228.

Moorman, C., Diehl, K., Brinberg, D., \& Kidwell, B. (2004). Subjective Knowledge, Search Locations and Consumer Choice. Journal of Consumer Research 31(3): 673-680.

Moorman, C., Zaltman, G., Deshpandé, R. (1992). Relationships Between Providers and Users of Market Research: The Dynamics of Trust Within and Between Organizations. Journal of Marketing Research 29 (3): 314-328.

Mowen, J.C. (1980). Further Information on Consumer Perceptions of Product Recalls. Advances in Consumer Research 7(1): 519-523.

Myerson, R.B. (1979). Incentive Compatibility and the Bargaining Problem. Econometrica 47(1): 6173.

$\mathrm{N}$

NABU. (2001). Annual Report of Nature Conservation League.

NCBA - National Cooperative Business Association (2009). About Cooperatives. (available online at: http://www.ncba.coop/abcoop.cfm)

Neumann J. von and Morgenstern, O. (1947). Theory of Games and Economic Behavior. $2^{\text {nd }}$ Edition. Princeton, NJ: Princeton University Press.

Newman, C., Henchion, M., Mathews, A. (2003). A Double-Hurdle Model of Irish Household Expenditure on Prepared Meals. Applied Economics 35(9): 1053-1061.

Nijs, V., Dekimpe, M.G., Steenkamp, J-M., Hanssens, D.M. (2001). The Category Demand Effects of Price Promotions. Marketing Science 20 (1): 1-22.

Nilson, T. (1995) Chaos Marketing, London, UK: McGraw-Hill Pub.

Nilsson, J. \& Van Dijk, G., (Eds). (1997). Strategies and Structures in the Agro-food Industries. Assen, the Netherlands: Van Gorcum Pub.

Nosic, A., \& Weber, M. (2007). Determinants of Risk Taking Behavior: The Role of Risk Attitudes, Risk Perceptions and Beliefs. Working paper No 07-56, Deutsche Forschungsgemeinschaft, University of Mannheim, Germany, pp. 1-33.

$\mathrm{O}$

Ojah, K., \& Manrique, J. (2005). Determinants of Corporate Debt Structure in a Privately Dominated Debt Market: A Study of the Spanish Capital Market. Applied Financial Economics 15(7): 455-468.

Olsen, R. A. \& Cox, C.M. (2001). The Influence of Gender on Perception and Response to Investment Risk. The Journal of Psychology and Financial Markets 2(1): 29-36

Olson, M. (1971). The Logic of Collective Action: Public Goods and the Theory of Groups. Cambridge, MA: Harvard University Press.

Oustapassidis, K., Vlachvei, A., Karantininis, K. (1998). Growth of Investor-owned and Cooperative Firms in Greek Dairy Industry. Annals of Public and Cooperative Economics 69(3): 399-417.

$P$

Palsson, A. M. (1996). Does the Degree of Relative Risk Aversion Vary with Household Characteristics? Journal of Economic Psychology 17(6): 1996. 
Pattison, D. (2000). Agricultural Cooperatives in Selected Transitional Countries (available online at: http://www.agricoop.org/resources.htm).

Pauwels, K., Hanssens, D.M., Siddarth, S. (2002). The Long-Term Effects of Price Promotions on Category Incidence, Brand Choice and Purchase Quantity. Journal of Marketing Research 39 (3): 421-439.

Payne, J.W., Bettman, J R., Johnson, E.J. (1993). The Adaptive Decision Maker. Cambridge, NY: Cambridge University Press.

Pearson, C.M., \& Clair, J.A. (1998), Reframing Crisis Management. Academy of Management Review 23(1): 59-76.

Pennacchi, G. (2008). Theory of Asset Pricing. Chicago, IL, US: Pearson Education.

Penning, J.M.E. (2002). Pulling the Triger or Not: Factors Affecting Behavior of Initiating a Position in Derivatives Markets. Journal of Economic Psychology 23(2): 263-278.

Pennings, J.M.E \& Smidts, A. (2003). The Shape of Utility Functions and Organizational Behavior. Management Science 49(9): 1251-1263.

Pennings, J.M.E. \& Garcia, P. (2001). Measuring Producers' Risk Preferences: A Global Risk Attitude Construct. American Journal of Agricultural Economics 83(4): 993-1009.

Pennings, J.M.E. (1998). The Information Dissemination Process of Futures Exchange Innovations: A Note. Journal of Business Research 43(3): 141-145.

Pennings, J.M.E. (2008). Marketing $\times$ Finance $=$ Product with a High Return \& Low Risk Profile. Inaugural Speech, Department of Marketing , Department of Finance, Maastricht University, Maastricht, The Netherlands, October 10, 2008.

Pennings, J.M.E., \& Garcia, P. (2004). Hedging Behavior in Small and Medium-sized Enterprises: The Role of Unobserved Heterogeneity. Journal of Banking \& Finance 28(5): 951-978.

Pennings, J.M.E., \& Garcia, P. (2009). Risk and Hedging Behavior: The Role and Determinants of Latent Heterogeneity. The Journal of Financial Research (forthcoming).

Pennings, J.M.E., \& Leuthold, R.M. (2000). The Role of Farmers' Behavioral Attitudes and Heterogeneity in Future Contracts Usage. American Journal of Agricultural Economics 82(4): 908-919.

Pennings, J.M.E., \& Smidts, A. (2000). Assessing the Construct Validity of Risk Attitude. Management Science 46(10): 1337-1348.

Pennings, J.M.E., \& Wansink, B. (2004). Channel Contract Behavior: The Role of Risk Attitudes, Risk Perceptions, and Channel Member Market Structures. Journal of Business 77(4): 697-723.

Pennings, J.M.E., Garcia, P., Hendrix, E. (2005). Towards a Theory of Revealed Economic Behavior. Journal of Bioeconomics 7(2): 113-127.

Pennings, J.M.E., Wansink, B., Meulenberg, M.T.G. (2002). A Note on Modeling Consumer Reactions to a Crisis: The Case of the Mad Cow Disease. International Journal of Research in Marketing 19(1): 91-100.

Peracchio, L.A. \& Tybout, A.M. (1996). The Moderating Role of Prior Knowledge in Schema-Based Product Evaluation. The Journal of Consumer Research 23(3):177-192.

Peterson, C.H., \& Anderson, B.L. (1996). Cooperative Strategy: Theory and Practice. Agribusiness: An International Journal 12(4): 371-383.

PIB (2004). Künast nimmt Ernährungswirtschaft in die Pflicht. Presse und Infromationsamt der Bundesregierung, Berlin, Germany, 14.06.2004. 
PIB, (2001). Künast: Verbrauchervertrauen ist Schlüssel zur Bewältigung der BSE-Krise. Presse und Infromationsamt der Bundesregierung, Berlin, Germany, 15.03.2001

PIB, (2003). Chronologie der BSE-Krise. Presse und Infromationsamt der Bundesregierung, Berlin, Germany, 19.02.2003.

Piggott, N. \& Marsh, T. Does Food Safety Information Impact U.S. Meat Demand? American Journal of Agricultural Economics 86(1): 154-174.

Pindyck, R.S., \& Rubinfeld, D.L. (1998). Econometric Models and Economic Forecasts. $4^{\text {th }}$ edition; Singapore: McGraw-Hill Book Co.

Porter, M.E. (1985). Competitive Advantage: Creating and Sustaining Superior Performance. NY, US: Free Press.

Pratt, J.W. (1964). Risk Aversion in the Small and in the Large. Econometrica 83(1-2): 122-136.

Prichett, J., Thilmany, D., Kamina, J. (2005). Animal Disease Economic Impacts: A Survey of Literature and Typology of Research Approaches. International Food and Agribusiness Management Review 8(1): 23-45.

$\mathbf{R}$

Reynolds, B.J. (1997). Decision Making in Cooperatives with Diverse Member Interests. RBS Service Rep. 155, April. Washington, DC: US Department of Agriculture.

Robins, R.W., Hendin, H.M., Trzesniewski, K.H. (2001). Measuring Global Self-Esteem: Construct Validation of a Single Item Measure and the Rosenberg Self-Esteem Scale. Personality and Social Psychology Bulletin 27(2): 151-161.

Robinson, W.T., \& Fornell, C. (1985). Sources of Market Pioneer Advantages in Consumer Good Industries. Journal of Marketing Research 22(3): 305-317.

Roe, B., Levy, A. Derby, B.M. (1999). The Impact of Health Claims on Consumer Search and Product Evaluation Outcomes: Results from FDA Experimental Data. Journal of Public Policy \& Marketing 18(1): 89-105.

Rogers, G. (1997) The Dynamics of Risk Perception: How Does Perceived Risk Respond to Risk Events? Risk Analysis 17(6): 745-757

Rohner, R.P. (1977). Advantages of the Comparative Method of Anthropology. Behavior Science Research 12(2): 117-144.

$S$

Satcher, D. Food Safety: A Growing Global Health Problem. Journal of American Medical Association 283(14): 1817.

Schoemaker, P.J.H. (1982). The Expected Utility Model: Its Variants, Purposes, Evidence and Limitations. Journal of Economic Literature 20(2): 529-563.

Schoemaker, P.J.H. (1993). Strategic Decisions in Organizations: Rational and Behavioral Views. Journal of Management Studies 30(1): 107-129.

Schrader, L.F. (1989). Economic Justification. In: Cobia, D.W. (Ed.), Cooperatives in Agriculture. Englewood Cliffs, NJ: Prentice Hall. 
Schroeder, T., Tonsor, G.T., Pennings, J.M.E., Mintert, J. (2008). Consumer Food Safety Risk Perceptions and Attitudes: Impacts on Beef Consumption Across Countries. The B.E. Journal of Economic Analysis \& Policy 7(1): Article 65 (available online at: http://www.bepress.com/bejeap/vol7/iss1/art65).

Sen, S. (1998). Knowledge, Information Mode, and the Attraction Effect. Journal of Consumer Research 25(1): 64-77.

Sexton, R.J. (1986a). The Formation of Cooperatives: A Game-Theoretic Approach with Implications for Cooperative Finance, Decision Making, and Stability. American Journal of Agricultural Economics 68(2): 214-225.

Sexton, R.J. (1986b). Cooperatives and the Forces Shaping Agricultural Marketing. American Journal of Agricultural Economics 68(5): 1167-1172.

Sexton, R.J. (1990). Imperfect Competition in Agricultural Markets and the Role of Cooperatives: A Spatial Analysis. American Journal of Agricultural Economics 72(3): 709-720.

Sexton, R.J., \& Sexton, T.A. (1987). Cooperatives as Entrants. The Rand Journal of Economics 18(4): 581-595.

Shaffer, J.D. (1987). Thinking About Farmer's Cooperatives, Contracts, and Economic Coordination, In: Royer, J.S. (Ed.), Cooperative Theory: New Approaches, Washington, D.C.: USDA ACS Service, Rep. 18, July 1987, pp. 61-86.

Shapira, Z. (1995). Risk Taking: A Managerial Perspective. NY: Russell Sage.

Shocker, A.D., \& Srinivasan, V. (1979). Multiattribute Approaches for Product Concept Evaluation and Generation: A Critical Review. Journal of Marketing Research 16(2): 159-180.

Shrivastava, P., Mitroff, I., Miller, D., \& Miglani, A.(1988). Understanding Industrial Crises. Journal of Management Studies 25(4): 285-303.

Siegrist, M., Earle, T. C., Gutscher, H. (2003). Test of a Trust and Confidence Model in the Applied Context of Electromagnetic Field (EMF) Risks. Risk Analysis 23(4): 705-716.

Simon, H.A. (1959). Theories of Decision-Making in Economics and Behavioral Science. American Economic Review 49(3): 253-283.

Simonson, I., \& Tversky, A. (1992). Choice in Context: Tradeoff Contrast and Extremeness Aversion. Journal of Marketing Research 29(3): 281-95.

Singh, J., \& Sirdeshmukh, D. (2000). Agency and Trust Mechanisms in Consumer Satisfaction and Loyalty Judgments. Journal of the Academy of Marketing Science 28(1): 150-167.

Sivadas, E., \& Dwyer, F.R. (2000). An Examination of Organizational Factors Influencing New Product Success in Internal and Alliance-Based Processes. Journal of Marketing 64(1): 31-49.

Slovic, P. (1987). Perception of Risk. Science 236(4799): 280-285.

Slovic, P. (1992). Perception of Risk: Reflections on the Psychometric Paradigm. In: Krimsky, S., \& Golding, D. (Eds.), Social Theories of Risk. NY: Praeger, pp. 117-152.

Slovic, P., Fishhoff, B., Lichtenstein, S. (1980). Facts and Fears: Understanding Perceived Risk. In: Albers, W.A. (Ed.), Societal Risk Assessment: How Safe Is Safe Enough? NY: Plenum Press, pp. 65102.

Smidts, A. (1990). Decision Making Under Risk: A Study of Models and Measurement Behavior with Special References to the Farmer's Marketing Behavior. Wageningen Economic Studies No. 18. Wageningen, The Netherlands: Academic Publishers. 
Smidts, A. (1997). The Relationship of Risk Attitude and Strength Preference: A Test of Intrinsic Risk Attitude. Management Science 43(3): 357-370.

Smith, K.V. \& Johnson, F. R. (1988). How do Risk Perceptions Respond to Information? The Case of Radon. The Review of Economics and Statistics 70(1): 1-8.

Smith, K.V., \& Johnson, F.R.(1998). How Do Risk Perceptions Respond to Information? The Cases of Radon. The Review of Economics and Statistics 70(1): 1-8.

Smith, K.V., Donald, H., Taylor, Jr., Sloan, F., Johnson, F.R., Desvousges, W. (2001). Do Smokers Respond to Health Shocks? The Review of Economics and Statistics 83(4): 675-687.

Smith, V.L. (1982). Microeconomic Systems as an Experimental Science. American Economic Review 72(5): 923-955.

Smith, V.L. (2003). Constructivist and Ecological Rationality in Economics. Nobel Prize Lecture, December 8, 2002, at Aula Magna, Stockholm University. American Economic Review 93(3): 465-508.

Srinivasan, N., \& Ratchford, B. T. (1991). An Empirical Test of a Model of Extended Search for Automobiles. Journal of Consumer Research 18(3): 233- 242.

Staatz, J.M. (1983). The Cooperative as a Coalition: A Game Theoretic Approach. American Journal of Agricultural Economics 65(5): 1084-1089.

Staatz, J.M. (1987a). The Structural Characteristics of Farmer Cooperatives and their Behavioral Consequences. In: J.S. Royer, (Ed.), Cooperative Theory: New Approaches. Washington, D.C.: U.S. Department of Agriculture, ACS Service Rep. 18, July, pp. 33-60.

Staatz, J.M. (1987b). Farmers' Incentives to Take Collective Action via Cooperatives: A Transaction Cost Approach. In: Royer, J.S. (Ed.), Cooperative Theory: New Approaches. Washington, D.C.: U.S. Department of Agriculture, ACS Service Rep. 18, July, pp. 87-107.

Steenkamp, J-B., E.M. (2000). Dynamics in Consumer Behavior With Respect to Agricultural and Food Products. In: Wierenga, B. Van Tilburg, A., Grunert, K., Steenkamp, J-B., E.M., \& Wedel, M. (Eds.), Agricultural Marketing and Consumer Behaviour in a Changing World, Norwell, MA: Kluwer Academic Publishers, pp.143-188.

Stern, L.W., \& El-Ansary, A. (1990). Marketing Channels. $3^{\text {rd }}$ Edition, Englewood Cliffs, NJ: Prentice Hall, Inc.

Sterns, J.A., Schweikhardt, D.B. \& Peterson, H.C. (1998). Using Case Studies as an Approach for Conducting Agribusiness Research. International Food and Agribusiness Management Review 1(3): $311-327$.

Sykuta, M.E., \& Cook, M.L. (2001). A New Institutional Approach to Cooperatives and Contracting. American Journal of Agricultural Economics 83(5): 1273-1280.

\section{T}

Taylor, J.W. (1974). The Role of Risk in Consumer Behavior. Journal of Marketing 38(2):54-60.

Teece, D.J., Pisano, G., Shuen, A. (1997). Dynamic Capabilities of Strategic Management. Strategic Management Journal 18(7): 87-110. 
Thilmany, D. Umberger, W. Ziehl, A. (2004). Consumer Response to Beef Due to the December 2003 BSE Incident in the US. Cooperative Extension, Colorado State University, Rep. No. 04-01. (available online at: http://dare.agsci.colostate.edu/csuagecon/extenison/pubstools.htm\#AgMarketing).

Thompson, G.J. (2005). Consumer Risk Perceptions in a Community of Reflective Doubt. Journal of Consumer Research 32(2): 235-248.

Tilburg, A. van, Moll, H.J., Kuyvenhoven, A. (2000). Agricultural Markets Beyond Liberalization. Dordrecht, The Netherlands: Kluwer Academic Publishers.

Titterington, D.M. (1990). Some Recent Research in the Analysis of Mixture Distributions. Statistics 21(4): 619-641.

Tse, Y., \& Hackard, J.C. (2006). Holy Mad Cow! Facts or (Mis)Perceptions: A Clinical Study. Journal of Futures Markets 26(4): 315-341.

$\mathrm{U}$

United Nations - UN (2009). Cooperatives in Social Development. UN General Assembly: Report of Secretary General, Session 64 ${ }^{\text {th }}, 13$ July, 2009.

US Consumer Product Safety Commission (2005). 2005 Performance and Accountability Report (available online at: http://www.cpsc.gov/about/gpra/05perfrpt.pdf)

USDA - United States Department of Agriculture (1995). What is a Cooperative? Rural Business and Cooperative Development Service, Cooperative Information Report 50, March. Washington DC: U.S. Department of Agriculture.

USDA - United States Department of Agriculture (2002). USDA Response to GAO Recommendations on BSE Prevention. Fact sheet. Release No. F.S. 0071.02, February 2002.

USDA - United States Department of Agriculture (2002). Agricultural Cooperatives in the 21st Century. Rural Business-Cooperative Service, Cooperative Information Report 60, Washington DC.

USDA - United States Department of Agriculture (2003). Announcing Additional Protection Measure to Guard Against BSE. Newsroom-Transcript of Agriculture Secretary Ann M. Veneman, Washington, DC, December, 30, 2003 (available online at: http://www.aphis.usda.gov/hot_issues/bse/bse_news2003.shtml).

USDA - United States Department of Agriculture (2007).An Economic Chronology of BSE in North America. Electronic Outlook Report from the Economic Research Service, Washington, DC, June, 2006 (available online at: http://www.ers.usda.gov ).

V

Van Bekkum, O-F. (2001). Cooperative Models and Farm Policy Reform: Exploring Patterns in Structure-Strategy Matches of Dairy Cooperatives in Protected vs. Liberated Markets. Ph.D. Thesis, Nyenrode University, the Netherlands Business School, Assen: van Gorcum Pub.

Van Bekkum, O-F., \& Bijman, J. (2006). Innovations in Cooperative Ownership: Converted and Hybrid Listed Cooperatives', In: S. Rajacopalan (Ed.), Managing Cooperatives, Ahmedabad, India: ICFAI Business School, pp. 34-56.

Van Bekkum, O-F., \& Van Dijk, G. (Eds.), (1997). Agricultural cooperatives in the European Union - Trends and Issues on the Eve of the 21st Century. Assen, the Netherlands: van Gorsum Pub. 
Van der Laan, M.J. \& McKeague, M (1998). Efficient Estimation From Right-Censored Data When Failure Indicators are Missing at Random. Annals of Statistics 26(1): 164-182.

Van der Laan, M.J. (1996). Efficient Estimation in the Bivariate Censoring Model and Repairing NPMLE. Annals of Statistics 24(2): 596-627.

Van Dijk, G. (1999). Evolution of Business Structure and Entrepreneurship of Cooperatives in the Horti- and Agribusiness. Finish Journal of Business Economics 4(3/4):471-483.

Van Dijk, G., \& Mackel, C. (1991). Dutch Agriculture Seeking for Market Leader Strategies. European Review of Agricultural Economics 189(3-4): 345-364.

Van Heerde, H.J., Helsen, K., Dekimpe, M.G. (2007). The Impact of Product-Harm Crisis on Marketing Effectiveness. Marketing Science 26(2): 230-245.

Van Kleef, E. Houghton, J.R., Krystallis, A., Pfenning, U., Rowe, G., Van Dijk, H. (2007). Consumer Evaluations of Food Risk Management Quality in Europe. Risk Analysis 27(6): 15651580.

Vazsonyi, A. (1990). Decision Making: Normative, Descriptive and Decision Counseling. Managerial and Decision Economics 11(5): 317-325.

Veerman, C.P. (1998). Ontwikkelingen Bij de Afzet van Glasgroenten. In: Allebas, J.T.M., \& Varekamp, M.J. (Eds.), De Glastuinbouw in het Derde Millennium: Wendingen en Kansen, Naaldwijk: Gemeente Naaldwijk, pp.49-55.

Viscusi, W.K. (1991). Age Variations in Risk Perceptions and Smoking Decisions. The Review of Economics and Statistics 73(4): 577-588.

Viscusi, W.K. (1993). The Value of Risks to Life and Health. Journal of Economic Literature 31(4): 1912-1946.

Vitaliano, P. (1983). Cooperative Enterprise: Alternative Conceptual Basis for Analyzing a Complex Institution. American Journal of Agricultural Economics 65(5): 1078-1082.

Vlaev, I. (2007). Instability and Relativity of Preferences: How Context Determines Utilities and Decisions. In: Hofmann, K.P. (Ed.). Psychology of Decision Making in Economics, Business and Finance. NY: Nova Publishers, pp. 65-86.

W

Wahlreng, E. (2004). Steak Chains: Sirloin or Chopped Liver. Business Week Online, January 23, 2004 (available online at: www.wlwt.com/money/2788745/detail.html)

Wansink, B. (2004). Consumer Reactions to Food Safety Crises. Advances in Food and Nutrition Research 48(1): 103-150.

Weber, E.U., \& Milliman R.A. (1997). Perceived Risk Attitudes: Relating Risk Perception to Risk Attitude. Management Science 43(2): 123-144.

Weber, W. (2001). Germany's Health and Agriculture Ministers Resign over Handling of BSE. The Lancet 357(January 20, 2001): 207.

Wedel, M., \& DeSarbo, W.S. (1995). A Mixture Likelihood Approach for Generalized Linear Models. Journal of Classification 12(1): 21-55.

Wedel, M., \& Kamakura, W.A. (1998). Market Segmentation: Conceptual and Methodological Foundations. $2^{\text {nd }}$ Edition, International Series in Quantitative Marketing. Boston: Kluwer Academic Publishers. 
Weick, K. (1993). The Collapse of Sensemaking in Organizations: The Mann Gulch Disaster. Administrative Science Quarterly 38(4): 628-652.

Weinberger, M. G., Romeo, B., Piracha, A. (1993). Negative Product Safety News: Coverage, Responses and Effects. Business Horizons 34(3): 23-31.

Wierenga, B., Tilburg, van, A., Grunert, K., Steenkamp, J-B. E.M. Wedel, M. (1997). Agricultural Marketing and Consumer Behavior in a Changing World. Dordrecht, the Netherlands: Kluwer Academic Publications.

Wiggins, M. W., \& O'Hare, D. (1995). Expertise in Aeronautical Weather-related Decision-making: A Cross-sectional Analysis of General Aviation Pilots. Journal of Experimental Psychology: Applied 1(4): 305-320.

Winter, W.F. (1975). Laboratory Measurement of Response to Consumer Information. Journal of Marketing Research 12(4): 390-401.

Winterfeldt D. von \& Edwards, W. (1986). Decision Analysis and Behavioral Research. Cambridge, NY: Cambridge University Press.

Wood, S.L., \& Lynch, J.G.Jr. (2002). Prior Knowledge and Complacency in New Product Learning. Journal of Consumer Research 29(3):416-426.

Wooldridge, J.M. (2006). Introductory Econometrics: A Modern Approach. $3^{\text {rd }}$ Edition; Mason, OH: Thomson High.

World Health Organization - WHO (2000). Food Safety - A Worldwide Public Health Issue. (available online at: http://www.who.int/fsf/fctshtfs.htm).

$\mathrm{Y}$

Yoo, S. (2005). Analysing Household Bottled Water and Water Purifier Expenditures: Simultaneous Equation Bivariate Tobit Model. Applied Economics Letters 12(5):297-301.

$\mathrm{Z}$

Zand, D.E. (1972). Trust and Managerial Problem Solving. Administrative Science Quarterly 17(2)229-239.

Zegers, F. E., \& Berge, ten, J.M.F. (1985). A Family of Association Coefficients for Metric Scales. Psycometrika 50(1): 17-24.

Zsambok, C. E., \& Klein, G. (1997). Naturalistic Decision Making. Mahwah, NJ: Lawrence Erlbaum Associates Inc. Publishers.

Zusman, P. (1982). Group Choice in an Agricultural Marketing Cooperative. Canadian Journal of Economics 15(2): 220-234.

Zusman, P. (1992). Constitutional Selection of Collective-choice Rules in a Cooperative Enterprise. Journal of Economic Behavior and Organization 17(3): 353-362.

Zusman, P., \& Rausser, G.C. (1994). Interorganizational Influence and Optimality of Collective Action. Journal of Economic Behavior and Organization 24(1): 1-17. 


\section{SAMENVATTING (DUTCH SUMMARY)}

In dit proefschrift erkennen we dat bij het bestuderen van economisch gedrag (i.e., voorkeuren, beslissingen) van individuen met betrekking tot investeren en consumeren rekening dient te worden gehouden met hun latente besluitvormingsproces, zowel vanuit een adequaat theoretisch als methodologisch gebaseerd perspectief. We gebruiken en integreren theoretische, methodologische en modelbenaderingen uit de bedrijfseconomie, het grensgebied van de marketing en financiën en de psychologie.

We onderzoeken het aan het licht gebrachte economische gedrag van individuele voedselproducenten en consumenten die respectievelijk marktpartijen in de keten van voedselvoorziening zijn. We trachten bij te dragen aan het begrip van het economisch gedrag van individuele producenten en consumenten in de voedingsmiddelen industrie, die dynamische strategische processen ondergaan. De voedingsmiddelen industrie is dynamisch en verandert voortdurend. De achtereenvolgende liberalisering van voedselmarkten (in het kader van het Gemeenschappelijk Landbouwbeleid) dwingt de voedingsmiddelen industrie te reageren op snelle en radicale veranderingen in de markt door middel van globalisering en grootschalige operaties. Het begrijpen van veranderend economisch gedrag in verschillende stadia van de voedselvoorzieningsketen is belangrijk bij het formuleren van bedrijfsinvesteringen en marketingstrategieën.

Eén van de hoofddoelen van dit proefschrift is het bestuderen van het onderliggend besluitvormingsgedrag van individuele marktpartiijen aan de hand van de gedrags- en experimentele micro-economische denkrichting. Experimentele microeconomie omvat het empirisch onderzoek van het besluitvormingsgedrag van "echte" individuen. Dit proefschrift bundelt drie empirische onderzoeken over economische gedrag van individuele marktpartijen en de latente en waarneembare factoren die tot dit gedrag aanzetten/dit gedrag voeden. De belangrijkste schakel tussen deze drie onderzoeken is de totale focus op het identificeren en begrijpen van de aard en de oorzaken/drijfveren van het latente besluitvormingsproces van "echte" individuele marktpartijen. Voortvloeiend uit de denkwijze van Vernon, L. Smith, Nobelprijswinnaar in de economie in 2002, omvatten de drie empirische onder- 
zoeken de volgende onderscheidende kenmerken in hun besluitcontexten: de relevantie van het beslis proces;; de hoge mate van vertrouwdheid van 'echte' individuele besluitvormers met de 'besluitcontexten'; de betrekkelijk grote steekproeven; en de gecombineerde toepassing van directe meettechnieken (kwalitatieve en kwantitatieve) op een gedesaggregeerd niveau.

De gegevens voor deze onderzoeken zijn verzameld in grootschalige veldonderzoeken van de Nederlandse agro-industrieële sector en in de Amerikaanse en Duitse markten van de voedingsdetailhandel. In hoofdstuk twee wordt het algemene nut vastgesteld dat mede-investeerders ontlenen aan de multidimensionale structuur van het marketinginstituut coöperatie. Hoofdstuk drie identificeert en analyseert de heterogene voorkeuren van mede-investeerders voor de kenmerken die ten grondslag liggen aan de structuur van een marketinginstituut, evenals de factoren (economische omvang en risicogedrag) die heterogeniteit veroorzaken. Ten slotte worden in hoofdstuk vier de drijfveren van risicogedrag van de consument bestudeerd binnen en via de fases van productschade crises en de factoren die de veranderingen van deze drijfveren in de loop der tijd beïnvloeden. Hieronder worden de bevindingen van elk onderzoek uitvoeriger besproken.

In hoofdstuk twee wordt onderzocht hoe mede-investeerders de aspecten evalueren die de structuur vormen van een vrijwillig marketinginstituut (VMI), zoals een Marketing Coöperatie (MC), en die verondersteld worden belangrijk te zijn voor de loyaliteit van mede-investeerders. Wij hypothetiseren dat het nut dat leden ontlenen aan de kenmerken van de structuur van een $\mathrm{MC}$ ons inzicht vergroot in de loyaliteit van de leden. Door gebruik te maken van conjoint experimenteel ontwerp brengen we het nut dat producenten aan de kenmerken van een $\mathrm{MC}$ hechten aan het licht. Deze kenmerken houden verband met de interne organisatorische structuur en het strategische gedrag van de MC. De resultaten van 120 producenten van een Nederlandse tuinbouw-MC laten zien dat de geselecteerde MCkenmerken belangrijke drijfveren zijn van het nut van de leden. Leden hechten met name groot belang aan strategische kenmerken en ze geven de voorkeur aan een meer geïndividualiseerde bedrijfsstructuur. Het grote belang dat leden hechten aan de strategische kenmerken suggereert dat leden er de voorkeur aan geven te profiteren van marktmogelijkheden via de verticale integratie die een MC biedt. Dit zou een element kunnen zijn dat hun loyaliteit ten opzichte van deelname in een vrijwillig marketinginstituut, en bereidheid te investeren in collectieve acties, aanzien- 
lijk versterkt. Zulke informatie zou kunnen worden gebruikt door co-op beleidsmakers bij het herstructureren van een MC. Recent onderzoek in de gedragseconomie toont het belang van de informatie die door de voorkeuren van de marktpartijen aan het licht is gebracht. Voorkeuren worden gevormd en derhalve gedreven door omgevingsfactoren, zoals de concurrentie omgeving. Vertrouwend op dit soort informatie zouden managers van VMI's, zoals MC's, daarom beleid kunnen ontwikkelen dat voldoet aan de eisen van mede-investeerders. Op dergelijke wijze zou de loyaliteit van mede-investeerders en hun bereidheid te investeren in collectieve activiteiten kunnen worden versterkt door de interne organisatie en het strategische gedrag aan te passen.

Hoofdstuk drie onderzoekt de heterogene voorkeuren van de medeinvesteerders van een MC. Dit onderzoek is geïnspireerd door Heckmans Nobellezing (2001), waarin wordt benadrukt dat de heterogeniteit in economisch gedrag slechts kan worden begrepen wanneer men het onderliggende besluitvormingsproces van individuele marktpartijen (bijv. producenten, investeerders, consumenten) identificeert en bestudeert. We bestuderen de heterogeniteit in de voorkeursstructuur van coöperative leden. Door middel een conjoint analyse wordt het nut dat mede-investeerders hechten aan intra-organisatorische en strategische kenmerken van hun bedrijf geïdentificeerd. Rekening houdend met het feit mede-investeerders niet homogeen zijn, wordt een mixture regressie model gebruikt waarmee voorkeuren vrij kunnen variëren voor verschillende ledensegmenten. Uit gegevens van 120 coöperatieve mede-investeerders blijkt dat de meeste leden betrekkelijk gelijkende voorkeuren voor strategische kenmerken vertonen, maar dat zij verschillen daar waar het gaat om intra-organisatorische controle- en managementgerelateerde kenmerken. Voorkeursstructuren van leden worden beïnvloed door bedrijfsgrootte en houdingen ten opzichte van risico. In het algemeen dragen onze resultaten bij aan de erkenning en formalisering van de heterogene structuur van een MC. Ze dragen in belangrijke mate bij aan de literatuur over groepskeuze en keuzes met betrekking tot bedrijfsstructuur door de heterogeniteit te identificeren in de voorkeursstructuren van leden. Daar de efficiëntie van de verdeling van middelen wordt bedreigd naarmate de heterogeniteit van de mede-investeerders toeneemt, zou kennis over het bestaan van segmenten en begrip van hun voorkeuren nuttig kunnen zijn voor co-op beleidsmakers om pogingen van leden-subgroepen om het bestuurlijk beleid te willen beïnvloeden beter te evalueren. Door het verkrijgen van zulke 
informatie zouden conflicterende situaties die het succes van co-ops in de markt ondermijnen kunnen worden voorkomen en kan een continue ontwikkeling en verbetering van diensten die beter beantwoorden aan de behoeften van leden worden bereikt.

Hoofdstuk vier onderzoekt "consumer risk behavior" in tijden van een produktcrisis, zoals een crisis door BSE besmetting in de rundvleesmarkt. Uit recent onderzoek blijkt dat we de "risk responses" van consumenten beter kunnen begrijpen wanneer we "risk behavior" uiteenrafelen in de onderliggende componenten risicoperceptie en risico-attitude. Tevens wordt benadrukt dat de invloeden van risico-attitude en risicoperceptie op het consumentengedrag kunnen worden gebruikt om effectieve(re) marketingstrategieën te formuleren wanneer dergelijke crises optreden. $\mathrm{Nu}$ rijst de vraag of de impact van deze variabelen door de tijd verandert, en waarom. De BSE crises in de V.S. en Duitsland in 2001 en 2004 stellen onderzoekers in de gelegenheid om middels een natuurlijk experiment de relaties tussen risico-attitude, risicoperceptie, en consumentengedrag tijdens verschillende fases van een crisis te onderzoeken. De bevindingen in dit hoofdstuk tonen aan dat de relatieve effecten van risico-attitude en risicoperceptie van tijd tot tijd sterk onderhevig zijn aan verandering, hetgeen benadrukt dat marketingstrategieën hierop moeten worden afgestemd. Deze verandering is het gevolg van zowel de kennis van de consument alsmede haar vertrouwen in de informatie van overheid en industrie. Hiermee bevestigt dit onderzoek dus niet alleen de recente theorieën over risico, die pleiten voor een opsplitsing van "risk behavior", maar laat het daarnaast ook zien dat risico-attitude en risicoperceptie door dynamiek in de beslissingscontext gevormd worden.

Over het algemeen kunnen we concluderen dat het geobserveerde economische gedrag van individuen in de markt (op verschillende plaatsen in supply chain) ons belangrijke inzichten verschaft in hoe beslissingsprocessen van marktparticipanten zich ontwikkelen in een specifieke beslissingscontext. Dergelijke inzichten in het beslissingproces van consumenten en producenten hebben mogelijk belangrijke praktische consequenties voor marketers, financiële analisten en beleidsmakers. Ze vormen een belangrijke ingrediënt in het samenstellen en updaten van bedrijfsinvesteringen, marketing, supply chain management, en overheidsbeleid. 


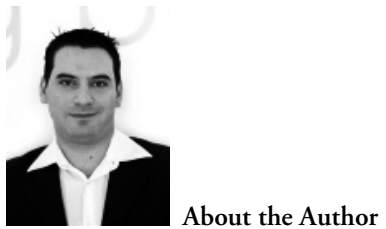

Nikolaos E. Kalogeras (Nikos) studied Economics (BSc), Economics \& Management Sciences (MA/DSPU), Marketing \& Consumer Behavior (MSc), and Financial Engineering \& Management (M.Eng). The current publication (dissertation) is the result of his $\mathrm{PhD}$ study that started in 2005 when he was a visiting scholar at the Marketing and Decisions Science Group and the Office for Futures \& Options Research (OFOR), both at the University of Illinois at Urbana-Champaign, IL, US (2005-2007), and completed through research collaboration between the Depts. of Marketing and Finance at the Maastricht University (UM), the Netherlands (2007-2009). From 2009 until 2010, he was a post-doc researcher at the Dept. of Marketing \& Supply Chain Management and a Senior Lecturer at the Dept. of Finance/UM.

Nikos has co-authored more than 15 peer-reviewed articles, 20 referred proceeding papers, 40 abstracts in scientific and business meetings, and many business reports and popular articles in Greek, American and Dutch newspapers and magazines. $\mathrm{He}$ is a visiting professor at the dept. of Business Economics \& Marketing, International Center for Advanced Mediterranean Studies (CIHEAM/MAICh), and he is affiliated with the Sustainability Lab of the European Centre for Corporate Engagement, Dept. of Finance/UM. As from November, 2010, he is employed as an Assistant Professor and Co-director of the Marketing-Finance Institute at the Dept. of Marketing \& Supply Chain Management/UM.

In parallel with his studies in economics, marketing and finance, Nikos also studied Theater: Theory \& Practice. He participated as an actor in several classical and modern plays based on the Greek, Italian, French, American, and Russian literature and directed two plays presented in the Netherlands in 2004 . He was a member of many professional and alternative theater teams (e.g., Black Theater) in Greece, France and the Netherlands. Till today, there is nothing Nikos enjoys more than performing on a theater's stage only for his soul!

\section{Selected Publications:}

Kalogeras, N., Baourakis, G., Mattas, K. (2011). Introduction to the Special Issue on Recent Trends in the Food Industry \& Food Chain. Journal of Food Products Marketing (forthcoming).

Kalogeras, N., Valchovska, S., Baourakis, G. Kalaitzis, P. (2010). Dutch Consumers' Willingness to Pay for Organic Olive Oil. Journal of International Food \& Agribusiness Marketing, 24(3): 286-311.

Kalogeras, N., Pennings, J.M.E., Van der Lans, I.A., Garcia, P., Vand Dijk G. (2009). Understanding Heterogeneous Preferences of Cooperative Members. Agribusiness: An International Journal, 25(1):90-111.

Kalogeras, N., Pennings, J.M.E., van Dijk, G., van der Lans, I.A. (2007). The Structure of Marketing Cooperative: A Members' Perspective.” In: K. Karantininis, \& J. Nilsson, (Eds.) Vertical Markets and Cooperative Hierarchies, Dordrecht: Springer Academic Publications, pp. 73-92.

Pennings, J.M.E., \& Kalogeras, N. (2006). Risk Perception and Risk Attitude in Transition towards Sustainability in Small and Medium-size Enterprises. In: H. van Trijp (Ed.), Sustainable Consumption \& Informed Entrepreneurship, The Netherlands: Drukkerij A-Twee. 3: 47-76.

Kalogeras, N., Baourakis, G., Zopounidis, C. (2005). Evaluating the Financial Performance of Agri-food Firms: A Multicriteria Decision-Aid Approach. Lournal of Food Engineering, 70(3): 365-371.

Migdalas, A, Kalogeras, N., Baourakis, G. Meriem, H.B. (2004). Sector Modeling for the Prediction and Evaluation of Cretan Olive oil. European Journal of Operational Research, 152(2): 454-464.

Baourakis, G., Kalogeras, N., Zopounidis, C., (2003). Assessing the Financial Performance of Marketing Cooperatives and Investor Owned Firms: A Multicriteria Methodology. Supply Chain and Finance, 2(1): 3045.

Dimara, E., Kalogeras, N., Baourakis, G. (2002). Consumer Preferences for Extrinsic versus Intrinsic Quality Cues for Image Products: The Case of Greek Quality Wine. In C. Zopounidis \& P. Pardalos (Eds.), Fuzzy Sets Systems in Management, Economics and Marketing, MA: World Scientific, pp. 83-98 


\section{EVERYTHING SEEMS LIKE A THEATER}

\section{PLAY!}

\section{Who Inspired my PhD "Play"?}

Not many $\mathrm{PhD}$ students have been blessed by meeting pioneers in the field of their study. Prof. M.T.G. Meulenberg, your "words" have been always my guide not only in research but also in life. Over the years, I have been missing more and more our discussions. I have been always feeling so honored for having the opportunity to discuss with and learn from you, the "father" of European Marketing. I had the great chance to experience closely your attitude, generosity, modesty and passion for research in marketing and decision sciences. I have been trying hard to focus and "walk" on that "scientific pathway" that you showed me. You gave me the inspiration that I needed in order to move on. You showed and explained me how I should start "making-up and writing the plot of this play" and "start acting" on the scientific stage. Without any hesitation, this dissertation is dedicated to you. Million thanks for all!

\section{Who Was the Director of this "Play"?}

Moreover, not many $\mathrm{PhDs}$ have been blessed by a supervisor who is not only a wonderful source of inspiration, but he has a "great eye" for detail, and unique skills for identifying inter-linkages among disciplines as well as bridging theory and practice. I am very fortunate to have had the opportunity to work so closely with Professor dr. ir. Joost, M.E. Pennings in the United States (US) and the Netherlands. Dear Joost, thanks for not only sharing several research opportunities with me, but for also teaching me how to evaluate if it is worth "taking the risk" in many research and real life contexts. Although we had the opportunity to experience great challenges, many "highs and lows", and several intensive and very loud dialogues, the bottom line may be that "...you and I may have the same research DNA..." as you pointed out in one of our lunch-break discussions in Champaign. Please accept my heartfelt appreciation for stating this, getting me "on board" for this wonderful journey, giving me the opportunity to "act" from a leading position and "direct" this "play". Thank you very much for sharing with me scientific and life experiences! 
Who Else Participated Actively in this "Play"?

I am grateful to so many colleagues and friends who accompanied my " $\mathrm{PhD}$ journey" and equipped me with the "necessary luggage". I would like to take this opportunity to thank many scholars, colleagues, and friends that supported me in one way or another.

Prof. E. Dimara and Prof. D. Skuras thanks for "pushing" me into the research pool. I really do not know whether my choice to follow a research rather than a theater career, was the best. Yet, I certainly feel that I owe you a lot! Prof. G. Baourakis, Prof. C. Zopounidis, Prof. M. Doumpos, and Prof. Migdalas, thanks for believing in me and gave me the opportunity to realize next to you my very first publications. Prof. van Dijk thanks for "opening" a new route in my scientific development when you invited me in the Netherlands and introduced me to the "world" of co-operatives. Prof. I. van der Lans, Dr. Y. van Dam, and Dr. Frans Verhees thanks for the nice discussions and the relaxing moments in Wageningen. Drs. Nika Dourou thanks for being such a sweet friend and the best theater partner I ever had in life! Prof. P. Garcia thanks for hosting me so generously in UrbanaChampaign and so patiently encouraged and taught me how to develop a systematic thinking and critical view when I conduct research. Dr. Joshua Woodard, Dr. Jason Franken, Prof. R. Westgren, and Dr. Fabio Mattos, thanks for the friendship and support throughout my stay in Illinois. Valerie Pennings, thanks for the nice welcome and the enjoyable moments in Urbana-Champaign.

Prof. P. Eicholtz and Prof. K. de Ruyter, thanks for hosting me so kindly into "your" departments "life". Looking back, I have to admit that it was a unique experience! Prof. Nils Kok, thanks for the friendship and for helping me enroll so nicely into the life of the dept. of Finance, when I arrived at Maastricht University. You have been the best office-mate ever! Drs. Daniel Hann and Prof. J. Derwall, thanks for the friendship, the sharing of very constructive scientific experiences, and giving me the opportunity to work with you on edge-cut research on the marketing-finance interface. Prof. Arvid Hoffmann, thank you very much for the nice collaboration, your great support in the framework of the Marketing-Finance educational and research programme and the enjoyable coffee breaks. Drs. Theo Benos thanks for always sharing with me your passion for research on marketing co-operative firms and being always so loyal to our scientific aspirations and efforts. Prof. G. Odekerken-Schöder, Prof. M. Wetzels, Prof. R. Bauer and Prof. S. Straetman, Prof. J. Semeijn, Prof. E. Bruggen, Prof. Rachel Campbell, Prof. F. Lutgens, and Prof. P. Schotman, thanks for the nice discussions and your kind willingness to offer me "your time" for exchanging scientific and social views.

I also want to warmly thank Francien, Pascalle, Carina, Nicole, Els, Eefje, and Cecile, for the everyday support throughout my PhD life in both depts. (Marketing-Finance), and all the junior members of the Marketing-Finance Research Lab 
(Anna, Mae, Roos, Robert, Simone) for the nice scientific and social interaction. I also would like to thank all my fellow PhD students: Daniela, Thies, Kathrin, Matthias, Rik, Bart, Thomas, Clemens, Paolo, Roy, Paul, Julieta, Sanne, Thao, Katie, Erkan, Michael, Tom, Anna, Charlotte, Nina, Claudia, as well as all my students from both, the University of Illinois at Urbana-Champaign and Maastricht University, from whom, throughout the years, I have learned much. Dear Eliza and Mirna, thank you so much for supporting the organization of my $\mathrm{PhD}$ defense day and your friendship.

My perception is that the "casting" did not determine any first- and/or second-order acting roles to each one of you. Yet, you all "acted" as a "co-operative team" in the way that I needed....to "feel" that you have been next to me.

\section{Who Assessed the "Prova-Generale"?}

I also want to thank the members of my dissertation's assessment committee (Prof. P. Eiccholtz, Prof. K. de Ruyter, Prof. P. Garcia, Prof. X. Gellynck) for their constructive and insightful comments.

Who May Assess the Quality of this "Play"?

You! The audience!

Who Has Been Always There to Applause?

And last, but not least, I extend my most heartfelt gratitude and love to my mother (Evgenia), my father (Emmanuel), my sister (Kyriaki) and my brother (SteliosRafael), who have been always there to provide with endless support.

Nikos Kalogeras,

Maastricht, The Netherlands, Winter, 2010. 